\title{
Organisational characteristics, work characteristics and psychological effects in nursing work
}

Citation for published version (APA):

Tummers, G. E. R. (2003). Organisational characteristics, work characteristics and psychological effects in nursing work. [Doctoral Thesis, Maastricht University]. Universiteit Maastricht. https://doi.org/10.26481/dis.20030509gt

Document status and date:

Published: 01/01/2003

DOI:

10.26481/dis.20030509gt

Document Version:

Publisher's PDF, also known as Version of record

\section{Please check the document version of this publication:}

- A submitted manuscript is the version of the article upon submission and before peer-review. There can be important differences between the submitted version and the official published version of record.

People interested in the research are advised to contact the author for the final version of the publication, or visit the DOI to the publisher's website.

- The final author version and the galley proof are versions of the publication after peer review.

- The final published version features the final layout of the paper including the volume, issue and page numbers.

Link to publication

\footnotetext{
General rights rights.

- You may freely distribute the URL identifying the publication in the public portal. please follow below link for the End User Agreement:

www.umlib.nl/taverne-license

Take down policy

If you believe that this document breaches copyright please contact us at:

repository@maastrichtuniversity.nl

providing details and we will investigate your claim.
}

Copyright and moral rights for the publications made accessible in the public portal are retained by the authors and/or other copyright owners and it is a condition of accessing publications that users recognise and abide by the legal requirements associated with these

- Users may download and print one copy of any publication from the public portal for the purpose of private study or research.

- You may not further distribute the material or use it for any profit-making activity or commercial gain

If the publication is distributed under the terms of Article $25 \mathrm{fa}$ of the Dutch Copyright Act, indicated by the "Taverne" license above, 


\section{Organisational characteristics,}

work characteristics and psychological effects

in nursing work

Gladys Tummers 
Organisational characteristics, work characteristics and psychological effects in nursing work.

Gladys Tummers

PhD thesis Maastricht University, Maastricht, The Netherlands.

With summary in Dutch.

Subject headings: organisational characteristics, work characteristics, psychological work reactions, longitudinal study, individual-level and group-level relationships, nursing work.

ISBN: $90-9016615-7$

(C) 2003 by Gladys Tummers

Maastricht University, Department of Health Organisation, Policy and Economics, PO Box 616,6200 MD Maastricht, The Nethetlands

Phone: $+31-43-3881727 / 3881560$ (secretary);

E-mail: Secretariaat@beoz.unimaas.nl

Printing: Datawyse B.V.|Univetsitaire Pers Maastricht, Maastricht, The Netherlands. Cover design: Maurice Franssen \& Datawyse B.V. 


\title{
Organisational characteristics,
}

\section{work characteristics and psychological effects}

\author{
in nursing work
}

\section{PROEFSCHRIFT}

ter verkrijging van de graad van doctor aan de

Universiteit Maastricht, op gezag van de Rector Magnificus, Prof. dr. A.C. Nieuwenhuijzen Kruseman volgens het besluit van her College van Decanen, in het openbaar te verdedigen op vrijdag 9 mei 2003 om 14.00 unr

door

Gladys Elisabeth Rudolf Tummers

geboren op 25 mei 1976 te Heerlen 


\section{Promotor:}

Prof. dr. G.G. van Merode

\section{Co-Promotor:}

Dr. J.A. Landeweerd

\section{Beoordelingscommissie:}

Prof. de. F. J. N. Nijhuis (voorzitter)

Prof. dr. W. N. J. Groot

Prof. dr. F, den Hertog

Dr. J. de Jonge (Universiteit Utrecht)

Prof. dr. R. Roe

The study presented in this thesis was financially supported by the Institute for Labour Studies (OSA), Tilburg, The Netherlands.

Financial support for the printing of the thesis has been kindly provided by the Institute for Labour Studies (OSA), and the Maastricht Health Research Institute for Prevention and Care (Health), which participates in the Netherlands School of Primary Care Research (CaRe), acknowledged in 1995 by the Royal Dutch Academy of Science $(\mathrm{KNAW})$. 
Voor May en pap 

"Tet idenal zal altijd de prikekel zijn woor bet werk, woor bet verlangen om wan een ideaal

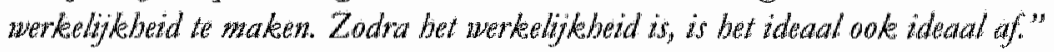

(Connie Palmen, De vtiendschap, blz. 235) 



\section{Contents}

1 Introduction

2 Organisational characteristics and work characteristics as determinants for nurses' psychological work reactions

3 A comparative study of work characteristics and psychological work reactions between general and mental health nurses

4 The diversity of work: Organisation, work and psychological work reactions in Intensive Care and non-Intensive Care nursing 55

$5 \quad$ Organisational characteristics as predictors of nurses" psychological work reactions

6 Individual-level and group-level relationships between organisational characteristics, work characteristics and psychological work reactions

7 Longitudinal relationships between organisational characteristics, work characteristics, and psychological work reactions

8 Discussion

Samenvatting (Summary in Dutch)

References

Dankwoord (Acknowledgement in Dutch) 

1

General Introduction 
There is btoad international recognition that occupational health and well-being are important issues (Kompier \& Cooper, 1999). Sexeral European countries have introduced legislation in this respect. The most prominent legal regulation on the quality of work is the European framework directive on health and safety at work (89/391/EEC; 1993). This directive applies to psychosocial job design and workrelated well-being and health. Such legislation is needed, because occupational stress and work-related negative outcomes (for example, psychosomatic health complaints, de-motivation, and turnover) are emerging as major problems in modern working life (Kompier, 2002). Illustrative in this respect are figures that reveal thar about twenty per: cent of sickness absence, and thirty per cent of disabled employees in the Netherlands can be explained by psychological disorders, such as burnout (Houtman, Schaufeli \& Taris, 2000). Only sickness absence because of musculoskeletal disorders has a similar high prevalence (Schaufeli \& Enzmann, 1998).

The health care sector particularly has become an area of growing interest for researchers in the field of organisation science as well as in work and organisational psychology to investigate employees' health and well-being (or psychological work reactions). This sector is one of the fast expanding service sectors that employs vast numbers of people (Cascio, 1995; De Jonge, 1995; Frese, 2000). Approximately 900,000 people are working in this sector in the Netherlands, which is about 13 per cent of the employed population (CBS, 2002). Health care work is "people-processing" work, indicating that the work process is focused on working with, and on people (Payne \& Firth-Cozens, 1987). This "people-processing" nature makes health care workers more vulnerable to occupational stress than other occupational groups (Baldwin, 1999; Bradley \& Cattwright, 2002; Schaufeli \& Buunk, 1996; Söderfeldt, Söderfeldt \& Warg, 1995). At the same time, health care organisations are being confronted with a changing environment (such as more diversity in the patient population), and with new organisational principles or designs. Most notably, in the last ten years, organisational structures in general, but more specifically, health care organisations have seemed to change rapidly in the Netherlands. They seem to be changing from a more functional- to a more client-oriented structure (Huijsmans, 2002; Van Merode, 1999). The latter means that dependencies within one patient category are organised within the same organisational unit. These changes are needed in order to react to changing environmental characteristics, and consequently, to maintain or improve organisational effectiveness.

In order to investigate work-related and individual determinants of employees' psychological wotk reactions, a huge amount of research has been done in the field of work and organisational psychology (see, for instance, De Jonge, 1995; De Jonge, Dormann, Janssen, Dollard, Landeweerd \& Niihuis, 2001; Hackman \& Lawler, 1971; Houkes, Janssen, de Jonge \& Nijhuis, 2001b; Schaufeli \& Enzmann, 1998; Van Veldhoven, 1996). Examples of frequently studied work characteristics in this context 
are workload, social support, job control, and job feedback, while hardiness, and negative affectivity (or neuroticism) have often been investigated as individual determinants for employees' well-being and health (Constantini, Solano, Di Napoli \& Bosco, 1997; Duquette, Kerouac, Sandhu \& Beaudet, 1994; Houkes, Janssen, de Jonge \& Nijhuis, 2001a; Piedmont, 1993).

Although considerable progress has been made in understanding these psychosocial risk factors and their possible consequences in the workplace, and although, at the same time, this area of research is still developing (for example, the application of sophisticated methodologies, and combination of theories) (Kompier, 2002), only limited attempts have been made until now to investigate organisational deferwinants of such psychological work reactions (Tummers, Landeweerd \& Van Merode, 2002a). In organisation science, the main field's of interest in this context seem to be the role of organisational characteristics in the prediction of "conomic measures" of organisational effectiveness, such as efficiency and productivity (see, for instance, Campbell, 1977). The influence of organisational characteristics on "social measures" of organisational effectiveness (such as intrinsic work motivation or burnour) have rarely been studied, although it is obvious that they are interconnected. For instance, a chent-oriented organisational principle might induce more co-operation that might enhance employees' job satisfaction and/or work motivation. Consequently, and in addition to work characteristics, organisational characteristics may play an important role in employees' psychological work reactions. To conclude, in organisation science, employees' well-being and health are seldom mentioned as indicators for organisational effectiveness. At the same time; in work and organisational psychology, such organisational characteristics as mentioned in organisation science have rarely been studied as determinants of employees' psychological work reactions. So, the current study's aim is to integrate theories from these different research approaches, and to investigate the "missing link" between them. More concretely, the relationships of organisational characteristics with work characteristics and psychological work reactions in nursing work are examined. In order to select the study variables, the contingency approach of organisations and the Demand-Control-Support (DCS) model were used as theoretical frameworks (Tummers, Van Merode \& Landeweerd, $2002 \mathrm{~d}, 2002 \mathrm{e}$ ). It should be noted that the contingency approach was not used for model testing, but primarily to select the organisational variables.

\section{$1.2 \quad$ Nursing work}

The health care worker and his or her health, safety and well-being are increasingly important topics. Since 1992, the International Commission on Occupational Health (ICOH) has included the division of the "Health of the health care worker", which suggests that working conditions in health care have become increasingly important (Tummers et al., 2002a). For instance, it is well-known that workload is very high in 
nursing work and that it is, consequently, an high underlying risk factor for negative psychological work reactions, such as burnout (Borrill et al, 1998; Duquette et al., 1994; Janssen, de Jonge \& Bakker, 1999a; Schaufeli \& Enzmann, 1998). Furthermore, nurses have often been termed "dependent practitioners", because of their reliance on physicians (De Jonge, 1995). The nature of the work (particularly irregular workflows) hampers nurses' opportunities to shift or delay particular tasks. Consequently, their autonomy is restricted. Also differences between nurses' expectations about their performance of the maintenance of professional norms, and the actual work performance often create stressful situations (Estryn-Behar et al, 1990), which might induce role ambiguity and role conflicts (Berkhout, 2000; Estryn-Behar et al,, 1990; Zwaga, 1983). Social support at work (from one's supervisor, but also from peers) is often seen as an important "tesource" to cope with such stressors (e.g., Cohen \& Wills, 1985; Tyler \& Cushway, 1992). Since nursing work can increasingly be characterised as "team work." (compare the development of more patient-oriented nursing care; Berkhout, 2000), mutual social support is a necessary condition for good co-operation, but also for nurses' work motivation, and health (De Jonge, 1995; De Jonge et al, 2001; Dollard, Winefeld, Winefield \& de Jonge, 2000; Tummers et al., 2002a; Winnubst \& Schabracq, 1996).

In this respect, the Dutch government has enacted several laws and regulations to stimulate health care organisations to involve themselves as much as possible in improving the quality of employees' work (Berkhout, 2000). The most important ones are the "Working Conditions Act 1998" (ARBO-law), that tegulates health, safety and well-being at the workplace (Lenderink, 1998), and the "Contract on the Policy of the Employment Situation in the Health Care Sector" ("Convenant Arbeidsmarktbeleid Zorgsector"). This contract was signed in 1998 between the social partners in health care, the Ministry of Health, Welfare and Sport, and the Centre for Work and Income (formerly "Dutch Employee Facility"). Its aim is to make commitments with regard to the reduction of sickness absence and the improvement of working conditions in health care.

Despite the attempts to reduce or solve the problems in nursing work by means of legislation on working conditions, sickness absence in health care is still very ligh in comparison with the national mean (7.1\% and $4.6 \%$ respectively) (CBS, 2002). About twenty per cent of sickness absence is due to occupational stress, such as burnout (Houtman et al., 2000). These high percentages of employees who are absent from work, or who are diagnosed unfit for work after one year of absence, indicate that high costs (for the individual, the organisation, and the society) are involved (Lourijsen, Houtman, Kompier \& Gründemann, 1999). In particular the -direct and indirect-costs that are associated with occupational stress, such as a reduction of productivity, quality loss of patient care, and de-motivaton, are immense Janssen \& Houkes, 2000; Schaufeli \& Enzmann, 1998). The costs involved with sickness absenteeism due to stress-related problems are estimated at around $40 \%$ of the total estimated costs for 
absenteism (i.e, 0.8 billion Euro per year), while the costs for disability pensions are estimated at around $42 \%$ of the total estimated costs fot disability pensions (i.e., 1.2 billion Euro per year) (Koningsveld \& Mossink, 1997).

In addition to the above-mentioned well-known psychosocial tisk factors in nursing work inducing negative psychological work reactions, several difficulties that are being reported in nursing wotk might be explained from an organisational point of view (Bodt, 1995). The way a nursing unit is organised can be seen not only as a condition for effectiveness or efficiency, but also for nurses' job quality. Organisational characteristics, such as complexity, could influence work characteristics like workload and autonomy, and, in line with this, psychological work reactions too. The organisational structure of a unit depends primarily on the patient flows, the existing quality norms (De Vries, 1984), and environmental uncertainties (see for instance, Galbraith, 1973, 1977; Lawrence \& Lorsch, 1967a; Lawrence \& Lorsch, 1967b).

Nursing care can be considered as a process. For the efficient delivery of health care, it is important that the different elements of this process are linked with each other (Tummers et al, 2002d). At unit level, especially the relationships between patient demand and staffing is of importance. One of the most relevant organisational (efficiency) problems in nursing units is that often there exists no equilibrium between these two aspects, causing over- or under-capacity. Consequently, workload is not stable, but fluctuates each day (Bodt, 1995; Van Tuijl, 1988). Other coordinating problems are concerned with the dependence on other units or professionals. For instance, in order to optimise the utilisation of capacities, it is important to pay attention to the efficient planning of leading (such as surgery room capacity) and following capacities (such as nursing unit capacity), because the utilisation of following capacities depends on the utilisation of leading capacities (De Vries, 1993; Tummers et al., 2002d). Especially when one realises that organisational characteristics might often. influence how jobs and work characteristics will look like, it seems to be important to extend nursing research in this field to such factors (Tummers et al., 2002a).

The current study investigates the role of organisational characteristics in nursing units and their impact on work characteristics and nurses' psychological work reactions in general hospitals in the Netherlands.

\subsection{The organisation of nursing units: theoretical perspectives on organisations, work and psychological work reactions}

Two theoretical perspectives are used in the current study to select organisational characteristics, work characteristics, and psychological work reactions, namely the contingency approach of organisations (Child, 1977; Galbraith, 1977; Lawrence \& 
Lorsch, 1967b), and the Demand-Control-Support (DCS) modell Johnson \& Hall, 1988; Karasek, 1979; Karasek \& Theorell, 1990). These two theoretical frameworks are derived from different research tradirions.

The contingency approach of organisations derives from organisational and business sciences, and belongs to the open system approaches of organisations (e.g., Miller \& Friesen, 1984; Mintzberg, 1983; Scott, 1992). It has been developed to study organisational effectiveness in particular (Donaldson, 2001a; Galbraith, 1977; Lawrence \& Lorsch, 1967b). According to this approach, design decisions depend are contingent - on environmental conditions ("there is no best way to organise"). In addition, organisational effectiveness is achieved by organisations whose structural characteristics (such as centralisation, formalisation, and stanclardisation; Child, 1.977; Gutek, 1990; Pennings, 1998) best match the demands of the envinonment or context, such as environmental uncertainty (Fry \& Slocum, 1984; Pennings, 1998; Perrow, 1970; Rundall \& Hetherington, 1988).

The DCS model (Johnson \& Hall, 1988; Karasek, Baker, Marxer, Ahlbom \& Theorell, 1981; Karasek \& Theorell, 1990) is an extension of Karasek's Job Demand-Control (JD-C) model (Karasek, 1979). Both the JD-C and the DCS model are considered as a synthesis of two research traditions (De Jonge, 1995): the job design tradition (e.g., Hackman \& Oldham, 1980), and the occupational stress tradition (Caplan, Cobb, French, Van Harrison \& Pinneau, 1975; Kahn, 1981)). The aim of these models is to provide a theoretical framework in which these two research traditions are integrated, and consequently, to generate a more profound insight into psychosocial risk factors at work (Karasek, 1979; Söderfeldt et al., 1996).

The contingency approach of organisations focuses on two levels of analysis: the level of the organisation and the level of elements within organisations, such as units (Child, 1977; Donaldson, 2001a). In the current thesis, the level of units is the focus of the study. An organisation consists of different sub-elements (such as units), and has different sub-goals (Donaldson, 2001b; Yuchtman \& Seashore, 1967). The diversity of nursing units within hospitals implies that these units are confronted with different external demands. Consequently, these units will all develop particular structural features to cope with these various environmental characteristics (Lawrence \& Lorsch, $1967 \mathrm{~b})$.

The contingency approach can be used to describe the caring ptocess in a unit and the relating organisational structure variables (Tummers et al., 2002e). The caring process can be described by means of environmental characteristics of a unit, and the patient mix (Bodt, 1995; Bodt \& Van Tuij1, 1985). The patient mix on a unit encompasses the composition with regard to the specialities, and the diversity of patients. Diversity means that patients" differences are due to the kind of disease, and the amount of health problems. So, nursing activities can differ with regard to the complexity. 
Furthermore, nursing units are characterised by high environmental uncertainty or unpredictable circumstances. In general, uncertainty means that there is a difference between the amount of information required to perform the task and the amount of information already possessed by the organisation (Galbraith, 1973). The effect of uncertainty is that the planining possibilities for the organisation are being constrained. Two aspects of uncertainty ate distinguished in the current study, namely environmental (or workflow) uncertainty, and task uncertainty (Galbraith, 1973; Van de Ven, Delbecq \& Koenig, 1976). Task uncertainty is less prominent in the current study, because of the high standardisation of work by means of rules and procedures. Environmental uncertainty is concerned with quantitative uncertainty (the amount of work supply, such as emergencies), and qualitative uncertainty (the kind of work supply, such as the severity of patients' conditions). In situations of low environmental uncertainty, mechanistic structures (characterised by, for instance, high formalisation, high centralisation, and high division of labour) are suitable (Morgan, 1992). Conversely, when environments are dynamic and unpredictable, the interaction with the environment should be managed flexibly. Organic structures instead of mechanistic structures are therefore more appropriate (Lawrence \& Lorsch, 1967a; Pertow, 1967; Thompson, 1967).

Applied to nursing work, units that are characterised by high environmental uncertainties should have a flexible (or "organic") unit structure to react adequately to these environmental conditions. Generally, a decentralised decision-making structure with regard to nursing activities, and an undifferentiated task structure will be most appropriate. A decentralised decision-making structure means that decisions with regard to the performance and planning of activities are delegated to less hierarchical levels in the organisation. If environmental uncertainty is high, it becomes more effective to bring the points of decisions down to the points of action where the information originates. This can be accomplished by increasing the amount of decision authority exercised by employees at lower levels of the organisation. By doing this, it is necessary that nursing executives have the opportunity to perform not only executive tasks, but also planning tasks (such as the admission policy). So, tasks are not differentiated.

An undifferentiated task structure can be compared with a patient-otiented task structure (such as primary mursing, and patient-oriented team nursing, Bodt, 1995; Boekholdt, 1981; Heeremans, Boumans, Algera \& Landeweerd, 1994). This means that all tasks are performed by one nurse or a group of nurses, while one has the responsibility for a group of patients. An undifferentiated task structure can nearly be seen as independent of a decentralised decision-making structure (Van Tuijl, 1988; Van Tuij] \& Bodt, 1988). Coordination is less difficult if units have an undifferentiated task structure instead of a differentiated task structure, particularly under conditions of high environmental uncertainty. Usually, environmental uncertainty is first signalled by the group, inducing an immediate reaction. Thus, decision authorities have to be delegated 
to nursing executives in order to react adequately to this environmental uncertainty (Tummers et al., 2002e).

In sum, decision authority is used as structural vatiable, and encompasses degree of decentralisation of decision-making and undifferentiated task structure. Environmental uncertainty and complexity are considered as the core variables of the organisational (i.e., unit) context or environment.

As mentioned earlier, as the contingency theory is primatily interested in economic outcomes (hardly on psychological outcomes) by investigating organisational effectiveness, and the JD-C and DCS models mainly focus on psychosocial risk factors at work and less on those organisational risk factors as mentioned in organisational theories on effectiveness, it is worthwhile to investigate the "missing link" in both theories, namely the relationship between organisational characteristics on the one hand and work characteristics and psychological effects on the other. Insight into these relationships is thus theoretically as well as practically important, since organisational characteristics may determine and shape employees' function profiles and the related task or work characteristics of employees' jobs. Consecuently, they may influence employees' work reactions (Oldham \& Hackman, 1981; Tummers et al., 2002d).

\subsection{Research questions and research model}

The central research question to be addressed in this thesis is: "What relationships exist between organisational characteristics, work characteristics and psychological work reactions in nursing work?"

This central research question has been divided into six sub-questions. These subquestions are very much intertwined with each other. For this reason, most subquestions are discussed throughout the whole thesis. The following sub-questions ate distinguished:

1 Which relationships exist between organisational characteristics and work characteristics? This question is addressed in the chapters $2,4,6$, and 7 ;

2 Which relationships exist between organisational charactetistics and psychological work reactions? This question is treated in the chapters $2,4,5,6$, and 7 ;

3 Which relationships exist between work characteristics and psychological work reactions? This question is the subject of the chapters $2,3,4,6$, and 7 ;

4 Are relationships between organisational characteristics and psychological work reactions direct or are they mediated by particular work characteristics? This question is addressed in the chapters 2,4 , and 6 ; 
5 Are there any differences between several types of nursing units with regard to the research questions, described above $(1-4)$ ? This question is treated in the chapters 3,4 , and 6 ;

6 Do nurses' psychological work reactions depend on the congruence of structural and environmental characteristics rather than on structural and environmental characteristics alone? This question is dealt with in chapter 5.

These research questions were investigated by means of an empirical field (survey) study in general hospitals in the Netherlands. All the variables under study were measured by means of questioninaires to the job incumbents (i.e., nurses). Instead of using such "subjective" measures, "objective" measures could be an alternative. Although the disadvantages of using subjective measures have often been discussed in the literature, objective measures (such as judgements by "independent" experts and registrations) have their pitfalls as well (Frese \& Zapf, 1988; Meijman \& Ouwerkerk; Spector, 1992). In order to get a complete picture of the work situation, it is important to ask the people most closely involved in the work situation about their perceptions (by using questionnaires to the job incumbents).

The research model that was used for the current study, is presented in Figure 1.1.

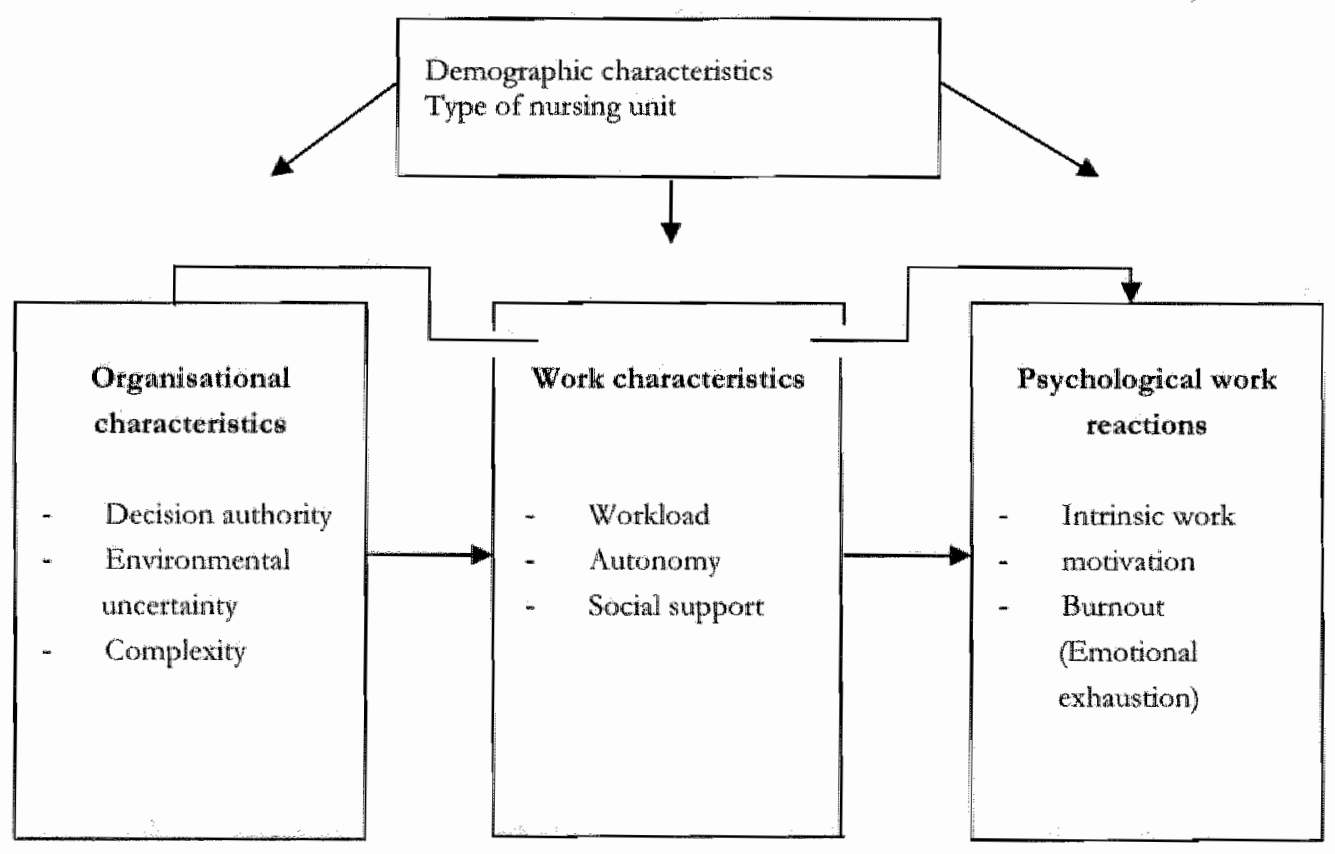

Figure 1.1 Research modell 
The organisational characteristics consist of decision authotity, environmental uncertainty and complexity, and ate independent variables in the curtent study. They refer to the organisational characteristics at anit-level. The main work characteristics are workload, autonomy, and social support. In the second chapter, role conflict and role ambiguity are also discussed. These work characteristics are dependent variables in the relationship with organisational characteristics, and independent variables in the relationship with psychological work reactions. In addition, they might also operate as mediator variables in the relationship between organisational characteristics and psychological work reactions. The psychological work reactions consist of positive and negative outcome measures. The main positive outcome is intrinsic work motivation (job satisfaction, and job involvement are discussed in the chapters two and three respectively), whereas burnout (also psychosomatic health complaints in the second chapter) has been selected as the main negative outcome. They are the dependent variables in all the relationships studied. Finally, demographic characteristics (ive, gender and age) and type of nursing unit are included. It is assumed that demographic characteristics can potentially bias relationships between work-related stressors and outcomes (see for instance, De Jonge et al., 2001; Houkes et al., 2001b). Consequently, correction is necessary. Since the literature emphasises that nurses cannot be regarded as a homogeneous category, and that, consequently, stressors may be different for different types of units (Marshall, 1980; Miller, 1979), type of nursing unit is taken into account when investigating the several patterns of relationships.

\subsection{Outline of the thesis}

The outline of the thesis is as follows. In chapter 2 , a general overview of the influence of organisational characteristics on several work characteristics and psychological work reactions is given. More specifically, the chapter examines which (cross-sectional) pattern of relationships exists between organisational characteristics and work characteristics on the one hand, and between organisational characteristics and psychological work reactions on the other. In addition, the tole of work characteristics in the relationship between organisational characteristics and psychological work reactions is investigated. The study was conducted among a representative sample of 1204 nurses from 15 general hospitals in the Netherlands.

In chapter 3, the quality of work of mental health nurses and general nurses is compared. According to some authors (Jones, 1987), it is an over-generalisation to state that nursing in general is very stressful. Psychosocial risk factors at work are found to be quite different for different types of nursing units in hospitals. So, in this chapter, two tesearch questions are addressed. First, differences are explored between general and mental health nurses in work characteristics (i.e., workload, autonomy, and social support) and in psychological work reactions (i.e., burnout and job involvement). The second aim is to validate whether a specific pattern of telationships between work 
characteristics and psychological work reactions was the same for mental health and general nurses. It is hypothesised that bumout is particularly predicted by low social support and high workload, whereas job involvement is hypothesised to be particularly predicted by high autonomy.

Chapter 4 reports on similarities and differences between the work of intensive care and general nurses. In addition to the research questions that are addressed in chapter 3 , organisational characteristics are added to this specific pattern of relationships. Insight into these relationships in different kinds of nursing units is needed for the validation of the research model. In addition, insight into differences and/or similarities might lead to more precise guidelines to improve the organisation and the work situation of intensive care and general nurses. Consequently, the following three research questions are central in this study. The first research question explores whether there are any differences as to organisational characteristics (decision authority, environmental uncertainty, and complexity), work characteristics (workload, autonomy, and social support), and psychological work reactions (burnout, and intrinsic work motivation). Second, it is investigated whether the postulated relationships between organisationall characteristics, work chatacteristics and psychological work reactions are the same in intensive care and non-intensive care nursing. Third, it is also explored whether the relationships between organisational characteristics and psychological work reactions are mediated by specific work characteristics in both types of nursing units.

Chapter 5 investigates the congtuence between organisational structure (i.e., decision authority) and organisational environment (i.e., environmental uncertainty) to predict nurses' psychological work reactions. These organisational characteristics are variables at unit level. The contingency approach of organisations is used as a framework to investigate these relationships. The psychological work reactions are seen as measures of "social effectiveness". "Two general (more explorative) research questions and three hypotheses are formulated. The explorative research questions delve into what relationships exist between environmental uncertainty and "health outcomes" (RQ1), and the role of task standardisation in the relationship between environmental uncertainty and "health ourcomes" (RQ2). Furthermore, it is hypothesised that intrinsic work motivation is patticularly predicted by decision authority $(\mathrm{H} 1)$, that high decision authority buffers the negative effect of environmental uncertainty on "health outcomes" ( $\mathrm{H} 2)$, and finally, we hypothesised that high environmental uncertainty enhances the positive effect of decision authority on intrinsic work motivation and job satisfaction (H3).

Chapter 6 reports on the individual-level and group-level relationships between organisational characteristics, work characteristics, and psychological work reactions by means of a multilevel analysis. This study extends the studies of the previous chapters in the sense that aggregated (group) variables (i.e., the organisational and work 
characteristics) are added in the prediction of bumout and intrinsic work motivation. As individuals within a same unit or organisation are not totally independent of each other, the effects of individual-level variables must be distinguished from the grouplevel variables. In this context, group-level variables are important for an adequate estimation of the individual-level effects.

In chapter 7 , the relationships between organisational characteristics, work characteristics, and psychological work reactions over time are presented. In this longitudinal cross-lagged panel study, all the study variables are measured twice with a one-year time lag. By means of such a longitudinal design, the causal chain of relationships can be established more definitely in comparison with a cross-sectional design that is presented in earlier chapters.

Chapter 8 comprises a general overview of the thesis in which the main study results ate presented and discussed. Furthermore, methodological reflections, and practical implications of the study are given. The thesis ends with some recommendations for future research. 



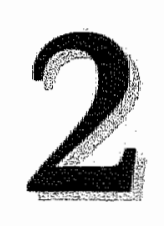

\section{Organisational characteristics}

\section{and work characteristics as determinants for}

\section{nurses' psychological work reactions}

\section{Published as:}

Tummers, G.E.R, Landeweerd, J.A. and Van Merode, G.G. (2002). Work Organisation, Work Characteristies and their Psychological Effects on Nurses in the Netherlands. International Jowrnal of Stress Management, 9(3), 183-206 

Globally, work life in health care has undergone tremendous changes during the past century (De Jonge, Dollard, Dormann, le Blanc \& Houtman, 2000; Frese, 2000). Today's nursing work, for example, is characterised by increasing complexity, more team work, expanding sophisticated medical technologies, increasing competition, and budget cuts (Bridges, 1995; De Vries \& Griever, 1991; Hockey, 2000; Howard, 1995). In addition, psychological demands particularly due to the direct patient and client contacts are becoming mote and more important with the ever-expanding service sector (De Jonge et al, 2000; Zapf, Dormann \& Frese, 1996).

Given the changing health care envitonment, insight into determinants of the work situation in nurses is becoming increasingly important. Research in stress in nursing has focused primarily on work characteristics, such as workload, autonomy, social support, feedback and role clarity, as important determinants of psychological, physiological and behavioural outcomes, including burnout and job motivation (e.g., Boumans, 1990; Dollard et al., 2000; Houkes et al., 2001a; Janssen et al., 1999a).

However, a relatively small amount of research has focussed on the work organisation and its impact on personnel well-being and health. The work organisation may be defined as the way in which the work is structured, distributed, processed and supervised (Hagberg et al., 1995) and depends on many factors, such as type of product or service, characteristics of the workforce, level and type of technology, and market conditions (Carayon \& Smith, 2000). Thus, the aim of the current study is to examine which relationships exist between characteristics of the work organisation, work characteristics and psychological work reactions.

\subsection{Conceptual framework}

\section{Work organisation}

Several models and theories exist about the structure of organisations, such as the contingency approach (Galbraith, 1973) and the sociotechnical system (STS) approach (De Sitter, Den Hertog \& Dankbaar, 1997; Kuipers \& Van Eijnatten, 1996; Trist, 1981). The contingency approach describes how dimensions of organisational structure (like standardisation, decentralisation of decision making and professionalisation) depend on characteristics of the organisational environment (for example, uncertainty and complexity) in order to obtain effectiveness. The STS approach focuses on the joint optimisation of the technical and social organisational (sub)systems which ate considered as mutually dependent for the performance of a task of the work system (Trist, 1981). This optimisation is needed to obtain economic performance and employees' job satisfaction and personal growth. A precondition for the latter is to give employees enough possibilities to participate in decision making.

Interventions that pay attention to the total work system instead of a particular single element are more likely to be successful, not only from an organisational and 
performance point of view, but particularly from a perspective focussing on the health and well-being of the individual (Smith \& Carayon-Sainfort, 1989). In line with the abovementioned theories that focus on the total work system rather than of certain aspects of the organisation, a number of organisational characteristics seem to be important. We selected both structural (i.e., decision authority) and environmental characteristics (i.e, complexity and environmental uncertainty) to represent the work organisation in rursing.

Complexity refers to the complexity of care, that is, characteristics of the patients (such as changes in patient's health), and characteristics of the environment (e.g., the intense interdependencies between other care disciplines) (Corcoran, 1986; Mandemakers, 1993; Nationale Raad voor de Volksgezondheid, 1988).

Environmental uncertainty zefers to the difference between the amount of information required to perform the task and the amount of information already possessed by the organisation (Galbraith, 1973). It involves the time span for feedback in situations where turbulence and change are high (Duncan, 1972; Emery \& Trist, 1965; Lawrence \& Lorsch, 1967a; Terreberry, 1968). The concept of environmental uncertainty we use, means workflow uncertainty. Workflow uncertainty refers to a lack of knowledge about when the inputs will arrive, for instance, patient inflow (Slocum \& Sims, 1980). Finally, decision authority refers to the way in which the authority to make decisions as to "who is going to do what and when" is distributed among members of a ward (Bodt \& Van Tuil1, 1988). The concept of decision authority as we use it, refers to kinds of tasks to be performed, and the decentralisation of decision-making.

\section{Work characteristics}

In the current study, we use the Demand-Control-Support (DCS) model as our conceptual framework for the selection of the work characteristics and the psychological work reactions (see, for example, Landsbergis, 1988; Janssen et al, 1999; De Jonge, Janssen \& Van Breukelen, 1996). This model focuses on three work characteristics, viz., job demands (e.g., workload), job control (e.g., autonomy), and social support. It is frequently being used and tested in nursing (e.g, De Jonge et al., 1996; Janssen et al., 1999a; Landsbergis, 1988). We added role stressors, namely, role conflict and role ambiguity to our framework, because research has shown that these variables are important organisational stressors that may cause job dissatisfaction and feelings of job-related strain (Jackson \& Schuler, 1985; Kahn, 1981, Kahn, Wolfe, Quinn, Snoek \& Rosenthal, 1964). Besides, role stress can be a particular problem for employees who are in direct contact with people, as in nursing (Boles \& Babin, 1996; Meertens \& Van Grumbkow, 1992).

Workload gives an indication how difficult the work is with respect to, for instance, mental load, and the pace of work (De Jonge, 1995; Stikwoort, Landeweerd \& de Jonge, 1996).

Autonomy refers to the opportunity workers have to determine several elements of their direct work situation and is mostly defined in terms of self-determination, discretion, and freedom (De Jonge, 1995). 
Social support refers to ovetall levels of social transactions available on the job from both supervisors and colleagues (De Jonge, 1995; Karasek \& Theorell, 1990).

Role conflict refers to the extent to which employees have to carry out conflicting tasks that are in conflict with their own norms and values. Role conflict implies incompatible goals with the result of problematic goal attainment. At the same time, since it is cleat that the organisation does expect some results, this leads to a loss of control over task performance, which in its turn may lead to stress reactions (Kalhn et al., 1964; Winnubst, de Jong \& Schabracq, 1996).

Role ambiguity refers to lack of clarity regarding what exactly employees are supposed to do during work and the subsequent performance evaluation. For example, work goals and procedures may be poorly specified and necessary feedback may be lacking. As a result, all work activities may become problematic, while at the same time employees know that they have to attain some results. This may amount to a completely unmanageable working sinuation, which can lead to serious strains (Kahn et al., 1964; Lysonski, 1985; Winnubst et al., 1996).

\section{Psychological work reactions}

As to the outcomes variables, the DCS model does not outline specific psychological stress reactions as potential work reactions. In this study, we selected four different variables with regard to the psychological work reactions: burnout, psychosomatic health complaints, job satisfaction, and intrinsic work motivation.

Burnout is generally conceptualised as a syndrome of emotional exhaustion, depersonalisation, and reduced personnel accomplishment that can occut among individuals who do 'people work' of some kind (Maslach \& Jackson, 1986). Emotional exhaustion is generally seen as the core dimension of butnout. It refers to feelings of being totally depleted, a lack of energy and a feeling that one's emotional resources are used up (Maslach, 1993). In this study, therefore, we selected emotional exhaustion to represent the concept of burnout (Buunk, Schaufeli \& Ybema, 1994; Cox, Kuk \& Leiter, 1993; Maslach, 1998; Shirom, 1989).

Psychosomatic health complaints refer to the general feclings of health complaints, which are an expression of the tendency to somatise psychosocial stress conditions, like fatigue and back pain (De Jonge, 1995). We selected butnout, and psychosomatic health complaints for several reasons. First, due to the increasing job demands (e.g., inadequate staffing, work overload, low salary, low career opportunities, and high physical work load), nurses are an occupational group that shows burnout and psychosomatic complaints levels that ate above average risk (Numerof \& Albrams, 1984; Reeves, 1994; Söderfeldt et al., 1995). Another reason to include burnout and psychosomatic health complaints is that workload, autonomy, social support, rolle conflict and role ambiguity have often been found to be predictors of burnout and, although to a lesser extent, to psychosomatic health complaints (De Jonge et al., 2000; Duquette et al., 1994; Schaufeli \& Enzmann, 1998).

Intrinsic work motivation is generally considered as an important issue in nursing work. Nurses often seem to choose a job in nursing because of intrinsic values, such as 
recognition, patient contact and task content. We selected intrinsic work motivation as an outcome variable because it reflects the intrinsic work values, mentioned above, and ir refers to the growth dimension of the DCS model (Cook, Hepworth, Wall \& Warr, 1981). In our study, intrinsic work motivation is viewed as the work motivation that exists when esteem, feelings of growth, and competence are tied to performance (Lawlet, 1969; Lawler \& Hall, 1970). It thus refers to the extent to which the work drives the behavioural actions of the worker, tresulting in, for instance, feelings of challenge (Thierry, 1990).

Finally, job satisfaction is included in the current study because research has shown that work characteristics, like autonomy and social support were related to job satisfaction, (e.g.; De Jonge, 1995; Dollard et al., 2000; Landeweerd \& Boumans, 1994). Job satisfaction, refers, just like intrinsic work motivation, to the growth dimension of the DCS model; it is the satisfaction of nurses with their work and working conditions (Boumans, 1990; Stikwoort et al., 1996). So, the aim of the present study is threefold. First, we explore the relationships between the abovementioned features of the work organisation and work characteristics. Second, we investigate the relationships between characteristics of the work organisation and psychological work reactions and what role the work characteristics might play in this relationship. Finally, we explore relationships between the work characteristics and psychological work reactions.

\subsection{Method}

\subsubsection{Research model}

The research model of the current study is presented in Figure 2.1.

\begin{tabular}{l|l|l|l|} 
Organisational \\
chatacteristics \\
Decision authority \\
$\begin{array}{l}\text { Environmental } \\
\text { Concertaingy }\end{array}$
\end{tabular}

Figure 2.1 Research model 
From Figure 2.1, the three research questions can be illustrated by the three different lines. The first research question is reptesented by line $A$, which shows the relationship between the characteristics of the work organisation and work characteristics. The second research question which refers to the relationship between characteristics of the work organisarion, psychological work reactions, and the possible tole of the work characteristics, is shown by lines $B_{1}$ and $B_{2}$. We may ask whether the relationship between the characteristics of the work organisation and the psychological work reactions is a direct relationship $\left(B_{1}\right)$ or an inditect one, going via the work characteristics $\left(B_{2}\right)$, which means that the work characteristics may be seen as mediator variables. A mediator variable can be defined as a variable that specifies how the association occurs between an independent variable and an outcome variable and thus provides additional information about how or why two variables are associated (Bennett, 2000). Finally, line $C$ represents the third research question, the relationship between the work characteristics and psychological work reactions.

\subsubsection{Measures}

\section{Characteristics of the work organisation}

Envinonmental ancertainty was measured by means of five items, developed by Wibbelink, (1995) and Tummers (1998). The response categories ranged from 1 "totally disagree" to 5 "totally agree". An item example is: "There are daily emergency admittances on this unit".

Complexity was measured by a 9-item questionnaire with a 5-point response scale, ranging from 1 "totally disagree" to 5 "totally agree". The scale was derived from Mandemakers (1993) and was further adapted by Wibbelink (1995) and Tummers (1998). An item example is: "Patients on this unit show various clinical pictures which can be divided into different specialities".

Decision authority was measured by means of six items. The response categories tanged from 1 "totally disagree" to 5 "totally agree". The scale was derived from Bodt (1995) and Boone and de Jonge (1996). An item example is: "A nurse is able to make decisions of the patient's cate independently".

\section{Work characteristics}

Autonony was measured by the Maastricht Autonomy Questionnaire (MAQ), developed by De Jonge, Landeweerd \& Nijhuis (1995), Respondents were asked to rate their work situations with regard to autonomy. This scalle consists of 10 items with a 5 point response scale ranging from 1 "very little opportunity" to 5 "very much opportunity". An item example is: "The opportunity that the work offers to determine the method of working yourself".

Worklond was measured by means of an 8-item scale, developed by De Jonge et al. (1995). The response categories ranged from 1 "never" to 5 "always". The scale consists of a relatively wide range of both quantitatively and qualitatively demanding aspects in the work situation, like working under time pressure, working hatd, 
strenuous work and task complexity (De Jonge et all, 1995). An item example is: "In the unit where I work, there is too little time to finish the work".

Sacial support at work (from colleagues and senior nursing officer) was measured by means of a 10-item scale, derived from a Dutch questionnaire on organisational stress "Vragenlijst Organisatie Stress-Doetinchem" - VOS-D; Bergers, Marcelissen \& de Wolff, 1986): An item example is: "To what extent can you count on your colleagues, when you have difficulties in your work?" The items were scoted an a 4-point response scale format, ranging from 1 "never" to 4 "always".

Role anbigwily was measured with the help of four items, detived from the VOS-D on organisational stress. The scale consisted of a 5-point response scale, ranging from 1 "very precisely" to 5 "not at all precisely". An item example is: "Do you know exactly what your responsibilities are?"

Role conflict was also measured with the VOS-D scale on organisational stress. The scale consists of three items. The response scale ranged from 1 "nearly always" to 5 "never". An item example is: "Do you sometimes have to carry out incompatible tasks?"

\section{Psychological work reactions}

Emotional exhaustion was measured by means of the Dutch version of the Maslach Burnout Inventory (Maslach \& Jackson, 1986): the MBI-NL (Cox et al., 1993; Maslach, 1993; Schaufeli \& Van Dicrendonck, 1993). The emotional exhaustion scale of the MBI-NL consists of eight items with a 7 -point response scale $(1=$ "never", $7=$ "always"). An item example is: "I feel emotionally drained from my work".

Psychosomatic bealth complaints were measured with 21 items of a general health questionnaire (in Dutch:" "VOEG") which was developed and validated by Dirken (1969). The scale consists of items encompassing fatigue, appetire, stomach complaints, cardiac complaints, and complaints about muscles $(0=$ "no" and $1=$ "yes"). An item example is: "Do you often have a headache"?

Intrinsic work motivation was measured by means of six items derived from a scale developed by Warr, Cook and Wall (1979). Its response items ranged from 1 "totally disagree" to 5 "totally agree". An item example is: "My opinion of myself goes down when I do this job badly".

Job satisfaction was measured with 21 items derived from the Maastricht Job Satisfaction Scale for Health Care (MAS-GZ), developed by Landeweerd, Boumans and Nissen (1996). The Job Satisfaction scale consists of seven separate satisfaction dimensions, each measured with a 5-point scale: satisfaction with the supervisor, career opportunities, quality of patient care, growth opportunities, social contact with colleagues, social contact with patients, and satisfaction with job clarity. An item example is: "How satisfied are you with the amount of skills and possibilities you can use?" 


\subsubsection{Procedure}

An intraduction letter was sent to fifteen randomly selected general hospitals in the Netherlands to ask whether they were willing to participate in the curtent study. After permission was given, managers informed staff during the ward meeting about the research topic and purpose, the data collection procedure, and the research report. Questionnaires were distributed in a sealed envelope together with a letter that explained the purpose of the study and anonymity procedures. After completing the questionnaires, the nurses were asked to retum them in an enclosed return envelope.

\subsubsection{Sample}

The sample consisted of 1855 nurses, $1253(68 \%)$ of whom returned the questionnaire. Nurses who had been employed for less than three months were excluded, because it was assumed that nurses need some time to adapt to their work siruation (cf. Boumans, 1990; De Jonge, 1995; Katz, 1978a, 1978b). This led to a final sample of 1204 nurses. Eighty-five percent of this sample were women. The mean age was 35.7 years $(\mathrm{SD}=8.7)$. The mean job experience was 15.5 years $(\mathrm{SD}=8.6$ ), while the mean working time on the ward was 6.8 years $(S D=6.2)$.

\section{$2.4 \quad$ Results}

\subsubsection{Descriptives}

The means, standard deviations, reliabilities, and the Pearson correlations for the variables under consideration are presented in Table 2.1 .

Although the correlations between the characteristics of the work organisation and the various work characteristics and psychological work reactions were not very high, it may be concluded from Table 2.1 that complexity appears to be positively corelated with workload, role conflict, emotional exhaustion, and psychosomatic health complaints. Complexity was negatively correlated with social support and job satisfaction. Environmentall uncertainty correlated positively with workload, role conflict, and intrinsic work motivation, and negatively with social support.

Decision authority correlated positively with autonomy, social support, intrinsic work motivation, and job satisfaction; it showed a negative correlation with role ambiguity.

The correlations between the different work characteristics and psychological work reactions were often significant and generally higher than $|.20|$. Workload, role conflict, and role ambiguity were positively correlated with emotional exhaustion and psychosomatic health complaints, whereas social support was negatively correlated with these outcome variables. 


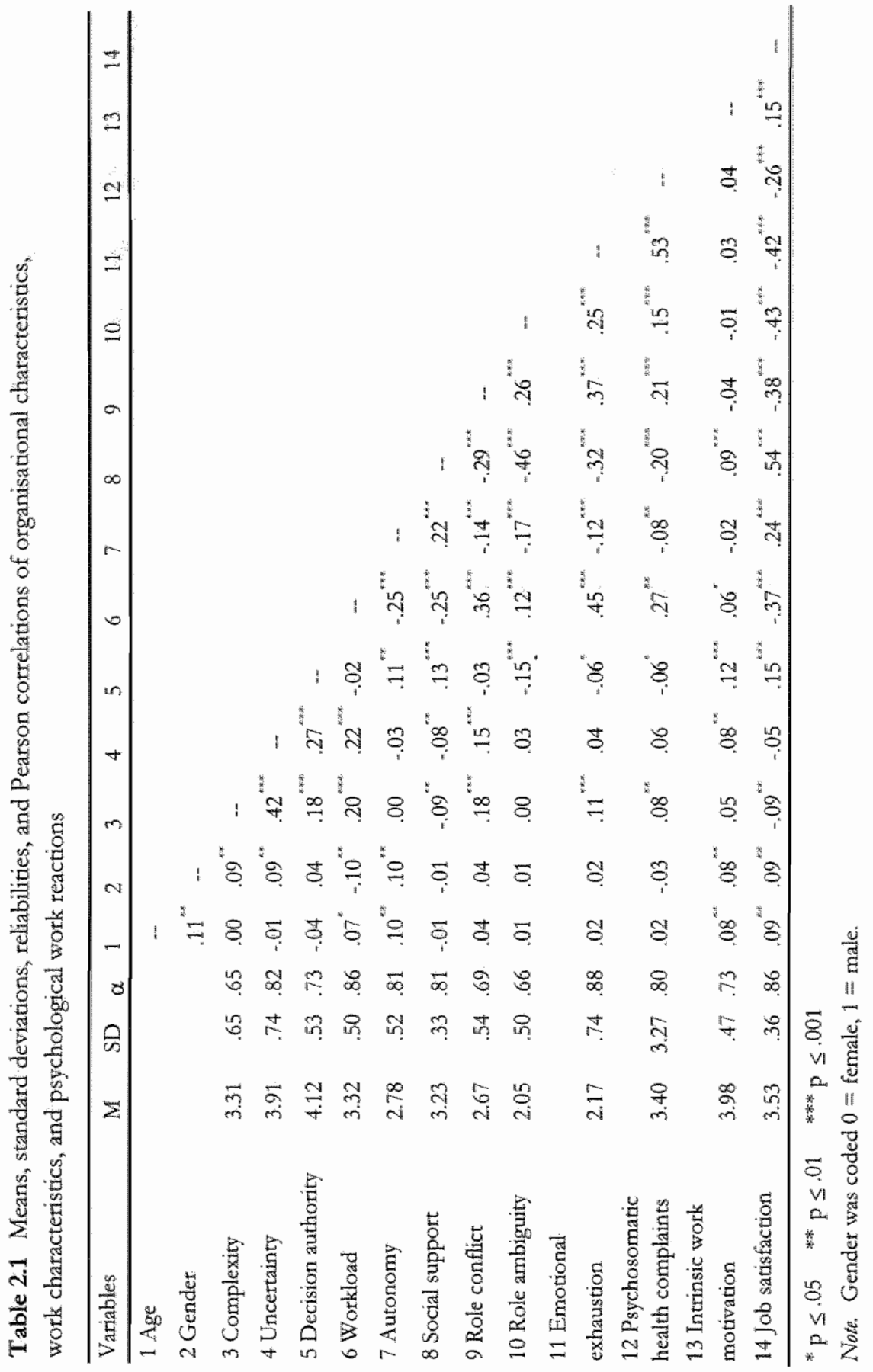


Workload and social support wete only weakly positively correlated with intrinsic work motivation. Finally, autonomy and social support appeared to correlate positively with job satisfaction, whereas workload, role conflict, and role ambiguity correlated negatively with job satisfaction.

\subsubsection{Regression analysis}

In order to investigate the relationships between: (a) characteristics of the work organisation and work characteristics, (b) characteristics of the work organisation and psychological work reactions and, (c) work characteristics and psychological work reactions, hierarchical multiple regression analysis was applied. All the variables included in the present study were standardised in order to reduce problems of multicollinearity (Aiken \& West, 1991; Kleinbaum, Kupper \& Morgenstem, 1982). Interaction effects were tested by computing cross-product terms of the standardised independent variables (Jaccard, Turrissi \& Wan, 1990; Kleinbaum et al., 1982).

\section{Relationships between characteristics of work organisation and work characteristics}

The characteristics of the work organisation decision authority, complexity, and uncertainty were entered as independent variables into the equation in two successive steps (Aiken \& West, 1991; Jaccard et al., 1990). Because gender and age appeared to be correlated with characteristics of the work organisation, work characteristics and psychological work reactions, both variables were entered in the first step of the regression analysis (see also Dallender, Nolan, Soares, Thomsen \& Arnetz, 1999; De Jonge, 1995; Roe, 1984). Thereafter, the characteristics of the work organisation, uncertainty, complexity, and decision authority, were entered respectively. In Table 2.2 , the results of the hierarchical multiple regression analysis concerning the relationships between complexity, uncertainty, and decision authority on the one hand, and workload, autonomy, social support, role conflict, and role ambiguity on the other, are presented.

We may conclude from Table 2.2 that relatively low percentages of the variances $\left(R^{2}\right)$ in workload, autonomy, social support, role conflict, and role ambiguity were explained by the selected predictors $(10 \%, 2 \%, 6 \%$ and $3 \%$, respectively). Nevertheless, the results showed that high uncertainty and complexity were predictive for high workload and high role conflict; to a lesser degree, these variables were predictive for low social support; high decision authority was predictive for high social support, low role conflict, and low role ambiguity. 
Table 2.2 Hicrarchical multiple regressions of organisational characteristics on wotk characteristics (N) $=1204$ )

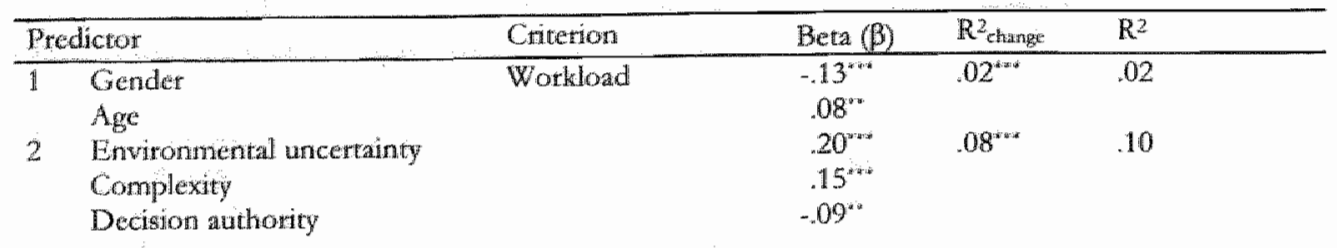

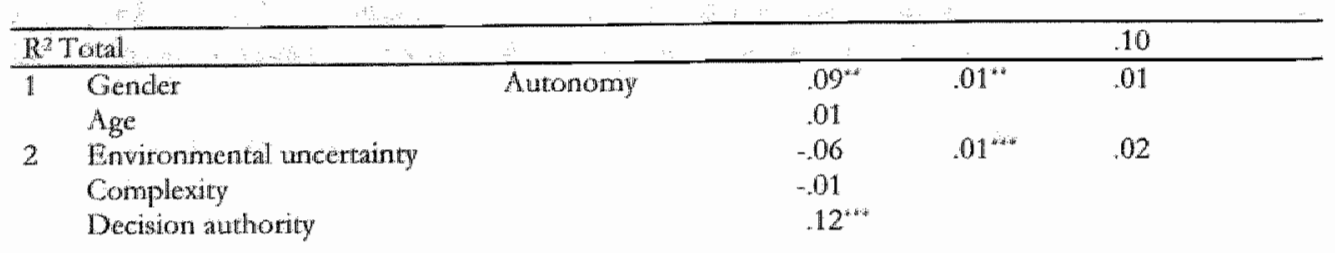

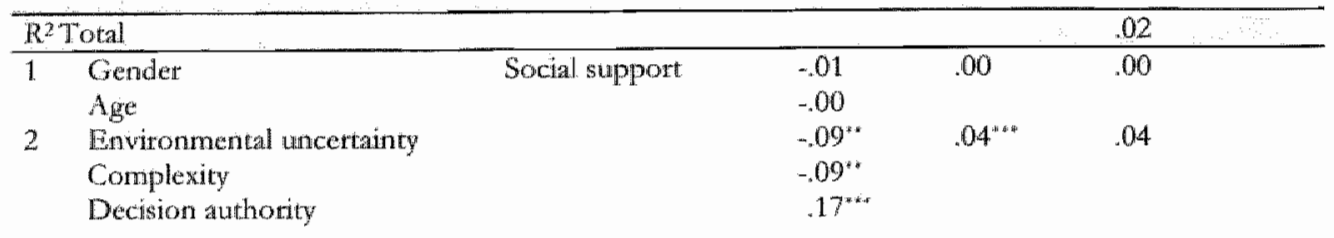

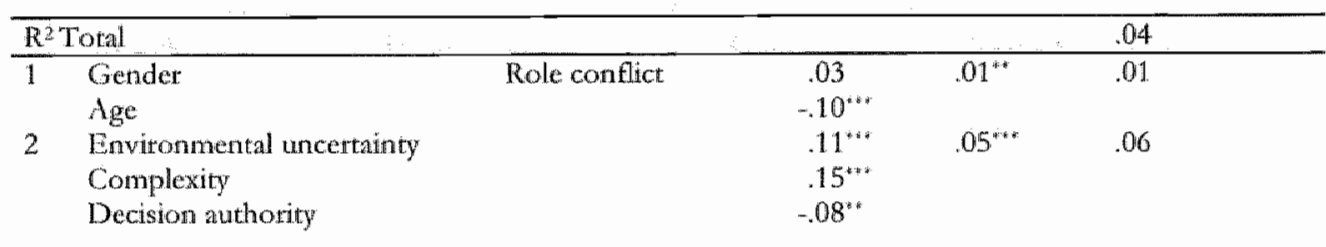

\begin{tabular}{|c|c|c|c|c|c|}
\hline \multicolumn{4}{|c|}{$R^{2}$ Total } & \multicolumn{2}{|r|}{.06} \\
\hline 1 & Gendar & Role ambiguity & .03 & .00 & .00 \\
\hline & Age & & -.06 & & \\
\hline \multirow[t]{3}{*}{2} & Banvifonmental uncertainty & & $.07^{*}$ & $.03^{4 * *}$ & .03 \\
\hline & Complexity & & .00 & & \\
\hline & Decision authority & & $-17^{1: 4}$ & & \\
\hline
\end{tabular}

Reriotal .03

"p $\leq .05 \quad$ "p $\leq .01 \quad$ "*4 $p \leq .001$

Notw. The $\beta$ values are the coefficients from the final stage of the regression analysis; due to rounding off, $\mathrm{R}^{2}$ differs 01 from the sum of $\mathrm{R}^{2}$ changw 


\section{Relationships between characteristics of work organisation and psychological work reactions}

In order to investigate which characteristics of the work organisation were predictive for emotional exhaustion, psychosomatic health complaints, job satisfaction, and intrinsic work motivation respectively, four hierarchical multiple regression analyses were performed for each criterion variable separately (see Table 2.3). We may conclude from Table 2.3 that again the percentages of explained variances and betas are relatively low: $2 \%, 2 \%, 5 \%$, and $3 \%$ respectively for emotional exhaustion, psychosomatic health complaints, job satisfaction, and intrinsic work motivation. Nevertheless, the results showed that high complexity and low decision authority were predictive for emotional exhaustion and psychosomatic health complaints. In addition, high decision authority was particularly predictive for job satisfaction and intrinsic work motivation. Besides, also low uncertainty and low complexity were predictive for high job satisfaction, although to a lesser degree.

\section{The mediating role of work characteristics}

In order to investigate the possible mediating role of work characteristics in the relationship between characteristics of the work organisation and psychological work reactions, hierarchical multiple regression analyses were performed, while controlling for the work characteristics in the second step of the regression analysis (in the first step, the background variables were entered into the analysis; see Table 2.4). After controlling for the work characteristics, the following conclusions can be drawn: complexity and decision authority did not additionally explain emotional exhaustion and psychosomatic health complaints. Twenty-nine per cent of emotional exhaustion was explained by the work characteristics. Characteristics of the work organisation only added $1 \%$ to the explained variance $\left(\Delta \mathrm{R}^{2}=.01\right)$. On the other hand, characteristics of the work organisation did not add any variance to the explanation of the psychosomatic health complaints $\left(\Delta \mathrm{R}^{2}=.00\right)$. Decision authority was still predictive for job satisfaction and intrinsic work motivation, although the betas were not very high $(\beta=.08$ and $\beta=.12$ respectively; $\mathrm{p} \leq .05)$. Complexity and uncertainty seemed not to additionally explain job satisfaction.

In summary, we may say that the relationship between the characteristics of the work organisation and psychological work reactions was explained by work characteristics. In orher words, work characteristics may be seen as mediator variables. An exception was decision authority. After controlling for work characteristics, decision authority was still predictive for job satisfaction and intrinsic work motivation. Thus, decision authority had a direct relationship with both variables. With the exception of intrinsic work motivation, the vatiances were explained by the work characteristics. Both work characteristics and the characteristics of the work organisation explained $2 \%$ of the variances of intrinsic work motivation. 
Table 2.3 Herarchical multiple regressions of organisational characteristics on psychological work reactions $(\mathrm{N}=1204)$

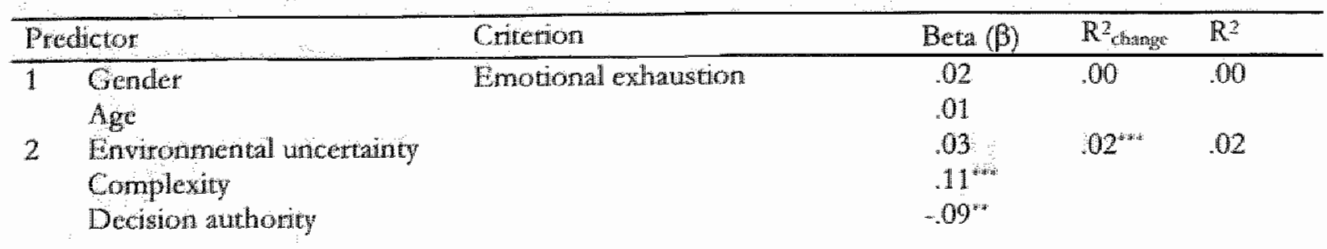

\begin{tabular}{|c|c|c|c|c|}
\hline Retotal & & & & .02 \\
\hline $\begin{array}{l}1 \text { Gender } \\
\text { Age }\end{array}$ & Psychosomatic health complaints & $\begin{array}{r}-.04 \\
.01\end{array}$ & .00 & .00 \\
\hline $\begin{array}{l}2 \text { Enwronmental uneertanty } \\
\text { Complexity } \\
\text { Decision authotity }\end{array}$ & & $\begin{array}{l}.06 \\
.08^{\circ} \\
.09^{*}\end{array}$ & $.02^{6 * *}$ & .02 \\
\hline
\end{tabular}

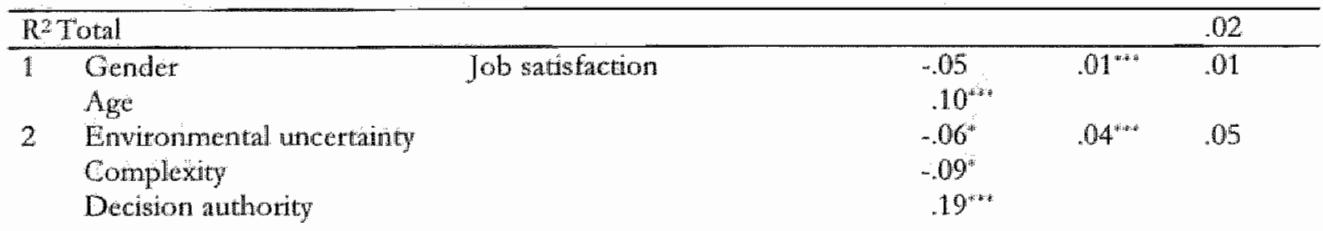

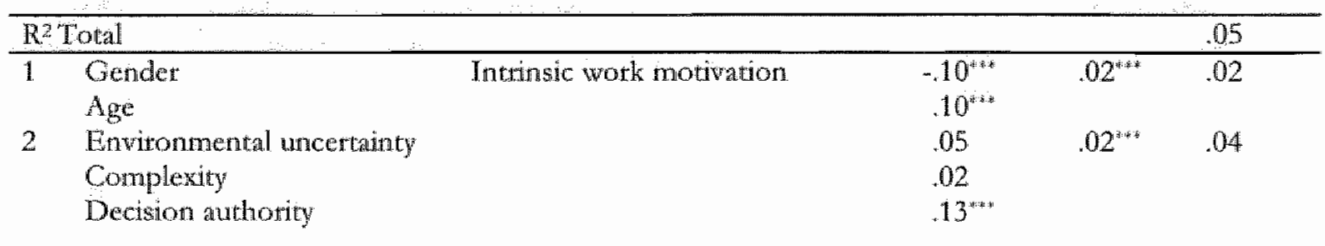

\begin{tabular}{lll}
\hline $\mathrm{R}^{2}$ Total & & 04 \\
\hline $\mathrm{p} \leq .05$ & $\mathrm{p} \leq .01$ &
\end{tabular}

Nort. The $\beta$ values are the coefficients from the final stage of the regression analysis; due to rounding off, $R^{2}$ differs 01 from the sum of $R^{2}$ daange. 
Table 2.4 Hierarchical multiple regressions of organisational characteristics on psychological wotk reactions with work chatacteristics as control variables $\mathrm{N}=1204$ )

\begin{tabular}{|c|c|c|c|c|c|}
\hline \multicolumn{2}{|c|}{ Predictor } & \multirow{2}{*}{$\begin{array}{l}\text { Citterion } \\
\text { Emotional exhatistion }\end{array}$} & \multirow{2}{*}{$\frac{\text { Betat }(\beta)}{.06^{i x}}$} & \multirow{2}{*}{$\begin{array}{l}\mathrm{R}^{2} \text { shinge } \\
.00\end{array}$} & \multirow{2}{*}{$\frac{\mathbb{R}^{2}}{.00}$} \\
\hline 1 & Gender & & & & \\
\hline & Age & & .01 & & \\
\hline \multirow[t]{5}{*}{2} & Workload & & $37^{\cdots}$ & $29^{i n i}$ & .30 \\
\hline & Autonomy & & .04 & & \\
\hline & Social support & & $-14^{x+1}$ & & \\
\hline & Role conflict & & $18^{i}$ & & \\
\hline & Role ambigurity & & $11^{\mathrm{nin}}$ & & \\
\hline \multirow[t]{3}{*}{3} & Envitonmental uncertainty & & $-.08^{* *}$ & .01 & .30 \\
\hline & Complexity & & .01 & & \\
\hline & Decision authority & & -.01 & & \\
\hline
\end{tabular}

\begin{tabular}{|c|c|c|c|c|c|}
\hline \multicolumn{5}{|c|}{$R^{2}$ Total } & \multirow{3}{*}{$\frac{.30}{.00}$} \\
\hline 1 & Gender & Psychosomatic healih & -.03 & .00 & \\
\hline & Age & complaints & .02 & & \\
\hline \multirow[t]{5}{*}{2} & Workload & & $19^{\circ}$ & $.10^{4+2}$ & .10 \\
\hline & Autconomy & & .02 & & \\
\hline & Social support: & & $-110^{* *}$ & & \\
\hline & Role conflict & & $09^{3 *}$ & & \\
\hline & Role ambiguity & & $.06^{*}$ & & \\
\hline \multirow[t]{3}{*}{3} & Enwrommental uncertaincy & &. .01 & .00 & .10 \\
\hline & Complexity & & .03 & & \\
\hline & Decision authorty & & -.05 & & \\
\hline
\end{tabular}

\begin{tabular}{|c|c|c|c|c|c|}
\hline \multicolumn{5}{|c|}{ R Toun } & \multirow{2}{*}{.01} \\
\hline 1 & Gender & Job satisfaction & $-.08^{0.8}$ & $.01^{* *}$ & \\
\hline & Age & & $.10^{4}$ & & \\
\hline \multirow[t]{5}{*}{2} & Workload & & $-21^{: *: k}$ & $41^{\cdots 3}$ & 42 \\
\hline & Autonomy & & $.00^{\circ}$ & & \\
\hline & Social support & & $.33^{* \cdots *}$ & & \\
\hline & Role conflict & & $\omega_{11} 15^{* *}$ & & \\
\hline & Role ambiguity & & $-118^{*+\cdots}$ & & \\
\hline \multirow[t]{3}{*}{3} & Environmental uncertanty & & .04 & $.01^{4 i x}$ & .43 \\
\hline & Complexity & & -.02 & & \\
\hline & Decision authority & & $.08^{* \prime}$ & & \\
\hline
\end{tabular}

\begin{tabular}{|c|c|c|c|c|c|}
\hline \multicolumn{5}{|c|}{$R^{2}$ Total } & \multirow{2}{*}{$\begin{array}{r}43 \\
.02\end{array}$} \\
\hline 1 & Gender & Intrinsic work motivation & $.09^{\prime \prime}$ & $.02^{n+4}$ & \\
\hline & Age & & $.09^{n+}$ & & \\
\hline \multirow[t]{5}{*}{2} & Workload & & $.08^{\circ}$ & $.02^{\prime *}$ & .03 \\
\hline & Autonomy & & -.03 & & \\
\hline & Social support & & $.13^{i+3}$ & & \\
\hline & Role contlict & & -.04 & & \\
\hline & Role ambignity & & 05 & & \\
\hline \multirow[t]{3}{*}{3} & Environmental uncertainty & & .04 & $.02^{n+\cdots}$ & .05 \\
\hline & Complexity & & .03 & & \\
\hline & Decision authority & & $.12^{n+s x}$ & & \\
\hline
\end{tabular}

$\mathrm{R}^{2}$ Total

"p $\leq .05 \quad " \mathrm{p} \leq .01 \quad$ "*** $\leq .001$

Note. The $\beta$ values are the coefficients from the final stage of the tegression analysis; due to rounding off, $\mathrm{R}^{2}$ differs 01 from the sum of $\mathbb{R}^{2}$ ethange- 


\section{Relationships between work characteristics and psychological work reactions}

Numetous studies in nursing have exploted the link between features of work charactetistics on the one hand and a variety of physical, behavioural, and psychological reactions on the other (e.g., De Jonge et al., 2000; Dollard et al, 2000; Janssen et al, 1999a; Landsbergis, 1988). In line with other studies that investigated interactions between autonomy, workload and social support (e.g., De Jonge, 1995; De Jonge et al, 2000), we included three (wo-way) interaction terms in our regression analyses, namely: wotkload sutonomy, workload $x$ social support and autonomy $x$ social support. In Tablc 2.5 , the results of the regression analyses are presented. From this Table, th can be seen that emotional exhaustion in nurses was relatively high if, in order of importance: workload was high $(\beta=.36)$; rolle conflict was high $(\beta=.18)$; social support was low $(\beta=-.14)$, and role ambiguity was high $(\beta=.11)$. In addition, a wo-way interaction effect was found between workload and social support $(\beta=-.08)$. This interaction effect suggests that high levels of social support buffet the negative effects of workload on emotional exhaustion. This is in line with findings of De Jonge (1995), for example.

High psychosomatic health complaints were predicted by: high wotkload $(\beta=.20) ;$ low social support $(\beta=-10)$, and high role conflict $(\beta=.09)$.

These results were also found in several other studies (e.g., Boumans, 1990 ; De Jonge et al., 2000). The explained variance of psychosomatic health complaints is, however, relatively low.

The explained variance of job satisfaction was relatively high $\left(R^{2}=.44\right)$. High job satisfaction was predicted by: high social support $(\beta=.33)$; low workload $(\beta=-21)$; low role ambiguity $(\beta=-19)$; low role conflict $(\beta=-14)$, and high autonomy $(\beta=.09)$.

Two two-way interaction effects for job satisfaction were found, namely: workload $x$ social support and autonomy $x$ social support. The interaction between workload and social support suggests that high levels of social support would buffer the negative effects of worliload on job satisfaction $(\beta=.08)$. If high levels of social support were received, the negative effect of workload on job satisfaction was weakened. This finding is in line with the results of the study of De Jonge et al. (1995). 
Table 2.5 Hierarchical multiple regtessions of work characteristics on psychological work reactions (N) $=1204)$

\begin{tabular}{|c|c|c|c|c|c|}
\hline \multicolumn{2}{|c|}{ Predictor } & \multirow{2}{*}{$\begin{array}{l}\text { Criterion } \\
\text { Ennotional exhaustion }\end{array}$} & \multirow{2}{*}{$\frac{\operatorname{Beta}(\beta)}{.05}$} & \multirow{2}{*}{ 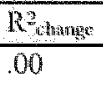 } & \multirow{2}{*}{$\frac{\mathrm{R}^{2}}{.00}$} \\
\hline 1 & Gender. & & & & \\
\hline & Age & & .01 & & \\
\hline 2 & Workload & & $.36^{* * *}$ & $20^{8 *}$ & .20 \\
\hline 3 & Autonomy & & .04 & .00 & .20 \\
\hline 4 & Social support & & $-.114^{\mathrm{nix}}$ & $.05^{232}$ & .25 \\
\hline 5 & Role conflice & & $.18^{4 n+}$ & $.04 * *$ & .29 \\
\hline & Role ambiguity & & $.11^{* 2}$ & & \\
\hline 6 & Workload $x$ autonomy & & .03 & .00 & .29 \\
\hline 7 & Workload $x$ social support & & $-.08^{\mathrm{ki}}$ & $.01^{\mathrm{k} *}$ & .30 \\
\hline 8 & Autonomy social support & & .03 & .00 & .30 \\
\hline
\end{tabular}

\begin{tabular}{|c|c|c|c|c|c|}
\hline \multicolumn{4}{|c|}{$\mathrm{R}^{2}$ Total } & & \multirow{2}{*}{$\begin{array}{c}.30 \\
.00\end{array}$} \\
\hline 1 & Gender & Psychosomatic health complaints & -.02 & .00 & \\
\hline & Age & & .01 & & \\
\hline 2 & Workload & & $.20^{* * * *}$ & $.07^{i \times \cdot d}$ & .07 \\
\hline 3 & Autonomy & & .01 & .00 & .07 \\
\hline 4 & Social support & & $-110^{6+4}$ & $.02^{* \cdots}$ & .08 \\
\hline 5 & Role conflict & & $.09^{* * 4}$ & $.02^{+.8}$ & .10 \\
\hline & Role ambiguity & & .06 & & \\
\hline 6 & Workload $\mathrm{x}$ autonomy & & .03 & .00 & .10 \\
\hline 7 & Workload x social support & & .04 & .00 & .10 \\
\hline 8 & Autonomy y social support & & .04 & .00 & .10 \\
\hline
\end{tabular}

\begin{tabular}{|c|c|c|c|c|}
\hline \multicolumn{4}{|c|}{$\mathrm{R}^{2}$ Total } & \multirow{2}{*}{.10} \\
\hline 1 & Job satisfaction & $-.07^{* h}$ & $.01^{t i b}$ & \\
\hline & Age & $.09^{\text {nin: }}$ & & \\
\hline 2 & Autonomy & $.07^{\mathrm{rkt}}$ & $.06^{* n+7}$ & .07 \\
\hline 3 & Social suppott & $.33^{*+1+0}$ & $.24^{* \text { *i. }}$ & .31 \\
\hline 4 & Workload & $-.21^{\cdots+\cdots}$ & $.06^{* \ldots+0}$ & .37 \\
\hline \multirow[t]{2}{*}{5} & Rolle conflict & $-.144^{n+10}$ & $.05^{\cdots+4}$ & .42 \\
\hline & Rolle ambiguity & $-19^{+1+2}$ & & \\
\hline 6 & Workload $x$ autonomy & .03 & $.00^{\circ}$ & .42 \\
\hline 7 & Workload $x$ social support & $.08^{w+1}$ & $.0 t^{\mathrm{wos}}$ & .43 \\
\hline 8 & Autonomy $x$ social support & $-.08^{*+1}$ & $.01^{+03}$ & .44 \\
\hline
\end{tabular}

\begin{tabular}{|c|c|c|c|c|c|}
\hline \multicolumn{5}{|c|}{$R^{2}$ Total } & \multirow{2}{*}{$\frac{44}{.02}$} \\
\hline 1 & Gender & Intrinsic work motivation & $-.09^{+1 *}$ & $.02^{*+4}$ & \\
\hline & Age & & $.08^{n *}$ & & \\
\hline 2 & Autonomy & &. .02 & .00 & .02 \\
\hline 3 & Social suppost. & & $.11^{n+3+}$ & $.01^{\circ+0.0}$ & .03 \\
\hline 4 & Workload & & $.07^{\prime \prime}$ & $.00^{\circ}$ & .03 \\
\hline 5 & Role conflict: & & -.04 & .00 & .03 \\
\hline & Role ambiguity & & .04 & & \\
\hline 6 & Workload $x$ autonomy & & .05 & .00 & .03 \\
\hline 7 & Workload $x$ social support & & .04 & .00 & .03 \\
\hline 8 & Autonomy $x$ social support & & .05 & .00 & .04 \\
\hline
\end{tabular}

\begin{tabular}{llll}
\hline $\mathbb{R}^{2}$ Total & & & 04 \\
\hline $\mathrm{p} \leq .05$ & "p $\leq .01$ & " $\mathrm{p} \leq .001$ &
\end{tabular}

Note. The $\beta$ values are the coefficients from the firal stage of the tegression analysis; due to rounding off, $\mathbb{R}^{2}$ differs .01 from the sum of $\mathbb{R}^{2}$ clantigic. 
The interaction effect between autonomy and social support $(\beta=-.08)$ suggests that high levels of social support enhanced the positive effect of autonomy on job satisfaction. This is in line with the buffer effect of social support found in comparable other studies (De Jonge et al., 1995).

Finally, although significant, the explained variance of intrinsic work motivation is relatively low. High intrinsic motivation was predicted by: high social support $(\beta=.11)$, and high workdoad $(\beta=.07)$.

\subsection{Discussion}

The aim of the current study was threefold. First, we explored relationships between characteristics of work organisation and work characteristics. Second, we investigated relationships between characteristics of the work organisation and psychological work reactions, and answered the question whether work characteristics operate as mediator variables in this relationship. Finally, we explored relationships between work characteristics and psychological work reactions.

With regard to the first aim of our study, we found that decision authority, in particular, appeared to be predictive for a high level of social support. When nurses perform several different kinds of tasks or have the authority to make decisions about ongoing nursing activities, social support appears to be higher. This finding might be explained by considering the organisational structure and its consequences for decision authority. In nursing practice, where the work is often organised to conform to the principles of task groups or self-autonomous teams, typical sociall relations are induced. Hence, one might expect a high level of decision authority to be related with high frequency and intensity of social relations.

Decision authority also appeared to predict autonomy. This finding is not surprising, since greater decision authority can be obtained by task enlargement (more different kind of tasks) and task enrichment (tasks from different organisational levels in the hierarchy), which enhances the autonomy of nurses.

Regatding the second aim of our study, the relationships between characteristics of the work organisation and psychological work reactions, we found that complexity and decision authority had an indirect effect on emotional exhaustion and psychosomatic health complaints.

The indirect effect of complexity on emotional exhaustion and psychosomatic health complaints was particularly due to the effect of complexity on workload, which, in turn, was related to both emotional exhaustion and psychosomatic health complaints. Workload therefore seems to operate as a mediator.

The indirect effect of decision authority on emotional exhaustion and psychosomatic health complaints seems to be due to the effects of decision authority on social support (positive) and role ambiguity (negative) which, in turn, were both related to emotional exhaustion and psychosomatic health complaints. Also in this relationship, we see the mediator effect. 
In addition to these indirect relationships of characteristics of the work organisation and psychological wotk reactions, direct positive relationships wete found, especially between decision authority and job satisfaction and intrinsic work motivation. High decision authority was associated with high job satisfaction and bigh intrinsic work motivation. By receiving more decision authority, personal needs may be met: workers have a greater responsibility which may enhance job attitudes like job satisfaction and intrinsic work motivation. This is in line with STS approach, and several psychological theories, such as the DCS model, and the Job Characteristics Model (Allgera, 1990; Hackman \& Oldham, 1975, 1976).

With regard to our third aim, we conclude that, in general, the relationships found were moderate to strong. Both main and interaction effects of work characteristics were found. High workload, low social support, high role conflict and high role ambiguity appeared to explain high emotional exhaustion. The level of autonomy, however, did not seem to predict emotional exhaustion. Schaufeli and Enzmann (1998) have conducted an extensive review of the burnout literature and concluded that burnout seemed to be less strongly correlated with work content variables (e.g, autonomy and feedback from the job) than with workload. Similat results were reported by Cronin-Stubbs and Brophy (1985), De Jonge (1995), Janssen, Schaufeli and Houkes (1999b) and Pines and Kanner (1982). In addition to the main effects on burnout, an interaction effect of workload and social support was found. Social support from colleagues or one's supervisor obviously helps nurses to cope effectively with their workload (Schaufeli, 1990).

Psychosomatic health complaints appeared to be explained by high workload, low social support, and high role conflicts. Several other studies confirm this finding (e.g., De Jonge et al., 2000; De Jonge \& Landeweerd, 1993).

Job satisfaction appeared to be particularly predicted by high social support, and low workload. To a lesser degree, low role conflict, low role ambiguity, and high autonomy were predictive for a high job satisfaction. Interaction effects were found between workload and social support and between autonomy and social support.

\subsection{Limitations}

Due to the cross-sectional data, the time sequence of the relationships among the variables could not be clearly assessed. Therefore, one must be caurious when interpreting them as causal (Zapf et al., 1996). The implied causal relationships are nevertheless in line with research in the work and health literature. $A$ longitudinal design may be advisable, although this design has also limitations, such as the problem of selecting appropriate time intervals (Frese \& Zapf, 1988; Kessler \& Greenberg, 1981) and the duration of such a study (time and financial restrictions).

A second limitation of our study was that only a relatively small amount of variance is explained. The explained variances found in our study tanged from $2 \%$ to $43 \%$. (Semmer, Zapf \& Greif, 1996) have argued that in stressor-strain relationships the 
amount of explained vatiance is in general not very high (ranging from $5 \%$ to $30 \%$ ). There are several reasons mentioned in the literature. The first is a substantive argument and tefers to the multi-causal aetiology of well-being and health, factors including, both work related and non-work related ones. Consequently, any separate study can not cover all relevant variables (Semmer et al, 1996). Second, the low variances may be due to the healthy worker effect (Koslowsky, 1998; Payne, Wall., Borrill \& Carter, 1999). A restriction of range in health and well-being outcomes might be possibly due to ill employees who are at home and have not participated in the study. The outcomes may therefore be an underestimation of the relationships. A last explanation might be that the data was analysed at the individual level with the consequence that group (or ward) characteristics might be averaged out over the wards. So, the explained variances at individual level might be lower than at ward level (Melchior, Van den Berg, Halfens, Huyer Abu-Saad, Philipsen \& Gassman, 1997b). To get insight into this phenomenon, future research probably might pay attention to individual-level and ward-level characteristics by performing, for instance, multillevel analysis.

However, since we found that characteristics of the work organisation are relevant in nurses' work, we think that our results are innovative and noteworthy despite the limitations. As such, they might offer a more precise insight into relationships between characteristics of the work organisation, the work itself and psychological work reactions. In addition, they may provide more empirically based suggestions for the improvement of nurses" work. 


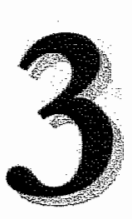

\title{
A comparative study of work characteristics and
}

\author{
psychological work reactions between
}

\author{
general and mental health nurses
}

Published as:

Tummers, G.E.R., Janssen, P.P.M. Landeweerd, J A. and Houkes, 1. (2001). A comparative study of work characteristics and teactions between general and mental health nurses: a multi-sample analysis. Jourval of Adwanced Nursing, 36(1), 151-162 



\subsection{Introduction}

Generally, health care workers are considered as an occupational group running an above-average risk of stress (Pines \& Kafry, 1978). In particular, hospital nurses have frequently been found to experience high levels of stress originating from a number of sources (e.g., Marshall, 1980; Tyler \& Cushway, 1992). "They are often underpaid considering the number of hours they work (Reeves, 1994). Workload is high and shift-working is distuptive to lifestyles. Consideration from superiors and adequate peer support is often lacking. These stress-related factors can eventually resulit in absenteeism and high staff turnover (Reeves, 1994).

Most work stress studies among health care workers have been conducted in general hospitals. This is understandable as general nurses are the largest and most visible group in health care (Cushway, Tyler \& Nolan, 1996; Dallender et al., 1999). However, health care is a diverse sector and the literature suggests important differences regarding the work of different categories in mursing, such as the work of general and mental health nurses (e.g., Cushway et all, 1996; Jones, Janman, Payne \& Rick, 1987). Insight into these differences and/or similarities might lead to more precise guidelines to improve the work simation of general and mental health nurses.

To gain insight into the processes that cause stress reactions and eventually illness, several theoretical frameworks have been developed. Two widely used and still wery prominent models in this context are the Job Demand-Control (DD-C) model (Karasek, 1979) and an extension of this, the Demand-Control-Support (DCS) model (Johnson \& Hall, 1988; Karasek \& Theorell, 1990). Research based on these models revealled that work aspects such as workload, autonomy, and social support are particularly important precursors of health complaints, stress reactions and job satisfaction. Some recent studies among health care workers have confirmed these results but suggested in addition that more specific predictions can be made regarding work characteristics and work reactions (e.g., De Jonge, 1995; Houkes et al., 2001a, 2001b, Houkes, 2002; Janssen et al., 1999). De Jonge (1995) reported, for example, that health complaints and emotional exhaustion are particularly predicted by workload and social support, and that job satisfaction is mainly predicred by autonomy. Janssen et al (1999) also found in their study among nurses working in a general hospital that emotional exhaustion is primarily predicted by mental work overload and social support, whereas intrinsic work motivation is predicted by quality of job content (e.g., autonomy, task identity, performance feedback).

A relatively small amount of research on this topic has been carried out in mental health care (Dallender et al., 1999). Some authors report that fundamental differences seem to exist between the work of general nurses and those working in psychiatric departments in general hospitals or in psychiatric hospitals (Cushway et al., 1996; Jones et al., 1987). Mental health nurses are primarily concerned with observing patients, guarding against violent behaviour, creating a therapeutic environment which will improwe parients' social behaviour, and, when necessary, providing medical care and attention (Jones et al., 1987). A typical aspect of mental health nurses' work, in 
addirion, is that they are frequently faced with patients who have relatively little chance of being resocialised or recovering (Landeweerd \& Boumans, 1988). This situation might lead to an imbalance between efforts and rewards (Melchior, Bours, Schmitz \& Wittich, 1997a), which is genetally conceived as very stressful. Other authors also consider mental health nurses' work as very stressful (Cushway et all, 1996; Jones et al,, 1987; Reeves, 1994; Savicki \& Cooley, 1987; Schaufeli, 1990).

To improve the work situation of general and mental health nurses, it would be helpful to investigate to what extent their work situation differs. More profound insight into specific relationships between work characteristics and reactions would in addition contribute to guidance on and underpinning of work-related interventions. In this study, we used the DCS model as a framework (see, for example, De Jonge, 1995; Landsbergis, 1988).

The purpose of the present study was first, to investigate whether thete are any differences concerning these work characteristics and work reactions between general and mental health nurses and second, to identify and walidate a pattern of specific rèlationships between work characteristics and work reactions in both groups.

\subsection{Theoretical background}

\subsubsection{The Demand-Control-Support model}

The DCS model (Johnson \& Hall, 1988; Karasek \& Theorell, 1990) is a threedimensional model that focuses on three work characteristics: job demands (e.g., workload), job control or decision latitude (e.g., autonomy) and social support. It is based on two central assumptions (e.g., De Jonge \& Kompier, 1997). The first is that psychological strains (such as psychosomatic health complaints and mental fatigue) occur particularly in jobs characterised by high job demands in combination with low decision latitude and low social support (high strain quadrant). The second important assumption is that work motivation as well as learning and development opportunities will occur in jobs characterised by high demands, high decision latitude and high social support (active collective quadrant). The DCS model is presented in Figure 3.1.

Several studies have tested the DCS model in nursing (e.g., De Jonge et al., 1996; Landsbergis, 1988; McLaney \& Hurrell, 1988). The results of these studies generally indicate that decision latitude or autonomy seems particularly to be related to job satisfaction and motivation, whereas job demands and social support seem particularly to be associated with health complaints and absenteeism. The DCS model is hypothesised to be a general model; that is, it should be applicable in multioccupational groups.

Therefore, in this study, we wanted to investigate whether the proposed pattern of relationships could be applied in both mental health and general nursing. 


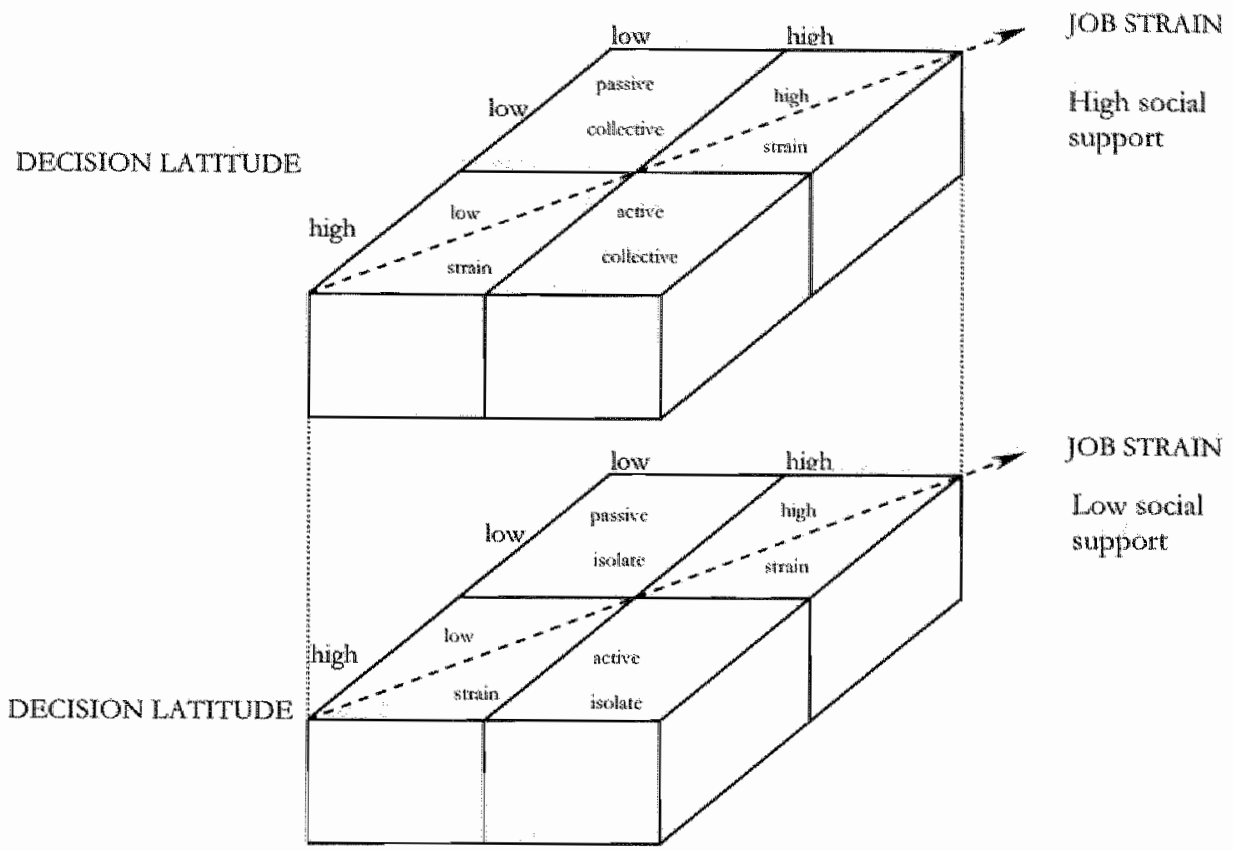

Figure 3.1 The Demand-Control-Support model

\subsubsection{Differences in work characteristics}

First, concerning the DCS variables, literature suggests that mental health murses have more autonomy than general nurses: mental health nurses are less dependent on each other in their work than general nurses because their roles primatily consist of individually observing and counselling mental health patients. Most mental health nurses' care occurs via nurse-patient interaction; hence, their interventions are less controllable than the work of general nurses (cf. Cronin-Stubbs \& Brophy, 1985; Dallender et al, 1999). De Jonge et al. (1995) compared work characteristics and work reacrions in several sectors of health care and reported that mental health nurses generally have more autonomy than their colleagues in general health care.

A second consecuence of the more individual working situation of mental health nurses is that peers have relatively few opportunities to enact in supportive interactions, and superiors thave limited opportunities to evaluate nurses" work tresults and give them adequate feedback. As a consequence, we expected social support to be lower in mental health nursing than in general nursing. Several studies support this expectation (Cronin-Stubbs \& Brophy, 1985; Jones et al., 1987). 
Third, as staff shortage is an overall problem in health care (and probably the main cause of high workload), we did not expect great differences in workload between general and mentall health nurses on the basis of the literature (Cushway et al., 1996).

\subsubsection{Differences in work reactions}

The DCS model does not outline specific psychological stress-teactions as potential work teactions. In the present study, we selected two different ontcome variables, namely burnout and job involvement, in order to represent the two assumptions of the DCS model regarding psychological strains and learning and development opportunities, respectively. We included burnout for three reasons. First, as a result of increasing job demands (e.g., budget constraints with the consequence of staff shortages, low salary, low carcer opportunities and less time for direct patient care), nurses show relatively high burnour levels (Reeves, 1994).

Second, health care workers differ significantly from other workers in the sense that they have frequent close contact with severe illness and death. Therefore, nurses are being considered as an occupational group running an above-average risk of bumout (Pines \& Maslach, 1978; Söderfeldt et al., 1995). They are expected to alleviate the distressing situation in which some patients and carers find themselves (Maslach \& Jackson, 1982). Often, they are exposed to intense physical and emotional suffering and they are regularly the focus of primitive transference reactions, both affectionate and hostile (Mowardi, 1983).

A third reason to include burnout in this study is that workload, social support, and, to a lesser extent, also autonomy have been found to be important predictors of burnout (Duquette et al., 1994; Lee \& Ashforth, 1996; Schaufeli \& Enzmann, 1998).

Although burnout might be an important stress reaction in both samples, it is suggested that burnout is higher in mental health nursing than in general nursing (Cushway et al., 1996; Jones et al., 1987; McLeod, 1997; Melchior et al, 1997a). The reason for this is that, as well as the problems mental health nurses share with general nurses (especially work overload because of staff shortages), mental health nurses are being confronted with a patient group that can be aggressive and suicidal (CroninStubbs \& Brophy, 1985; Cushway et al., 1996; Dawkins, Depp \& Selzer, 1985; Jones et al., 1987; Mcleod, 1997; Melchior et al., 1997a). Also, in mental health nursing, work is characterised by a greater inequity in the exchange process between nurses and patients, and by the unrealistic expectations nurses might have with regard to patients' potential for rehabilitation (Melchior et al., 1997a). According to Cronin-Stubbs and Brophy (1985) and Brown, Bartlett, Leary and Carson (1995), higher levels of emotional detachment and butnout among mental health nurses are a direct result of a restricted sense of personal accomplishment and less recognition and affirmation of their work from colleagues and supervisors.

Job inwolvement (an indicator of job motivation) is generally considered as an important issue in nursing work. Nurses often seem to choose a job in nursing because of intrinsic values, such as recognition, patient contact and task content. Job extrinsic 
factors, like sallary and careet opportunities are often low and can hardly be considered as major motivators in nurses' work. We selected job involvement as an outcome variable because it reflects the intrinsic wotk values mentioned above, and it refers to the growth dimension of the DCS model (Cook et al., 1981). We used the following classical definition of job involvement: "Job involvement is the degree to which one identifies psychologically with one's work, or the importance of one's work in one's total self-image" (Lodahl \& Kejner, 1965).

Only a few studies have investigated differences in job involvement between mental health and general nurses. According to Cronin-Stubbs and Brophy (1985), mental health nurses work more closely and intensively with patients over an extended period of time than general nurses do. In mental health nursing, patient counselling is often considered the most important task (e.g., Jones et al. 1987) which primarily leads to motivation and is relatively more important than in general hospitals. In general hospitals, technical skills are relatively more important, with the consequence of less emotional contact with patients (Schmitz \& Wittich, 1994). Therefore, we expected job involvement to be higher in mental health nursing.

\subsubsection{Specific relationships between work characteristics and work reactions}

The second purpose of this study was to identify specific relationships between the selected work characteristics and work reactions. In addition, we aimed to validate whether this pattern of relationships is similar in the two groups. Therefore, we now focus on specific relationships between the selected work characteristics and work reactions.

Schaufeli and Enzmann (1998) have conducted an extensive review of the burnout literature and has concluded that burnout is strongly related in particular to work overload, lack of social support and tole stress. Duquette et al. (1994) studied 300 documents on nursing burnout and found that the strongest correlates of bumout, besides social support and work overload, were role ambiguity, hardiness and active coping. Burnout seems to be less strongly related to work content variables (e.g., autonomy and feedback from the job). Simillat results were reported by, for instance, Pines and Kanner (1982), Janssen et al. (1999), and Houkes (2002). These findings may be explained by the Conservation of Resources 'Theory (COR) which states that individuals strive to obtain or maintain things (resources) they value (Hobfoll \& Freedy, 1993). In work, examples of these resources are satisfied clients and social support. Stress occurs when resources are threatened by demands (e.g., work overload), when resources are lost, or when investments of resources do not reap the expected level of return. Hobfoll and Freedy (1993) argue that demands are likely to make people feel insecure about their abilities to maintain or obtain resources and therefore trigger strain that is manifested in physical or emotional exhaustion. Resources help to overcome the need for defensive coping and enhance one's selfefficacy (Janssen et al., 1999a). In addition, lack of social support may contribute to the 
development of burnout, because opportunities to benefit from the protective effects of positive social contacts are reduced Janssen et all, 1999a; Sarason, Shearin, Pierce \& Sarason, 1987; Thoits, 1995). Social support from colleagues or one's supervisor in the working environment may help professionals to cope effectivelly with emotional experiences they are confronted with (Schaufeli, 1990). Social support may convince them that others care for them, respect and value them and that they are part of a network of communication and mutual support (Winnubst, 1993).

As mentioned previously, we used job involvement as a concept closely related to work motivation. According to Job Characteristics Theory, work motivation is primarily predicted by work content variables, like autonomy, skill variety, feedback and task significance (Hackman \& Oldham, 1976). Empirical evidence seems to support this theory (Hackman \& Oldham, 1976).

The literature on job involvement, however, is sparse (Lodahl \& Kejnex, 1965). Lawler and Hall (1970) found a significant, but low positive correlation, between several work characteristics (for example, autonomy) and job involvement. Because of the similarities between the concepts of job motivation and job involvement, we assumed that job involvement, like work motivation, is primarily predicted by autonomy.

Finally, as Karasek's model is considered to be a general model (i.e., the model holds in different samples), as mentioned previously, we hypothesised that the specific relationships discussed above are similar in both general and mental health nurses.

In sum, regarding our first purpose to investigate differences between general and mental health nurses with respect to work characteristics and work reactions, the following hypotheses were formulated:

(1) Autonomy is higher in mental health nursing than in general nursing;

(2) Social support is lower in mental health nursing than in general nursing;

(3) Workload is similar in mental health and genetal nursing;

(4) Burnout is higher in mental health nursing than in general nursing;

(5) Job involvement is higher in mental health nursing than in general nursing.

With regard to the second purpose of our study, the identification and validation of specific relationships between work characteristics and work reactions among genetal and mental health nurses, the following hypotheses were formulated:

(6) Burnout is primarily predicted by workload and social support;

(7) Job involvement is primarily predicted by autonomy;

(8) This pattern of relationships is similar and equivalent in the two groups.

These relationships are graphically presented in Figure 3.2. 


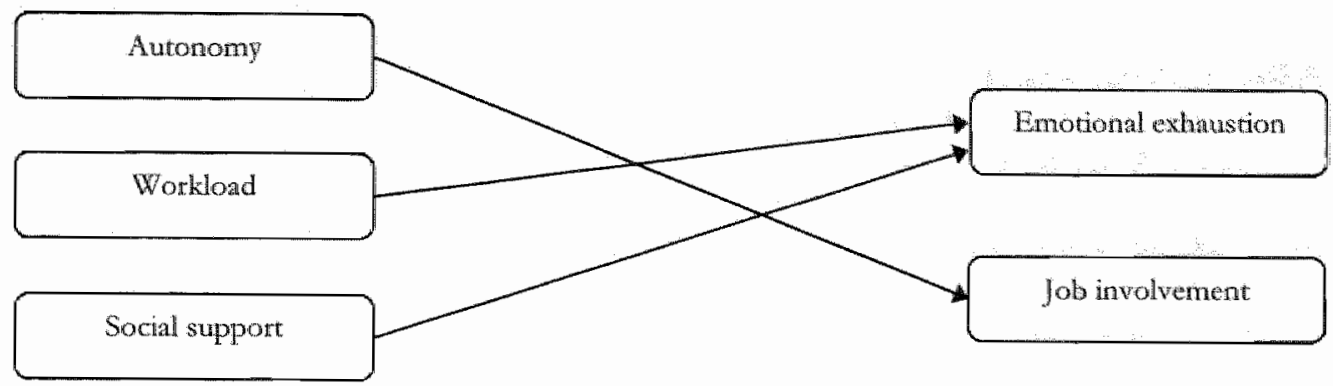

Figure 3.2 Research model

\subsection{Method}

\subsubsection{Procedure}

In order to measure the variables under study, self-report questionnaires wete administered in a general and psychiatric hospital in the Netherlands. Managers of both hospitals were asked to inform staff during wand meetings that a survey was about to be carried out. They also explained the purpose of the investigation. Questionnaires were distributed to all nurses from different departments. Participation was voluntary. We restricted our study to nurses who had been employed for more than three months. The questionnaires were distributed in a sealed envelope including an introductory letter. Respondents wete not asked to give their names. After completing the questionnaire, they were asked to return it in an enclosed neturn envelope. The completed questionnaires were thus treated anonymously. No one except the reseatchers could examine them.

\subsubsection{Samples}

In the geneal hospital (sample 1), questionnaires were administered to 317 genetal nutses, working on five different wards. In total, 196 usable questionnaires were returned (response $=61.8 \%$ ). The majorty of respondents wetre registered nurses $(77 \%)$, whereas the rest were student nurses. This sample consisted of mone women than men $(88.3 \%)$. The mean age of the general nurses was 28.3 years $(\mathrm{SD}=7.9)$. Mean job experience was 3.4 yeats $(S D=1.3)$, while mean working rime on the ward was 2.2 years $(\mathrm{SD}=1.3)$.

In the psychiatric hospital (sample 2), the questionnaire was administered to 280 mental health nurses, also from five different wards. One hundred and seventyweight usable questionnaires were returned (response $=63.6 \%$ ). Eighty-frve percent of the 
mental health nurses were registered nutses, whereas the remaining part of the sample consisted of student murses. Forty-three percent of respondents were female. Mean age in this sample was 34 years $(S D=7.2)$. Mean job experience was 8.8 years $(S D=6.0)$, with a mean working time on the ward of 5.3 years $(S D=4.6$ ).

\subsubsection{Measures}

We used self-report questionnaires to measure the work variables under study. The ratings we acquired are thus perceptions of the respondents.

\section{Work characteristics}

Antonomy was measured by the Maastricht Autonomy Questionnaire (MAQ), developed by De Jonge et al. (1995). Respondents were asked to rate their work situation as to the opportunities it offers for autonomy. This scale consists of 10 items with a 5 -point response scale ranging from 1 "very little opportunity" to 5 "very much opportunity". An example-item is: "The opportunity that the work offers to leave your workplace whenever you want". Cronbach's $\alpha$ in sample 1 was .82 and .83 in the secolnd sample.

Workload was measured by means of an 8-item scale, developed by De Jonge et al. (1995), with a response scale ranging from 1 "never" to 5 "always". The scale consists of a relatively wide range of both quantitatively and qualitatively demanding aspects in the work situation, like working uncler time pressure, working hard, strenuous work and task complexity (De Jonge, 1995). An example item is: "In the wnit where I work, thete is too little time to finish the work". Cronbach"s $\alpha$ was .80 for general nurses, compared with 83 for mental health nurses.

Social support at work (from colleagues and senior nursing officer) was measured by a 10 item scale, derived from a Dutch questionnaire on organisational stress ("Vragenlijst Organisatie Stress-Doetinchem" - VOS-D, Bergets et al., 1986). An example item is: "To what extent can you count on your colleagues, when you have difficulties in your work?" The items were scored on a 4 -point response scale format, ranging from 1 "never" to 4 "always". Cronbach's $\alpha$ was .81 for general nurses and .87 for mental health nutses.

\section{Work reactions}

Barnont is generally conceptualised as a syndrome of emotional exhaustion, depersonalisation, and reduced personal accomplishment (Maslach \& Jackson, 1986). Emotional exhaustion is considered as the core dimension of burnout (Buunk et all, 1994; Cox et al, 1993; Maslach, 1998; Shirom, 1989). Therefore, we selected emotional exhaustion to represent the concept of burnout. Emotional exhaustion was measured by means of the Dutch version of the Maslach Bumout Inventory (MBI, Maslach \& Jackson, 1986): the MBI-NL (Cox et al, 1993; Maslach, 1993; Schaufeli \& Van Dierendonck, 1993). The emotional exhaustion scale of the MBI-NL consists of eight items with a 7-point response scale ( $1=$ "never", $7=$ "always"). An example item is: "I 
feel emotionally drained by my work". Cronbach's $\alpha$ was .83 for general nurses and .85 for mental health nurses.

Jol inwolvement was measured by means of four items $1=$ "totally disagree", $5=$ "totally agree"), derived from a scale developed by Ladewig and White (1984) (see also Janssen, 1992). An example item is: "The most important things which happen to me involve my job." Cronbach"s $\alpha$ was .69 for general nurses and .74 for mental health nurses.

\subsection{Results}

\subsubsection{Testing differences between groups}

In order to test the first hypotheses (1-5) regarding the expected differences between general and mental health nurses' work (e.g., autonomy, workload, social support), and work reactions (e.g., emotional exhaustion and job involvement), MANOVA was carried out. MANOVA is used to evaluate mean differences regarding two or more dependent variables simultaneously. First, however, we investigated whether the background variables differed significantly between mental health and general nurses. The results showed that age and gender differed significantly between the two groups. Therefore, we decided to control for these variables: they were entered as covariates into MANOVA. MANOVA is preferred to ANOVA, because it can test more dependent variables simultaneously, and also controls for intercorrelations among the various dependent variables: it protects against Type I error due to multiple tests of (likely) correlated dependent vatrables (Tabachnick \& Fidell, 1996).

MANOVA showed that the differences in mean scores between general and mental health nurses were significant $(\mathrm{F}(5,342)=4.28, \mathrm{p} \leq .01)$. Also univatiate test results were calculated to explore whether specific variables might differ between the two groups. These results are presented in Table 3.1.

It may be concluded from Table 3.1 that the general and mental health nurses differed significantly in autonomy, emotional exhaustion, and job involvement. Mental health nurses showed significantly more autonomy and emotional exhaustion and significantly less job involvement. Workload and social support did not differ significantly between the two groups. 
Table 3.1 Unwariate teret results

\begin{tabular}{lllll}
\hline Vatiables & Mean genetal nurses & Mean mental health nurses & F & P \\
\hline Autonomy & 2.68 & 3.10 & 5.99 & $.02^{*}$ \\
Worklond & 3.16 & 3.12 & .01 & .92 \\
Social support & 3.21 & 3.30 & .66 & .42 \\
Emotional exhaustion & 2.65 & 3.05 & 5.63 & $.02^{\circ}$ \\
Job irvolvement & 2.27 & 2.07 & 5.03 & .03 \\
\hline
\end{tabular}

p $\leq .05$

\subsubsection{Testing the proposed pattern of relationships}

\section{Preliminary analysis}

In order to gain a global insight into the second and third research questions (hypotheses 6-8), some preliminary analyses were conducted in both samples (1.e., Pearson correlation analysis). The results of this preliminary analysis are shown in Table 3.2.

Table 3.2 Means, standard deviations, and Pearson correlations of sample 1 (general nurses; left-lower comer; $N=196$ ) and sample 2 (mental health aurses; tight-upper corner; $N=178$ )

\begin{tabular}{|c|c|c|c|c|c|c|c|c|c|}
\hline \multirow[b]{2}{*}{ Varimbles } & \multicolumn{2}{|c|}{ Samplle 1} & \multicolumn{2}{|c|}{ Sample 2} & \multicolumn{5}{|c|}{ Correlations } \\
\hline & M & $\mathrm{SD}$ & $M$ & $\mathrm{SD}$ & 1 & 2 & 3 & 4 & 5 \\
\hline 1 Autonomy & 2.68 & .58 & 3.10 & .56 & - & $-.34^{i .4}$ & $.29^{6 *}$ & $-.20^{24}$ & .05 \\
\hline 2. Workload & 3.16 & .49 & 3.12 & .58 & $-.24^{k-4}$ & - & -.02 & $.43^{*}$ & .03 \\
\hline 3 Social support & 3.21 & .39 & 3.30 & .51 & $.27^{* *}$ & -.17 & -- & $-.31^{k *}$ & -.06 \\
\hline 4 Emotional Exhaustion & 2.65 & .73 & 3.05 & .78 & $-.21 *$ & $.38^{*}$ & $-.27^{\text {vi:t }}$ & -- & .04 \\
\hline 5 Job involvement & 2.27 & .60 & 2.07 & .66 & .13 & -.05 & .04 & -.14 & -- \\
\hline
\end{tabular}

${ }^{\circ} \mathrm{p} \leq .05, " \mathrm{p} \leq .01$

The results show that the pattern of hypothesised relationships largely holds in both samples and that the relationships point in the expected directions. However, the hypothesised relationship between autonomy and job involvement was not significant in both samples.

\section{LISREL analysis}

In order to test the specific proposed pattern of relationships integrally and in both samples simultaneously, we used covariance structure analysis by means of LISREL 8.30 (Jöreskog \& Sörbom, 1996). IISREL uses structural equation modelling (SEM) as a statistical methodology that takes a confirmatory (i.e., hypothesis-testing) approach to the multivariate analysis of a structural theory (Byme, 1998). To investigate whether the proposed pattern of relationships is similar in general and mental health nurses, we used Multi-Sample Analysis (MSA). 
MSA can be used to analyse data from several samples simultaneously, with some or all parameters constrained to be equal over groups. More specifically, one can test whether the covariance or correlation matrices of the observed variables or relationships are equal for different groups (Jöreskog \& Sörbom, 1996). In addition, it is possible to test whether the proposed pattern of relationships is equal ("same pattern", or non-invariant) or even invariant ("same pattern" and "same strength") across groups (Byme, 1998). To test for invariance, we use the procedure recommended by Byme (1998). As a prerequisite to test for invariance, it is customary to consider a baseline model that is estimated separately for each sample. By means of these preliminary single-sample analyses, it is possible to detect a priori differences between samples. If the baseline model fits in both samples, this pattern of specific relationships can be tested simultaneously in the second step of the analysis (Byme, 1998). In the present study, we used the following recommended goodness-of-fit indices: the chi-square statistic (Chi-2 or $\chi^{2}$ ), the LISREL adjusted goodness-of-fit index (AGFI), the non-normed fit index (NNFI), the root mean square error of approximation (RMSEA), and, finally, the comparative fit index (CFI) (Bentler \& Bonett, 1980; Browne \& Cudeck, 1993; Jöreskog \& Sörbom, 1996; Schumacker \& Lomax, 1996). In addition to these fit measures, LISREL also reports $t$-values to indicate whether a relationship is significant $(t \geq 1.96)$ and 'Modification Indices'. 'The latter provide information about what specific relationships should be added to the model, when theorerically plausible, in order to improve the fit between the hypothesised model and the data (Hayduk, 1987; Jöreskog \& Sörbom, 1996; Saris \& Stronkhorst, 1984).

In the second step, invariance can be tested by means of MSA. Testing for invariance implies specifying a model in which particular parameters (i.e., specific paths in our proposed pattern of relationships) are constrained to be equal across groups and then comparing this model with a less restrictive model (non-invariant) in which these parameters are free to take any value by means of the $\chi^{2}$-difference test (Byrne, 1998). A non-significant $\Delta \chi^{2}$ indicates invariance. Our research model consists of three exogenous (independent) variables (workload, autonomy, and social support) and two endogenous (dependent) variables (emotional exhaustion and job involvement). The error variances of the endogenous variables themselves and the error variances regarding the relationship between the two endogenous variables were specified, because the model is not likely to be exhaustive. The endogenous variables may partly be predicted by other variables that are not included in the research model (MacCallum, Wegener, Uchino \& Fabrigar, 1993). The structural paths were specified according to hypotheses 6 and 7 (see also Figure 3.2).

Table 3.3 shows the results of the LISREL analysis for sample 1 and sample 2 separately. 
Table 3.3 Fit measures of sample 1 and sample 2 separately

\begin{tabular}{lllllll}
\hline Fir meiasures & $\chi^{2}(\mathrm{df})$ & AGFI & RMSEA & AlC & NNFI & CFI \\
\hline Sarmple 1 & $1.49(3)$ & .98 & .00 & 25.49 & 1.07 & 1.00 \\
Satruple 2 & $1.57(3)$ & .98 & .00 & 25.56 & 1.05 & 1.00 \\
\hline
\end{tabular}

"None of the Chi-squared tests were significant

We may conclude from Table 3.3 that the model fit is very good in both samples. The $\chi^{2}$ measures in both samples are not significant which means that the estimated cowariance matrices are a good approximation of the observed data (Schumacker \& Lomax, 1996). The other fir-indices show that the model fit in both samples is very good (NNFI $\geq .90$; AGFI $\geq .85$, RMSEA $\leq .05$; (Bentler, 1990; Schumacker \& Lomax, 1996; Verschuren, 1991).

When we consider the $t$-values of the specific relationships, it appears that the $\gamma$ of the hypothesised relationship between autonomy and job involvement was not significant in both samples ( $t=1.70$ in sample 1 and $t=0.69$ in sample 2). All other $t$-values were significant, whereas the modification indices showed that no further improvements could be made ( $\mathrm{MI}<5$ ).

We hypothesised that there are no significant differences between general and mental health nurses with regard to the hypothesised pattern of relationships (hypothesis 8). In order to test this hypothesis, we conducted MSA and compared the following nested models (i.e., each model is a special case of the preceding model by placing restrictions on particular parameters of the models, see Bentler \& Bonett, 1980; Jöreskog \& Sörbom, 1996):

MO: This independent (most restrictive: largest number of degrees of freedom) model assumes zero relationships between the variables ( $\Sigma$ is diagonal);

M1: The specified pattern of relationships (see Figure 3.2) was specified as invariant (i.e., relationships have the same strength and direction in both samples) actoss the two samples;

M2: The specified pattern of relationships (see Figure 3.2) was specified as 'same pattern". This means that the relationships show the same pattem, but the strength of the telationships is not constrained to be equal across the groups.

The results of these model comparisons are shown in Table 3.4. The specified M1 was compared with MO by means of the $\Delta \chi^{2}$-test. The difference between the $\chi^{2}$ of the two models proved to be significant, which means that M1 better accounts for the data than M0. Finally, we compared M2 with M1 in order to examine whether the hypothesis of the invariant model may be considered tenable (Byme, 1998; Jöreskog \& Sorrbom, 1996). Comparison of M2 with M1 showed that the difference in $\chi^{2}$ between these two models was not significant. This means that specification of more parameters, as is done in M2, does not yield a better model fit. When we consider the practical fit indices, it appears that M1 is also the best model in terms of moded companions: M1 shows the best combination of NNFI and CFI (relatively the highest). In terms of parsimony (in the sense of number of parameters, or degrees of freedom), M1 shows the lowest Akaike Information Criterion (AIC). Thus, M1 appears to be the 
best model in terms of both fit and parsimony. The pattern of relationships is invariant across both samples.

Table 3.4 Fit measures and likelihood ratio test of structural models in the multi-sample analysis

\begin{tabular}{lcllll}
\hline Model & $\chi^{2}$ & df & Comparison & $\Delta \chi^{2}$ & $\Delta$ df \\
\hline Null model (M0) & $103.38^{*}$ & 12 & & & \\
Invariant model (M1) & 3.67 & 9 & Mo ws. M1 & $99.71^{* *}$ & 3 \\
Non-invariant model (M2) & 3.06 & 6 & M1 ws. M2 & .61 & 3 \\
\hline Model & AGFI & RMSEA & AIC & NNFI & CFI \\
\hline Null model (M0) & .90 & .19 & 126.77 & .01 & .41 \\
Invariant model (M1) & 1.00 & .00 & 45.66 & 1.08 & 1.00 \\
Non-invariant model (M2) & 1.00 & .00 & 51.05 & 1.06 & 1.00 \\
\hline
\end{tabular}

${ }^{*} \mathrm{p} \leq .05,{ }^{* 4 *} \mathrm{p} \leq .001$

The complete LISREL model is depicted in Figure 3.3. It can be concluded from this Figure that emotional exhaustion is predicted by high workload and low social support.

Exogenous variables

Gammas

Endogenous variables

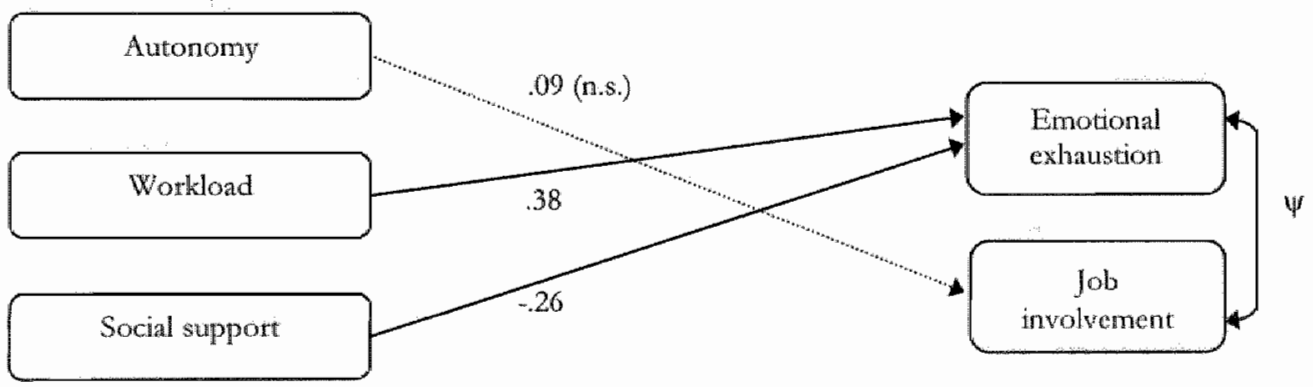

Figure 3.3 Complete ISRTiL model

\subsection{Discussion and conclusions}

The aim of the present study was twofold. First, we investigated whether there were differences in work characteristics (autonomy, workload, and social support) and work. reactions (emotional exhaustion and job involvement) between mental health and general nurses. We hypothesised that autonomy, emotional exhaustion and job involvement would be higher in mental health nursing, whereas social support was hypothesised to be lower in this group. Our second aim was to identify and validate a pattern of specific relationships between work characteristics and work reactions for 
both groups of nurses. We hypothesised that workload and social support would be primarily related to emotional exhaustion and that autonomy would be primarily related to job involvement. Finally, our last hypothesis was that there are no significant differences with regard to the hypothesised pattern of specific relationships between general and mental health nurses.

The hypotheses regarding the differences in work characteristics and work reactions were confirmed, except with regatd to social support and job involvement. Social support did not differ significantly between the two groups. Job involvement was even lower in mental health nurses than in general nurses. We also found that mental health nurses showed higher levels of emotional exhaustion than genetal nurses. It might be that higher emotional exhaustion leads to lower job involvement. Mental health nurses might withdraw from their work as a kind of protection or coping mechanism. Particularly in mental health work, where intensive patient contact is unavoidable, nurses may react to their feelings of emotional exhaustion by becoming less committed to their jobs (Eisenstat \& Felner, 1984).

The hypothesis that emotional exhaustion is primarily predicted by workload and social support was confirmed in both samples. High workload and limited social support appeared to increase emotional exhaustion. This is in line with the results of Janssen et al. (1999), who tested a similar pattern of relationship among a sample of nurses working in a general hospital.

The hypothesis that job involvement is primarily predicted by autonomy, however, was not confirmed. This might be explained by the fact that job involvement is also a function of the person, and not merely a reaction to characteristics of the job (Lawler \& Hall, 1970; Lodahl \& Kejner, 1965). This means that it may be mote of an individual difference factor than expected.

Considering the final hypothesis regarding the invariance of our proposed pattern of relationships, the results of MSA revealed that this pattern was invariant actoss both samples. This finding implies a strong validation of our tesearch model (cf. Byme, 1998) and is in line with previous studies in this sector (e.g., Janssen et al., 1999a).

\subsection{Practical implications}

The results of this study suggest several improvements regarding the work situation of mental health and general nurses.

First, we found that the workload was high in both categories of nursing. These scores do seem not to differ much from those found in other studies (e.g., De Jonge et al, 1995): standard references show a workload of 3.12 for general nurses $(3.16$ in this study) and 3.05 for mental health nurses ( 3.12 in this study). In addition, it proved that workload was an important predictor of emotional exhaustion. Workload can, for instance, be reduced by spreading it more equally among more units (Grünveld, 1992) or by balancing the work and spreading nursing activities over a working day (De Jonge, 1995). 
Second, we found that emotional exhaustion was higher among mental health nutses compared with general nurses. In addition, social support proved to be an important predictor of emotional exhaustion. Social support could be improved, for example, by creating social networks and social resources by providing courses on team building (De Jonge, 1995).

\subsection{Limitations of the study}

Because of the self-report nature of the data, and the correlational analyses employed, any attempt at a causal explanation of the results must remain tentative. A longitudinal study might reduce these limitations, although this design has also limitations, such as the problem of selecting appropriate time intervals (cf. Frese \& Zapf, 1988; Kessler \& Greenberg, 1981). Furthermore, we used subjective (self-report) measures to measure work characteristics and work reactions. Some authors suggest that the use of selfreport measures as indicators of the objective environment can be inappiopriate (see, for instance, Spector \& Jex, 1991; Taber \& Taylor, 1990). Other authors suggest, however, that perceptual measures of work variables reflect the objective environment to a large extent (Spector, 1992). Boumans and Landeweerd (1993) found, for example, that the correllations between 'objective' and 'subjective' measures were moderate to high. Even if changes rely on objective measures, it is generally advisable to take notice of the way nurses experience their work in order to complete the picture (cf. Spector, 1992) and to reduce resistance to change (Cummings \& Worley, 1997).

Nevertheless, as our results are in line with theory and the pattern of relationships holds in two samples, we think they are noteworthy and provide challenges for future research.

\section{Acknowledgements}

We gratefully acknowledge assistance from dr. Nicolle Boumans in a preliminary phase of this article. 


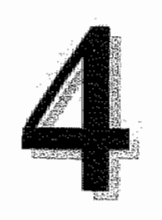

\title{
The diversity of work: Organisation, work
}

\author{
and psychological work reactions in
}

Intensive Care and non-Intensive Care nursing

Published as:

Tummers, G.E.R., Van Merode, G.G. \& Landeweerd, J.A. (2002). The diversity of work differences, similarities and relationships concerning characteristics of the organisation, the work and psychological work reactions in intensive care and non-intensive cate nursing. International Journal of Nursing Studies, $39(8), 841-855$ 


\subsection{Introduction}

Duting the last few decades, the work of nurses is of growing interest in the field of work and organisational psychology (Hockey, 2000; Wheeler, 1997; Wheeler \& Riding, 1994). Research has shown that murses are more prone to high stress levels in comparison with other occupational groups (Bourbonnais, Comean, Vézina \& Guylaine, 1998; Heim, 1991; Jayaratne \& Chess, 1984; Söderfeldt et al., 1995). In most nursing studies reviewed, frequently noted stressors that have been found were caused by psychosocial characteristics of the work: problems among staff, interpersonal conflicts with physicians or other nurses (Fornés Vives, Gallego Caminero, Barceló Oliver, Crespi Capó \& Gutierrez Casad, 1994; Numerof \& Abrams, 1984) and high workload (Fornés Vives et al., 1994; Keijsers, Schaufeli, Le Blanc, Zwerts \& Reis Miranda, 1995; Numerof \& Abrams, 1984).

Work stress studies among health care workers have been conducted in several health care setrings, such as in general nursing (Cash, 1997; Chiriboga \& Bailey, 1986; Cushway et al., 1996; Dallender et al., 1999; Keane, Ducette \& Adler, 1985; Kirkcaldy \& Martin, 2000; Reeves, 1994), psychiatric nursing (Cushway et al., 1996; Jones et al,, 1987; Laubach, Milch \& Ernst, 1999; McLeod, 1997; Reeves, 1994; Tummers, Janssen, Landeweerd \& Houkes, 2001) and intensive care nursing (Boumans \& Landeweerd, 1994; Cash, 1997; Keijsers et al., 1995; Rosenthal, Schmid \& Black, 1989; White \& Tonkin, 1991).

However, health care is a very diversified sector and literature suggests that stress reactions may not only be caused by work characteristics, but also by the type of nwring winit. A distinction that is often used in this context is the work in intensive care units (ICUs) and in non-ICUs. Particular features of the job of ICU nurses concern the responsibilities for the critically ill patients, the use of highly advanced technology and the need to make quick decisions as to sudden deterioration of patients. These factors make their work mentally and emotionally demanding (Iskra Golec, Folkard, Marek \& Noworol, 1996). Much debate exists as to whether in ICU nurses these emotional demands and stress, are greater than, equal to or less than among non-ICU nurses (White \& Tonkin, 1991), because the findings of comparative research between these two types of nursing are inconsistent (Cronin-Stubbs \& Rooks, 1985). Cross and Fallon (1985) and Oates and Oates (1996), for instance, found that ICU nurses had greater stress levels. On the other hand, Boumans and Landeweerd (1994) and Büssing and Schmitt (1998) reported less stress levels among ICU nurses. Also, some researchers did not find any differences between ICU nurses and non-ICU nurses (Chiriboga \& Bailey, 1986; Cronin-Stubbs \& Rooks, 1985; Dewe, 1988; Harris, 1989; Nichols, Springford \& Searle, 1981).

Differences in stress levels between ICU and non-ICU nurses might be explained by differences in work chatacteristics (e.g., workload or autonomy) or differences in the organisation of both types of units, such as the organisational structure (division of labour; Hollenbeck, 2000). This lack of clarity justifies that a more profound insight into differences and/or similatities between. ICUs and non-ICUs concerning the 
organisation of units, nurses' work and their psychological attitudes (e.g., stress) is needed.

To gain insight into the processes that cause stress reactions in nursing, several theoretical frameworks were developed. Two widely used and still very prominent models in this context are the Job Demand-Control (JD-C) model (Karasek, 1979) and an extension of this model, the Demand-Control-Support (DCS) model Johnson \& Hall, 1988). Research based on these models revealed that work aspects such as workload, autonomy, and social support are particulatly precursors of health complaints, stress reactions, job satisfaction and work motivation.

However, these models do not pay attention to the possible influence of organisational characteristics of nursing units. These models, and other well-known psychological models as well (such as the Job Characteristics model), only outline how work characteristics affect employees' well-being and health (1.e., the psychological work reactions), but do not make explicit which organisational factors determine work characteristics. It is worthwhile to explore whether organisational characteristics affect work characteristics and employees' attitudes (Lee \& Ashforth, 1991; Oldham \& Hackman, 1981; Schulz, Greenley \& Brown, 1995; Tummers, Landeweerd \& Van Merode, 2000). In this context, Oldham \& Hackman (1981) described the "Job Modification Framework". According to this framework, organisational characteristics may put specific demands on the work or tasks. The individual may conceive them as stressors which in turn may contribute to strains such as burnout or job dissatisfaction (Lee \& Ashforth, 1991; Oldham \& Hackman, 1981).

The inconclusive findings regarding differences in stress levels between ICU and nonICU nurses, together with the assumption that organisational characteristics may be precursors for work characteristics and nurses' attitudes, bring us to the aims of the current study. First, we want to investigate whether thete are any differences concerning organisational characteristics, work characteristics and psychological work reactions in both types of nursing units. Our second aim is to investigate and validate postulated relationships between organisational characteristics, work characteristics and psychological work reactions in these two groups.

\subsection{Theoretical Background}

\subsubsection{Differences in organisational characteristics}

In order to characterise nursing units with respect to organisational characteristics, the contingency approach has been used as a suitable theoretical framework in this context (Child, 1977; Galbraith, 1977; Lawrence \& Lorsch, 1967b). This approach describes characteristics of the technology of an organisation or unit (such as the complexity, and predictability) in relationship with its organisational structure (decentralised or centralised structure) and suggests that high effectiveness (such as job satisfaction) could only be obtained if the structure is adapted to its environmental conditions. 
Due to the critical conditions of patients, the work environment of an $1 \mathrm{CU}$ is very complex (Groen, 1995), because patients" needs involve continuous monitoring, the use of high medical technologies at the bedside, and cooperating with a diversity of health care disciplines (Boumans \& Landeweerd, 1994; Groen, 1995; Medcof \& Wegener, 1992).

There seem to be at least two uncertainty dimensions in ICUs that make the work more unpredictable for ICU nurses than for non-ICU nurses. The first is that a great number of patients suffer of unstable health conditions, such as a sudden deteriotation of their health states (Bodt, 1995; Bodt \& Van Tuill, 1988; Iskta Golec et al, 1996; Slocum \& Sims, 1980). The second dimension refers to the lack of sufficient information about the arrival of patients, because emergencies are a very common feature in ICUs (Slocum \& Sims, 1980). This uncertainty refers more to environmental uncertainty than to task uncertainty. The latter plays a less prominent role in ICUs (Bodt, 1995), because skills are standardised by means of professional training (Mintzberg, 1983), and concrete nursing and caring activities are formally written down in protocols.

Unpredictability in ICUs confronts the work organisation with the need for rapid adaptations (Bodt \& Van Tuijl, 1988; Bodt \& Van Tuijl, 1985; Groen, 1995). High uncertainty implies that the organisational structure should be such that it can adequately be addressed (Van Rossum, 1998). Dealing with the uncertainties of ICUs in combination with the frequent high-tisk situations of patients requires a flexible unit structure (Groen, 1995). The work could be co-ordinated by standardisation of skills and concrete activities (Crozier, 1964; Mintzberg, 1983), formalised in protocols. To much co-ordination, however, might be ineffective. Nurses must have the opportunity to make decisions on their own (Bodt, 1995; Galbraith, 1977; Slocum and Sims, 1980; Van Rossum, 1998). In that case, nurses have high decision authority which implicates that they are responsible for the whole caring process of a small group of patients. Because units operating in a continuously changing environment must response with a flexible unit structure (Hollenbeck, 2000), we expect decision authority to be higher in ICUs than in non-ICUs.

\subsubsection{Differences in work characteristics}

In order to characterise specific work characteristics and their psychological work reactions, we use the Demand-Control-Support model as our theoretical framework (see, for example, De Jonge, 1995; De Jonge et al., 1996; Dollard et al., 2000; Houkes et al., 2001a; Janssen et al., 1999a; Landsbergis, 1988).

We hypothesised autonomy to be higher in ICU nurses than in non-ICU nurses. The task of the ICU nurse requires more autonomous functioning (Mohl, Denny, Mote \& Coldwater, 1982) than does the task of non-ICU nurses because of their independent roles in observing patients (Groen, 1995). Mohl et al. (1982) and Boumans and Landeweerd (1994) found in their studies that autonomy among ICU nurses was significantly higher than among nurses who worked in other types of nursing units. 
in lack of control which may affect nurses' psychological and psychosomatic health. Landeweerd and Boumaris (1994), Melchior et al. (1997b) found that nurses who are working under complex circumstances reported higher levels of burnout. In the current study we hypothesise that uncertainty and complexity are primarily predictive for burnout.

\section{Relationships between organisational characteristics, work characteristics and psychological work reactions}

As mentioned earlier, the DCS model does not pay attention to factors that are precursors for work characteristics. Furthermore, we suppose that the relationships between organisational charactetistics and psychological work reactions are largely indirect, which means that the effects of the organisational characteristics on psychological work reactions are caused by the work chatacteristics. This assumption is consistent with Oldham \& Hackman's Job Modification Framework (Oldham \& Hackman, 1981).

In line with this theoretical framework, we assume that the relationship between decision authority and intrinsic work motivation is through autonomy. Decision authority is a structural characteristic indicating the degtee to which tasks and decisions about the work are decentralised. By means of decentralising decisions to nurses, nurses get greater responsibility and autonomy to fulfil their tasks. Hence, we expect that degree of autonomy can be influenced by the degree of decision authotity (unit structure). Our hypothesis is that the degree of decision authority will influence the degree of autonomy and thus the degree of intrinsic work motivation.

Next, we suppose that the relationship between uncertainty and complexity on the one hand and burnout on the other is through the workload. Workload is not only a function of task load, but also a function of organisational and environmental factors (Bi \& Salvendy, 1994). In the current study, we selected uncertainty and complexiry as characteristics of the organisational (unit) environment. According to Bi and Salvendy (1994), workload can be predicted by system parameters, like complexity and uncertainty. Uncertainty induces swings between the extremes of quiet and hectic periods with consequences for mental workload. Empirical evidence exists that as uncertainty decreases, workload is reduced (Knight \& Salvendy, 1981). Complexity of care may cause that more diagnostic and therapeutic procedures are possible, so that nurses are involved in more work diversity (Groen, 1995). An increase in the amount of work may cause higher workload. So, we hypothesise that uncertainty and complexity are primarily predictive for burnout through the workload.

Finally, the level of social support depends on the decision-making structure of a unit. A unit with a decentralised decision-making structure implies that nurses have to perform several kinds of tasks (in "depth" and in "broadness") with the consequence that the organisation of the unit is more "product"- or patient-oriented than taskoriented (Bodt, 1995; Bodt \& Van Tuill, 1988). Social relations are part of this "product" oriented organisational principle because nurses not only have an individual tesponsibility, but also have a "shared" responsibility for a group of parients (Groen, 
1995). This "shared" responsibility may lead to more consultation between nurses in comparison with a task-oriented organisation. Hence, one might expect that decision authority is positively related with social support.

To summarise, regarding our first aim to investigate differences between ICUs and non-ICUs with respect to organisational characteristics, and differences as to work characteristics and psychological work reactions between ICU and non-ICU nurses, the following hypotheses can be formulated:

(1) Complexity is higher in ICUs than in non-ICUs;

(2) Uncertainty is higher in ICUs than in non-ICUs;

(3) Decision authority is higher in ICUs than in non-ICUs;

(4) Autonomy is higher in ICU nurses than in non-ICU nurses;

(5) Burnout is higher in ICU nurses than in non-ICU nurses.

With regard to the second aim of our study to identify and validate relationships between the organisational characteristics and psychological work reactions, the following hypotheses can be formulated:

Relationships between work, characteristics and psycbological marke reactions:

H1: Burnout is primarily predicted by workload and lack of social support;

$\mathrm{H} 2$ : Intrinsic work motivation is primarily predicted by autonomy;

Relationsbips between organisational characteristics, work characteristics and psychological work reactions:

143: Workload is primarily predicted by uncertainty and complexity;

H4: Burnout is primarily predicted by uncertainty and complexity through workload;

H5: Autonomy is primarily predicted by decision authority;

H6: Intrinsic work motivation is primarily predicted by decision authority thivorgh autonomy;

H7: Social support is primarily predicted by decision authority.

These hypothesised relationships are presented in Figure 4.1.

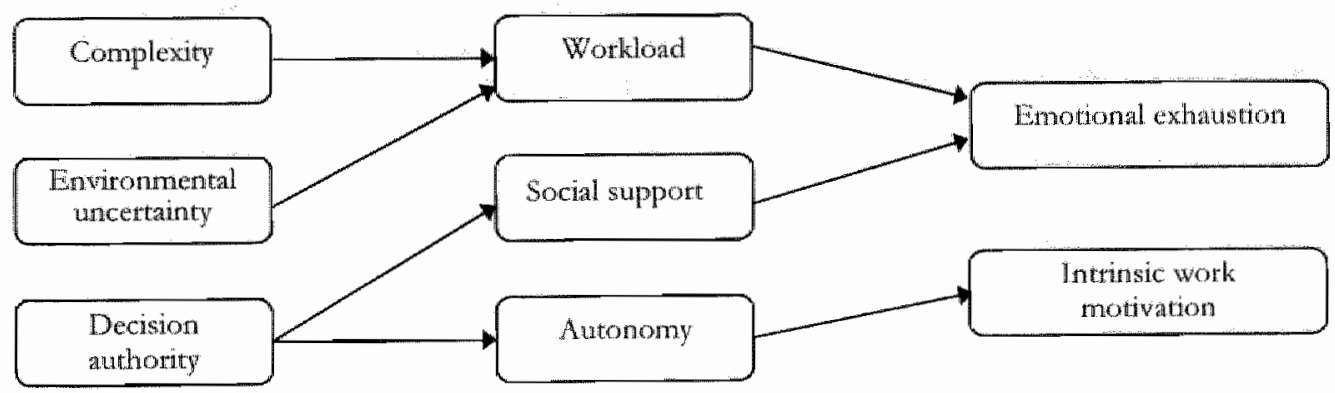

Figure 4.1 Research model 


\subsection{Method}

\subsubsection{Procedure}

Questionnaires were distributed among 98 nursing units from 15 general hospitals in the Netherlands. The settings of the 15 hospitals from which the research participants were selected included intensive cate units, medical, and surgical units. Managers of the units were asked to inform staff and nurses during the ward meeting about the purpose of the investigation and asked them to take part in it. The questionnaires were distributed in a sealed envelop including an introductory letter and they were told that their anonymity would be preserved (they were not asked to flll out their names). After three weeks, a reminder was sent to all the managers of the participated units to ask those who had not filled out the questionnaires to do this as yet. Thereafter, the questionnaires were sent back to the researchers.

\subsubsection{Samples}

\section{Sample 1 (ICU nurses)}

Two hundred and sixty-one questionnaires were distributed among nurses in 13 ICUs. In total, 184 questionnaires were returned (response rate is $71 \%$ ). The sample of ICU nurses consisted of 118 women $(64 \%)$. The mean age of the ICU nurses was 35.8 years $(\mathrm{SD}=6.4)$. The mean job expetience was 17.0 years $(\mathrm{SD}=6.5)$, while the mean working time on the unit was 8.0 years $(\mathrm{SD}=6.2)$.

\section{Sample 2 (non-ICU nurses)}

The original sample of non-ICU nurses consisted of 927 nurses (response rate is 65\%) who worked in units of internal medicine, cardiology, paediatrics, oncology, pneumonology, (neuro-) surgery, gynaecology and orthopaedics. In order to analyse the data, we have used the LISREL computer program. However, it is not advisable to analyse the whole sample of non-ICU nurses with LISREL because the $\chi^{2}$, which is the only staristical fit inclex that LISREL estimates, is sensitive to sample size. As sample size increases (generally above 200), the $\chi^{2}$ test has a tendency to indicate a significant probability level (Schumacker \& Lomax, 1996). To deal with this problem of sample size, 200 non-ICU nutses were tandomly selected out of the original sample of 927. This sample appeared to be tepresentative for all the non-ICU nurses that participated in our study, because no significant differences were found regarding demographic characteristics nor regarding to the research variables (see also Browne \& Cudeck, 1993; Schumacker \& Lomax, 1996). Ninety-one per cent of this sample were women, wherens the mean age was 35.7 years $(\mathrm{SD}=9.2$ ). The mean job experience in this sample was 15.3 years $(S D=9.1)$, whereas the mean working time on the unit was 6.3 years $(\mathrm{SD}=6.0)$. 


\subsubsection{Measures}

\section{Organisational characteristics}

Enwronytental whertainty was measured by means of five items, developed by Wibbelink (1995) and Tummers (1998). Its response categories ranged from 1 "totally disagree" to 5 "totally agree". An item example is: "There are daily emergency admittances on this unit".

Complexity was measured by a 9-item questionnaire with a five-point response scale, ranging from 1 "totally disagree" to 5 "totally agree". The scale was derived from (Mandemakers, 1993) and was further adapted by Wibbelink (1995) and Tummers (1998). An item example is: "Patients on this unit show various clinical pictures that can be divided into different specialities".

Decision aythority was measured by means of six items. The response categories ranged from 1 "totally disagree" to 5 "totally agree". The scale was derived from Bodt (1995) and Boone and de Jonge (1996). An item example is: "A nurse is able to make decisions about patient care on her own".

\section{Work characteristics}

Antonony was measured by the Maastricht Autonomy Questionnaire (MAQ), developed by De Jonge et al. (1995). Respondents were asked to tate their work situations as to the oppottunities it offers for autonomy. This scale consists of 10 items with a 5 -point response scale ranging from 1 "very little opportunity" to 5 "very much opportunity". An item example is: "The opportunity that the work offers to determine the method of working yourself".

Workload was measured by means of an 8 -item scale, developed by De Jonge et al. (1995), with a response scale ranging from 1 "never" to 5 "always". "The scale consists of a relatively wide range of both quantitatively and qualitatively demanding aspects in the work situation, like working under time pressure, working hatd, and strenuous work (De Jonge, 1995). An item example is: "In the unit where I work, there is too little time to finish the work".

Social support at iwork (from colleagues and senior nursing officer) was measured by means of a 10-item scale, derived from a Dutch questionnaire on organisational stress ("Vragenlijst Organisatie Stress-Doetinchem" - VOS-D, Bergers et al, 1986). An item example is: "To what extent can you count on your colleagues, when you have difficulties in your work?" The items were scored on a 4-point response scale format, ranging from 1 "never" to 4 "always".

\section{Psychological work reactions}

Bumout is generally conceptualised as a syndrome of emotional exhaustion, depersonalisation, and reduced personal accomplishment (Maslach \& Jackson, 1986). Emotional exhaustion is considered as the core dimension of bumout (Buunk \& Schaufeli, 1993; Cox et al, 1993; Maslach, 1998; Shirom, 1989). Thetefore, we selected 
emotional exhaustion to represent the concept of burnout. Emotional exhaustion was measured by means of the Dutch version of the Maslach Burnout Inventory (MBI, Maslach \& Jackson, 1986): the MBI-NL (Cox et al., 1993; Maslach, 1993; Schaufeli \& Van Dierendonck, 1993). The emotional exhaustion scale of the MBI-NL consists of eight items with a 7 -point response scale $(1=$ "never", $7=$ "always"). An example-item is: "I feel emotionally drained from my work".

Intrinsic work motivation was measured by means of six items derived from a scale developed by Warr et al. (1979). It tesponse categories ranged from 1 "totally disagree" to 5 "totally agree". An item example is: "My opinion of myself goes down when I do this job badly".

\subsubsection{Data analysis}

In order to test simultaneously whether the proposed pattern of relationships is similar in both samples, we performed Multi-Sample Analysis (MSA) by means of the LISREL. 8 computer program (Jöreskog \& Sörbom, 1996). MSA can be used to analyse data from several samples simultaneously with some or all parameters to be equal over groups. More specifically, one can test whether the covariance matrices of the observed variables or telationships are equal ("same pattern", or invariant) or even invariant ("same pattern" and "same strength") across groups (Byrne, 1998; Jöreskog \& Sörbom, 1996). "To test for invariance, we use the procedure recommended by Byrne (1998). As a prerequisite to test for invariance, it is customary to consider a baseline model that is estimated separately for each group or sample because these analyses offer the opportunity to detect a priori differences between samples. After the estimation of the baseline model for each sample separately, the specified pattern of relationships can be tested for invariance in both samples simultaneously if certain relationships appeared to be the same for both groups (Byrne, 1998). Besides, additional relationships can be specified for each sample separately, where appropriate (Hoyle \& Smith, 1994; Schumacker \& Lomax, 1996). Testing for invariance implies specifying a model in which particular parameters (i.e., specific paths in our proposed pattern of relationships) are constrained to be equal across groups and then comparing this model with a less restrictive model (non-invariant) in which these parameters are free to take any value by means of the $\chi^{2}$-difference test (Byme, 1998; Jöreskog \& Sorrbom, 1993, 1996). A non-significant $\chi^{2}$ indicates invariance.

In order to test the mediation hypotheses ( 4 and 6 ), we use the procedure suggested by Holmbeck (1997). We first assess the fit of the direct effect model which can be charactetised as the most restrictive model (only $\gamma$ paths from the exogenous variables (complexity and uncertainty) to the endogenous variables (intrinsic work motivation and emotional exhaustion) are specified). Thereafter, we specify the indirect (less restrictive) model which also included the specification of the mediation paths ( $\gamma$ paths from the exogenous variables to the mediational variables and $\beta$ paths from the mediation variables to the endogenous variables). The indirect model is preferred to 
the direct model if the $\chi^{2}$ - difference test between the indirect and the direct model is significant.

In order to support the mediation variables in the indirect model, the following conditions must be met: (a) variations in levels of the exogenous variable significantly accounts for variations in the presumed mediator, (b) variations in the mediator significantly account for variations in the endogenous variable, and (c) when these variations are controlled, a previously significant relationship between the exogenous and endogenous variable (the direct effect between the exogenous and the endogenous variable in the $\Gamma$ matrix) is no longer significant, with the strongest effect of mediation occurring when the relationship between the exogenous and endogenous variable is zero (Baron \& Kenny, 1986; Brown, 1997).

In the present study, we use the following, commonly used goodness-of-fit indices in order to evaluate the overall fit of our models: the chi-square statistic (Chi-2 or $\chi^{2}$ ), the LISREL adjusted goodness-of-fit index (AGFI), the non-normed fit index (NNFI), the root mean square error of approximation (RMSEA), and, finally, the compatative fit index (CF) (Bentler, 1990; Browne \& Cudeck, 1993; Jöreskog \& Sörbom, 1996; Schumacker \& Lomax, 1996).

\subsection{Results}

\subsubsection{Testing differences between ICU and non-ICU nurses}

In order to test whether ICUs and non-ICUs differ regarding the organisational characteristics and whether nurses differ in work characteristics, and psychological work reactions (hypotheses 1 to 5), MANOVA was carried out. First, we investigated whether the background variables differed significantly between ICU and non-ICU nurses. The results showed that gender $\left(\chi^{2}(1)=37.51, p \leq .001\right)$, education $\left(\chi^{2}\right.$ $(6)=69.73, p \leq .001$ ), job experience (Mann-Whitncy $Z=-2.55, \mathrm{p} \leq .01$ ), working time on the ward (Mann-Whitney $Z=-3.14, p \leq .01$ ), and working time in the hospital (Mann-Whitney $Z=-2.25, p \leq .05)$ differed significantly between the two groups. Therefore, we decided to control for these variables by entering them as covariates into MANOVA. MANOVA is preferred to ANOVA because it can test more dependent variables simultaneously, and also controls for the intercortelations among the various dependent variables: it protects against Type I error due to multiple tests of (likely) correlated dependent variables (Bray \& Maxwell, 1985; Tabachnick \& Fidell, 1996). MANOVA showed that the differences between the mean scores of the $1 \mathrm{CU}$ and non- ICU nurses were significant $(\mathrm{F}(8,356)=27.19, \mathrm{p} \leq .001)$. Therefore, univariate analysis (ANOVA) was done to locate the sources of the differences. These results are presented in Table 4.1.

It may be concluded from Table 4.1 that complexity, uncertainty, and decision authority were significantly higher in ICUs than in non-ICUs, whereas ICU nurses showed significantly less workload, and less emotional exhaustion. As expected, the 
two groups did not differ significantly as to autonomy, social support and intrinsic work motivation.

Table 4.1 Univariate tost results

\begin{tabular}{|c|c|c|c|}
\hline Variables: & Mean ICU & Mean non $1 \mathrm{CU}$ & $\mathrm{F}$ \\
\hline Complexiry & 4.01 & 3.29 & $88.31^{1+2.35}$ \\
\hline Environmental uncertainty & 4.47 & 3.85 & $74.48^{i=* x}$ \\
\hline Decision 2uthority & 4.37 & 4.11 & $14.56^{* \alpha x}$ \\
\hline Autonony & 2.87 & 2.80 & 1.74 \\
\hline Workloaxi & 3.09 & 3.35 & $19.12^{\text {ain }}$ \\
\hline Social support & 3.20 & 3.26 & 1.46 \\
\hline Emotional exhaustion & 2.01 & 2.23 & $8.72^{* \text { in }}$ \\
\hline Intrinsic work motivation & 3.87 & 4.00 & 3.80 \\
\hline
\end{tabular}

"p $\leq .01 " \mathrm{p} \leq .001$

\subsubsection{Testing the proposed relationships}

\section{Preliminaty analysis}

Prior to the LISREL analyses, the means, standard deviations, Cronbach's alphas, and Pearson correlations were computed for both samples in order to gain a first insight into the data (see Table $4.2 \mathrm{a}$ and Table $4.2 \mathrm{~b}$ ). We may conclude that the internal consistencies were in generall quite acceptable. The results of the correlation analysis revealed that the proposed pattern of relationships was partly confirmed in both samples. Contrary to our expectations, we found that uncertainty was negatively correlated with emotional exhaustion in ICU nursing. We shall offer possible explanations for this finding in the discussion.

Table 4.2a Means, standard deviations, and Cronbachs alphas of sample 1 and sample 2

\begin{tabular}{|c|c|c|c|c|c|c|}
\hline \multirow[b]{2}{*}{ Vatiables } & \multicolumn{3}{|c|}{ Saniple $1(N=184)$} & \multicolumn{3}{|c|}{ Sample $2(\mathrm{~N}=200)$} \\
\hline & $\mathrm{M}$ & SD & $\alpha$ & $\mathrm{M}$ & $\mathrm{SD}$ & $\alpha$ \\
\hline 1 Complexigy & 4.01 & 0.57 & 0.72 & 3.29 & 0.58 & 0.60 \\
\hline 2 Ervitonmental uncertaingy & 4.47 & 0.82 & 0.81 & 3.85 & 0.69 & 0.77 \\
\hline 3 Decision nuthonity & 4.37 & 0.66 & 0.77 & 4.11 & 0.47 & 0.71 \\
\hline 4. Autonomy & 2.87 & 0.62 & 0.80 & $2: 80$ & 0.48 & 0.78 \\
\hline 5 Worklond & 3.09 & 0.48 & 0.78 & 3.35 & 0.54 & 0.89 \\
\hline 6 Social support & 3.20 & 0.32 & 0.81 & 3.26 & 0.34 & 0.82 \\
\hline 7 Butrtout & 2.01 & 0.77 & 0.88 & 2.23 & 0.77 & 0.88 \\
\hline 8 Intrinsic work motivation & 3.87 & 0.43 & 0.72 & 400 & 0.51 & $0.7 ?$ \\
\hline
\end{tabular}


Table 4.2b Pearson correlations of sample 1 (ICU nurses; left-lower comer) and sample 2 (non-liCU) nurses; right-upper comer)

\begin{tabular}{|c|c|c|c|c|c|c|c|c|}
\hline \multirow[b]{2}{*}{ Wariables } & \multicolumn{8}{|c|}{ Correlations } \\
\hline & 1 & 2 & 3 & 4 & 5 & 6 & 7 & 8 \\
\hline 1 Complexity & - & $.38^{4 * x}$ & .05 & .02 & $.32^{\sin }$ & .08 & $.25^{2.20}$ & .07 \\
\hline 2. Environmental uncertainty & .08 & - & $.22^{* * *}$ & -.02 & $.32^{* i k}$ & -10 & $29^{2+3}$ & .00 \\
\hline 3. Decision authority & .14 & $.50^{* * *}$ & - & .07 & .02 & .09 & .04 & $.16^{\circ}$ \\
\hline 4 Autonony & -10 & -10 & .09 & $\cdots$ & $-23^{* \ldots+\cdots}$ & $.30^{t+*}$ & -13 & .03 \\
\hline 5 Workload & $.18^{\circ}$ & .12 & .07 & -.12 & $\ldots$ & $-34^{\prime \prime}$ & $51^{\infty 40}$ & -.04 \\
\hline 6 Social support & .07 & .05 & $.18^{*}$ & .14 & -.13 & -. & $-34^{2+4}$ & .14 \\
\hline Burnout & .13 & $-15^{*}$ & $-29^{* * i r}$ & -.08 & $.44^{3.40}$ & $-29^{* * i n}$ & $\ldots$ & .01 \\
\hline 8 Intrinsic work motivation & .05 & .10 & $.17^{\mathrm{B}}$ & -.08 & .02 & 14 & -.03 &.- \\
\hline
\end{tabular}

$p \leq .05 \quad p \leq 001$

\section{LISREL analysis}

As mentioned before, we first tested a baseline model for each sample separately (Byrne, 1998). Thereafter, we tested for invariance of the hypothesised relationships over the two samples simultaneously.

\section{Testing a baseline model in each sample separately}

\section{Sample 1 (ICU nurses)}

Our research model (Figure 4.1) consists of three exogenous (independent) variables (complexity, uncertainty and decision authority), three mediator variables (autonomy, workload and social support; they were specified in LISREL as endogenous variables) and two endogenous variables (emotional exhaustion and intrinsic work motivation). Besides, two demographic variables were entered into the research model, viz. gender and age, because they have been mentioned in the literature to correlate with psychological outcomes (see also Dallender et al., 1999; De Jonge, 1995; Roe, 1984) Daliender et al., 1999; De Jonge, 1995; Roe, 1984).

The error variances of the endogenous variables themselves and the error variances regarding the relationship between the endogenous variables were specified, because the model is not likely to be exhaustive (MacCallum, Roznowksi, Mar \& Reith, 1994; MacCallum et al., 1993).

In order to investigate whether the work characteristics operate as mediator variables (the indirect model), we first tested the direct model (M0) as suggested by Btown (1997) and Holmbeck (1997) in which only direct structural paths were specified (relationships between complexity and emotional exhaustion, uncertainty and emotional exhaustion, and between decision authority and intrinsic work motivation). Thereafter, we tested the complete, indirect model in which the relationships of the mediator variables were specified (hypotheses $1-7$ ). The results of these analyses are shown in Table 4.3. 
Table 4.3 Fit measures of sample 1 and sample 2 separately

\begin{tabular}{|c|c|c|c|c|c|}
\hline Fit mesqures & $x^{2}$ & df & comparison & $\Delta x^{2}$ & $(\Delta d i)$ \\
\hline \multicolumn{6}{|l|}{ Sartingle I (TCU Murses) } \\
\hline Direct model (Mo) & 102.63 & 24 & & & \\
\hline Direct model madified $\left(\mathrm{MO}_{\mathrm{i}}\right)$ & $89.70^{i \times 6}$ & 23 & $M O$ ve. $\mathrm{MO}_{\mathrm{a}}$ & $1293^{\prime \prime}$ & 1 \\
\hline Indirect model (M1) & $26.96^{*}$ & 17 & $\mathrm{MO}_{\mathrm{i}} \mathrm{ve} \mathrm{M} 1$ & $6274^{4}$ & 6 \\
\hline Indirect model modified $\left(\mathrm{M}_{2}\right)$ & 21.64 & 16 & $\mathrm{M} 1$ rs. $\mathrm{M1}_{\text {s }}$ & $5.32^{2}$ & 1 \\
\hline \multicolumn{6}{|l|}{ Sample 2 (Nors $1 \mathrm{ICU}$ marses) } \\
\hline Direct model (MOH & $98.55^{100}$ & 24 & & & \\
\hline Indlirect model (M1) & 16.83 & 17 & Mows. M1 & $81.72^{*}$ & 7 \\
\hline Dit merisures & $A G F I$ & RMSEA & AIC & $\mathrm{NNF}$ & $\mathrm{CFI}$ \\
\hline \multicolumn{6}{|l|}{ Sawtble (1CU nursex) } \\
\hline Ditect model (MO) & .78 & .13 & $159.1 \mathrm{i}$ & .11 & .52 \\
\hline Dinect model modified $\left(\mathrm{MO}_{3}\right)$ & .81 & 11 & 140.86 & .21 & .60 \\
\hline Indirect model (M1) & .91 & .06 & 102.33 & .84 & .94 \\
\hline Indirect model modifred $\left(\mathrm{ML}_{3}\right)$ & .92 & .04 & 99.17 & .90 & .97 \\
\hline \multicolumn{6}{|l|}{ Sample 2 (nom-ICU matres) } \\
\hline Direct model (MO) & .82 & .11 & 144.69 & .28 & .62 \\
\hline Indifect model (M1) & .95 & .00 & 92.53 & 1.00 & 1.00 \\
\hline
\end{tabular}

" $\mathrm{p} \leq .05 \quad \mathrm{p} \leq .001$

Table 4.3 shows the results of sample 1 and sample 2 separately. We may conclude from this Table that the fit of the direct model (M0) was not acceptable. The t-values of the thiree specified relationships were all significant, which means that the hypothesised (direct) relationships were confirmed. LISREL also provided suggestions (modification indices) to improve the fit of the model. According to these modification indices, the relationship between decision authority and emotional exhaustion should be added. The addition of this relationship yielded an increase in model fit ( $\left.\mathrm{MO}_{\mathrm{a}}\right)$. This model fitted significantly better to the data in terms of the $\chi^{2}$-difference test than M0, although the model fit was still low.

Our next step was to compare this modified model $\left(\mathrm{MO}_{\mathrm{i}}\right)$ with the indirect model (M1). The indirect model better fitted to the data than $\mathrm{MO}_{\mathrm{a}}$ because the $\chi^{2}$-difference test was significant. This model could still be improved because the $\chi^{2}$ is still significant and the NNEI was not quite high. LISREL suggested to add a path between decision authority and emotional exhaustion $\left(\mathrm{M1}_{\mathrm{z}}\right)$. The fit of this model was acceptable now (see Table 4.3). Comparing this model with M1 revealed that the $\chi^{2}$-difference test was significant which means that $M 1$, better accounts for the data than $\mathrm{M} 1$.

The additional telationships between autonomy and intrinsic work motivation $(\beta)$ and between decision authority and autonomy ( $\gamma$ ) were not significant. This means that autonomy is not a mediator in the relationship between decision authority and intrinsic work motivation. The relationship between decision authority and intrinsic work motivation is thus a direct one. The relationship between complexity and emotional exhaustion was indirect through workload. The relationship between uncertainty and 
emotional exhaustion was a direct one because the path between uncertainty and workload appeated not to be significant $(t \leq 1.96)$.

\section{Sample 2 (non- $I C U$ nurses)}

We followed the same procedure in non-ICU nurses as we did in sample 1. We first specified the direct relationships (M0). We may conclude from Table 4.3 that the fit of the model was not acceptable. The t-values of the specified relationships were significant, whereas no additional rellationships need to be specified according to the modification indices. Comparing this model with the indirect model (M1) showed a significant $\chi^{2}$-difference test, which means that the indirect model holds tenable. This model also yielded a perfect practical fit as well as a satisfying statistical fit (NNFI = 1.00 and $\chi^{2}$ is not significant respectively). No improvements could be made according to the Modification Indices. When we considered the t-values, we may conclude that decision authority is directly related with intrinsic work morivation (autonomy did not mediate this relationship). The relationships between uncertainty and emotional exhaustion on the one hand and complexity and emotional exhaustion on the other were indirect through workload. So, workload is a mediator variable. Finally, the relationship between decision authority and social support was not significant.

\section{Testing for invariance}

The analyses of the two samples separately have shown that the indirect model in both samples fitted significantly better than the direct model. Our next step was to test whether the indirect model was invariant across the two samples. As a consequence, we performed multi-sample analysis in which the following three nested models were tested and compared by means of the $\chi^{2}$-difference test (Bentler $\&$ Bonett, 1980; Jöreskog \& Sörbom, 1993):

M1 (Invariant): 'The hypothesised pattern of relationships (see figure 4.1) was specified as invariant (i.e., relationships have the same stuength and dircction in both samples) across the two samples, except the relationship between uncertainty and emotional exhaustion (this relationship appeared not to be in the same direction), the relationship between uncertainty and workload (not significant in sample 1) and the relationship between decision authority and social support (not significant in sample 2). M1 is the most restrictive model (largest number of degrees of freedom);

M2 (Inpariant modified): The hypothesised pattern of relationships (M1) was specified as in M1. Furthermore, the relationship between decision authority and emotional exhaustion was specified for each sample separately because this relationship seemed to be significant in sample 1 ;

M3 (Non-imariant wodified): The hypothesised pattern of relationships (like M1) was specified as non-inwariant (only "same pattern"). The relationships between uncertainty and emotional exhaustion, uncertainty and workload, decision authority and social support and the relationship between decision authority and emotional exhaustion, were specified for each sample separately.

The results of the model comparisons are shown in Table 4.4 . 
that ICU nurses have greater stress tolerance than nurses working in non-ICUs. According to Maloney (1982), ICU nurses may build up defence mechanisms against the consequences of constant exposure to death and suffering by rationalising their feelings to protect themselves. Further research should pay more attention to such coping strategies. Another explanation of this finding might be the selection effect among nurses. Nurses might voluntary select the area in which they prefer working and may have certain coping strategies or petsonality characteristics (e.g., "hardiness", see Constantini et al., 1997; Duquette et al., 1994; Duquette, Kerouac, Sandhu \& Ducharme, 1995; Harris, 1989; Neubauer, 1992; Turnipseed, 1999) to deal with stressful circumstances or operate in specific organisational structures (Hollenbeck, 2000). As a consequence, ICU nurses may be less emotional exhausted.

The hypothesis that emotional exhaustion was primarily predicted by workload and social support was supported in both samples: high workload and low social support appeared to increase emotional exhaustion. Workload was found to be predicted by complexiry, whereas complexity was a predictor for emotional exhaustion through the workload in both samples. This means that the relationship between complexity and emotional exhaustion was indirect via workload. We found only in non-ICU nursing that workload was predicted by uncertainty, whereas uncertainty was also predictive for emotional exhaustion through workload. On the other hand, we found that high uncertainty was predictive for lower levels of emotional exhaustion in ICU nursing. "This finding could again be explained by a selection effect among ICU nurses, as mentioned earlier. ICU nurses may possess certain personality traits that enable them to better handle high uncertainty. In addition, the task structure is supposed to be different (more standardisation of tasks).

The hypothesis that autonomy was primarily predicted by decision authority was not confirmed in the two samples. A possible explanation may be that autonomy has an informal character, implying that decisions about for instance working hours, can only be made by mutual adjustment of one's colleagues and/or supervisor(s), whereas. decision authority has a formal character which means that kind of decision making about tasks to be performed has been laid down in employees' formal function profiles.

Testing our hypothesised pattern of relationships with multi-sample analysis yielded that this pattern was invariant across samples. This means that the postulated relationships between wotkload and emotional exhaustion, between social support and emotional exhaustion (see also Houkes et al., 2001a; Janssen et al., 1999a; Tummers et al., 2001), between complexity and workload, and finally between decision authority and intrinsic work motivation were strongly validated. 


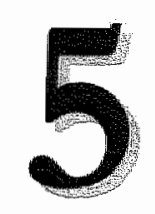

\title{
Organisational characteristics as predictors
}

\author{
of nurses' psychological work reactions
}

Submitted as:

Tummers, G.E.R., Van Merode, G.G. \& Landeweetd, J.A. Organisational characteristics as predictors of nurses' psychological work reactions. Organization Studies. 


\subsection{Introduction}

Work in the health care sector has undergone tremendous changes during the last decennium (De Jonge et al., 2000; Frese, 2000). New sources of job-related risk factors are emerging, psychosocial risk factors in particular (De Jonge, 1995), such as a high workload. These psychosocial risk factors at work may cause several negative effects on employees' well-being and health, such as burnout and work motivation (Cooper, 1998; De Jonge \& Kompier, 1997; Schaufeli \& Enzmann, 1998).

However, although these changing psychosocial risk factors have received much attention, little efforts have been paid until now to explore organisational factors in nursing work that might also account for employees' well-being and health. Also organisational structures of health care organisations (hospitals in particular) are changing. They seem to change from, for instance, a more functional- to a more clientoriented organisational structure (Huijsmans, 2002; Van Merode, 1999). Consecuently, they may affect organisational effectiveness (Scott, 1992), both in tems of efficiency and productivity, as in terms of burnout and work motivation. An important theory in this area is the contingency approach of organisations (Child, 1977; Donaldson, 2001a; Galbraith, 1977; Lawrence \& Lorsch, 1967b).

According to the contingency approach of organisations, organisational effectiveness depends on the congruence between structural characteristics of organisations (such as centralisation, formalisation, and standardisation, see Child, 1977; Ford \& Slocum, 1977; Gutek, 1990; Hage \& Aiken, 1967; Pennings, 1998) and characteristics of the organisational context or environment (such as uncertainty and complexity, see Fry, 1982; Fry \& Slocum, 1984; Pennings, 1998; Perrow, 1967, 1970; Rundall \& Hetherington, 1988). This means that organisational effectiveness depends not on singular structural and environmental characteristics, but on the fit of both. The organisational structure is then determined by the environmental circumstances that organisations are confronted with.

Although the contingency approach has dominated the study of organisational design and performance in the past thirty years, one major limitation of this approach as it has been developed so far is that measures of organisational effectiveness thave mainly been related to economic variables such as organisational efficiency or productivity (Kleinet, 1983). Kleiner alteady in 1983 argued that the contingency approach as a whole remains somewhat apart from important issues of today's working life, such as employees' well-being and health. Employees" well-being and health can be seen as social measures of organisational effectiveness itself Jehn \& Chatman, 2000; Kraft, Puia \& Hage, 1995; Scott \& Shortell, 1988). Organisational effectiveness is a multidimensional concept including efficiency, profitability (Child, 1977), employee's well-being and health, like job satisfaction (Drazin \& Van de Ven, 1985), innovation rate and parient well-being (Alexander \& Randolph, 1985; Pennings, 1998). It can be defined as the ability of the organisation to attain the goals set by itself (Parsons, 1961), or by its ability to function well as a system. This system consists of different groups and has different sub goals. So, its effectiveness is equated to various aspects of 
systems functioning (Donaldson, 2001c; Yuchtman \& Seashore, 1967). An noneconomical aspect of systems functioning is, for instance, the maintenance of the social climate in the organisation or the reduction and prevention of sickness absence and turnover. As a consequence, enhancing the health, satisfaction and motivation of employees becomes an organisational goal on its own.

The current study aims at using the framework of the contingency approach for elucidating whether nurses' well-being and health depend not only on singular organisational characteristics, but also on the congruence of structural and environmental characteristics.

\subsection{Theoretical background}

\subsubsection{Contingency approach}

As mentioned in the introduction, the essence of the contingency approach is that organisational effectiveness depends on the degree of congruence between the structure of organisations and their environment (Child, 1977; Donaldson, 2001a; Galbraith, 1977; Lawrence \& Lorsch, 1967b). Organisational structure concerns the choice of the grouping of individuals into departments (the division of labour), as well as the co-ordination of this differentiated labor (Fry, 1982; Gutek, 1990; Pennings, 1998; Pfeffer \& Salancik, 1978; Thompson, 1967), such as the standardisation of tasks (Mintzberg, 1983; Thompson, 1967). The most frequently cited dimensions of the organisational structure are "centralisation of authority and decision making", "formalisation of rules and procedures" and "standardisation" (Hage \& Aiken, 1967; Mintzberg, 1983).

The organisational environment can be seen as the set of external factors with which it has relations or in which organisations or units are embedded. Complexity and uncertainty are factors that are often used to describe and measure the environment (Pennings, 1998; Smither, 1994). The organisation's structure should be suited to the organisation's environmental characteristics in order to achieve high effectiveness. If organisations or units are confronted with rapidly changing circumstances (e.g. high environmental uncertainty), the organisational structure must make it possible to react to this environmental uncertainty. Then, the organisational structure is often more decentralised and less hietarchical than in stable and predictable organisational environments. In such cases, decisions are delegated to employees who are responsible for the task execution.

Several studies have applied the contingency approach in different settings, particularly in industrial organisations. However, comparison of these studies is difficult, because no uniform measures and definitions are used to measure structure, environment, effectiveness, and congruence (Alexander and Randolph 1985; Drazin \& Van de Ven, 1985; Fry 1982; Gurek 1990; Donaldson 2001b). 


\subsubsection{Conceptualisation of structural and contingency factors in nursing units}

In addition to the well-known and often investigated work chatacteristics (e.g., De Jonge and Kompier 1997; De Jonge et al. 2000, 2001; Houkes et al. 2001a, 2001b) we suppose that organisational characteristics may not only be important for economic effectiveness, but for the social effectiveness as well (Kraft et al., 1995). In the curtent study, aspects of the social effectiveness that we have investigated are aspects as to employees "health" on the one hand, such as a low level of burnout and few psychosomatic health complaints, and aspects as to "well-being", such as high work motivation, and high job satisfaction on the other hand.

The context of nursing units can be chatacterised by environmental uncertainty (Iskra Golec et al., 1996; Slocum \& Sims, 1980), Environmental uncertainty in this context means that there is insufficient information about new or ongoing work activities. Three degtees of environmental uncertainty can be distinguished (Bodt, 1995). The first concerns the situation in which a priori is known that particular activities have to be performed, but one has some 'planning freedom' (Van Merode, Groothuis, Schoenmakers \& Boersma, 2002; Van Merode et al., 1995) to determine the time to start performing these activities, such as caring activities. The second concetas expected events (one knows a priori that they are going to happen), although the time of occurrence is unknown (for example, emergencies). The last degree of environmental uncertainty refers to events which are unexpected to occur as well as the time of occurrence is unexpected. An example of the latter is the sudden deteriotations of patients' health conditions. These three aspects of uncertainty are, as already mentioned, particularly related with the environment. Another aspect of uncertainty in nursing units is the degree of task uncertainty. Task uncertainty means that it is not a priori known how tasks have to be performed. In nursing work, skills are standardised by means of professional training (Mintzberg, 1983). In addition, tasks are often written down in protocols. This task uncertainty might not wholly be independent of the degree of environmental uncertainty. For instance, the performance of particular tasks (by employees' actions) might influence patients' conditions and thereby might have consequences for the environmental uncertainty.

Nevertheless, despite the plausibility of the relationship between task uncertainty and environmental uncertainty, task uncertainty is less prominent in nursing units in compatison with environmental uncertainty. This high task standardisation by means of, for instance, protocols, might reduce task uncertainty compared to situations in which task standardisation is lower. The degree of task standardisation depends on the tgpe of nursing unit. Intensive Care Units (ICUs) have higher standardisation of tasks than non-ICUs (general and medical units) have. This means that on ICUs, application of technical skills are particularly prescribed by means of protocols. As a consequence of the differences in degree of standardisation between these two types of units, the effects of environmental uncertainty on nurses' well-being and health might depend on the degree of task uncertainty, i.e., the congruence between task uncertainty and 
environmental uncertainty. In the current stady, this means more concretely that the relationship between environmental uncertainty and nurses' well-being and health might be different for ICUs and non-ICUs. "Health" is conceptualised by burnout and psychosomatic health complaints, while "well-being" is conceptualised by intrinsic work motivation and job satisfaction.

From the results of empirical research, it is not yet clear what effects standardisation might have on burnout. (Lee \& Ashforth, 1991; Van Rossum, 1998) Lee and Ashforth (1991) and Van Rossum (1998) have found that the more tasks are standardised, the lower burnout will be. Because we suppose that the effect of environmental uncertainty on well-being and health depends on the degree of standardisation, together with the fact that the differences in standardisation can be explained by the difference in type or nursing unit, different effects for ICU and non-ICUs are to be expected.

The structure of organisations is the arrangement of people, departments, and other subsystems in the organisation (Fry, 1982; Pfeffer \& Salancik, 1978; Thompson, 1967), and the co-ordination of the activities within these subsystems. An important characteristic of the structure of nursing units is the degree of decentralisation of decision-making or the decision authority of the nursing unit, and the standardisation of tasks (see above, Mintzberg, 1983). Decision authority means that nurses have the authority to make decisions on their own. These decisions refer to the "variety" of tasks (not only responsible for just one task, but for a whole "product" or several coherent tasks), and to the "depth" of tasks. The latter refers to the possibilities nurses have to plan nursing or caring activities.

To conclude, the structural variables in the current study are decision authority and standardisation of tasks or procedures. 'The latter will be conceptualised by the difference between ICU and non-ICUs. The context or contingency factor is represented by environmental uncertainty.

\subsubsection{Structural and contingency factors in nursing units as determinants for nurses' well-being and health}

As mentioned earlier, the exploration of the effects of organisational characteristics on well-being and health is needed in order to investigate the congruence between organisational structure (i.e., decision authority) and organisational environment (environmental uncertainty).

With regard to the effects of structural and environmental chatracteristics on well-being and health, we hypothesise that environmental uncertainty is particularly predictive for stress reactions, such as burnout. If nurses have to perform tasks in uncertain circumstances or when the time at which tasks have to be performed is uncertain, nurses might experience stress, because they perceive an imbalance between environmental demands and individual resources to cope with these demands (Gärling et al., 1998; Pugh \& Payne, 1977). 
Furthermore, we hypothesise that decision authority is particularly predictive for nurses' growth and learning oppottunities, such as intrinsic work motivation and job satisfaction (see Tummers, Landeweerd \& Van Merode, 2002b; Tummers, Van Merode \& Landeweerd, 2002c). Cummings and Berger (1976), for instance, in a research overview on relations between organisational structure and attitudes found that decentralisation of decision structure (i.e., decisions are delegated to less hierarchical levels in the organisation) generates less alienation from work, less dissatisfaction with work, and increased performance.

As we have already mentioned, high environmental uncertainty per se might not have a negative effect on stress reactions, but might depend on the organisational structure belonging to this environmental uncertainty. In line with the contingency approach of organisations, an adequate organisational structure in order to adapt to uncertain circumstances might reduce or even prevent stress reactions. According to McGtath and Beehr (1990), two features are important in the prediction of stress, viz., predictability and controllability. Events can not always be planned or forecasted, such as uncertain events, described earlier. But if uncertain events occur, nurses must normally react immediately by quick decision-making, which means that they must have controllability over the situation. The degree of individual controllability is partly determined by the organisational structure. Quick decision-making means that the organisational structure allows that decisions are decentralised to those who have to react on this environmental uncertainty. Nurses then have more decision authority to perform and plan tasks in order to reduce environmental uncertainty. As a consequence, uncertain events are more controllable for nurses, because of the delegation of authorities. So, high decision authority might reduce or prevent the negative effects of environmental uncertainty on stress reactions.

In addition to this supposed congruence between decision authority and environmental uncertainty in the prediction of health outcomes, we also expect a congruence between decision authority and environmental uncertainty in the prediction of well-being, intrinsic work motivation in prirticular. We suppose that high environmental uncertainty will enhance the positive effect of decision authority on intrinsic work motivation. Uncertain conditions can be seen as innovation, as a challenge, because they may provide opportunities to develop one's own skills and fulfil ones' needs.

With regard to the effects of the standardisation of tasks on nurses' well-being and health, we suppose that the effect of environmental uncertainty on health (i.e., butnout and psychosomatic health complaints) will depend on the level of standardisation. Tasks are more standardised in ICUs, which means that the degree of task uncertainty might be different between ICUs and non-ICUs. Higher standardisation of tasks might lead to a lower task uncertainty, which might in its turn be positively correlated with burnout. Because we mentioned earlier that ICUs and non-ICUs differ with regard to task standardisation and as a consequence to task uncertainty, we expect different relationships between environmental uncertainty and nurses' well-being and health in 
ICUs ass compared to non-ICUs. The difference in ICUs and non-ICUs might thus shed more light on the role of the task uncertainty factor.

In sum, as a consequence of the partly explorative character of the study, we have formulated hypotheses ( $\mathrm{H}$ ) as well as general research questions (RQ):

H1: Intrinsic work motivation is particularly predicted by decision authority;

H2: High decision authority buffers the negative effect of environmental uncertainty on burnout and psychosomatic health complaints;

H3: High environmental uncertainty enhances the positive effect of decision authority on intrinsic work motivation and job satisfaction;

RQ1: What telationships exist between environmental uncettainty on the one hand and bumout and psychosomatic health complaints on the other?;

RQ2: What is the role of task standardisation in the relationship berween environmental uncertainty on the one hand and burnout and psychosomatic health complaints on the other? (differences ICUs and non-ICUs).

\subsection{Method}

\subsubsection{Procedure}

Thousand hundred and eighty-eight questionnaires were distributed among 98 different nursing units (intensive care, medical and surgical units) in 15 general hospitals in the Netherlands. Supervisors of the units were asked to inform nurses during the ward meeting about the purpose of the investigation and asked them to take part in it. The questionnaires were distributed in a sealed envelop including an introductory letter and they were told that each response would remain confidential and anonymous (they were not asked to fill out their names). After three weeks, a reminder was sent to all the supervisors of the participated units to ask those who had not filled out the questionnaires to do this as yet. Thereafter, the questionnaires were sent back to the researchers.

\subsubsection{Samples}

\section{Sample 1 (ICU nurses)}

Two hundred and sixty-one questionnaires were distributed among nurses in 13 ICUs. In total, the study yielded 184 usable replies, providing a response rate of $71 \%$. The sample of ICU nurses consisted of 118 women (64\%). The mean age of the ICU nurses was 35.8 years $(\mathrm{SD}=6.4)$. The mean job experience was 17.0 years $(\mathrm{SD}=6.5$ ), whereas the mean working time on the unit was 8.1 years $(S D=6.2)$. 


\section{Sample 2 (non-ICU nurses)}

The sample of non-ICU nurses consisted of 927 nurses (response rate is $65 \%$ ) who worked in units of internal medicine, cardiology, paediatrics, oncology, pneumonology, (neuro-)surgery, gynaecology and orthopaedics. Eighty-nine per cent of this sample were women, whereas the mean age was 35.3 years $(S D=9.0)$. The mean job experience in this sample was 14.8 years $(S D=8.8$ ), whereas the mean working time on the unit was 6.5 years ( $\mathrm{SD}=6.2$ ).

\subsubsection{Measures}

\section{Structural and contingency characteristics}

Decision authority was measured by means of six items. The response categories ranged from 1 "totally disagree" to 5 "totally agree". The scale was derived from Bodt (1995) and Boone and de Jonge (1996). An item example is: "A nurse is able to make decisions about patient care on her own".

Envirunnental uncertainty was measured by a 5 -item questionnaire with a five point response scale, ranged from 1 "totally disagree" to 5 "totally agree". The scale was developed by Wibbelink (1995) and Tummers (1998). An item example is: "There are daily emergency admittances on this unit".

The items of environmental uncertainty and decision authority are depicted in Table 5.1 .

Table 5.1 Organisational items

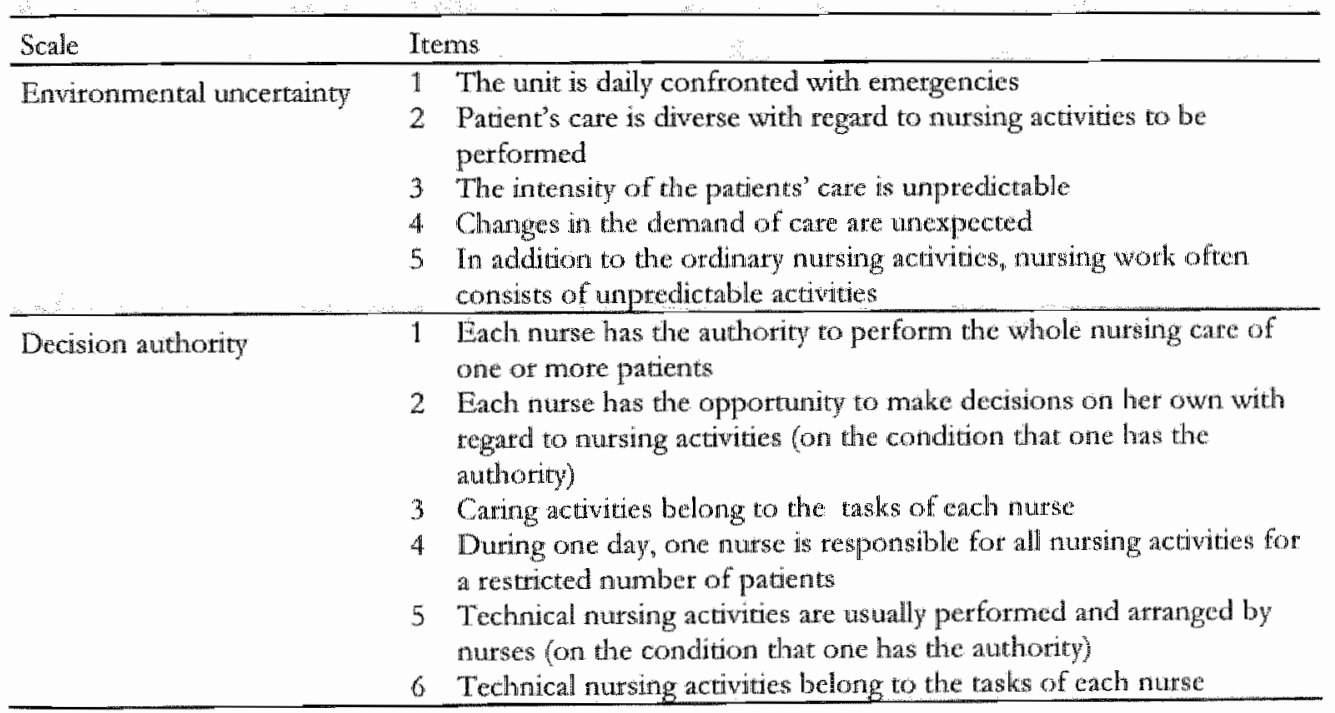




\section{Nurses" well-being and health}

Intrinsic work motivation ("well-being") was measured by means of six items derived from a scale developed by Warr et al. (1979). Its response categories ranged from 1 "totally disagree" to 5 "totally agree". An item example is: "My opinion of myself goes down when I do this job badly".

Job satisfaction was measured with 21 items derived from the Maastricht Job Satisfaction Scale for Health Care (MAS-GZ), developed by Landeweerd et al. (1996). The Job Satisfaction scale consists of seven separate satisfaction dimensions, each measured with a 5-point scale: satisfaction with the supervisor, career opportunities, quality of patient care, growth opportunities, social contact with colleagues, social contact with patients, and satisfaction with job clarity. An item example is: "How satisfied are you with the amount of skills and possibilities you can use?"

Burnout ("health") is generally conceptualised as a syndrome of emotional exhaustion, depersonalization, and reduced personal accomplishment (Maslach \& Jackson, 1986). Emotional exhaustion is considered as the core dimension of burnout (Buunk \& Schaufeli, 1993; Cox et al., 1993; Maslach, 1998; Shirom, 1989). Therefore, we selected emotional exhaustion to represent the concept of burnout. Emotional exhaustion was measured by means of the Dutch version of the Maslach Burnout Inventory (MBI, Maslach \& Jackson, 1986): the MBI-NL (Cox et al., 1993; Maslach, 1993; Schaufeli \& Van Dierendonck, 1993). The emotional exhaustion scale of the MBI-NL consists of eight items with a 7-point" response scale $(1=$ "never", 7 = "always"). An example-item is: "I feel emotionally drained from my work".

Psychosonatic bealth complaints were measured with 21 items of a general health questionnaire (in Dutch: "VOEG") which was developed and validated by Dirken (1969). The scale consists of items encompassing fatigue, appetite, stomach complaints, cardiac complaints, and complaints about muscles $(0=$ "no" and $1=$ "yes"). An item example is: "Do you often have a headache"?

\subsubsection{Data analysis}

The study has a cross-sectional design, which means that the time sequence of the relationships among the variables could not be clearly assessed. Therefore, one must be cautious when interpreting them as causal (e.g., Zapf et al, 1996).

In order to analyse the data, we have used correlation and hierarchical regression analysis. 


\subsection{Results}

\subsubsection{Descriptives}

The means, standard deviations, Cronbach's alphas and Pearson correlations for the variables under consideration are presented in Table $5.2 \mathrm{a}$ and Table $5.2 \mathrm{~b}$ for both ICUs (sample 1) and non-ICUs (sample 2).

Table 5.2a Means, standard deviations, and Cronbach's alphas of sample 1 and sample 2

\begin{tabular}{|c|c|c|c|c|c|c|}
\hline \multirow[b]{2}{*}{ Variables } & \multicolumn{3}{|c|}{ Sample $1(\mathrm{~N}=184)$} & \multicolumn{3}{|c|}{ Sample $2(N=927)$} \\
\hline & M & SD & $\alpha$ & M & $\mathrm{SD}$ & $\alpha$ \\
\hline 1 Gender & -- & - & -- & - & -- & -- \\
\hline 2 Age & 35.80 & 6.40 & -- & 35.30 & 9.00 & $-\infty$ \\
\hline 3 Envitonmental uncertainty & 4.47 & .82 & .81 & 3.87 & .69 & .78 \\
\hline 4 Decision authority & 4.37 & .66 & .77 & 4.09 & .50 & .70 \\
\hline 5 Emotional exhaustion & 2.01 & .77 & .88 & 2.21 & .75 & .87 \\
\hline 6 Psychosomatic health complaints & 0.15 & .17 & .84 & .16 & .15 & .78 \\
\hline 7 Intrinsic work motivation & 3.87 & .43 & .72 & 3.99 & .47 & .73 \\
\hline 8 Job satisfaction & 3.58 & 32 & .86 & 3.51 & .37 & .86 \\
\hline
\end{tabular}

${ }^{*} \mathrm{p} \leq .05 \quad " \mathrm{p} \leq .01 \quad$ * $\mathrm{p} \leq .001$

Note. Gender was coded $0=$ female, $1=$ male.

Table 5.2b Pearson correlations of sample 1 (ICUs; left-lower corner) and sample 2 (non-ICUs; rightupper corner')

\begin{tabular}{|c|c|c|c|c|c|c|c|c|}
\hline \multirow[b]{2}{*}{ Variables } & \multicolumn{8}{|c|}{ Correlations } \\
\hline & 1 & 2 & 3 & 4 & 5 & 6 & 7 & 8 \\
\hline 1 Gender & $-\ldots$ & $.09^{8,7}$ & .01 & .00 & .03 & -.01 & -.03 & $-.07^{*}$ \\
\hline $2 \mathrm{Age}$ & $.25^{\prime * * x}$ & - & .03 & -02 & .01 & -.01 & $11^{\text {*a* }}$ & $10^{*+}$ \\
\hline 3. Environmental uncertainty & .00 & -.07 & $\ldots$ & $.15^{\text {:4t }}$ & $.13^{3 *+}$ & $.10^{43}$ & $.11 * *$ & $-.09^{* *}$ \\
\hline 4. Decision authority & .08 & .03 & $.50^{\text {atiin }}$ & -. & .00 & -.02 & $.14^{8 * x}$ & $13^{* 06}$ \\
\hline 5 Emotional exhaustion & .09 & .08 &. $.15^{4}$ & $-29^{*+1+8}$ & $\therefore$ & $53^{\cdots+}$ & .03 & $-.4 \|^{1+*}$ \\
\hline $\begin{array}{l}6 \text { Psychosomatic health } \\
\text { complaints }\end{array}$ & -.06 & .08 & .02 & -.14 & $60^{\circ+\cdots}$ & -. & .03 & $-.25^{3+4}$ \\
\hline TIntinsic work motivation & $-.20^{w+4}$ & .03 & .10 & $.17^{\circ}$ & -.03 & -.00 & - & $.16^{n+k}$ \\
\hline 8 Job satisfaction & -.01 & -.06 & .02 & $18^{2}$ & $-42^{+4}$ & $-30^{\mathrm{ki}}$ & $24^{*}$ & $\ldots$ \\
\hline
\end{tabular}

$\mathrm{p} \leq .05 \quad \mathrm{p} \leq .01 \mathrm{p}$ * $\mathrm{p} \leq .001$

Note. Gender was coded $0=$ female $_{3} 1=$ male.

From Table 5.2a, we may conclude for both samples that the internal consistencies (Cronbach's $\alpha$ ) of the study variables were all moderate to high. To get a first insight into the data, Pearson correlations were conducted. The correlations between the organisational characteristics and well-being and health were in general not very high, although many of them were significant. In order to test the magnitude of the differences in correlation between ICUs and non-ICU's, we have used Fisher's z test (Ferguson, 1976). 
From Table $5.2 \mathrm{~b}$, several relationships appeared to be significant. Decision authority appeared to correlate positively with intrinsic work motivation and job satisfaction in both samples $(r=.17$ and. 14 for intrinsic work motivation and $r=.18$ and .13 for job satisfaction respectively). The differences between these correlations in ICUs and nonICUs were not significant ( $z=.38$ and $z=.63$ respectively). An additional significant (negative) correlation was found between decision authority and emotional exhaustion in ICUs $(r=-.29)$ : the higher the decision authority, the lower the emotional exhaustion. This relationship was not found in non-ICUs $(r=.00)$. Moreover, these two differed significantly $(z=3.68 ; \mathrm{p} \leq .01)$.

Environmental uncertainty showed a positive significant correlation with psychosomatic health complaints in non-ICUs $(r=.10)$. The correlation found in ICUs $(r=.02)$ was not significant; also the difference between the correlations was not significant $(z=.98)$.

The correlation between enwironmental uncertainty and emotional exhaustion was significant in both ICUs and non-ICUs. However, environmental uncertainty appeared to correlate negatively with emotional exhaustion in ICUs $(r=-.15)$, whereas a positive correlation was found in non-ICUs $(r=.13)$. This difference was significant $(z=8.54$; $\mathrm{p} \leq .01)$.

Furthermore, environmental uncertainty was positively correlated with intrinsic work motivation in non- $\mathbb{C C U S}(r=.11)$. This relationship was not significant in ICUs $(r=$ .10); the difference between these correlations was not significant $(z=.12)$.

The correlation between environmental uncertainty and job satisfaction was low, but significant in non-ICUs $(r=-.09)$, but not in ICUs $(r=.02)$. The correlation in ICUs and non-ICUs did not differ significantly $(z=1.35)$.

\subsubsection{Regression analysis}

Hierarchical regression analysis was performed in order to investigate our specific hypotheses and research questions. "The predictor and outcomes variables included in the present study were standardised in order to reduce problems of multicollinearity (Aiken \& West, 1991; Kleinbaum et al., 1982). The congruence between decision authority and environmental uncertainty was operationalised by means of interaction terms. The interaction effect was tested by computing the cross-product tem of the standardised independent variables (Jaccard et al., 1990; Kleinbaum et al., 1982).

Gender and age were entered as covariates in the first step of the regression analysis, because they appeared to be correlated with well-being and health (see also De Jonge et al., 2001; Houkes et al, 2001b; Roe, 1984). Thereafter, the structural and contingency characteristics, namely, decision authority and environmental uncertainty respectively, were entered. Finally, the (two-way) interaction term between decision authority and environmental uncertainty was entered. The results of the regression analysis are presented in Table 5.3. 
Table 5.3 Hierarchical multiple regressions of organismional characteristics on employees" psychological wotk reactions of the two sub samples (IC nurses, $N=184$ non-IC nurses, $N=927$ )

\begin{tabular}{|c|c|c|c|c|c|}
\hline \multirow{2}{*}{\multicolumn{2}{|c|}{ Predictor }} & \multirow{4}{*}{$\begin{array}{l}\text { Critetion } \\
\text { Emotional } \\
\text { exhaustion }\end{array}$} & \multicolumn{3}{|c|}{ Sample $1 /$ sanple 2} \\
\hline & & & \multirow{2}{*}{$\frac{\operatorname{Beta}(\beta)}{0.08 / .03}$} & \multirow{3}{*}{$\frac{\mathrm{R}^{\mathrm{X}} \text { clangers }}{.01 / .00}$} & \multirow{3}{*}{$\frac{\mathrm{R}^{2}}{.01 / .00}$} \\
\hline 1 & Gende: & & & & \\
\hline & Age & & $.05 / .00$ & & \\
\hline 2 & $\begin{array}{l}\text { Environmental uncertainty } \\
\text { Decision authority }\end{array}$ & & $\begin{array}{l}-.09 / .13^{+* 4} \\
-.27^{* 0 *} /-.02\end{array}$ & $.08^{238} / .02^{648}$ & $.09 / .02$ \\
\hline 3 & $\begin{array}{l}\text { Interaction environmental } \\
\text { uncertaincy } x \text { decision authority }\end{array}$ & & $.14 / .04$ & $.02 / .00$ & $.11 / .02$ \\
\hline
\end{tabular}

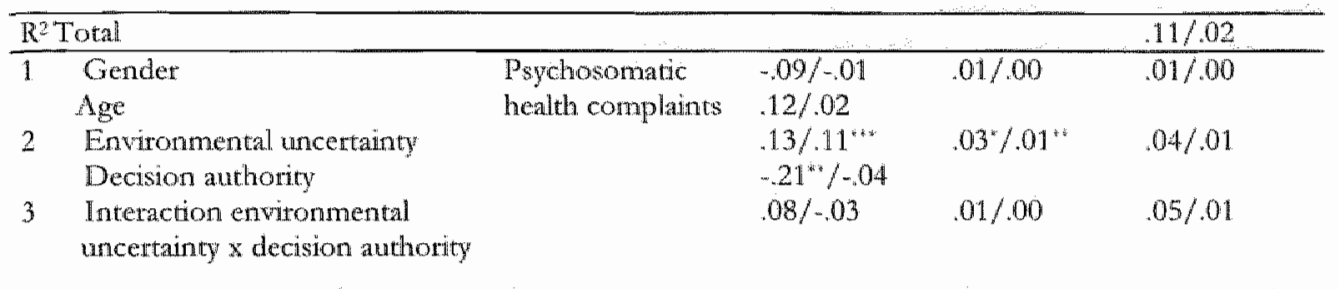

\begin{tabular}{|c|c|c|c|c|c|}
\hline & otal & & & & $.05 / .01$ \\
\hline 1 & Gender & Lntrinsic work & $-.22=.04$ & $.06^{* 1} / .01^{* 4}$ & $.06 / .01$ \\
\hline & Age & motivation & $.11 / .11^{n+m}$ & & \\
\hline 2 & Environmental uncertainty & & $.06 / .09^{\mathrm{sit}}$ & $.03^{*} / .03^{4 . * *}$ & $.09 / .04$ \\
\hline & Decision authority & & $.14 \% .12^{i * i}$ & & \\
\hline 3 & $\begin{array}{l}\text { Interaction environmental } \\
\text { uncertainty } x \text { decision authority }\end{array}$ & & $.19^{+8} / .05$ & $.03 \% / .00$ & $.12 / .04$ \\
\hline
\end{tabular}

\begin{tabular}{|c|c|c|c|c|c|}
\hline \multicolumn{5}{|c|}{ R2 Tokal } & \multirow{2}{*}{$.012 / .04$} \\
\hline 1 & Gendet: & Job satisfaction & $-.05 /-.10^{4 \%}$ & $.01 / .02^{\sin }$ & \\
\hline & Age & & $-.01 /-.08$ & & \\
\hline 2 & Environmental uncertainty & & $-.09 /-.12^{x+1}$ & $.04^{*} / .03^{x+x}$ & $.04 / .05$ \\
\hline & Decision authority & & 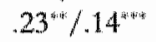 & & \\
\hline 3 & $\begin{array}{l}\text { Interaction environmental } \\
\text { uncertanty } \mathrm{x} \text { decision authotity }\end{array}$ & & $.11 /-.03$ & $.01 / .00$ & $.06 / .05$ \\
\hline
\end{tabular}

\footnotetext{
$\mathrm{R}^{2}$ Total $.06 / .05$ "p $\leq .05, " \mathrm{p} \leq .01, " \mathrm{v}, \mathrm{p} \leq .001$

Not The $\beta$ walues are the coefficients from the final stage of the tegtession analysis; duc to rounding off, $R^{2}$ differs 01 from the sum of $\mathbb{R}^{2}$ sharrgen
} 
We may conclude from Table 5.3 that emotional exhaustion, psychosomatic health complaints, intrinsic work motivation and job satisfaction were explained by the selected predictors, although the explained variances $(R)$ were not very high (range from .05 to .12 in ICUs and from .01 to .05 in non-ICUs). The results with regard to the main effects showed that environmental uncertainty was predictive for emotional exhaustion and psychosomatic health complaints in non-ICUs $\beta=.13$ and .11 tespectively). However, in $1 \mathrm{CU}$ s, emotional exhaustion and psychosomatic health complaints seemed to be predicted by decision authority $\beta=-.27$ and -.21 respectively).

In ICUs as well as in non-ICUs, intrinsic work motivation was predicted by decision authority ( $\beta=.14$ and .12 respectively): higher levels of decision authority were related with higher levels of intrinsic work motivation. Furthermore, in both samples, job satisfaction was predicted by decision authority $(\beta=.23$ and .14 respectively). Higher levels of decision authority were predictive for higher levells of job satisfaction. These two findings were not quite surprising, as decision authority refers to the work or task content. High decision authority implicates that nurses have more opportunities to make decisions independently and that they are able to perform different kinds of tasks. The consequence is that their work might be enriched and/or enlarged. Empirical research supports the view that particularly content variables in work (such as autonomy and responsibility, but also variables as to organisational structure, as measured in the current study) ate predictive of particullarly work motivation (Fried and Ferris 1987; Hackman and Lawler 1971; Hackman and Oldham 1976, 1980; Houkes et al., 2001a; Tiegs et al., 1992).

In non-ICUs, intrinsic work motivation was predicted by high environmental uncertainty, whereas job satisfaction was predicted by environmental uncertainty. These effects were not found in ICUs, although the differences between the coefficients were not significant, as described earlier. Besides these additive effects, an interaction effect between decision authority and environmental uncertainty was found in ICUs $(\beta=.19)$. This interaction effect suggests that in situations of high environmental uncertainty the positive effect of decision authority on intrinsic work motivation may be enhanced (see Figure 5.1). This interaction effect was not found in non-ICUs. 


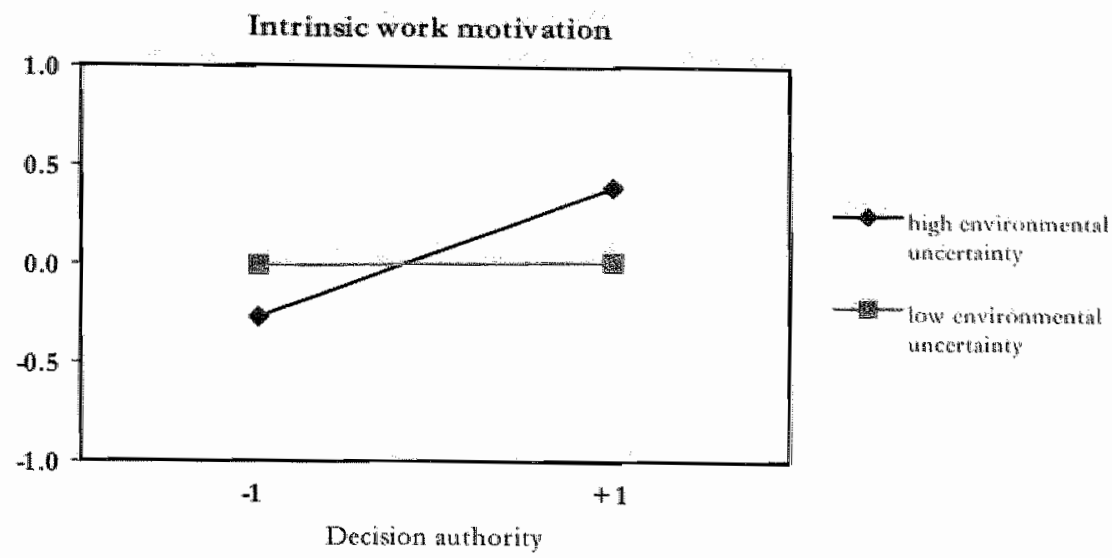

Figure 5.1 Interaction of decision authority and uncertainty for intrinsic wotk motiwation in lCUs

\subsection{Conclusions and discussion}

The aim of the present study was to investigate the effects of organisational characteristics (decision authority and environmental uncertainty), and the congruence of decision authority and environmental uncertainty on nurses' well-being (intrinsic work motivation and job satisfaction) and health (emotional exhaustion and psychosomatic health complaints). For this aim, three hypotheses and two general tesearch questions were formulated. First, it was hypothesised that intrinsic work motivation is particularly predicted by decision authority. The second hypothesis was that high decision authority buffers the negative effect of environmental uncertainty on burnout and psychosomatic health complaints. Third, it was hypothesised that high environmental uncertainty enhances the positive effect of decision authority on intrinsic work motivation and job satisfaction. The two research questions were formulated in a more explorative way. First, we investigated what relationslips exist between environmental uncertainty on the one hand and burnout and psychosomatic health complaints on the other. In addition, we investigated whether task standardisation, conceptualised as the difference between ICUs and non-ICUs, had an effect on the relationship between environmental uncertainty on the one hand and nurses' burnout and psychosomatic health complaints on the othet.

The first hypothesis that intrinsic work motivation and job sarisfaction ate primarily predicted by decision authority, was confirmed. This finding is in line with several theoretical frameworks in the field of work and organisational psychology, such as Job Characteristics Model (JCM) (Hackman \& Oldham, 1976), and empirical evidence as well (Cook et al., 1981; Fried \& Ferris, 1987; Hackman \& Lawlet, 1971; Hackman \& 
Oldharn, 1976; Hackman \& Oldham, 1980; Lawler \& Hall, 1970; Tiegs et al., 1992). The JCM states that work content variables, like skill variety, feedback and autonomy are particularly predictive for work motivation. Although these variables refer to work characteristics, it is plausible that characteristics as to organisational structure, like decision authority in the current study, are also related with work motivation and satisfaction (possibly through their influence on work content variables, like autonomy (see Tummers et al., 2002d).

The second hypothesis with regard to the congruence of decision authority and environmental uncertainty in the prediction of bumout and psychosomatic health complaints was not confirmed in either of the two samples. As environmental uncertainty seemed to be positively correlated with emotional exhaustion only in nonICUs, the non-existence of this supposed "buffer-effect" might be explained by the fact that protocols in non-ICUs are used in a more restrictive way than in ICUs. If nurses have high decision authority, but at the same time have to perform activities that are not written down in protocols, uncertain events may be experienced as stressful. Despite high decision authority, non-ICU nurses might not adequately cope with uncertain events due to this relatively high task uncertainty.

The hypothesis that high environmental uncertainty would enhance the positive effect of decision authority on intrinsic work motivation was confirmed, but only in ICUs. This congruence between decision authority and environmental uncertainty might be explained by the fact that ICU nurses see uncertain circumstances as a challenge that provides them the opportunity to develop one's own skills and needs. ICU nurses. might have other personal characteristics or coping strategies (for instance, active coping instead of passive coping) that enable them to be intrinsically motivated by high environmental uncertainty. Another possible explanation is the standardisation of tasks in ICUs, as mentioned earlier. Because of the "certainty" about the way rasks have to be performed, environmental uncertainty might draw nurses out of their "routine ness", and thus might offer them more challenges. In this context, one should observe that we have investigated the "external congruence" (structure and environment) in the current study. It is plausible, however, that the "internal congruence" might also play a role. This means that the structural characteristics of an organisation or unit must be consistent with other aspects of the organisational structure (for instance, the congruence between task standardisation and decision authority).

With regard to the explorative research question as to the relationship between environmental uncertainty on the one hand and emotional exhaustion and psychosomatic health complaints on the other and the possible influence of task standardisation, we found that higher levels of environmental uncertainty were related with higher levels of emotional exhaustion and psychosomatic health complaints. This relationship was only found in non-ICUs. An explanation for this finding might be the clifferent task structure on ICUs, as already mentioned. These differences between ICUs and non-ICUs might be explained by the fact that the task structure is different in ICUs (Tummers et al., 2002c), because in ICUs tasks are more standardised. Standardisation might enable nurses to handle better highly uncertain environmental 
circumstances. So, enritonmental uncertainty might not negatively influence nurses' health (i.e., emotional exhaustion and psychosomatic health complaints?.

In ICUs, two additional significant relationships were found between decision authotity on the one hand and emotional exhaustion and psychosomatic health complaints on the other. The more decision authority, the lower emotional exhaustion and psychosomatic health complaints. This difference between ICUs and non-ICUs might be explained by the fact that the task structure is supposed to be different in ICUs in the sense that tasks are more standardised in ICUs (Tummers et al., 2002c).

With regard to the two explorative research questions as to the relationship between emvironmental uncertainty on the one hand and emotional exhaustion and psychosomatic health complaints on the other and the possible influence of task standardisation, we found that higher levels of environmental uncertainty were related with higher levels of enotional exhaustion and psychosomatic health complaints. This relationship was only found in non-ICUs. An explanation for this finding might, again, be the different task structure on ICUs, as already mentioned.

To conclude, the current, partly explorative study, is a first step to show that organisational characteristics, such as mentioned within the framework of the contingency approach, may also be applicable in the prediction of nurses' well-being and health. However, the hypotheses with regard to the congruence of decision authority and envitonmental uncertainty have only been partially confirmed. Nevertheless, the results have shown that it is worthwhile to refine organisational characteristics within the context of the contingency approach (such as task standardisation and the concept of uncertainty (see Tymon, Stout \& Shaw, 1998) and their relationships with well-being and health in nursing.

\subsection{Study limitations}

Although we found significant relationships between organisational characteristics and employees" well-being and health, the explained variances were relatively low. This finding is, however, not uncommon in this kind of research (see, for example, Semmer et al, 1996). According to Semmer et al. (1996), any separate study can not coves all relevant variables. In line with this, in the current study we selected only a limited number of organisational variables (and interaction effects), those that were theoretically the most plausible. In addition, sick workers who were at home have not participated in the current study. The consequence of this "healthy worker effect" might be that the outcomes are an underestimation of the relationships that is caused by a restriction of range in outcomes (Payne et al., 1999).

Furthermore, we conceptualised the degree of task standardisation by the difference between ICUs and non-ICUs. However, the difference between ICUs and non-ICUs is not only determined by the difference in task standardisation, but by other organisational characteristics (for instance, the span of control) and work 
characteristics as well (for instance, autonomy, see Boumans \& Landeweerd, 1994). As a consequence, other factors than task standardisation could be relevant.

Finally, the cross-sectional design of the current study does not permit causal inferences on the relationships between the variables (Zapf et al., 1996). In the future, a longitudinal study would be recommended with additionally a multilevel design, because of the hierarchical data structure (individuals are nested within organisations) in order to get more accurate parameter estimations (Bryk \& Raudenbush, 1992; Snijder \& Bosker, 1999).

Fowerer, taken these limitations into account, and since we found that not only organisational characteristics, but also the congruence of these characteristics were related with nurses' well-being and health, the current study has innovative elements. The results may give rise to a further elabotation of structural and contingency characteristics and their relationships with well-being and health and put these into a longitudinal perspective. This insight is needed in order to improve nurses" work organisation, their well-being and health and hereby organisational effectiveness as well. 


\title{
6
}

\section{Individual-level and group-level relationships between}

\section{organisational characteristics, work characteristics}

\author{
and psychological work reactions
}

Submitted as:

Tummers, G.E.R, Van Merode, G.G., Landeweerd, I.A \& Candel, M. Individual-fevel and group-lewel relationships berween organisational characteristics, work characteristics and psychological wotk reactions: in nursing work. Intethational Journal of Stress Management. 


\subsection{Introduction}

During the past decades, stress research is becoming a growing area of interest for researchers in the freld of work and organisational psychology. This growing interest is particularly caused by important changes work life has undergone in this period. To give an illustration of these changes, Paoli (1997) concluded, for example, on the basis of a large survey-study conducted among European employees that a growing number of employees (from 35 per cent in 1991 to 42 per cent in 1996) reported working at high speeds "most of the time". So, work demands and workload seem to be increasing.

These changes in working life can be observed in different sectors of work, among which industrial and health care organisations. Especially the health care sector, including nursing work, employs a large number of people (Cascio, 1995; Frese, 2000), and is confronted with a number of problems with regard to the turnover and health of nursing personnel. In this sector, mental demands are emerging as potential risk factors in work (De Jonge, 1995). Nursing work is genetally considered as mentally demanding. Nurses have to cope with stressful work conditions, such as high workload, low control opportunities (Janssen et al., 1999a), and a repeated exposute to patients' loss and suffering. These demands may cause negative effects for the individual as well as for the organisation, such as burnout, psychosomatic complaints, turnover and performance-loss (Cooper, 1998; De Jonge \& Kompier, 1997).

In order to get insight into the processes that cause such work-related stress reactions, several theoretical models that relate work-related psychosocial risk factors (such as workload) to employees' well-being and health, were developed. In this context, one of the most influential and most widely tested models of the psychosocial work environment is Karasek's Demand-Control-Support (DCS) model (Johnson \& Hall, 1988; Karasek, 1979; Karasek \& Theorell, 1990). This model focuses on three work characteristics as potential risk factors for employees' health and learning behaviour or motivation, namely psychological job demands (workload), job control (autonomy) and social support. Although the DCS model has primarily been used to investigate occupations in industry, a number of studies has also applied the DCS model in health care (De Jonge et al., 2000; Dollard et al., 2000). Research based on this model revealed that work characteristics, such as autonomy, workload and social support are particularly important predictors of health complaints, stress reactions, job sarisfaction and work motivation (De Jonge et al., 2001; Janssen et al., 1999a; Schaufeli \& Enzmann, 1998).

Despite the strengths of the DCS model, it does not account for the theory that organisational chatacteristics (organisational structure and organisational context) may be important in the prediction of work characteristics as well as employces psychological outcomes (Tummers et al, 2002b). The DCS model, and other wellknown psychological models as well, only outline how work characteristics affect employees' psychological work reactions, but do not consider the organisation and its characteristics in which these work characteristics are embedded. So, they do not make 
explicit which organisational factors determine work charactetistics and psychological work reactions. The current study incorporates organisational characteristics in investigating relationships between work characteristics and psychological work reactions, and in that sense extends former studies in this area.

Additionally, stress research that aims at investigating work-related risk factors as potential determinants of employees" health and well-being, primarily assessed these risk factors with individual assessments (this means: measured at the individual level). Group assessments are a fruitful addition to individual assessments (Frese \& Zapf, 1988; Semmer et al, 1996; Spector, 1992). By using these aggregated data, it is possible to investigate whether the effects at individual-level (vatiation within-units) are the same as the effects at group-level (variation between-units). In this context, group-level variables are necessary for an adequate estimation of the individual-level effects (cf. Heck \& Thomas, 2000; Hox, 1995; Snijders \& Bosker, 1999).

A multilevel design is necessaty to analyse aggregated data. At least several individualls nested within an organisation should be investigated to have such aggregated data. As a consequence, a multilevel analysis is more adequate in comparison with ordinary regression analysis. The latter method ignores the shared-variance of incumbents (nonindependence of individuals within the same unit). By means of multilevel statistical techniques, the effects of individual variables (leading to within-group differences) can be disentangled from those of group variables (leading to betweengroup differences) in order to get more adequate parameter estimations.

Some studies have simultaneously analysed data from both individual- and group-level when investigating the influence of wotk-related characteristics on psychological work reactions (De Jonge, van Breukelen, Landeweerd \& Nijhuis, 1999; Elovainio, Kivimaeki, Steen \& Kalliomaeki Levanto, 2000; Jex \& Bliese, 1999; Söderfeldt et al,, 1997; Van Yperen \& Snijders, 2000). There are no studies in this context, according to our knowledge, that have analysed organisational characteristics as individual- and group-level variables with adequate statistical techniques. So, it is worthwhile from a theoretical point of view as well as a methodological one, to investigate relationships between individual- and group-level organisational characteristics on the one hand and work characteristics and psychological work reactions on the other.

To conclude, the DCS model does not refer to organisational characteristics as possible determinants for work characteristics and psychological work reactions. The current study incorporates organisational characteristics into these relationships. Furthermore, a multilevel design seems more adequate to investigate these relationships, because of the hierarchical structure of the data. These issues led to the current study. We want to investigate whether aggregated organisational and work characteristics predict better individual's psychological work reactions than individual organisational and work characteristics alone. 


\subsection{Relationships between organisational characteristics, work characteristics and psychological work reactions}

The next three categories of relationships were distinguished: the relationships between organisational characteristics and work characteristics, the relationships between work: characteristics and psychological work reactions and finally, the relationships between organisational characteristics and psychological work reactions. The latter relationships can be direct, but also indirect through the mediating role of work characteristics (see also Tummers et al., 2002b; Tummers et al., 2002c).

In order to gain more insight into the (individual- and group-level) relationships between organisational characteristics, work characteristics and psychological work reactions, two theoretical frameworks were applied. The DCS model was used as an underpinning of the relationships between work characteristics and psychological work reactions. We used the contingency approach as our conceptual framework in order to model relationships between organisational characteristics on the one hand and work characteristics and psychological work reactions on the other.

\subsubsection{Relationships between organisational characteristics and work characteristics}

In order to investigate relationships between organisational characteristics and work characteristics in nursing, several variables with regard to work characteristics and organisational characteristics have been deduced from the DCS model and the contingency approach respectively. The DCS model is a three-dimensional model that focuses on three work characteristics, namely workload, autonomy, and social support at work (Johnson \& Hall, 1988; Karasek, 1979; Karasek \& Theorell, 1990). These particular work charactetistics also seem to be important in nursing work (see De Jonge, 1995).

In order to conceptualise organisational characteristics, we used the contingency approach of organisations. The contingency approach has received much attention in studies investigating organisational design and effectiveness. According to the contingency approach, there is no best way of organising (Child, 1977; Galbraith, 1973; Lawtence \& Lorsch, 1967b). Organisational effectiveness depends on the congruence between the organisational structure and the environment to which the organisation is related. Congruence in this context means that an organisation has a particular organisational structure that is suitable to the environmental characteristics it is confronted with (see, for instance, Donaldson, 2001c).

Various structural chatacteristics of organisations have been studied, with decentralisation of decision-making, formalisation and standardisation being the most frequently cited factors (eg., Draft, 1992; Fry \& Slocum, 1984). Complexity and environmental uncertainty are factors that are often used to describe and measure environmental characteristics of organisations (Fry \& Slocum, 1984; Pennings, 1998; Perrow, 1970). Also in nursing work, these structural and contextual characteristics 
seem to be relevant (see, for instance, Bodt, 1995). An important structural characteristic of nursing units is the degree of decision authority. Decision authority means the degree of authority nurses have to make decisions on their own with regard to the performance of several tasks (they are responsible for a whole "product" instead of only one particular task) as well as the degree they can plan nursing or caring tasks (such as planning a patient admission). So, it gives an indication for the degree of decentralisation of decisions within units.

The enwironment (or context) of nursing units can be characterised by environmental uncertainty (Iskra Golec et al., 1996; Slocum \& Sims, 1980) and complexity (Bodt, 1995). Environmental uncertainty means that there is insufficient information about the quantity (such as the number of emergencies) and/or the quality (such as the severity of patients' conditions) of new or ongoing activities (Bodt, 1995). Complexity tefers to the characteristics of the patients (such as patients' health conditions), and characteristics of the environment (e.g., the intense interdependencies with other care disciplines (Mandemakers, 1993).

As mentioned earlier, relationships between organisational characteristics and work characteristics have rarely been empitically investigated neither in organisation science nor in work and organisational psychology. According to Oldham and Hackman's Job Modification Framework (Oldham \& Hackman, 1981), organisational characteristics determine employees" function profiles (i.e., job descriptions) and characteristics of their jobs. For instance, highly centralised organisations often limit employees' control opportunities in carrying out their work. So, the autonomy in their jobs is relatively low.

We suppose that decision authority particularly influences autonomy and sociall support. If the level of decision authority is high, this means that decisions about tasks as to "who is going to do what and when" are delegated to nurses on a unit instead of being made by one particular person. In addition, high decision authority also means that nurses are not only responsible for one particular task, but for more different kinds of tasks. Because decisions within units are delegated to the persons who have most knowledge about the work processes to be executed, employees might also determine themselves the evaluation of their work or the order in which the work is carried out (both examples reflect parts of the autonomy concept; De Jonge, 1995). In other words: decision authority might enhance nurses' autonomy. So, we expect that high levels of decision authority lead to high levels of autonomy. Moreover, we expect that high levels of decision authority positively influence the level of social support. Having high decision authority means that nurses are not merely responsible for one specific task, but for several kinds of tasks. In practice, nurses often work in teams to perform these tasks together, which may lead to a "shared responsibility", in addition to an individual responsibility. Consequently, actual social support is expected to increase.

Finally, we expect that environmental uncertainty and complexity both influence workload in particular. Workload is not only a function of task load, but also a function of organisational and environmental factors (Bi \& Salvendy, 1994). According 
to Bi and Salvendy (1994), workload can be predicted by complexity and uncertainty. Uncertainty induces swings between the extremes of quiet and hectic periods with consequences for workload. Empirical evidence exists that as uncertainty decreases, wotkload is reduced (Knight \& Salvendy, 1981; Tummers et al., 2002b). Complexity of care may call for more diagnostic and therapeutic procedures, so that nurses are involved in more work diversity. An increase in the quantity of work means higher workload (Tummers et al., 2002b).

The studies of Tummers et al. $(2002 \mathrm{~b}, 2002 \mathrm{c})$ elaborate further on the organisational concepts used in the current study together with the theoretical underpinnings of the relationships that are investigated here. The empitical results of these studies have shown that most of the above mentioned suppositions were confirmed. The current study is an extension of these studies by investigating group effects in addition to individual effects. So, there are both theoretical and methodological arguments for using a multilevel approach.

To conclude, we suppose that decision authority predict nurses' autonomy and social support. Environmental uncertainty and complexity are supposed to predict nurses' workload.

\subsubsection{Relationships between work characteristics and psychological work reactions}

In order to investigate relationships between work characteristics and psychological work reactions in nursing, we address the same type of outcomes that were discussed in the DCS model. As the DCS model does not outline specific psychological work reactions as outcomes, we included burnout and intrinsic work motivation in order to represent the two outcomes of the DCS model, namely the psychological strains and learning and development opportunities, respectively (see also De Jonge et al., 2001; Janssen et al., 1999a). These relationships have been investigated extensively (see for instance, De Jonge et al., 2001; Houkes et al., 2001b). Some recent studies among health care workers suggest that more specific predictions can be madc regarding these relationships (e.g., De Jonge et al., 2001; Janssen et al., 1999a). Janssen et al. (1999), for example, found in their study among nurses that emotional exhaustion is primarily predicted by mental work overload and lack of social support, whereas intrinsic work motivation is predicted by quality of job content (e.g., autonomy, task identity, performance feedback).

Despite the huge number of empirical studies on relationships between work characteristics and psychological work reactions, studies that analyse aggregated data in addition to individual data are far less prominent in the literature. The scarce studies that used a multilevel design in investigating individual-level work characteristics as well as group-level work characteristics in the prediction of employees' psychological work reactions, concluded that aggregated work characteristics are important in the explanation of work motivation, job satisfaction and bumout (De Jonge et al., 1999; Elovainio et al., 2000; Söderfeldt et al., 1997; Van Yperen \& Snijders, 2000). Group- 
level variables generally explain some variance that could not be explained by individual-level wariables. Elovainio et al. (2000) found, for example, that the total explained variance of individual mental health increased significantly after adding group-level job control in addition to individual-level job control.

We suppose that emotional exhaustion is predicted by workload and social support. Intrinsic work motivation is supposed to be predicted by autonomy.

\subsubsection{Indirect relationships between organisational characteristics and psychological work reactions}

As mentioned earlier, the DCS model does not pay attention to factors that are precursors for both work characteristics and psychological work reactions. In addition, we also suppose that the relationships between organisational characteristics and psychological work reactions are largely indirect (see also Tummers et al., 2002b, 2002 c). This means that the relationships between the organisational characteristics and psychological work reactions go via the work characteristics. In other words: after partialling out the influence of work characteristics, the relationships between the organisational characteristics and psychological work reactions might fade away. This assumption of the mediation function of work characteristics is in line with Oldham and Hackman's Job Modification Framework (Oldham \& Hackman, 1981). According to this framework, organisational chatacteristics may pur specific demands on the work or tasks. The individual may conceive them as stressors which in turn may contribute to strains such as burnout or job dissatisfaction (Lee \& Ashforth, 1991; Oldham \& Hackman, 1981). For instance, a centralised decision-making structure may hamper employees' job autonomy. Low job autonomy on its turn may lead to dissatisfaction and de-motivation. Applied to the current study, we assume that the relationship between decision authority and intrinsic work motivation goes via employees' atutonomy. Decision authority is a structural characteristic indicating the degtee to which tasks and decisions about the work are decentralised. By means of decentralising decisions to nurses, nurses get greater responsibility and autonomy to fulfil their tasks. It is well-known that high autonomy is, generally, associated with well-being, such as intrinsic work motivation and job satisfaction. So, we suppose that decision authority positively influences the level of autonomy and that autonomy on its turn positively influences intrinsic work motivation.

Next, we suppose that the relationship between environmental uncertainty and complexity on the one hand and burnout and psychosomatic health complaints on the other is through the workload. Workload is not only a function of task load, but also a function of organisational and environmental factors (Bi \& Salvendy, 1994). In the current study, we selected environmental uncertainty and complexity as characteristics of the organisational (unit) environment. According to Bi and Salvendy (1994), workload can be predicted by system paramerers, like complexity and environmental uncertainty. Empirical evidence exists that as uncertainty decreases, workload is reduced (Knight \& Salvendy, 1981). High complexity of care may cause an increase of 
diagnostic and therapeutic procedures, so that nurses are involved in more work diversity (Groen, 1995). An increase in the amount of work may cause higher workload. So, we suppose that environmental uncertainty and complexity are prinarily related with butnout through workload.

Finally, we suppose that the level of social support depends on the decision-making structure of a unit. A unit with a decentralised decision-making structure is often more "product"- or patient-oriented than task-oriented (Bodt, 1995). Social relations are part of this "product"-oriented organisational principle. Nurses not only have an individual responsibility, but also have a 'shared' tesponsibility for a group of patients. This "shared" responsibility may lead to more consultation between nurses in comparison with a task-oriented organisation. Hence, one might expect that decision authority positively influences social support, whereas social support on its turn has often been shown to be negatively related with burnout, as mentioned earlier. Summarising, we suppose that decision authority is positively related with social support, whereas social support on its turn is expected to lower the level of burnout.

\subsection{Method}

\subsubsection{Design and sample}

The current study is a survey study with one measurement time. This means that the design has a cross-sectional nature implying that one must, of course, be cantious with causal inferences (Taris, 2000).

We followed a three-stage sampling procedure. This means that the sample of out: research respondents was drawn from three subpopulations. First, a random sample of 15 general hospitals was drawn from all general hospitals in the Netherlands. Thereafter, 95 different units (intensive care ( $(\mathrm{CU})$, medical, and surgical units) were selected within these hospitals. Finally, all the 1721 registered nurses from these 95 units were included in our sample.

In order to analyse our nested data (different hierarchical levels), we have used a threelevel multilevel model. These three levels are, going from the lowest to the highest level, individuals, units and hospitals respectively.

In order to measure the variables under study, self-administered questionnaires were distributed among these 1721 nurses. One thousand hundred and fifty-four nurses returned the questionnaire, yielding a response rate of 67 per cent. Nurses who had been employed for less than three months were excluded, because it was assumed that nurses need some time to adapt to their work situation (cf. Boumans, 1990). This led to a final sample of 1111 nurses. Eighty-five per cent of this sample were women. The mean age was 35.35 years $(S \mathrm{D}=8.62)$, whereas the mean work experience was 15.19 years $(\mathrm{SD}=8.49)$. 


\subsubsection{Procedure}

Managers of the hospitals were asked if they wanted to participate in the current investigation. After permission they were informed about the research topic and purpose. The questionnaires were distributed in a sealed envelope with the name of the respondent on it and an introductory letter. Respondents were urged to fill out the questionnaite and to return it in an enclosed return envelope. Anonymity of the respondents was guaranteed: the questionnaifes could only be examined by the researchers and were destroyed afterwards. After three weeks, a reminder was sent to all the supervisors of the participating units to ask those who had not filled out the questionnaires to do this as yet. Thereafter, the questionnaires were sent back to the researchers.

\subsubsection{Measures}

The measures consisted of organisational characteristics, work characteristics, psychological work reactions, and of potential confounders (gender, age, and type of unit). The variables that are central to this study are:

\section{Organisational characteristics}

Environmental uncertainty was measured by means of five items, developed by Wibbelink (1995) and Tummers (1998). The response categories ranged from 1 "totally disagree" to 5 "totally agree". An item example is: "There are daily emergency admittances on this unit". Cronbach's alpha in this study was 82 .

Complexity was measured by a 9-item questionnaire with a five-point response scale, ranged from 1 "totally disagree" to 5 "totally agree". The scale was derived from Mandemakers (1993) and was further adapted by Wibbelink (1995) and Tummers (1998). An item example is: "Patients on this unit show various clinical pictures that can be divided into different specialities". Cronbach's alpha in this study was found to be .65 .

Decision authorily was measured by means of six items. The response categories ranged from 1 "totally disagree" to 5 "totally agree". The scale was derived from Bodt (1995) and Boone and De Jonge (1996). An item example is: "A nurse is able to make decisions about patient cate on her own". Ctonbach's alpha in this study turned out to be 73 .

\section{Work characteristics}

Autonomy was measured by the Maastricht Autonomy Questionnaire (MAQ), developed by De Jonge, Landeweerd and Nijhuis (1995). Respondents were asked to rate their work situations as to the opportunities they offer for autonomy. This scale consists of 10 items with a 5-point response scale ranging from 1 "very little opportunity" to 5 "very much opportunity". An item example is: "The opportunity that 
the work offers to determine the method of working yourself'. Cronbach's alpha was .81 .

Workload was measured by means of an 8 -item scale, developed by De Jonge; Landeweerd and Nijhuis (1995), with a response scale ranging from 1 "never" to 5 "always". The scale consists of a relatively wide range of both quantitatively and qualitatively demanding aspects in the work situation, like working under time pressure, working hard, and strenuous work (De Jonge et al., 1995). An item example is: "In the unit where I work, there is too little time to finish the work". We found Cronbach's alpha to be 86 .

Social suppont at work (from colleagues and senior nursing officer) was measuted by means of a 10-item scale, derived from a Dutch questionnaire on organisational stress ("Vragenlijst Organisatic Stress-Doetinchem" - VOS-D, Bergers et al., 1986). An item example is: "To what extent can you count on your colleagues, when you have difficulies in your work?" The items were scored on a 4-point response scale, ranging from 1 "never" to 4 "always". Cronbach's alpha was .81.

\section{Psychological work reactions}

Bumout is genetally conceptualised as a syndrome of emotional exhaustion, depersonalisation, and reduced personal accomplishment (Maslach \& Jackson, 1986). Emotional exhaustion is considered the core dimension of burnout (Cox et al., 1993; Maslach, 1998). Therefore, we selected emotional exhaustion to represent the concept of bumout. Emotional exhaustion was measured by means of the Dutch version of the Maslach Burnout Inventory (MBI, Maslach \& Jackson, 1986): the MBI-NL (Cox et al., 1993; Maslach, 1993; Schaufeli \& Van Dierendonck, 1993). The emotional exhaustion scale of the MBI-NL consists of eight items with a 7-point response scale $(1=$ "never", $7=$ "always"). An example-item is: "I feel emotionally drained from my work". We found a Cronbach's alpha of .88.

Intrinsic work motivation was measured by means of six items derived from a scale developed by Warr, Cook and Wall (1979). Its response categoties ranged from 1 "totally disagree" to 5 "totally agree". An item example is: "My opinion of myself goes down when I do this job badly". Cronbach's alpha in this study was .73.

\subsubsection{Data analysis}

Because of the nonindependence of the observations due to the hieratchical structure of the data, the relationships between the organisational characteristics, work characteristics and psychological work reactions were analysed using multilevel analyses by means of the MLwiN 1.1 computer program (Rasbash et al, 2000).

The multilevel model is a regression model for data with a hierarchical structure (Bryk \& Raudenbush, 1992; Goldstein, 1995; Longford, 1993), and is also known in the literature as random coefficient model (Longford, 1993), hierarchical linear model (Bryk \& Raudenbush, 1992), mixed effects model, or variance component model (Berkhof, 2000). Conventional statistical techniques (e.g., regression analysis) ignore 
the hierarchical structure of the data and the dependence of observations, and may; therefore, lead to biased results (Bryk \& Raudenbush, 1992; Goldstein, 1995).

In order to analyse the group-level and individual-level relationships, we first computed for each independent variable individual and group (aggregated) scores. These group scores were mean group scores of each unit, leading to 95 different scores. The organisational characteristics were the independent variables in their relationships with work characteristics. The work characteristics and organisational characteristics operated as independent variables in their relationships with the psychological work reactions.

Thereafter, the actual multilevel analyses were performed. In the present study, a threelevel model was used (cf. Bryk \& Raudenbush, 1992; De Jonge et all, 1999). The macro-level contained a random sample of 15 institutions (i.e., general hospitals). The meso-level consisted of 95 units. Finally, the micro-level comprised 1111 nurses. The basic hierarchical regression model for a three-level model can be described as a general regression equation with a dependent variable $Y$ and independent variables $x_{1}$ to $x_{11}$ in which the subscript $i$ refers to the micto-level (nurse), $j$ to the meso-level (unit) and $k$ to the macro-level (hospital) (De Jonge et al., 1999). This equation is as follows (1):

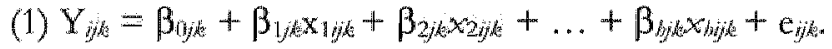

This equation is a micro-equation and pertains to individuals. The dependent variable $(\mathrm{Y})$, (for instance, emotional exhaustion) of individual $i$ in unit $j$ within institution $k$, is a function of the mean level of emotional exhaustion for unit $j$ within institution $k$ $\left(\beta_{0 j k}\right)$ plus a residual unaccounted for vatiation between individuals ( $e_{\text {;ik }}$ ) (Elovainio et al., 2000). In this general multilevel micro-equation model, the intercept $\left(\beta_{0, j}\right)$ and regression coefficients $(\beta$ s) of micro-level predictors (such as the work characteristics) may vary across meso-level (units) and macro-level (institutions). This variation across units and/or institutions can be modelled by random coefficients (random intercept and random slope), but also by including measured variables at the meso- and/or macro-level (cf. Bryk \& Raudenbush, 1992). The meso-equation as depicted in (2) shows how the variable intercept can be decomposed into random effects:

(2) $\beta_{0, j k}=\beta_{0}+u_{0 y k}+v_{0 k}$.

In this meso-equation, the response in unit $j$ within institution $k\left(\beta_{0, k}\right)$ is a function of the mean level of emotional exhaustion across all units and institutions $\left(\beta_{0}\right)$ plus a residual unaccounted for variation between groups (utojk) and institutions ( $v_{0 k}$ ). In equation (2), $\mathrm{u}_{0 / 2}$ is the random effect of the factor unit within the institution (differences between units), and $v_{0}$ is the random effect of the factor institution (differences between institutions). This meso-equation is different from the microequation in that it describes relations at the meso-level. In our multilevel model, both the random intercept and random effects were estimated. This means that it was 
assumed that units and institutions differ randomly in their overall level on the dependent variable (random intercept: $\beta_{0, k}$ ). In addition, we assumed that units and institutions differ randomly in the regression coefficients of individual-level variables (random slope: $\beta_{1 j k}$ to $\beta_{b i k}$ ) and the group-level variables. This decision was made, because we expect some differences between the units regarding the effects of the independent variables on the outcome measures (see Tummers et al, 2002c). So, in addition to the assumed variation of the intercept at group-and institution-level, we included random parameters for individual-level factors and meso-level factors in our model to explain vatiance. Because the type of unit may function as a confounding variable (De Jonge et al., 1999; Tummers et al., 2002c), we control for this variable. So, the intercept part of our model can be rewritten as follows:

(3) $\beta_{0, k}=\beta_{0}+\sum_{q=1}^{2} \gamma_{0 q} z_{q j k}+u_{0, j}+v_{0 k}$

In this model (3), $z_{1}$ to $z_{2}$ refer to the two dummy variables for type of unit (meso-level fixed factor). We also included some interaction terms in the model, because we expect: some differences between the types of unit with regard to the pattern of relationships (see Tummers et al., 2002c).

In order to investigate the relationships between (1) individual- and group-level organisational characteristics and work characteristics, (2) individual-and group-level work characteristics and psychological work reactions and, finally (3) (direct and/or indirect) individual and group-level organisational characteristics and psychological work reactions, several multilevel models were compared by means of the difference in $\log$-likelihood or deviance ( $\Delta D$ ) (Bosker \& Snijders, 1990; Bryk \& Randenbush, 1992; Goldstein, 1995). For each multilevel model, we followed a top-down model testing procedure. This means that we started with the most complex model in which all the relevant parameters (as hypothesised) were defined and estimated (Snijders \& Bosker, 1999). This model is the most complex model including all covariates (gender and age at the individual level and type of unit at the group level) and both the individual-and the group-level (aggregated) independent variables (each of them having fixed and random effects). We first tested whether the random parameters (group-level and institution-level variances) were significant. Thereafter, we tested the significance of the fixed parameters by investigating successively the interaction effects, the grouplevel effects, and the individual-level effects. We followed this model testing procedure for each dependent variable separately. These are autonomy, workload and social support in the regression of work characteristics on organisational characteristics, and emotional exhaustion and intrinsic work motivation in the regression of psychological work reactions on work- and organisational characteristics. 


\subsection{Results}

\subsubsection{Regression of work characteristics on organisational characteristics}

\section{Autonomy}

The first multilevel model (M1) is a model that only includes a random intercept and no random slopes (the random slopes appeared not to be significant in former analyses). In addition, no interaction effects between type of unit and organisational characteristics were included. This decision was made, because the results of our former study (Tummers et al., 2002c) showed no significant differences between type of unit regatding the relationships between organisational characteristics and autonomy.

The independent (individual- and group-level) variables were centered, particularly because it reduces problems of multicollinearity (Kleinbaum et al., 1982). Because of centering, the scores should be interpreted relatively to their group's mean (Bosker \& Snijders, 1990; Hox, 1995). The results of the multilevel analyses with regard to the regression of autonomy on the organisational characteristics are depicted in Table 6.1. Table 6.1 reveals that the variation in autonomy between individuals was larger than between units (group-level variance was $8.0 \%$ of the total variance). We compared four nested models by means of the difference between the deviances $(\Delta D)$. The increase in model fit (represented by the decrease in D) has a chi-squared distribution with degrees of freedom equal to the difference in the number of parameters between two models. One-tailed tests were performed for the random effects, and two-tailed tests for the fixed effects (Bosker \& Snijclets, 1990; Goldstein, 1995).

We first compared the most complex model (M1) with a less complex model in which no group variables were included (M2). This model comparison showed that the omission of the gtoup-level organisational variables did not significantly deteriorate model fit $(\Delta \mathrm{D}(3)=3.79, \mathrm{p}=.29)$. This means that the unexplained group level variance in model 2 cannot be explained by the group-level organisational characteristics. Finally, we compared M2 with M3 (model without individual-level organisational characteristics). The model comparison yielded a significant difference in model fit $(\Delta \mathrm{D}(3)=19.15, \mathrm{p} \leq .001)$, indicating that the individual-level variables were significant. So, M2 appeared to be the best fitting model. Both individual-level decision authority and individual-level uncertainty appeared to predict autonomy significantly. High levels of clecision authority predicted high autonomy, whereas low levels of environmental uncertainty predicted high autonomy. 
Table 6.1 Multilevel estimates for models of autonomy $(\mathbb{N}=1111,95$ units, 15 institurions); Unstandardised regression coefficients (and standard errors)

\begin{tabular}{|c|c|c|c|}
\hline Muntilewe mordids & MI & M2 & M3 \\
\hline \multicolumn{4}{|l|}{ Fixed effects } \\
\hline Intercept & $2.25(51)$ & $2.82(.19)$ & $2.85(09)$ \\
\hline \multicolumn{4}{|l|}{ Indiwidust laved } \\
\hline Gended" & $.09(.04)$ & $.09(.04)$ & $.09(.04)$ \\
\hline Age & $.00(.00)$ & $.00(00)$ & $.00(.00)$ \\
\hline Decision authority & $.09(.03)$ & $.11(.03)$ & \\
\hline Uncertainty & $-.05(.03)$ & $-.07(.03)$ & \\
\hline Complexity & $-.06(.03)$ & $-.04(.03)$ & \\
\hline \multicolumn{4}{|l|}{ Grouph lovel } \\
\hline \multicolumn{4}{|l|}{ Type of unite } \\
\hline Meclical & $-10(.08)$ & $-.14(.07)$ & $-.11(.07)$ \\
\hline Surgical & $-14(09)$ & $-.18(07)$ & $-.12(.07)$ \\
\hline Decision auchority & $.19(.10)$ & & \\
\hline Uncertainty & $-.06(.06)$ & & \\
\hline Complexity & $-.05(.08)$ & & \\
\hline \multicolumn{4}{|l|}{ Random effects: variances } \\
\hline \multicolumn{4}{|l|}{ Intercept } \\
\hline Individual level & $.23(.01)$ & $.23(01)$ & $.23(.01)$ \\
\hline Group level & $.02(.01)$ & $.02(.01)$ & $.02(.01)$ \\
\hline Institution level & $.00(.00)$ & $.00(.00)$ & $.00(00)$ \\
\hline Model fit: Deviance (D) & 1497.10 & 1500.89 & 1520003 \\
\hline
\end{tabular}

a The scores of the predictor wariables were centered (i.e, subtracting the mean of each score: $x_{\text {txilk }}-\sum x_{\text {kimil }}$ $/ 1111$ for wariables at individual-level, and $x_{\text {lijk }}-\Sigma x_{\text {hjk }} / 95$ for variables at group-level).

i Gender was coded $0=$ female, $1=$ male.

" Reference Category: ICU.

\section{Workload}

In the first multilevel model (M1), we included interaction effects between type of unit and (individual-level, and group-level) organisational characteristics in addition to the individual-level and group-level organisational characteristics. Empirical support exists that the relationship between environmental uncertainty and workload depends on the type of unit (Tummers et al., 2002c), inducing the necessity for including these interaction effects. The results of the multilevel analyses for workload as a dependent variable are shown in Table 6.2 . 
Table 6.2 Muluilewel estimates for models of workload $(\mathrm{N}=1111,95$ units, 15 institurions); Unstandaxdised regression coefficients (and standand errors)

\begin{tabular}{|c|c|c|c|c|c|}
\hline Mulinilenel modals & M1 & $\mathrm{M2}$ & M3 & M4 & MS \\
\hline \multicolumn{6}{|l|}{ Fixed affects } \\
\hline Intercept & $3.28(12)$ & $3.18(.10)$ & $3.34(0.03)$ & $3.34(.03)$ & $3.33(05)$ \\
\hline \multicolumn{6}{|l|}{ Indinidual level } \\
\hline Gendex & $.08(.04)$ &. $.08(.04)$ & $-.08(04)$ & $-.08(04)$ & $-.08(04)$ \\
\hline Age & $.01(01)$ & $.01(01)$ & $.01(.01)$ & $.01(01)$ & $.01(01)$ \\
\hline Decision authority & $-.06(.03)$ & $-.06(.03)$ & $-.06(.03)$ & $-.05(.03)$ & \\
\hline Uncertainty & $.17(.03)$ & $.17(.03)$ & $.17(.03)$ & $17(02)$ & \\
\hline Complexity & $.17(.03)$ & $.17(.04)$ & $.22(03)$ & $.22(.03)$ & \\
\hline \multicolumn{6}{|l|}{ Group lewel } \\
\hline \multicolumn{6}{|l|}{ Type of unit } \\
\hline Medical & $.23(17)$ & $.43(10)$ & $.48(10)$ & $48(08)$ & $.31(.09)$ \\
\hline Surgical & $.06(31)$ & $.11(.28)$ & $.53(.11)$ & $55(.09)$ & $.27(09)$ \\
\hline Decision authotity & $-.05(.14)$ & $-.05(.12)$ & $-.06(.12)$ & & \\
\hline Uncertainty & $.02(.09)$ & $.04(.07)$ & $.04(.07)$ & & \\
\hline Complexity & $.07(.11)$ & $.05(.09)$ & $.08(.09)$ & & \\
\hline Medical unit $x$ decision authonty (i) & $.10(.08)$ & $.10(.08)$ & & & \\
\hline Surgical unit $x$ decision authority (ii) & $.15(.08)$ & $.15(.08)$ & & & \\
\hline Medical unit x uncertainty (1) & $-.05(.08)$ & $-.05(.08)$ & & & \\
\hline Surgical unit $x$ uncertainty (i) & $-09(.08)$ & $-.06(.08)$ & & & \\
\hline Medical unit $x$ complexity (i) & $.14(.07)$ & $.14(.07)$ & & & \\
\hline Surgical unit $x$ complexity (i) & $.09(.08)$ & $.11(.07)$ & & & \\
\hline Medical unit $x$ decision authority (j) & $\approx 18(.62)$ & & & & \\
\hline Surgical unit $x$ decision authority (j) & $-.02(.62)$ & & & & \\
\hline Medical unit x uncertainty (0) & $.32(39)$ & & & & \\
\hline Sutgical unit $x$ uncertaincy $(0)$ & $.51(.38)$ & & & & \\
\hline Medical unit $x$ complexity (j) & $-11(.27)$ & & & & \\
\hline Surgical unit $x$ complexity (j) & $.23(.22)$ & & & & \\
\hline \multicolumn{6}{|l|}{ Random effects: varionces } \\
\hline \multicolumn{6}{|l|}{ Intercept } \\
\hline Individual level. & $.15(.01)$ & $.15(01)$ & $.15(.01)$ & $.15(.01)$ & $.17(.01)$ \\
\hline Group level & $.04(.01)$ & $.05(.01)$ & $.05(.01)$ & $.05(.01)$ & $.00(.01)$ \\
\hline Institution level & $.00(00)$ & $.00(00)$ & $.00(00)$ & $.00(.00)$ & $.00(.00)$ \\
\hline Model fit: Deviance (D) & 1113.13 & 1121.09 & 1129.65 & 1130.58 & 1289.75 \\
\hline
\end{tabular}

"The scores of the predictor wariables were centered.

! Gender was coded $0=$ fernale, $1=$ male.

"Reference Category: $1 \mathrm{CU}$.

d(i) refers to the interactions with the individual-level organisational characteristics, and (0) tefers to the interactions with the group-level organisational characteristics.

As Table 6.2 reveals, the group-level variance encompassed a relatively high percentage of the total variance $(25.0 \%)$. In order to investigate whether the interactions of type of unit with the group-level organisational charactetistics were significant, we first compared M1 (including interaction terms with group-level organisational characteristics) with M2 (without interactions with group-level organisational 
characteristics). This model comparison yielded a non-significant difference in deviance $(\Delta \mathrm{D}(6)=7.96, \mathrm{p}=.24)$. Thereafter, we compared M2 with M3 (without any interaction terms) to investigate whether the interactions of the individual-level organisational characteristics were significant. The difference in deviance between the models was not significant, meaning that M2 did not hold $(\Delta D(6)=8.56, p=.20)$. M4 (without the group-level variables) was compared with $\mathrm{M} 3$ to investigate the importance of the group-level variables. This model comparison showed that the organisational variables at group-level were not significant either $(\Delta \mathrm{D}(3)=0.93, \mathrm{p}=$ .82). Finally, we compared M5 (without the individual-level organisational variables) with M4. It appeared that M5 leads to a deterioration in model fit $(\Delta \mathrm{D}(3)=159.17, \mathrm{p}$ $\leq .001$ ), indicating the significant effects of the individual-level organisational vatiables (M4). High workload was significantly predicted by high environmental uncertainty, and high complexity.

\section{Social support}

Because the effect of decision authority on social support appeared to depend on the type of unit (see Tummers et al., 2002c), we included interaction effects between type of unit and (individual-level and group-level) organisational characteristics in our first multilevel model. The results of the different multilevel model estimates are depicted in Table 6.3. From this Table, we may conclude that none of the interaction effects were significant $(\Delta \mathrm{D}(6)=5.21, \mathrm{p}=.52$ when comparing M2 with $\mathrm{M} 1$; and $\Delta \mathrm{D}(6)=$ $5.84, \mathrm{p}=.44$ when comparing M3 with M2). In order to investigate whether the omission of the organisational group-level variables deteriorated the model fit significantly, we compared M3 with M4. The results of this model comparison showed that these group-level variables were not significant either $(\Delta \mathrm{D}(3)=2.22, \mathrm{p}=.53)$. The organisational characteristics at the individual-level appeared, however, to be significant (comparing $M 5$ with $M 4: \Delta D(3)=35.56, \mathrm{p} \leq .01$ ). In sum, M4 appeared to be the best fitting model. High individual-level decision authority seemed to significantly predict high level of social support. In addition, high individual-level complexity predicted low levels of social support. 
Table 6.3 Multelevel estimates for models of social support $(\mathrm{N}=1111,95$ units, 15 institurions); Unstandardised regression coefficients"s (and standard errors)

\begin{tabular}{|c|c|c|c|c|c|}
\hline Mathilevel models & M1 & $M 2$ & $\mathrm{M}$ & $\mathrm{M}$ & M5 \\
\hline \multicolumn{6}{|l|}{ Fixed uffects } \\
\hline Intercept & $3.43(09)$ & $3.37(08)$ & $3.23(02)$ & $3.23 \cdot(.02)$ & $3.23(02)$ \\
\hline \multicolumn{6}{|l|}{ Individual level } \\
\hline Gendet" & $.00(03)$ & $.01(.03)$ & $.00(.03)$ & $.01(03)$ & $.00(.03)$ \\
\hline Age & $.00(.00)$ & $.00(.00)$ & $.00(.00)$ & $.00(.00)$ & $.00(00\rangle)$ \\
\hline Decision authority & $10(02)$ & $.10(.02)$ & $.11(.02)$ & $.11(.02)$ & \\
\hline Uncertainty & $-.01(02)$ & $-.01(.02)$ & $-.02(.02)$ & $.03(.02)$ & \\
\hline Complexity & $-.01(.03)$ & $-.02(03)$ & $-.06(.02)$ & $-.05(.02)$ & \\
\hline \multicolumn{6}{|l|}{ Group level } \\
\hline \multicolumn{6}{|l|}{ Type of unite } \\
\hline Medicall & $-.03(.11)$ & $.03(.06)$ & $-.01(.06)$ & $.00(.05)$ & $.01(05)$ \\
\hline Surgical & $.37(.23)$ & $.33(.20)$ & $-.04(.07)$ & $-.03(.02)$ & $.01(05)$ \\
\hline Decision authority & $.02(.09)$ & $.00(.01)$ & $.01(.08)$ & & \\
\hline Uncertainty & $-05(.06)$ & $-.05(.04)$ & $-.06(.04)$ & & \\
\hline Complexity & $.04(.07)$ & $.01(.06)$ & $.03(.06)$ & & \\
\hline Medical unit $x$ decision authority $(\mathrm{i})^{\mathrm{d}}$ & $-.03(.06)$ & $-.02(.06)$ & & & \\
\hline Sutgical unit $x$ decision athority (i) & $.00(.06)$ & $.00(.06)$ & & & \\
\hline Medical unit x uncertainty (i) & $.02(.06)$ & $.03(.06)$ & & & \\
\hline Surgical unit $x$ uncertainty (a) & $.00(.06)$ & $-.01(.06)$ & & & \\
\hline Medical unit x complexity (i) & $-14(.06)$ & $-.12(.06)$ & & & \\
\hline Surgical unit $x$ complexity (i) & $-.13(.06)$ & $-.10(.05)$ & & & \\
\hline Medical unit x decisions authonty (j) & $.29(.39)$ & & & & \\
\hline Surgical unit $\mathrm{x}$ decision authority (j) & $.03(.39)$ & & & & \\
\hline Medical unit x uncertainty (0) & $.07(.24)$ & & & & \\
\hline Surgical unit $x$ uncertainty (j) & $-.02(.23)$ & & & & \\
\hline Medical unit $x$ complexity $(j)$ & $.09(.17)$ & & & & \\
\hline Surgical unit $x$ complexity (j) & $.13(.14)$ & & & & \\
\hline \multicolumn{6}{|l|}{ Rundom effects: variances } \\
\hline \multicolumn{6}{|l|}{ Intercept } \\
\hline Individual level & $.09(00)$ & $.09(.00)$ & $.09(.00)$ & $.09(.00)$ & $.10(00)$ \\
\hline Group level & $.01(00)$ & $.01(.00)$ & $.01(00)$ & $.01(.00)$ & $.01(.00)$ \\
\hline Instrtution level & $.00(.00)$ & $.00(.00)$ & $.00(.00)$ & $.00(.00)$ & $.00(.00)$ \\
\hline Model fit: Deviance (D) & 565.21 & 570.42 & 576.26 & 578.48 & 614,04 \\
\hline
\end{tabular}

"The scores of the predictor tariables were centered.

isender was coded $0=$ female, $1=$ male.

c Reference Category: ]CU.

i) (i) refers to the interactions with the individual-level organisational chatacteristics, and (0) refers to the interactions with the groupwewel organisational characteristics. 


\subsubsection{Regression of organisational and work characteristics on psychological work reactions}

\section{Intrinsic work motivation}

Several multilevel models were compared in subsequent steps in investigating the regression of work characteristics as well as organisational characteristics on intrinsic work motivation and emotional exhaustion. We included only main effects, because no significant differences were expected between the different types of units with respect to the relationships to be investigated (Tummers et al., 2002c). We included random effects of the individual-level organisational characteristics, because these parameters appeared to be significant in former analyses (not depicted in the Table). The results of the model comparisons are shown in Table 6.4.

The first model (M1) is the most complex model, encompassing the work characteristics and organisational characteristics at both levels. In order to investigate whether the group-level organisational characteristics are significant after the introducrion of the group-level work characteristics, M1 was compared with a model in which the group-level organisational characteristics were not included (M2). The difference in deviance between these two models was not significant $(\Delta \mathrm{D}(3)=2.09, \mathrm{p}$ $=.55)$, indicating that the group-level organisational characteristics were not significant. Comparing M2 with M3 revealed that the group-level work characteristics were also not significant $(\Delta \mathrm{D}(3)=2.64, \mathrm{p}=.45)$. When we compared M3 with M4, we may conclude that the individual-level organisational characteristics were significant $(\Delta D(6)=42.75, p \leq .001)$. Finally, we compared M3 with M5 to investigate whether the individual-level work characteristics were also significant. The significant difference in deviance revealed that the individual-level work characteristics were important predictors of intrinsic work motivation $(\Delta \mathrm{D}(3)=11.52, \mathrm{p} \leq .01)$. So, M3 appeared to be the best fitting model. High individual-level decision authority seemed to significantly enhance nurses' intrinsic work motivation. Also high environmental uncertainty seemed to predict high intrinsic work motivation. Finally, high levels of individual-level social support were predictive for high intrinsic work motivation. 
Table 6.4 Multileyel estimites for models of intrinsic work motivation $(N=1111,95$ units, 15 institutions); Unstandardiscel regression coefficiencs (and standard errors)

\begin{tabular}{|c|c|c|c|c|c|}
\hline Mullikenel models & M1 & M2 & M3 & M4 & $\mathrm{M} 5$ \\
\hline \multicolumn{6}{|l|}{ Fued effects } \\
\hline Intercept & $3.97(.02)$ & $3.97(02)$ & $3.97(02)$ & $3.98(.02)$ & $3.97(.02)$ \\
\hline \multicolumn{6}{|l|}{ Ladiwdual hotel } \\
\hline Gender & $-.10(.04)$ & $-.10(.04)$ & $-.10(04)$ & $-.10(04)$ & $-.10(.04)$ \\
\hline Age & $.01(00)$ & $.01(00)$ & $.01(04)$ & $.01(.00)$ & $.01(.00)$ \\
\hline Autcinomy & $.04(.03)$ & $.04(.03)$ & $.04(.03)$ & $.03(.03)$ & \\
\hline Social support & $.17(.05)$ & $.17(.05)$ & $.15(.05)$ & $.18(.05)$ & \\
\hline Workload & $-.01(.04)$ & $-.01(.04)$ & $-.00(.03)$ & $.05(.03)$ & \\
\hline Decision authority & $.13(.04)$ & $.12(.03)$ & $.12(.03)$ & & $.13(.03)$ \\
\hline Uncertainty & $.06(.03)$ & $.06(.03)$ & $.06(.03)$ & & $.05(.03)$ \\
\hline Complexity & $.05(.03)$ & $.05(.03)$ & $.05(.03)$ & & $.05(.03)$ \\
\hline \multicolumn{6}{|l|}{ Growp levef } \\
\hline \multicolumn{6}{|l|}{ Type of unite } \\
\hline Medical & $.16(.08)$ & $.15(.06)$ & $.16(06)$ & $.05(05)$ & $.17(.06)$ \\
\hline Suigical & $.23(09)$ & $.21(.07)$ & $.22(.06)$ & $.06(.05)$ & $.22(.06)$ \\
\hline Autonony' & $.03(.09)$ & $.00(.09)$ & & & \\
\hline Social support & $-14(.13)$ & $-.17(.13)$ & & & \\
\hline Workload & $04(.08)$ & $.05(.08)$ & & & \\
\hline Decision authorty & $10(09)$ & & & & \\
\hline Uncertainty & $.06(.05)$ & & & & \\
\hline Complexity & $.01(.07)$ & & & & \\
\hline \multicolumn{6}{|l|}{$\begin{array}{l}\text { Random effects: vatiances } \\
\text { Interept }\end{array}$} \\
\hline Individual level & $.19(.01)$ & $.19(.01)$ & $.19(.01)$ & $.21(.01)$ & $.19(.01)$ \\
\hline Group lovel & $00(00)$ & $.00(.00)$ & $.01(.00)$ & $.01(.00)$ & $.00(.00)$ \\
\hline Institution level & $.00(.00)$ & $.00(.00)$ & $.00(.00)$ & $.00(.00)$ & $.00(.00)$ \\
\hline \multicolumn{6}{|c|}{$\begin{array}{l}\text { Random effects: (group level) vatiances } \\
\text { Slopes }\end{array}$} \\
\hline \multicolumn{6}{|l|}{ Individual level } \\
\hline Docision authotty & $.02(01)$ & $.01(.01)$ & $.01(.01)$ & & $.01(.01)$ \\
\hline Uncertainty & $.02(.01)$ & $.02(.01)$ & $.02(.01)$ & & $.02(.01)$ \\
\hline Complexity & $.00(.00)$ & $.00(.00)$ & $.00(.00)$ & & $.00(.00)$ \\
\hline Model fut Deviance (D) & 1322.14 & 1324.23 & 1326.87 & 1369.62 & 1338.38 \\
\hline
\end{tabular}

" The scores of the predictor watisbles were centered.

- Gender was coded $0=$ female, $1=$ male.

- Reterence Category: $₫ \mathrm{CU}$. 


\section{Emotional exhaustion}

The first multilevel model for the prediction of emotional exhaustion encompassed interaction terms between type of unit and (individual-level and group-level) organisational characteristics, because the relationships between decision authority and environmental uncertainty on the one hand and emotional exhaustion on the other have been shown to differ between different types of units (see Tummers et al, $2002 \mathrm{c}$ ). No random slopes were included, because these did not seem to be significant in former analyses. The model comparisons of the six different multilevel models are shown in Table 6.5.

After comparing $\mathrm{M} 2$ with $\mathrm{M} 1$, it was concluded that the interaction effects between type of unit and the group-level organisational characteristics were not significant $(\triangle D$ $(G)=8.29, \mathrm{p}=.22)$. The difference in deviance between $\mathrm{M} 3$ and $\mathrm{M} 2$ revealed, however, that the interaction effects between type of unit and individual-level organisational charactetistics were significant $(\Delta \mathrm{D}(6)=21.66, \mathrm{p} \leq .001)$. In order to investigate whethet removing the group level organisational characteristics did significantly deteriorate model fit, M2 was compared with M4 (without the group-level organisational characteristics). This model comparison showed also a significant effect of these group-level variables $(\Delta \mathrm{D}(3)=15.75, \mathrm{p} \leq .001)$. The group-level work characteristics were, however, not significant after comparing M2 with $M 5(\Delta \mathrm{D}(3)=$ $4.90, p=.18$ ). Finally, M5 was compared with M6 to investigate whether the individual-level work characteristics were significant. "The difference in deviance between the two models revealed a significant effect of the individual-level work characteristics $(\Delta D(3)=287.96, p \leq .001)$. So, M5 seemed to be the best fitting model. When we take the separate effects of the vatiables into account, the following were significant: the effect of individual-level environmental uncertainty on emotional exhaustion appeared to significandy depend on type of unit. In surgical and medical units, high individual-level environmental uncertainty leads to high emotional exhaustion. Additional analyses showed, however, that the main effect of individuallevel environmental uncertainty on emotional exhaustion (without type of unit taken into account) was not significant. So, workload could not operate as a mediator variable in the direct relationship between individual-level uncertainty and emotional exhaustion, because a necessary condition for mediation is that the relationship between the independent variable (i.e., environmental uncertainty) and the dependent variable (i.e., emotional exhaustion) is significant (see, for instance, Holmbeck, 1997). Furthermore, the effect of individual-level decision authority on emotional exhaustion significantly depended on the type of unit. This relationship seemed to be significant only for ICUs, and not for surgical and medical units: for ICUs, it holds that the higher the individual-level decision-authority, the lower the emotional exhaustion. Finally, high individual-level workload, low individual-level social support, low group-level decision authority, and low group-level environmental uncertainty were predictive for high emotional exhaustion. 
Table 6.5 Multlevel sstimates for models of enctional exhaustion ( $\mathrm{N}=1111,95$ units, 15 instioutions); Unstandardised tegression coefficientsis (and standatd crors)

\begin{tabular}{|c|c|c|c|c|c|c|}
\hline Munthilewe lonodels & M1 & M2 & $\mathrm{M3}$ & M4 & M5 & M6. \\
\hline \multicolumn{7}{|l|}{ Fixed effects } \\
\hline Intercept & $2.48(19)$ & $233(13)$ & $2.17(.02)$ & $2.28(13)$ & $2.31(.13)$ & $1.75(11)$ \\
\hline \multicolumn{7}{|l|}{ Inothwdual tewel } \\
\hline Gender & $.10(06)$ & $.10(.06)$ & 1. $(00)$ & $.12(.00)$ & $.12(.06)$ & $.06(.06)$ \\
\hline Age & $.00(00)$ & $.00(.00)$ & $.00(00)$ & $.00(.00)$ & $.00(.00)$ & $.00(.00)$ \\
\hline Autonomy & $-.03(.04)$ & $-.03(.04)$ & $-03(.04)$ & $-.03(04)$ & $-.03(.04)$ & \\
\hline Socital support & $-.54(.07)$ & $-.54(.07)$ & $-.54(.07)$ & $-.53(.07)$ & $-.53(.07)$ & \\
\hline Workload & $.60(.05)$ & $.60(05)$ & $.60(.05)$ & $.63(.07)$ & $.63(.05)$ & \\
\hline Decision athority & $.01(04)$ & $.01(04)$ & $-.03(.04)$ & $-06(0.4)$ & $-.06(.04)$ & $-.02(.04)$ \\
\hline Uncertanty & $-.09(.08)$ & $-.01(.04)$ & $-.01(.04)$ & $-.05(.03)$ & $-.01(.03)$ & $-.01(.03)$ \\
\hline Complexity & $.15(.07)$ & $.12(.06)$ & $.09(.05)$ & $.07(05)$ & $.08(.06)$ & $.11(.06)$ \\
\hline \multicolumn{7}{|l|}{ Grousp tewer' } \\
\hline \multicolumn{7}{|l|}{ Type of unitc } \\
\hline Medical & $-.14(.16)$ & $-.22(.10)$ & $-16(.09)$ & $-.03(09)$ & $-.20(.09)$ & $-.09(.12)$ \\
\hline Surgical & $.25(.28)$ & $.06(.34)$ & $-.19(.10)$ & $.21(.35)$ & $.03(.34)$ & $-.95(.31)$ \\
\hline Autonomy & $.11(16)$ & $.13(.12)$ & $.13(.12)$ & $.06(12)$ & & \\
\hline Social support & $.28(.16)$ & $.28(.16)$ & $.28(.16)$ & $29(10)$ & & \\
\hline Workload & $.06(.11)$ & $.08(11)$ & $.11(.11)$ & $.05(.10)$ & & \\
\hline Decision authority & $-.39(.13)$ & $-.28(.11)$ & $-.22(.11)$ & & $-.22(.11)$ & $-.27(.13)$ \\
\hline Uncertainty & $-.09(.08)$ & $-13(.07)$ & $-.11(.07)$ & & $-.16(.07)$ & $-.03(.07)$ \\
\hline Complexity & $-.09(.10)$ & $-.14(.09)$ & $-14(.08)$ & & $-.12(.08)$ & $-.01(.09)$ \\
\hline $\begin{array}{l}\text { Medical unit x } \\
\text { decision authority (i) d }\end{array}$ & $.18(.13)$ & $.17(.12)$ & & $.18(.12)$ & $.18(.12)$ & $.20(.14)$ \\
\hline $\begin{array}{l}\text { Surgical unit } x \\
\text { decision authority (i) }\end{array}$ & $.12(.1 .2)$ & $.11(12)$ & & $.17(.12)$ & $.16(.12)$ & $.18(.14)$ \\
\hline $\begin{array}{l}\text { Medical unit } x \\
\text { uncertainty (i) }\end{array}$ & $.19(.13)$ & $.10(.12)$ & & $.09(12)$ & $.11(.12)$ & $.11(14)$ \\
\hline $\begin{array}{l}\text { Surgical unit } \mathrm{x} \\
\text { uncertainty (i) }\end{array}$ & $.26(1.2)$ & $.20(.11)$ & & $.19(.11)$ & $.20(.11)$ & $.26(.13)$ \\
\hline $\begin{array}{l}\text { Medical unit } \mathrm{x} \\
\text { complexity (i) }\end{array}$ & $-.16(.15)$ & $-.14(10)$ & & $-.12(.10)$ & $-.14(.10)$ & $.13(.11)$ \\
\hline $\begin{array}{l}\text { Surgical unit } x \\
\text { complexity (i) }\end{array}$ & $-.11(.23)$ & ${ }_{-} 09(.09)$ & & $-.06(09)$ & $-.08(.09)$ & $.33(.08)$ \\
\hline $\begin{array}{l}\text { Medical unit } x \\
\text { decision authority (ij) }\end{array}$ & $.23(.31)$ & & & & & \\
\hline $\begin{array}{l}\text { Surgical unit } x \\
\text { decision authotity (i) }\end{array}$ & $.12(.32)$ & & & & & \\
\hline $\begin{array}{l}\text { Medical unit } x \\
\text { uncertainty }(0)\end{array}$ & $-.17(.33)$ & & & & & \\
\hline $\begin{array}{l}\text { Sutgical unit } x \\
\text { uncettainty (j) }\end{array}$ & $-.21(.31)$ & & & & & \\
\hline $\begin{array}{l}\text { Medical unit } x \\
\text { complexity }(0)\end{array}$ & $-.04(.25)$ & & & & & \\
\hline $\begin{array}{l}\text { Surgical unit } x \\
\text { complexicy (0) }\end{array}$ & $.19(.20)$ & & & & & \\
\hline
\end{tabular}


Table 6.5 Multilevel estimates for models of emotional exhaustion $(\mathrm{N}=1111,95$ unirs, 15 institutions); Unstandardised regression coefficients (and standard ertors) (continued)

\begin{tabular}{|c|c|c|c|c|c|c|}
\hline Mostitienel models & MI & $\mathrm{M} 2$ & M3 & M4 & M5 & MG \\
\hline \multicolumn{7}{|l|}{ Fixed eftects } \\
\hline \multicolumn{7}{|l|}{$\begin{array}{l}\text { Random effects: } \\
\text { Fatiances }\end{array}$} \\
\hline \multicolumn{7}{|l|}{ Intercept } \\
\hline Individual level & $.38(.02)$ & $.39(.02)$ & $.39(.02)$ & $.38(.02)$ & $.38(.02)$ & $.49(.02)$ \\
\hline Group level & $.00(.00)$ & $.00(.00)$ & $.00(.01)$ & $.00(.01)$ & $.00(.01)$ & $.02(01)$ \\
\hline Instinution level & $.00(.00)$ & $.00(.00)$ & $.00(00)$ & $.00(00)$ & $.00(00)$ & $.00(.00)$ \\
\hline $\begin{array}{l}\text { Model fit: Deviance } \\
\text { (D) }\end{array}$ & 1992.08 & 2000.37 & 2022.03 & 2016.12 & 2005.27 & 2293.23 \\
\hline
\end{tabular}

The scores of the predictor variables were centered.

b Gender was coded $0=$ female, $1=$ male.

c Reference Category: ICU.

di) tefers to the interactions with the inclividual-level organisational characteristics, and (b) refers to the interactions with the group-level otganisational characteristics.

\subsection{Discussion}

"The aim of the present study was to investigate individual-level and group-level relationships between organisational characteristics, work characteristics and psychological work reactions in nursing work. For this aim, several multilevel models were estimated to investigate whether the group-level parts of organisational characteristics (decision authority, complexity and environmental uncertainty) significantly added explained vatiance to the individual-level patts in the prediction of nurses' autonomy, workload, and social support. Also nurses' intrinsic work motivation and emotional exhaustion were predicted by means of group-level work- and organisational characteristics in addition to individual-level work- and organisational characteristics.

With regard to the regression of the work characteristics on the organisational characteristics, we supposed that group-level decision authority better predicts nurses" autonomy and social support than solely individual-level decision authority. Furthermore, the addition of group-level environmental uncertainty and complexity was supposed to have a better prediction of nurses' workload than individuallevel environmental uncertainty and complexity. Although the results of our multilevel analyses confirmed our suppositions at the individual-level, we did not found any additional effects of the group-level organisational characteristics. This means that the relationships between group-level organisational characteristics and work characteristics did not seem to differ from those between individual-level organisational characteristics and work characteristics. This finding could mainly be 
explained by the significant effects of medical and surgical type of unit. In some additional multilevel analyses, we did not adjust for these variables. In this case, grouplevel decision authority, group-level environmental uncertainty and complexicy did turn out to significantly add explained variance (in the prediction of autonomy and workload respectively) to the variance explained by the individual-level part of this variable. So, the group-level otganisational characteristics reflect not only individual organisational characteristics, but also characteristics of type of unit. The finding that the group-level organisational characteristics did not add any variance to the individuallevel organisational characteristics when type of unit was taken into account, might be explained by a selection effect or a learning process. A selection effect means that a certain type of unit attract individuals with particular individual characteristics, typical for that type of unit. When adjusting for type of unit, the group-level effect might not differ from the individual-level effect. Otherwise, a learning process means that people adapt themselves to the specific chatacteristics belonging to a certain type of unit, implying that, in the long term, the group-level effects are the same as individual-level effects.

With respect to the regression of the psychological work reactions on the organisational and work characteristics, we first supposed that work motivation is predicted by group-level autonomy, and group-level decision authority in addition to the individual-level parts. Emotional exhaustion was supposed to be predicted by group-level workload, social support, environmentall uncertainty, and complexity in addition to the individual-level parts. Second, we supposed that the relationships between the organisational characteristics and psychological work teactions are mediated by work characteristics. The results of our multilevel analyses partially supported these suppositions. With regard to nurses' intrinsic work motivation, individual-level decision authority and individual-level social support led to higher intrinsic work morivation. It appeared that individual-level autonomy could not be a mediator variable in the relationship between individual-level decision authority and intrinsic worlk motivation, since individual-level autonomy was no significant predictor of intrinsic work motivation (which is a necessary condition for a mediator). So, high individual-level decision authority directly predicted high intrinsic work motivation. Furthermore, and contrary to our expectations, the effects of individual-level decision authority and social support on intrinsic work motivation seemed not to differ significantly from the effects of group-level decision authority and social support on intrinsic work motivation. This finding implies that intrinsic work motivation could sufficiently be explained by individual-level decision authority and social support.

The suppositions with regard to the individual-level predictors of emotional exhaustion were confirmed. Individual-level workload and social support clearly accounted for most of the variability on individual-level: individual-level variance decreased from $96 \%$ of the total variance to $38 \%$ after adding these individual-level work characteristics. Additionally, these individual-level work characteristics explained some group-level variance (after adding individual-level work characteristics, group-level variance decreased from $3.90 \%$ of the total variance to $0 \%$ ). The group-level work 
characteristics did not, however, add any variance to the individual-level variables, indicating that the within-group relationships do not differ significantly from the between-group relationships.

The results concerning the mediation suppositions showed that individual-level decision authority adds significant variance after adjusting for the effects of the individual-level work characteristics: in ICUs, high individual-level decision authority predicted low emotional exhaustion. This characteristic of the organisational structure thus seemed to be more important in ICUs than in medical and surgical units for the prediction of emotional exhaustion. As expected, environmental uncertainty seemed to be positively related with emotional exhaustion in surgical and medical units. No significant (positive) main effect was, however, found of individual-level complexity on emorional exhaustion when workload was adjusted for. This relationship appeared, however, to be significant when workload was not taken into account. This finding seems an indication for the mediator role of workload, as expected (see also Tummers et al., 2002b).

Surprisingly, group-level decision authority added variance to emotional exhaustion (in all the three types of units), over and above the individual-level effect of decision authority. This means that low unit decision authority, in compatison with individual decision authority (this effect was unit-specific: only found in ICUs), can be seen as the major source of emotional exhaustion. The individual-level effect of decision authority seemed to be different from the group-level effect. This finding might be explained by particular views on group behaviour, stating that a group is more than the sum of its members. In other words: a group exists as distinct from an aggregation of individuals. The co-operation of individuals within an organised group, make them behave or act differently than if they would act individually (cf. Bion, 1961).

To conclude, the current multilevel study has shown that organisational characteristics are important predictors for both work characteristics and psychological work reactions. In addition, group-level estimates appeared to be necessary for an adequate estimation and interpretation of these individual-level relationships. 


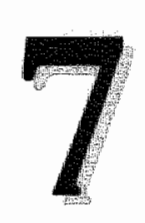

\section{Longitudinal relationships between}

\section{organisational characteristics, work characteristics, and psychological work reactions}

Submitted as:

Tummers, G.E R, Landeweerd, J.A., Van Merode, G.G. \& Janssen, P.P.M. Onganisational chatacteristics, work chatacteristics, and psychological work reactions in nursing: A longindinal study. European Journal of Work and Organizarional Psychology. 
8 


\subsection{Introduction}

In work stress literature; several theoretical frameworks that relate job-related psychosocial risk factors (i.e., work characteristics) with psychological outcome variables (i.e., psychological work reactions) have been developed to get insight into the processes that cause stress reactions. One of the most influential models in this context is the Demand-Control-Support (DCS) model Johnson \& Hall, 1988; Karasek, 1979; Karasek \& Theorell, 1990). The DCS model distinguishes itself from other work stress models by its simplicity and the extent to which it has gained a paradigmatic function in research in the field of work and health (De Jonge et al, 1996).

Despite the strengths of the DCS model, it does not account for the idea that organisational characteristics (organisational structure and organisational context) may be important in the prediction of work characteristics as well as employees ${ }^{*}$ psychological work reactions (Tummers et al., 2002b; Tummers et al., 2002c). The DCS model only outlines how work characteristics affect employees' psychological work reactions, but it does not make explicit which organisational factors determine work characteristics and psychological work reactions.

Organisational scientists developed theories to study organisational effectiveness, such as the contingency approach of organisations (Galbraith, 1977; Lawrence \& Lorsch, 1967b). According to this approach, organisational effectiveness depends on the congruence between structural chatacteristics (such as centralisation, formalisation, and standardisation; Gutek, 1990; Pennings, 1998) and characteristics of the organisational context or environment, like environmental uncertainty (Fty \& Slocum, 1984; Pennings, 1998; Perrow, 1986). However, in the relationship between structural and contingency characteristics, measures of organisational effectiveness have mainly been related to economic variables, like organisational efficiency or productivity (Kleiner, 1983). Psychological variables (such as work motivation, and psychological disorders) have rarely been studied in this context, although these may also be seen as measures of organisational effectiveness in itself ( $\mathrm{rraft}$ et al., 1995; Scott \& Shottell, 1988). Sometimes they are subsumed under the headings of "social effectiveness" (Kraft et al, 1995). As theories in otganisation science are primarily interested in economic outcomes by investigating otganisational effectiveness, and theories in work stress literature mainly focus on psychosocial risk factors and less on those organisational risk factors mentioned in organisation theories on effectiveness, it is worthwhile to investigate the "missing llink" in both kind of theories, namely: the relationship between organisational characteristics on the one hand and wotk characteristics and psychological outcomes on the other. Insight into these relationships is theoretically as well as practically important, since organisational characteristics may determine and shape employees" function profiles and the related task or work characteristics of employees' jobs. Consequently, they may influence employees' reactions (see also Oldham and Hackman's Job Modification Framework; Oldham \& Hackman, 1981). 
This article explores the possible influence of organisational characteristics on work characteristics and psychological work reactions in nursing work. Nursing work is becoming more and more important as a research topic in organisarions and of organisation scientists. As a consequence of tremendous changes work in the health care sector has undergone during the last decades, more attention has been drawn to aspects of the work of nurses, such as a high workload and low autonomy that may negatively affect employees' work reactions. In addition to these well-known workrelated factors in nursing work that may cause stress reactions, onganisational factors may also play a tole in this respect (Bodt \& Van Tuill, 1988; Tummers et al., 2002b). If tasks are, for instance, allocated among nurses, each nurse can only perform a small part of the total number of tasks. This might cause, for instance, dissatisfaction and demotivation.

To conclude, we want to investigate which relationships in nursing work exist between organisational characteristics and work characteristics, between work characteristics and psychological work reactions, and finally, between organisational characteristics and psychological work reactions.

\subsection{Theoretical background}

Our starting point was to develop a research model that encompasses relationships between organisational characteristics, work characteristics and psychological work reactions. In order to gain more insight into these relationships in nursing work, two theoretical frameworks were applied. The DCS model was used as an underpinning of the relationships between work characteristics and psychological work reactions. We used the contingency approach, in a more explorative way, however, than the application of the DCS model, to investigate relationships between organisational characteristics on the one hand and work characteristics and psychological work reactions on the other. Accordingly, the next three categories of relationships were distinguished: the relationships between organisational characteristics and work chatacteristics, the relationships between work characteristics and psychological work reactions and finally, the relationships between organisational characteristics and psychological work reactions.

\subsubsection{Relationships between organisational characteristics and work characteristics}

In order to investigate relationships between organisational characteristics and work characteristics in nursing, several variables with regard to work characteristics and organisational characteristics are being deduced from the DCS model and the contingency approach respectively. The DCS model is a three-dimensional model that focuses on three work characteristics, namely job demands (workload), job control (autonomy), and social support at work. These particular work characteristics also 
seem to be important in nursing work, because they often appeated to be important stressors nurses are faced with. Workload is relatively high in mursing (cf. Greenglass, Burke \& Riksenbaum, 2001; Reeves, 1994). Overall staff shortage is probably the main cause for this high workload. Furthermore, nurses have often been termed "dependent practitioners", because of their reliance on physicians. This implies a telative hack of autonomy (De Jonge, 1995). In addition, the nature of the work (particularly irtegular workflows) hampers nurses" opportunities to shift or delay particular tasks. Consequently, their autonomy is testricted. Finally, social support is an important work characteristic, because nurses" work is often characterised as "team work" whereby mutual social support is a necessary condition.

The contingency approach, that we used to explore organisational characteristics for the current study, has received much attention in studies directed at organisational design and effectiveness. The core of the contingency approach (Child, 1977; Galbraith, 1973, 1977; Lawtence \& Lorsch, 1967b) is that there is no best way of organising. Organisational effectiveness depends on the congrwente between the organisational structure and the environment to which the organisation is related. In this respect, various structural characteristics have been studied, with decentralisation of decision-making (the extent to which decisions are delegated to less hierarchical levells of the organisation), formalisation (the degree to which activities and social relationships are governed by rules, procedures, and contracts), and standardisation (work processes, outputs or skills are specified and/or programmed) as the most frequently cited factors (e.g., Draft, 1992; Fry \& Slocum, 1984). Complexity and environmental uncertainty are factors that are often used to describe and measure the environment of organisations (Fry, 1982; Fry \& Slocum, 1984; Pennings, 1998; Perrow, 1967, 1970; Rundall \& Hethetington, 1988). Also in nursing work, these structural and contextual characteristics seem to be relevant (see Bodt., 1995). An important structural characteristic of nursing units is the degree of decentralisation of decision-making or the decision authority. Decision authority means the degree of authority nurses have to make decisions on their own with regard to the performance of several tasks (they are responsible for a whole "product" instead of only one particular task) as well as the degree they can plan nursing or caring tasks (such as planning a patient admission). The environment (or context) of nursing units can be characterised by environmental uncertainty (Iskra Golec et al., 1996; Slocum \& Sims, 1980) and complexity (Bodt, 1995). Environmental uncertainty means that there is insufficient information about the quantity (such as the number of emergencies) and/or the quality (such as the severity of patients' conditions) of new or ongoing activities (Bodt, 1995). The degree of environmental uncertainty depends on the "planning freedom" (see Van Merode et al., 1995) employees have to decide when to start performing activities. Planning freedom is a part of environmental uncertainty, involving the time span of activities. In addition, the degtee of planning freedom determines the extent to which employees perceive uncertain circumstances as a stressor. Complexity refers to the characteristics of the patients (such as patients' health conditions), and characteristics of the 
environment ( $\mathrm{g}$, the intense interdependencies between other care disciplines (Corcoran, 1986; Mandemakers, 1993).

As mentioned earlier, relationships between organisational characteristics and work characteristics have rarely been empirically investigated, although it is obvious that these aspects are related to each other. According to Oldham and Hackman's Job Modification Framework (Oldham \& Hackman, 1981), organisational characteristics determine cmployees' function profiles (i.e., job descriptions) and characteristics of their jobs. For instance, highly centralised organisations often limit employees' control opportunities in carrying out their work. So, the autonomy in their jobs is relatively low. With respect to the relationships between decision authority, environmental uncertainty and complexity on the one hand and workload, autonomy and social support on the other, it seems plausible that decision atthority particularly influences. autonomy and social support. If the level of decision authority is high, this means that decisions about tasks as to "who is going to do what and when" are delegated to nurses on a unit instead of being made by one particular person. In addition, high decision authority also means that nurses are not only responsible for one particular task, but for more different kind of tasks. So, nurses are responsible for a whole "product" instead of only a part of it, inducing that they have a total overview of their work. This makes it possible to determine self, for instance, the evaluation of their work or the order in which the work is carried out (both examples reflect parts of the autonomy concept, see De Jonge, 1995). Hence, we expect that high levels of decision authority lead to high levels of autonomy. Moreover, we expect that high levels of decision authority positively influence the level of social support. High decision authority means, as mentioned before, that nurses perform several kind of tasks (a whole "product") instead of only one specific part of it. In practice, nurses often work in teams to perform together these tasks inducing a "shared responsibility" (Groen, 1995), besides an individual responsibility. Consequently, actual social support is expected to increase.

Finally, we expect that emenronsental sncertaing and complexity both influence workload in particular. Workload is not only a function of task load, but also a function of organisational and environmental factors (Bi \& Salvendy, 1994). According to $\mathrm{Bi}$ and Salvendy (1994) workload can be predicted by complexity and uncertainty. Uncertainty induces swings between the extremes of quiet and hectic periods with consequences for workload. Empirical evidence exists that as uncertainty decreases, workload is reduced (Knight \& Salvendy, 1981; Tummers et al., 2002b). Complexity of care may call for more dingnostic and therapeutic procedures, so that nurses are involved in more work diversity (Groen, 1995). An increase in the quantity of work means higher workload (Tummers et al., 2002b).

To conclude, we hypothesise that:

(1) Decision authority influences autonomy and social support;

(2) Environmental uncertainty and complexity influence workload. 


\subsubsection{Relationships between work characteristics and psychological work reactions}

In order to investigate relationships between work characteristics and psychological work reactions in nursing, we addresses to the same type of outcomes that were discussed in the DCS model: As the DCS model does not outline specific psychological work reactions as outcomes, we included bumout and intrinsic work motivation in order to represent the two assumptions of the DCS model, namely the psychological strains and learning and development opportunities, respectively (see also De Jonge et al., 2001; Janssen et al., 1999a; Tummers et al, 2001; Van der Doef \& Maes, 1999). We included burnout, since it seems to be an important rariable in nursing work. Nurses seem to show relatively high burnout levels as a result of high job demands (budget constraints with the consequence of staff shortages, low career opportunities and little time for direct patient care; see Tummers et al., 2001). In addition, nurses are a relatively vulnerable occupational group, because they are running an above-average tisk of bumout in comparison with other occupational groups. We included intrinsic work motivation (Cook et al., 1981), because it is presumed that people's motivation to work in the health care sector is not primarily driven by external factors (Janssen et al., 1999a; Speedling, 1990), like salary, but is determined by intrinsic values of the job, like recognition, patient contact and task content (Tummers et al., 2001).

Much empirical evidence exists regarding the relationships between work characteristics and psychological work reactions (see, for instance, Duquette et al., 1994, Houkes et al., 2001 a, 2001b; Janssen et al., 1999a, De Jonge, 1995; De Jonge et al., 2001; Schaufeli, 1998; Tummers et al., 2001). High levels of burnout seemed to be particularly predicted by high workload and low social support, whereas intrinsic work motivation seemed to be particularly predicted by autonomy.

De Lange, Kompier, de Jonge, Taris and Houtman (2001) have concluded on the base of an extended review on high quality longitudinal studies that there is strong evidence for the influence of work characteristics on employees health and well-being. De Jonge et al. (2001) found some empirical support for the causal predominance of work characteristics on psychological well-being. They reported, for instance, that job demands and social support influence job satisfaction. Houkes et al. (2001b) found that workload positively influences emotional exhaustion, whereas the Motivating Potential Score (MPS; this means a single index that composes of skill variety, task identity, task significance, autonomy and job feedback, Hackman \& Oldham, 1976; Hackman \& Oldham, 1980) seemed to influence intrinsic work motivation positively. On the base of these studies as well as the propositions of the DCS model, we hypothesise that:

(3) Workload and social support influence burnout;

(4) Autonomy influences intrinsic work motivation. 


\subsubsection{Relationships between organisational characteristics and psychological work reactions}

As relationships between work characteristics and psychological work reactions have been studied extensively, research with regard to the influence of organisational characteristics on psychological work reactions is less prominent in the literature. Until now, outcome variables that have been studied in the contingency approach were particularly economic variables in the context of organisational effectiveness. As mentioned earlier, psychological variables, like work motivation, refer also to organisational effectiveness: the social effectiveness. These kind of variables have, however, been studies less extensively. The psychological work reactions (i.e., intrinsic work motivation and burnout) refer to the social effectiveness of organisations when investigating relationships with organisational characteristics.

On the base of the literature as well as the results of our cross-sectional research, we expect that decision authority, environmental uncertainty and complexity influence bumout and intrinsic work motivation (Cummings \& Berget, 1976; James \& Jones, 1976; Lee \& Ashforth, 1991; Porter \& Lawler, 1965; Tummers et al, 2002a). It seems plausible that decision authority is particularly predictive for nurses' intrinsic work motivation. Having the responsibility of a whole "product" generates more identification with the work. Consequently, intrinsic work motivation might increase. Empirical research supports the view that content variables in work, such as responsibility, are predictors for particularly work motivation (Fried \& Ferris, 1987; Hackman \& Lawler, 1971; Hackman \& Oldham, 1980; Hobfoll \& Freedy, 1993; Houkes et al., 2001a; Tiegs et al., 1992).

Furthermore, we expect that environmental uncertainty and complexity might both influence burnout. If the time at which tasks have to be performed, is uncertain, nurses might experience stress, because they perceive an imbalance between environmental demands and individual resources to cope with these demands (Gärling et al., 1998). So, cnvironmental uncertainty is expected to increase burnout.

Complexity of care might be a demanding factor, because it involves both more therapeutic activities and coordination with care disciplines. Hence, we suppose that these additional demands influence burnout positively.

To summarise, the following hypotheses can be formulated:

(5) Decision authority influences intrinsic work motivation;

(6) Complexity and environmental uncertainty influence burnout.

\subsection{Method}

\subsubsection{Design}

The current study is a survey-study with two measurement moments. In order to analyse the longitudinal data, we have used a full two-wave cross-lagged panel design. 
This means that both the independent and the dependent variables were measured at time 1 and time 2 (Finkel, 1995; Taris, 2000). Longitudinal designs give a much better insight than cross-sectional designs into the causal inferences of relationships (Bijleveld \& Van der Kamp, 1998; Frese \& Zapf, 1988; Zapf et al., 1996). This means that the carsal chain of relationships can be established more plausible. The following three conditions must be fulfilled for a plausible causal inference of a relationship: there is a covatiation of the stressor with the outcome, the stressor appeared before the outcome variable occurred, and other plausible explanations can be ruled out (Cook \& Campbell, 1979; Menard, 1991; Zapf et al., 1996). So, causal inferences cannot be proven, but can be made plausible by ruling out alternative explanarions (Dwyer, 1983; Zapf et al., 1996).

\subsubsection{Procedure}

In order to measure the variables, self-administered questionnaires were distributed at two measurement times to nurses employed at 6 general hospitals in the Netherlands. The time interval between the two measurement times was one year. A time lag of one year in this kind of research seems long enough to measure possible changes in individual scores (compare Frese \& ZapP's 'exposure time effect' [p. 388]) (Frese \& Zapf, 1988). In addition, a one year time interval is not too long for much nonresponse in the sample (De Jonge et al., 2001; Frese \& Zapf, 1988) and may prevent instability of seasonal influence (Frese \& Zapf, 1988; Zapf et al., 1996).

At the first measurement, managers of the hospitals were asked if they wanted to participate twice. After permission, they were informed about the research topic and purpose. The questionnaires were distributed in a sealed envelope with the name of the respondent on it and an introductory letter. Moreover, the questionnaites contained an administration code in order to identify respondents at the second measurement time and to connect the data from both measurement times. Respondents were urged to fill out the questionnaire and to return it in an enclosed return envelope. The same procedure was used at the second measurement. Anonymity of the respondents wass guaranteed, because the lists that connected the administration codes with the respondents' names could only be examined by the researchers and were destroyed after the second measurement.

\subsubsection{Sample}

At the first measurement (time 1), questionnaires were distributed to 596 nurses of which 379 nurses returned the questionnaire (response $=64 \%$ ). At the second measurement (time 2), the same questionnaires were sent to the 379 nurses who had responded at time 1. Finally, 211 nurses returned the questionnaire (response $=56 \%$ ). As a consequence, the final "panel group" (the respondents who participated at both times) consisted of 211 nurses. Eighty per cent of the panel group (measured at time 1) 
were women. The mean age was 35.44 years $(\mathrm{SD}=8.41)$, whereas the mean work experience was 15.04 years $(\mathrm{SD}=8.48)$.

\subsubsection{Measures}

The measures consisted of demographic chatacteristics (gender, age), organisational characteristics, work chatacteristics and psychological work reactions.

\section{Organisational chatacteristics}

Enwronmentat ancertaingy was measured by means of five items, developed by Wibbelink Wibbelink (1995) and Tummers (1998), ranging from 1 "totally disagree" to 5 "totally agree". An item example is: "There are daily emergency admittances on this unit". Complexity was measured by a 9-item questionnaire with a five-point response scale, ranging from 1 "totally disagree" to 5 "totally agree". The scale was derived from Mandemakers (1993) and was further adapted by Wibbelink (1995) and Tummers (1998). An item example is: "Patients on this unit show various clinical pictures that can be divided into different specialities".

Decision antbority was measured by means of six items, ranging from 1 "totally disagree" to 5 "totally agree". The scale was derived from Bodt (1995) and Boone and de Jonge (1996). An item example is: "A nurse is able to make decisions about patient care on her own".

\section{Work characteristics}

Autonomy was measured by the Maastricht Autonomy Questionnaire (MAQ), developed by De Jonge et al. (1995). Respondents were asked to rate their work situations as to the opportunities it offers for autonomy. This scale consists of 10 items with a 5-point response scale ranging from 1 "wery little opportunity" to 5 "very much opportunity". An item example is: "The opportunity that the wotk offers to determine the method of working yourself".

UVorkload was measured by means of an 8-item scale, developed by De Jonge et al. (1995), with a response scale ranging from 1 "never" to 5 "always". The scale consists of a relatively wide range of both quantitatively and qualitatively demanding aspects in the work situation, like working under time pressure, working hard, and strenuous work (De Jonge et al., 1995). An item example is: "In the unit where I work, there is too little time to finish the work".

Sonial suppow at work (from colleagues and senior nursing officer) was measured by means of a 10-item scale, derived from a Dutch questionnaire on organisational stress ("Vragenlijst Organisatie Stress-Doetinchem" - VOS-D, Bergers et al., 1986). An item example is: "To what extent can you count on your colleagues, when you have difficulties in your work?" "The items wete scored on a 4-point response scale format, ranging from 1 "never" to 4 "always". 


\section{Psychological work reactions}

Bumout is generally conceptualised as a syndrome of emotional exhaustion, depersonalisation, and reduced personal accomplishment (Maslach \& Jackson, 1986). Emotional exhaustion is considered as the core dimension of bumout (Bunnk \& Schaufeli, 1993; Cox et al., 1993; Maslach, 1998; Shirom, 1989). Therefore, we selected emotional exhaustion to represent the concept of burnout. Emotional exhaustion was measured by means of the Dutch version of the Maslach Bumout Inventory (MBI, Maslach \& Jackson, 1986): the MBI-NL (Cox et al., 1993; Maslach, 1993; Schaufeli \& Van Dierendonck, 1993). The emotional exhaustion scale of the MBI-NL consists of eight items with a 7 -point response scale ( 1 = "never", $7=$ "always"). An example-item is: "I feel emotionally drained from my work".

Intrinsic work motivation was measured by means of six items derived from a scale developed by Warr et al. (1979), ranging form 1 "totally disagree" to 5 "totally agree". An item example is: "My opinion of myself goes down when I do this job badly".

\subsubsection{Data analysis}

In order to test the proposed pattem of relationships, we used Structural Equation Modelling (SEM) by means of the L.ISREJ 8.0 computer program forreskog \& Sörbom, 1996). SEM is recommended by several authors to analyse longitudinal data (Dwyer, 1983; Kessler \& Greenberg, 1981; Zapf et al., 1996). By means of SEM it is possible to include measurement errors and reciprocal relationships into the models in comparison with cross-lagged panel correlational analysis and hierarchical regression analysis (see for instance De Jonge, 1995; Rogosa, 1980, 1987; Zapf et al., 1996). In addition, it allows for correlated disturbances resulting from omitted variables in simultaneous equations (Williams \& Podsakoff, 1989).

In order to investigate the relationships between the organisational characteristics, work characteristics and psychological work reactions, four different kind of analyses were performed in subsequent steps (see also De Jonge et al, 2001; Houkes et al, 2001). In the first step, we performed non-response analyses in order to investigate whether selection effects (due to wave non-tesponse) might occur and consequently whether the internal validity might be threatened (Bijleveld \& Van der Kamp, 1998). In the current study, attrition bias might bias the internal validity (Bijleveld \& Van der Kamp, 1998; Daniels \& de Jonge, 2001). Attrition bias could occur due to the tespondents who leave the panel after having participated at the first measurement (i.e., "dropouts"). In order to test whether this has occurred, we investigated whether the panel group and the dropouts differed with regard to the demographic variables, the research variables as well as the hypothesised pattern of relationships.

In the second step, several preliminary analyses were performed to get a first insight into the pattern of relationships at time 1 as well as time 2 . Hereby, the means, standard deviations, test-retest reliabilities of the variables ("temporal stabilities"), and zero-order Pearson intercorrelations of the variables were computed. 
In order to test for stationarity, that is a prerequisite for inferring the causal chain of relationships (James, Mulaik \& Brett, 1982), we compared two models with (M1) and without (M2) invariant synchroneous covariances in the third step. Stationarity means that the proposed pattern of relationships are stable over time (i.e, $X_{1} Y_{1}=X_{2} Y_{2}$ ) (Kenny, 1975). This equality of synchtoneous telarionships (i.e., the relationships at the same time point, viz, $\mathrm{X}_{1} \mathrm{Y}_{1}$ and $\mathrm{X}_{2} \mathrm{Y}_{2}$ ) were tested by means of comparing two models with an invariant (this means that the relationships have both the same direction and same strength) and a non-invariant pattem of relationships. A non-significant difference in chi-square $\left(\Delta \chi^{2}\right)$ means that the relationships are stable over time (invariant pattern holds tenable).

In the final step, we tested the causal chain of relationships (i.e., our hypotheses) by comparing several subsequent structural equation models by means of the chi-square difference test (De Jonge et al., 2001; Jöreskog \& Sörbom, 1993, 1996). It must be noted that the causal chain of telationships between the organisational characteristics, the work characteristics on the psychological work reactions cannot be tested integrally in one complete structural equation panel model. Testing the complete structural panel model at once tequites at least a three-wave design, because the work characteristics might mediate the relationships between organisational characteristics and the psychological work reactions (Tummers et al, 2002b).

Taken together, in the current study, we tested three separate structural parterns of relationships, namely a pattern of relationships between the organisational characteristics and the work characteristics, a pattern of relationships between the work characteristics and the psychological work reactions, and a pattern of relationships between the organisational characteristics and the psychological work reactions.

In order to analyse the pattern of relationships between organisational characteristics and work characteristics, we compared the following structural panel models (see also De Jonge et al, 2001; Houkes et al., 2001b):

M1: A model with synchroneous parhs (from time 1 organisational characteristics to time 1 work characteristics and from time 2 organisational characteristics to time 2 wotk characteristics) and tempotal stabilities, but without cross-lagged structural paths; M2: A model like M1, but also with cross-lagged structural paths from Time 1 organisational characteristics to Time 2 work characteristics (regular causal chain of relationships);

M3: A model like M1, but also with cross-lagged structural paths from Time 1 work characteristics to Time 2 organisational characteristics (reverse causal chain of relationships);

M4: A model like M1, but also with both cross-lagged structural paths as defined in M2 and $M 3$ representing reciprocal chain of relationships.

The same procedure for model comparison was followed for the second (relationships work characteristics and psychological work reactions) and third structural pattern of relationships (relationships organisational characteristics and psychological work reactions). 
Furthermore, each pattern of cross-lagged structural relationships consisted of different variables and model parameters. The demographic variables gender and age were defined as exogenous, whereas all other variables (the organisational characteristics, work characteristics, and psychological work reactions) were defined as. endogenous variables. The following different model parameters could be distinguished in our panel models: regression coefficients between the synchtoneous and cross-lagged paths, test-retest coefficients (temporal stabilities) between the measurement scales, covariances between the demographic variables, residual covariances between the organisational characteristics, the work chatactetistics and between the psychological work reactions, and the errot variances of the relationships between the endogenous variables. The latter were allowed to correlate, because the endogenous variables might partly be predicted by other variables that were not included in this study (De Jonge et al., 2001; MacCallum et al., 1993).

\subsection{Results}

\subsubsection{Non-response analyses}

In order to investigate whether attrition bias might occur in our study, several analyses were performed. The comparison of the panel group with the dropouts regarding age and gender by means of an independent t-test and a chi-square test respectively, revealed that no significant differences were found between these two groups. With regard to the endogenous variables, only mean level of emotional exhaustion differed significantly between the two groups $(t=-2.11, \mathrm{p} \leq .05)$. The dropouts showed significantly higher levels on emotional exhaustion than the panel group. "This finding means that the panel group consisted of relatively "healthy" workers compared to the dropouts. The dropouts" reason for not participating in the second measurement might be sickness absence due to high levels of emotional exhaustion which might cause the "healthy worker effect". This might have the consequence that the mean level of emotional exhaustion was underestimated due to a restriction of range.

Then, we tested by means of Multi-Sample Analysis (MSA) whether our proposed pattern of telationships (i.e., the covariance matrix at time 1) was the same (i.e., the same) for the panel group and the dropouts. The cross-sectional results of this MSA showed that no significant differences were found between the panel group and the dropouts regarding the three groups of relationships $\left(\Delta \chi^{2}(4)=2.55, \mathrm{p}=\mathrm{n} . \mathrm{s} ., \Delta \chi^{2}\right.$ (3) $=7.41, p=n . s$. and $\Delta \chi^{2}(3)=7.12, p=n$.s. respectively). Because the panel group and the dropouts were quite comparable, we may conclude that no serious selection problems seemed to exist. 


\subsubsection{Preliminary analyses}

Prior to the LISREL analyses, means, standard dexiations, Cronbach's alphas, and Pearson correlations were computed for the research variables time 1 and time 2 in order to get a first insight into the data (see Table 7.1).

We may conclude from Table 7.1 that the internal reliabilities of the scales as well as the test-retest-reliabilities were all moderate too high (at least .65 and .50 respectively; Bollen, 1989; Nunnally, 1978), with the exception of the test-retest-teliability of intrinsic work motivation $(x=.40)$.

Furthermore, the cross-sectional Pearson correlations at both time 1 and time 2 showed that the hypothesised pattern of relationships largely holds true. Contrary to our expectations, environmental uncertainty didn't correlate with emotional exhaustion at both measurement times. We also found some additional relationships at both measurement times. Complexity correlated negatively with social support at time 1 as well as time $2(r=\ldots .15$ and $r=-.28$ respectively). At time 2 , we also found a negative correlation between environmental uncertainty and social support $(t=-.25)$.

With regard to the cross-lagged Pearson correlations, the hypothesised pattern of relationships between time 1 organisational characteristics and time 2 work characteristics were largely confirmed. The hypothesised relationship between time 1 decision authority and time 2 social support, however, was found to be the other way around. The hypothesised cross-lagged relationships between time 1 work characteristics and time 2 psychological work reactions were largely confirmed, with the exception of the relationship between autonomy and intrinsic work motivation. Finally, the hypothesised cross-lagged correlations between time 1 organisational characteristics and time 2 psychological work reactions showed a somewhat different pattern than expected: time 1 complexity and envitonmental uncertainty did not correlate with time 2 emotional exhaustion.

\subsubsection{Stationarity of the relationships}

In order to test the stability of the pattern of relationships over time, we compared two models with (M1) and without (M2) invariant synchroneous covariances for each structural pattem of relationship (i.e., the three different categories of relationships).

With regard to the relationships between organisational characteristios and worte characteristics, we tested whether the invariant model, in which the hypothesised relationships were specified (M1), fitted to our data. According to the "Modification Indices" LISREI estimates (Hayduk, 1987; Jöreskog \& Sörbom, 1996; Saris \& Stronkhorst, 1984), two additional relationships should be added to improve the fit of the model, namely: the relationship between gender and environmental uncertainty ( $t 1)$, and the relationship between envitonmental uncertainty and workload ( $\mathrm{t} 2$ ). So, these relationships are set free in the analysis. Comparing this less restrictive model with the basic invariant model M1 showed a significant difference in chi-square $\left(\Delta \chi^{2}(4)=40.10, \mathrm{p} \leq .05\right)$. This means that this modified model better fitted to the data than the basic invariant model. 
In order to test whether this modified pattern of relationships was stable over time, we compared this model with a model in which these relationships were specified as noninvariant. Compatison of the non-invariant model with the invariant model revealed that the difference in chi-squate was not significant $\left(\Delta \chi^{2}(3)=2.07, \mathrm{p}=\mathrm{n}\right.$.s.). This means that the invariant model better accounts for the data (the goodness-of-fit indices were also acceptable: $\mathrm{NNFI}=.90, \mathrm{AIC}=212.14, \mathrm{CFI}=.91, \mathrm{AGFI}=.90, \mathrm{RMSEA}=$ .05). So, the relationships between organisational characteristics and work characteristics are stable over time.

Furthermore, a model with an invariant pattern of the hypothesised relationships between work cbaracteristics and psycbological work reations was tested. The relationship between autonomy and intrinsic work motivation was not significant at either of the two time measurements. Omission of this relationship, however, did not increase the model fit any further; rather, it decreased the model fit. In order to test for the stability of this pattern of relationships over time, the invatiant model was compared with a non-invariant model. Comparison of these two models showed that the difference in chi-square was not significant $\left(\Delta \chi^{2}(3)=2.35, p=n\right.$.s.). This means that the invariant model better accounts for the data than the non-invariant model (this model showed quite good fit indices: $\mathrm{NNFI}=.94, \mathrm{AIC}=127.07, \mathrm{CFI}=.95, \mathrm{AGFI}=.92, \mathrm{RMSEA}=$ .04). So, the hypothesised pattern of relationships appeared to be stable over time. Finally, we tested whether the basic invariant model in which the hypothesised pattern of relationships were specified between organisational dharacteristios and prychological mork reactions fitted well tot the data. This model could be improved according to the modification indices as well as the fit indices. The hypothesised relationship between environmental uncertainty and emotional exhaustion was not significant in either of the two time measurements. The modification indices of the basic invariant model suggest to add a relationship between environmental uncertainty and intrinsic work motivation (time 1), and between gender and environmental uncertainty (time 1). Comparison of this modified invariant model with the basic invariant model showed a significant difference in chi-square $\left(\Delta \chi^{2}(3)=14.88, \mathrm{p} \leq .05\right)$. This means that the modified invariant model better fits than the basic invariant model. In order to test whether this modified pattern of relationships was stable over time, we compared this model with a model in which these relationships were specified as non-invariant. Comparison of these two models yield a non-significant difference in chi-square $\left(\Delta \chi^{2}\right.$ (2) $=1.51, \mathrm{p}=$ n.s.). This means that the invariant model better accounts for the data (fit indices: $N N F I=.97, \mathrm{AIC}=118.38, \mathrm{CF} I=.98, \mathrm{AGFI}=.93, \mathrm{RMSE} A=.03$ ). Thus, the relationships between organisational characteristics and psychological work. reactions are stable over time.

In sum, we may conclude from these multi sample analyses that the assumption of stationarity of the three different categories of relationships has largely been confirmed. 


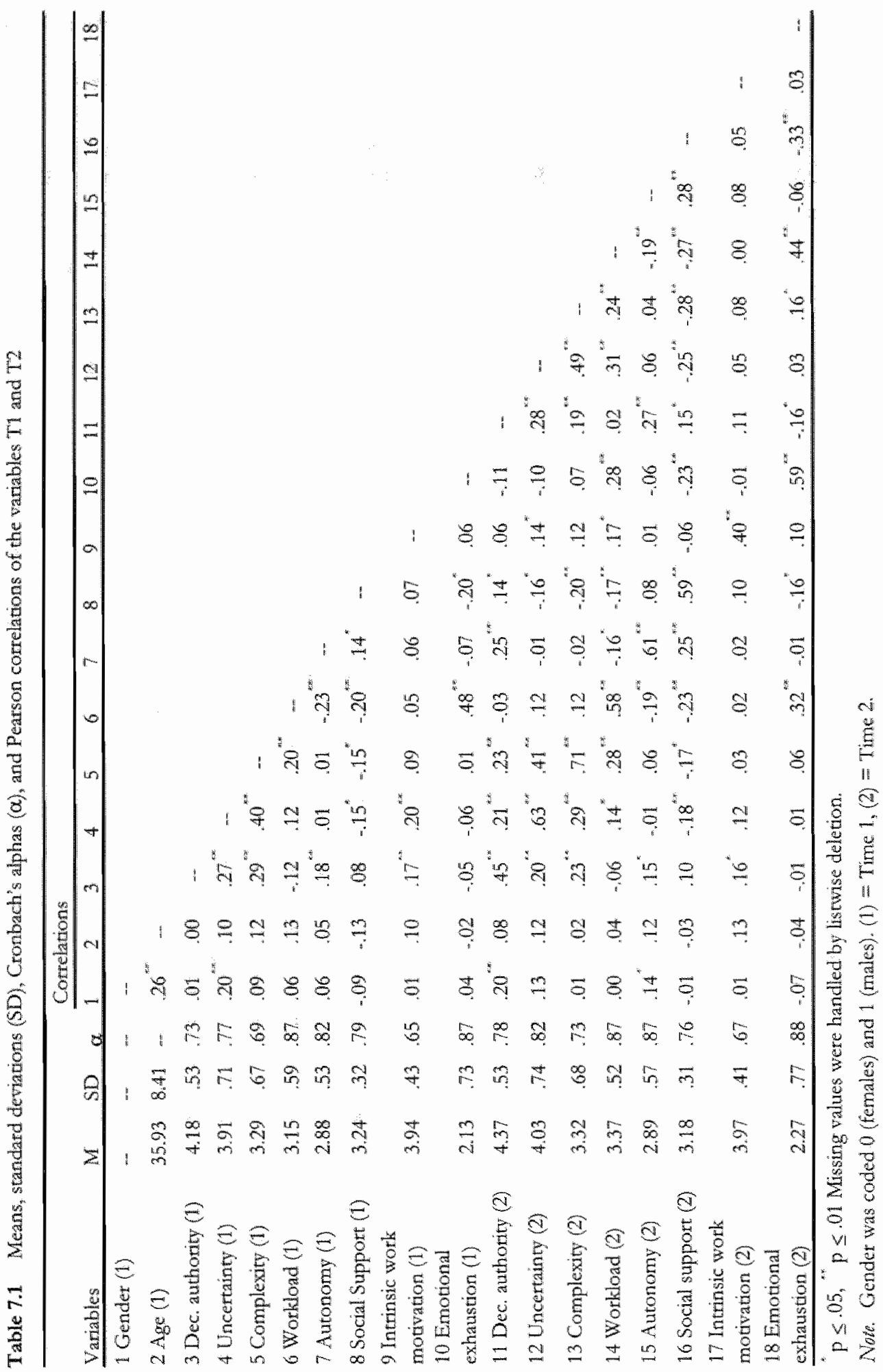




\subsubsection{Cross-lagged structural panel analysis}

After testing the stability of the hypothesised relationships over time, the actual crosslagged panel analyses were performed in order to test for "causal predominance". The cross-lagged analyses were performed separately for the three categories of relationships. The best fitted model of the former performed analyses was used as starting model (i.e., M1) for the cross-lagged analyses.

\section{Cross lagged relationships between organisational chatacteristics and work characteristics}

In order to investigate the causal inferences of the relationships between organisational characteristics and work characteristics, four different structural equation models were compared subsequently by means of the chi-square difference test (see Table 7.2).

Table 7.2 Fir measures and chi-square difference tests of models tegarding the relationships between organisational characteristics and work characteristics $(\mathrm{N}=209)$

\begin{tabular}{|c|c|c|c|c|}
\hline Model & $x^{2}(d)$ & Comparison & $\Delta \chi^{2}(\Delta \mathrm{d} f)$ & AGI I \\
\hline $\mathrm{M}_{1}$ (no cross-lagged) & $103,32^{n+*}(60)$ & & & .89 \\
\hline$M_{2}\left(\operatorname{cross} O C_{\mathrm{n}}{ }^{3}-W C_{2^{n}}\right)$ & $100.90^{\text {sx }}(56)$ & $\mathrm{M}_{1} \mathrm{M} . \mathrm{M}_{2}$ & $2.42(4)$ & .88 \\
\hline $\mathrm{M}_{3}\left(\operatorname{cross} \mathrm{WC}_{11} \mathrm{H}^{\mathrm{H}}-\mathrm{OC} 2^{\mathrm{in}}\right)$ & $89.76^{4+13}(56)$ & $\mathrm{M}_{1} \mathrm{ws.} \mathrm{M}_{3}$ & $13.56^{4}(4)$ & .89 \\
\hline \multirow[t]{3}{*}{ Ma (both cross) } & $87.34^{b+1}(52)$ & $M_{1}$ vs. M. & $15.98 *(8)$ & .89 \\
\hline & & $\mathrm{M}_{2}$ vs. $\mathbb{M}_{4}$ & $13.56^{*}(4)$ & \\
\hline & & $\mathrm{M}_{3} \mathrm{vs}_{\mathrm{s} .} \mathrm{M}_{4}$ & $2.42(4)$ & \\
\hline Model & RMSEA & $\mathrm{AIC}$ & NNFI & $\mathrm{CHI}$ \\
\hline$M_{i}$ (no cross-llagged) & .05 & 190.74 & .92 & .95 \\
\hline $\mathrm{M}_{2}\left(\operatorname{cross} O \mathrm{CT}^{\mathrm{n}}-\mathrm{WCO}_{2}\right)$ & .06 & 196.23 & .91 & .94 \\
\hline$M_{3}\left(\operatorname{cross} W_{T^{2}}-O C_{2}\right)$ & .05 & 188.65 & .93 & .96 \\
\hline$M_{4}$ (both cross) & .05 & 193.66 & .92 & .96 \\
\hline
\end{tabular}

$\mathrm{OC}=$ organisarional characteristics, $W \mathrm{C}=$ work characteristics

" $\mathrm{p} \leq .05^{\circ \cdot \mathrm{p} p} \leq .001$

The comparison of M2 (cross-lagged relationships between time 1 organisational characteristics and time 2 work chatacteristics were specified) with M1. (no crosslagged relationships were specified) showed a non-significant difference in chi-square $\left(\Delta \chi^{2}(4)=2.42, \mathrm{p}=\mathrm{n} . \mathrm{s}.\right)$, indicating that M2 did not better fit the data than M1. Thereafter, we compared M3 (cross-lagged relationships between time I wotk chatacteristics and time 2 organisational characteristics were specified) with $M 1$. The difference in chi-square was significant $\left(\Delta \chi^{2}(4)=13.56, \mathrm{p} \leq .05\right)$, indicating that the addition of the reversed cross-lagged relationships (from time 1 work characteristics to time 2 organisational characteristics) to the synchroneous relationships (M1) improved the fit of the model. Furthermore, M1 was compared with a model including both 
cross-lagged relationships (i.e., relationships from time 1 organisational characteristics to time 2 work characteristics and relationships from time 1 work characteristics to time 2 organisational characteristics: M4). The chi-square difference between M1 and M4 was significant $\left(\Delta \chi^{2}(8)=15.98, p \leq .05\right)$. This means that $M 4$ better accounts for the data than M1. Next, we compared M2 with M4. The difference in chi-square between these two models was significant $\left(\Delta \chi^{2}(4)=13.56, \mathrm{p} \leq .05\right)$, indicating that $\mathrm{M} 4$ better fitted to the data than M2. Finally, in order to investigate whether addition of the regular cross-lagged relationships (from timel organisational characteristics to time 2 work characteristics, M4) to the reversed cross-lagged relationships (M3) improved the fit of the model, comparison of M4 with M3 showed a non-significant difference in chi-square $\left(\Delta \chi^{2}(4)=2.42, \mathrm{p}=\mathrm{n} . \mathrm{s}_{\mathrm{v}}\right)$. This means that the model including the reversed cross-lagged relationships better (M3) fitted to the data than a model in which also regular cross-lagged relationships were specified (M4). When we consider the practical fit indices, $\mathrm{M} 3$ also showed the best model fit (NNFI $=.93, \mathrm{AIC}=188.65, \mathrm{CFI}=.96$, AGFI $=.89$, RMSEA $=.05$ ). In addition to the determination of the causal inferences of the relationships, the strength of the cross-lagged relationships were examined (cf. De Jonge et al., 2001; Rogosa, 1980). The results of the structural model coefficients (from the best fitted M3) are shown in Figure 7.1.

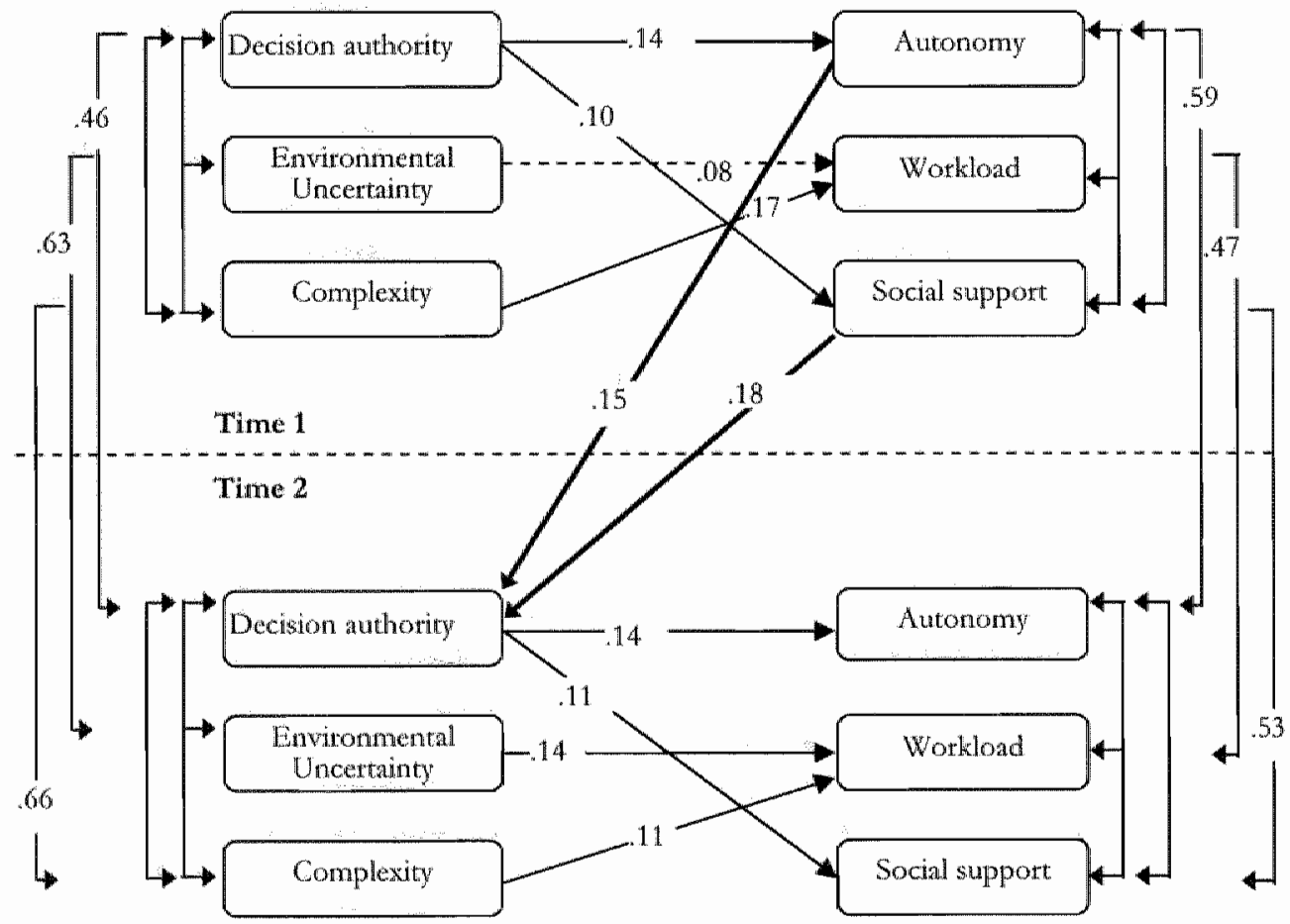

Figure 7.1 The final cross-lagged structural panel model with significant relationships between orgunisational characteristics and work. characteristics 
From this Figure, it appears that two relationships wete significant. A positive relationship was found from time 1 autonomy to time 2 decision authority $(\beta=15)$, indicating that high levels of autonomy lead to high levels of decision authority. Furthermore, we found a positive relationship between time 1 social support and time 2 decision authority $(\beta=.18)$. This means that high levels of social support influence high levels of decision authority.

\section{Cross lagged relationships between work characteristics and psychological work reactions}

In order to investigate the causal inferences of the relationships between work characteristics and psychological work reactions, we first compared a model (M1) in which no cross-lagged relationships were specified (and only consists of synchronous relationships and stability coefficients between the variables) with a model in which also cross-lagged relationships from time 1 work characteristics to time 2 psychological work reactions (M2) were specified. The results of these model comparisons are shown in Table 7.3.

Table 7.3 Fit measures and chi-square difference tests of models regarding the relationships between work characteristics and psychological work teactions $(\mathrm{N}=207)$

\begin{tabular}{|c|c|c|c|c|}
\hline Model & $x^{2}(\mathrm{df})$ & Comparison & $\Delta \chi^{2}(\Delta \mathrm{d} f)$ & AGEI \\
\hline $\mathrm{M}_{1}$ (no cross-lagged) & $73.09 \quad(46)$ & & & .91 \\
\hline$M_{2}$ (cross $\left.W C^{n}-P R+2^{n}\right)$ & $62.09^{\circ}(43)$ & $\mathrm{M}_{1}$ ves. $\mathrm{M}_{2}$ & $11^{\circ} \quad(3)$ & .92 \\
\hline $\mathrm{M}_{3}\left(\operatorname{cross} \mathrm{PR}_{\mathrm{T} 1^{\mathrm{i}}}-\mathrm{WCT}^{\mathrm{a}}\right)$ & $69.03^{\text {tin: }}(43)$ & $\mathrm{M}_{1}$ vs. $\mathrm{M}_{3}$ & $4.06(3)$ & .91 \\
\hline \multirow[t]{3}{*}{ Ma (both cross) } & $58.03^{*}(40)$ & $\mathrm{M}_{1}$ vs. $\mathrm{M}_{4}$ & $15.06^{*}(0)$ & .92 \\
\hline & & $\mathrm{M}_{2} \mathrm{vs} \cdot \mathrm{M}_{4}$ & $4.06(3)$ & \\
\hline & & $\mathrm{M}_{3}$ vs. $\mathrm{M}_{4}$ & $11 * \quad(3)$ & \\
\hline Model & RMSEA & AIC & NNFI & $\mathrm{CII}$ \\
\hline M. (no cross-lagged) & .05 & 131.66 & .93 & .95 \\
\hline$M_{2}\left(\operatorname{cross} W C_{11}{ }^{n}-P R_{12}{ }^{n}\right)$ & .04 & 128.76 & .95 & .97 \\
\hline$M_{3}\left(\operatorname{cross} P_{\mathrm{II}_{1}^{\mathrm{a}}}-\mathrm{WC}_{\mathrm{T} 2^{\mathrm{a}}}\right)$ & .05 & 134.28 & 93 & .95 \\
\hline $\mathrm{M}_{4}$ (both cross) & .04 & 131.38 & .95 & .97 \\
\hline
\end{tabular}

aR $=$ work characteristics, $\mathrm{PR}=$ psychological work teactions

$p \leq .05^{* * 2} \mathrm{p} \leq .001$

From Table 7.3, it seems that the chi-square difference between M1 and M2 was significant $\left(\Delta \chi^{2}(3)=11.00, \mathrm{p} \leq .05\right)$. This means that $\mathrm{M} 2$ better fits to the data than M1. Thereafter, M1 was compared with a model in which cross-lagged relationships from time 1 psychological work reactions to time 2 work characteristics (M3) were specified. The difference in chi-square between $M 1$ and M3 was not significant, indicating that M3 does not better fit the data than $M 1\left(\Delta \chi^{2}(3)=4.06, p=n . s.\right)$. So, psychological work reactions at time 1 appeared not to influence work chatacteristics 
at time 2. Third, we compared M1 with a model in which all cross-lagged relationships were specified (i.e., relationships from time 1 work characteristics to time 2 psychological work reactions and relationships from time 1 psychological work reactions to time 2 work characteristics; M4). Comparison of M1 with M4 showed a significant difference in chi-square $\left(\Delta \chi^{2}(6)=15.06, \mathrm{p} \leq .05\right)$. This means that a model in which all cross-lagged relationships were specified fitted better to the data in comparison with a model in which no cross-lagged relationships were specified. However, after comparing $M 4$ with $M 2$, the difference in chi-square was not significant $\left(\Delta \chi^{2}(3)=4.06, \mathrm{p}=\right.$ n.s. $)$. This finding indicates that the fit of M2 did not improve after adding the reversed cross-lagged relationships from time 1 psychological work reactions to time 2 work characteristics. Otherwise, after adding relationships from time 1 work characteristics to time 2 psychological work reactions to the model in which the reversed relationships were specified (M3), the fit of the model increased (M3 vs. M4: $\left.\Delta \chi^{2}(3)=11.00, \mathrm{p} \leq .05\right)$. Thus, M2 appeared to be the best fitted model, also when the practical fit indices were reviewed (NNFI $=.95, \mathrm{AIC}=128.76, \mathrm{CFI}=$ $.97, \mathrm{AGFI}=.92, \mathrm{RMSEA}=.04$ ).

The results of the structural model coefficients (from the best fitted M2) are shown in Figure 7.2. It appears from this Figure that the relationship between time 1 workload and time 2 emotional exhaustion was significant. However, the direction of the relationships was contrary to our expectations, since the relationship appeared to be negative ( $\beta=-.25$ ). This finding could be explained by "negative suppression" (i.e., a statistical artifact; see Maassen \& Bakker, 2000; "Tzelgov \& Henik, 1991) and is often found in this type of longitudinal research (see also De Jonge, 1995; Houkes, 2002). Negative suppression occurs when two or more independent variables have a positive stability (test-retest) coefficient, and one of the independent variables (i.e., the suppressor variable) receives a negative regression coefficient in the regression equation (cf. Maassen \& Bakker, 2000; Tzelgov \& Henik, 1991). The chance of the occurrence of suppression in structural equation models with two measurement times is high if the stability coefficients and the coefficients of the synchroneous relationships are higher than the cross-lagged coefficients (Maassen \& Bakker, 2000). This situation might be occurred in the cutrent study. A common way to interpret the results if a suppression situation might have taken place, is to take both direct and total effects of variables into account (cf. Houkes, 2002; Saris \& Stronkhorst, 1984; Schumacker \& Lomax, 1996) as recommended by, for instance, Saris and Stronkhorst (1984). The indirect effects of time 1 workload on time 2 enotional exhaustion go via two pathways, namely time 2 workload and time 1 emotional exhaustion. The sum of the total indirect effect is .60. So, the total effect of time 1 workload on time 2 emotional exhaustion is $.35(-.25+.60)$.

We also found a significant relationship between time 1 social support and time 2 emotional exhaustion. Just as the other significant relationship, this relationship was also contrary to our expectations: higher levels of social support seemed to increase level of emotional exhaustion $(\beta=.21)$. The same explanation might be given for this finding, namely a suppression situation. After calculating the indirect effect of time 1 . 
social support on time 2 emotional exhaustion (via the two pathways: time 1 social support to time 2 social support to time 2 emotional exhaustion and time 1 social support to time 1 emotional exhaustion to time 2 emotional exhaustion), we found a sum of the indirect effects of -43 . So, the total effect of time 1 social support on time 2 emotional exhaustion was $-.22(-.43+.21)$, indicating that higher levels of social support lead to lower levels of emotion exhaustion.

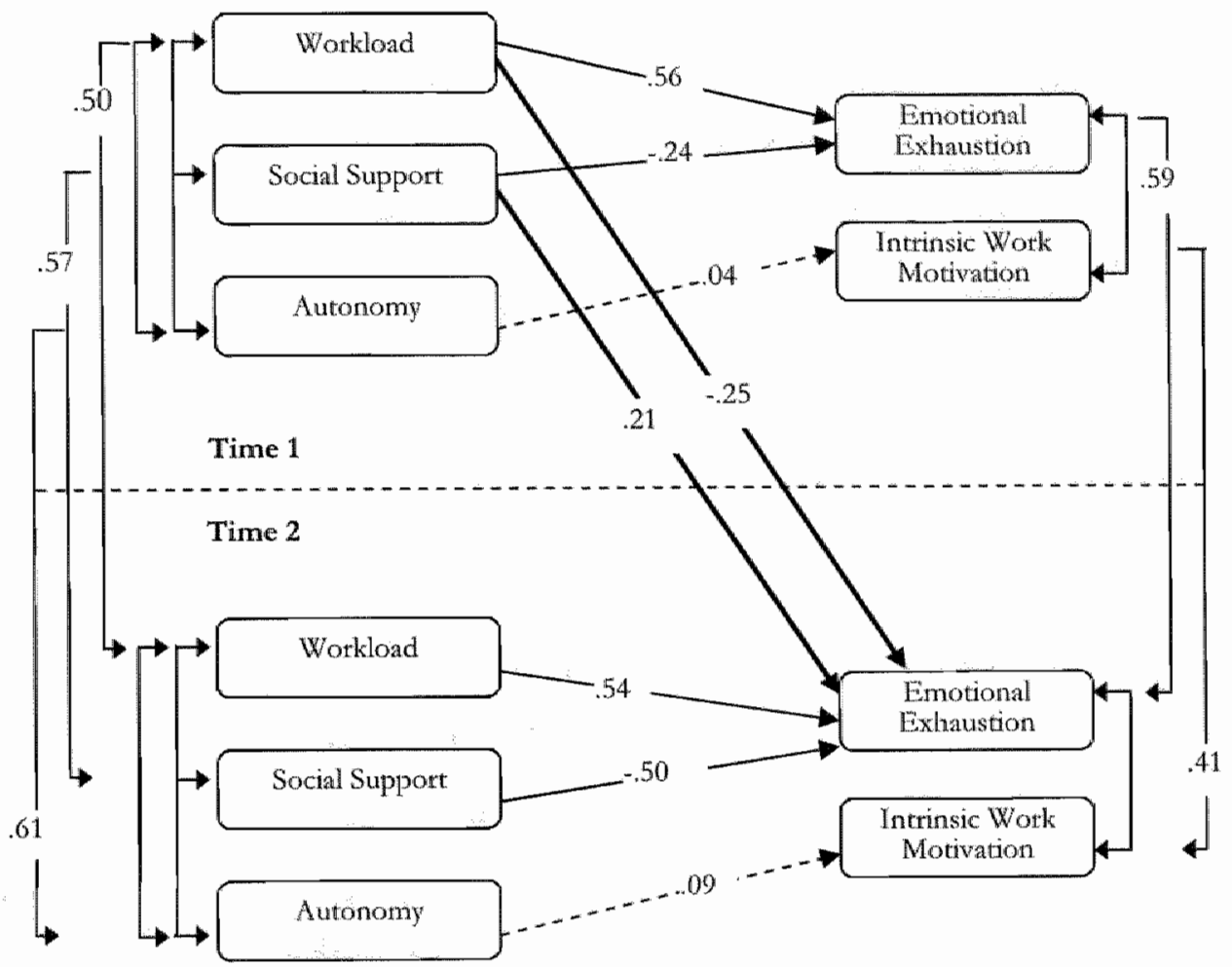

Figure 7.2 The final cross-lagged structural panel model with significant relationships between wotk characteristics and psychological work reactions

\section{Cross lagged relationships between organisational characteristics and psychological work reactions}

In otder to investigate the causal predominance of organisational characteristics on psychological work reactions, we first compared M1 with M2 (see Table 7.4). 
Table 7.4 Fit measures and chi-square difference tests of models tegarding the relationships betwen organisational chatacteristics and psychological work reactions $(\mathrm{N}=211)$

\begin{tabular}{|c|c|c|c|c|}
\hline Model & $\chi^{2}(d t)$ & Comparison & $\Delta x^{2}(\Delta d f)$ & AGFI \\
\hline$M_{1}$ (no cross-lagged) & $56.95(46)$ & & & .93 \\
\hline$M_{2}$ (ctoss $\left.O C_{n}{ }^{a}-P R_{2^{a}}\right)$ & $55.36(44)$ & $\mathrm{M}_{1} \mathrm{ws} \mathrm{M}_{2}$ & $1.59(2)$ & .93 \\
\hline $\mathrm{M}_{3}\left(\mathrm{cross} \mathrm{PR} \mathrm{T}^{ \pm}-O \mathrm{Cr}^{2}\right)$ & $53.00(44)$ & $M_{1}$ vs: $M_{3}$ & $3.95(2)$ & .93 \\
\hline \multirow[t]{3}{*}{$\mathrm{M}_{4}$ (both cross) } & $51.41(42)$ & $\mathrm{M}_{1}$ vs. $\mathrm{M}_{4}$ & $5.54(4)$ & .93 \\
\hline & & $\mathrm{M}_{2} \mathrm{vs} \cdot \mathrm{M}_{4}$ & $3.95(2)$ & \\
\hline & & $M_{3} \vee s, M_{4}$ & $2.41(2)$ & \\
\hline Model & RMSEA & AIC & NNEI & $\mathrm{CFI}$ \\
\hline $\mathrm{M}_{1}$ (no cross-lagged) & .03 & 120.33 & 97 & .98 \\
\hline $\mathrm{M}_{2}\left(\operatorname{ctoss} O C_{11}^{\mathrm{a}}-\mathrm{PR}_{\mathrm{T}^{2}}\right)$ & .03 & 122.32 & .97 & .98 \\
\hline $\mathrm{M}_{3}\left(\operatorname{ctoss} P R_{\pi r^{a}-O C r} \mathrm{r}^{\mathrm{a}}\right)$ & .03 & 121.11 & .98 & .98 \\
\hline M (both cross) & .03 & 123.05 & 97 & .98 \\
\hline
\end{tabular}

aC $=$ organisational characteristics, $P R=$ psychological work teactions

" $\mathrm{p} \leq .055^{* * *} \mathrm{p} \leq .001$

The difference in chi-square between these two models was not significant $\left(\Delta \chi^{2}(2)=\right.$ $1.59, \mathrm{p}=\mathrm{n} . \mathrm{s}$.), indicating that the addition of the cross lagged relationships from time 1 organisational characteristics to time 2 psychological work reactions did not increase the fit of the model. Thereafter, M1 was compared with M3. Comparison of these models revealed a non-significant difference in chi-square $\left(\Delta \chi^{2}(2)=3.95, p=n . s\right.$.). This means that the addition of the reversed cross-lagged relationships from time 1 psychological work reactions to time 2 organisational characteristics did not improve the fit of the model. Finally, M1 was compared with M4 (in which both cross-lagged relationships were specified). The difference in chi-square was not significant $\left(\Delta \chi^{2}\right.$ (4) $=5.54, \mathrm{p}=\mathrm{n} . \mathrm{s}$.), indicating that $\mathrm{M} 1$ better fitted to the data than M4. From these model comparisons, M1 appeared to be the best fitted model. The practical fit indices of this model were also good $(\mathrm{NNFI}=.97, \mathrm{AIC}=120.33, \mathrm{CFI}=.98, \mathrm{AGFI}=.93$, RMSEA $=.03$ ).

To conclude, no cross-lagged relationships were found between organisational characteristics and psychological work reactions. The path coefficients of the synchroneous relationships as well as the test-retest relationships are presented in Figure 7.3. 


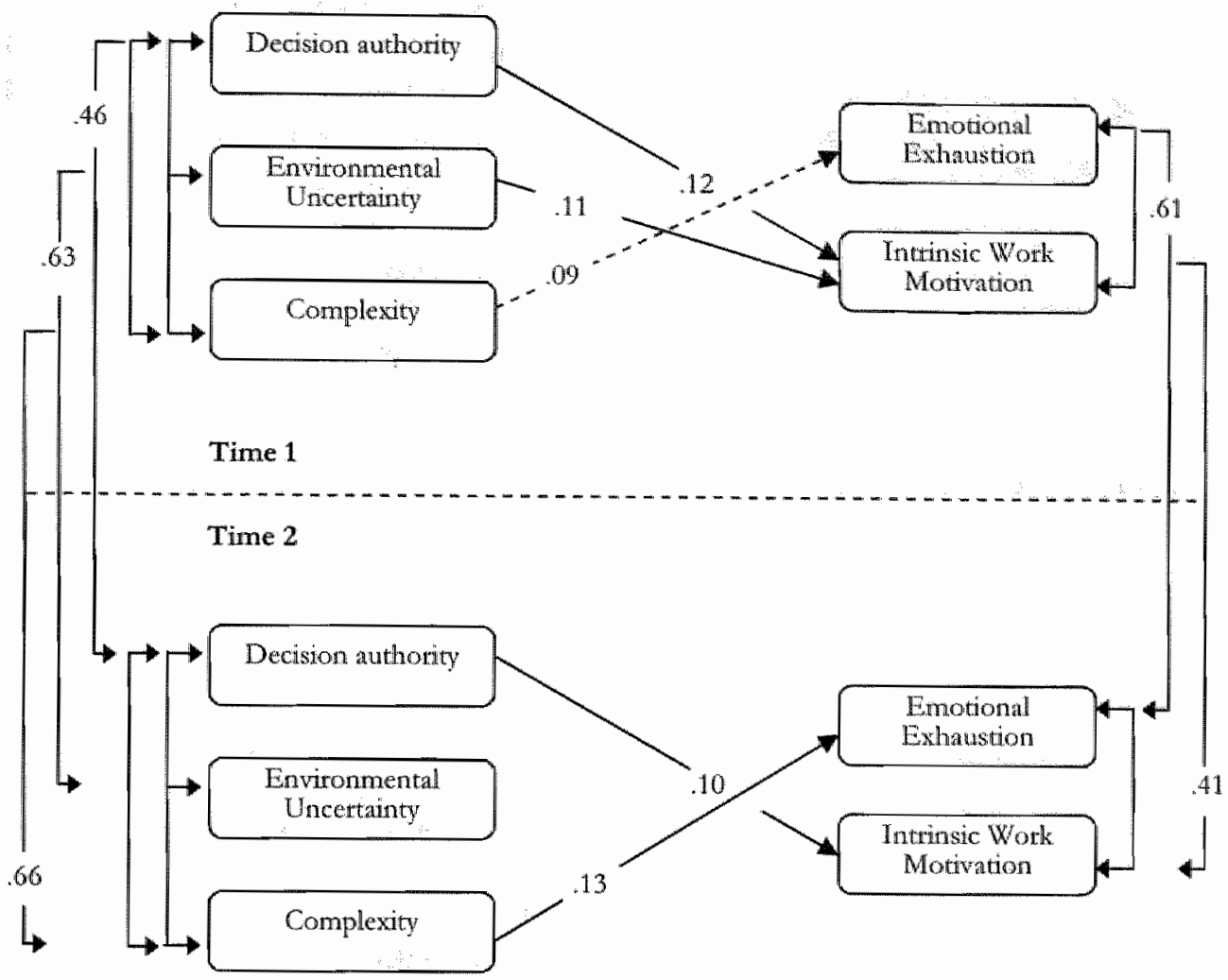

Figure 7.3 The final cross-lagged structural panel model with significant relationships berween organisational charicteristics and psychological work reactions

\subsection{Discussion}

The aim of the present study was to investigate three categories of longitudinal relationships at two measurement times, viz., the relationships between organisational characteristics and work characteristics, the telationships between work chatacteristics and psychological work reactions and the relationships between organisational characteristics and psychological work teactions.

With regard to the relationships between organisational characteristics and worts characteristics, we hypothesised decision authority to be related to social support and autonomy, whereas environmental uncertainty and complexity were assumed to be related to workload. Most of these hypotheses were confirmed cross -sectionally at time 1 and time 2. The cross-lagged analyses, showed, however, a somewhat different and more complex pattern than the cross-sectional (i.e., synchroneous) relationships. In 
addition to the supposed causal predominance ("regular causality") of the organisational characteristics on work characteristics, we also found support for a reversed pattern of telationships. Although the regular causal pattem of relationships showed good fit indices, the reversed pattern of relationships fitted better to the data than the regular pattern of relationships. More specifically, time 1 social support and autonomy appeared to influence time 2 decision authority. High levels of social. support and autonomy seemed to predict high levels of decision authority. A possible, albeit speculative, explanation for these two reversed relationships might be that the workplace has learned over time that a particular organisational structure is needed to be effective (we refer, of course, to a process that lasts longer than the one year period in which the current study has taken place). As a result, it might adapt its organisational structure to the characteristics of the workplace. "This means that workplaces or units that are characterised by, for instance, high autonomy at work, might adapt in the long term their organisational structure. Workplaces in which autonomy is high might need a suitable (decentralised) organisational structure in which this autonomy can be further maintained and developed.

With regard to the relationships between work characteristics and psychological work reactions, we hypothesised that workload and social support predict emotional exhaustion, whereas autonomy was hypothesised to be a predictor for intrinsic work morivation. The cross-sectional results confirmed the hypotheses that emotional exhaustion was predicted by high workload and also by low social support at time 1 and time 2 separately. The cross-lagged analyses also showed that high workload and low social support lead to high levels of emotional exhaustion over time. However, the direct cross-lagged effect of workload on emotional exhaustion was negative, whereas the direct cross-lagged effect of social support on emotional exhaustion was positive. Both findings were opposite to our expectations and were explained by the suppression phenomenon (Maassen \& Bakker, 2000). This statistical artefact has also been reported by Burke and Greenglass (1995), Houkes (2002), Lee and Ashforth (1.993) and is a common phenomenon in longitudinal research. In particular in the case when the direct and indirect effects do not have the same magnitude and strength, Saris and Stronkhorst (1984) recommended to consider, besides direct effects, also total effects (including also indirect effects). Taken together, both the total effects and the cross-sectional results (in which the relationships were in the expected direction), we may conclude that high levels of workload and low levels of social support lead to high levels of emotional exhaustion over time. This regular causation pattern is, generally, in line with the limited number of longitudinal studies where relationships between work characteristics and psychological outcomes variables were studied (De Jonge et al., 2001; De Lange et al., 2001; Houkes, 2002; Schaufeli \& Enzmann, 1998; Vogelaar \& Van der Vlist, 1995).

Finally, with regard to the relationships between organisational characteristics and psychological work reactions, we hypothesised that decision authority predicts intrinsic work motivation. In addition, we hypothesised that complexity and environmental uncertainty predict emotional exhaustion. These hypotheses were largely confirmed 
cross-sectionally at time 1 and time 2 . We found, however, no significant cross-lagged relationships. Three possible explanations for this lack of relationships over time might be given. A first, theoretical, explanation might be that the work characteristics are possible mediator variables in the relationship between organisational characteristics and psychological work reactions (Tummers et al., 2002b). As the cross-sectional relationships between organisarional characteristics and psychological work reactions were significant, the cross-lagged relationships might be eroded by the influence of work characteristics on these telationships. A second explanation might be that the propositions of the contingency approach are not totally valid, because they are based on cross-sectional study designs. This means that the factor "time" is not taken into account. Consequently, although the propositions of the contingency approach are mostly confirmed cross-sectionally, they might not hold over time.

A third, explanation might be that the used time lag of one year does not match the actual causal time lag (c.g., Kessler \& Greenberg, 1981). The actual time lag might be different for the several cross-lagged relationships between organisational characteristics and psychological work reactions. For instance, if work characteristics possibly mediate these relationships, the effect of organisational characteristics on psychological work reactions will take more time (than the used time lag of one year). Otherwise, after a certain period of time, people may get used to these "stressors" and know how to cope with. Accordingly, the positive effect of decision authotity on intrinsic work motivation is likely to develop soon. This implies that, if the "true" time lag is much shorter than one year, the synchroneous relationships might be more valid than the cross-lagged relationships (Zapf et al., 1996). This time lag problem is difficult: to solve and is a common phenomenon in longitudinal research (Taris, 2000; Zapf et al., 1996). In our study, this problem seems to be emphasised due to the three different categories of relationships. They all might have different actual time lags, as argued before. In this context, Sandefur and Tuma (1987) propose that the results of a crosslagged panel analysis should always be reported in relation to the time lag in a particular study, as the findings of the cross-lagged panel analysis can not be generalised beyond the specific time lag used in the study (cited in Taris, 2000). So, there is a plea for investigating the longitudinal relationships between organisational characteristics and psychological work reactions more extensively and with shorter time lags than one year.

In sum, the current study has shown that organisational characteristics are important factors regarding the work itself and employees psychological work reactions. More evidence is found for the reversed relationships between organisational characteristics and work chatacteristics over time than the regular causal pattern of relationships. This finding was, although more speculative, explained by a possible adaptation process of the workplace over time. The work characteristics appeared to be the predominant factors regarding the psychological work reactions. Finally, three possible explanations were given for the lack of relationships between organisational characteristics and psychological work reactions over time. First, the possible mediator function of work characteristics. This issue coulld be clarified in future reseatch by using a three-wave 
panel design. Second, the cross-sectional nature of the contingency approach on which the contingency propositions are based, and finally, the selected time lag. In addition to the frequently studied and well-known work chatacteristics and their influences on psychological outcomes, the present study has shown that also organisational characteristics might play a role in these relationships. When changing work characteristics to improve employees' health and well-being, managers should additionally take organisational characteristics into account.

\section{Acknowledgements}

We gratefully acknowledge our students Gea Hoddenbagh-Sterk and Alied Van den Berg-Hooiveld, for their help with the data-collection for the current study. 


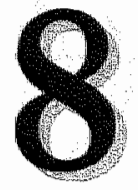

Discussion 


\subsection{Introduction}

The previous chapters addressed the effects of organisational characteristics on the one hand and work characteristics and psychological work teactions on the other. the inicial explorative way to acquire insight into these relationships was extended to more specific suppositions with regard to these relationships. In addition, these relationships were tested in several types of nursing units in order to validate these relationships.

In this final chapter, the study results are discussed. An overview of the main study results is given in section 8.2 . Some methodological reflections are made in section 8.3 . Section 8.4 discusses the theoretical implications. The practical implications of the study results are reported in section 8.5 The chapter ends (8.6) with some recommendations for future research.

\subsection{Main findings of the study}

In this section, the main findings of the study are given. They are presented in accordance with the several sub-questions formulated in the first chapter. These concern successively the relationships between organisational characteristics and work characteristics (section 8.2.1), the (ditect and indirect) relationships between organisational characteristics and psychological work reactions (section 8.2.2), the relationships between work characteristics and psychological work reactions (section 8.2.3), the congruence between structural and environmental characteristics in the prediction of psychological work reactions (section 8.2.4), and finally, the comparison between different kinds of nursing (section 8.2.5).

\subsubsection{Relationships between organisational characteristics and work characteristics}

\section{Cross-sectional study results}

In order to gain insiglat into relationships between organisational chatacteristics and work characteristics, they were first explored cross-sectionally, and without any stringent hypotheses a priori. Three organisational characteristics were investigated: decision authority, environmental uncertainty, and complexity; and five work characteristics were studied: workload, autonomy, social support, role conflict, and role ambiguity. The latter two work characteristics are discussed only in the second chapter. First, the results of our cross-sectional study indicated that high complexity, and high environmental uncertainty are particularly predictive for high workload, and high role conflict. The positive relationships between complexity and environmental uncertainty on the one hand and workload on the other are not surprising, as workload is not only a function of the task to be performed, but also of environmental characteristics (Bi \& Salvendy, 1994). The positive relationships with role conflict might be explained by 
possible co-ordination problems involved with high uncertainty and complexity. Consequently, tole conflicts are likely to occur.

Pinally, decision authority was particularly predictive for high social support, high autonomy, and low role ambiguity. This finding implies that the decentralisation of decisions, and the undifferentiated structure of tasks are associated with high freedom to make decisions about one's own job, with high social support of peers and supervisor(s), and with a reduction of unclear information about task performance.

\section{Longitudinal study results}

In order to investigate whether the cross-sectional relationships between organisational characteristics and work characteristics hold over time, cross-lagged panel analyses were performed. It was hypothesised that decision authority influences autonomy and social support, while environmental uncertainty and complexity were hypothesised to influence workload. Before investigating the cross-lagged relationships, the stability of the relationships over time was tested, because this is a precondition for inferring the causal chain of relationships (James et al., 1982). The multi-sample analyses showed that all the proposed relationships were stable over time, with the exception of the relationships between environmental uncertainty and workload. This relationship was only found at ume 2 , and might thus be less salient (i.e., time specific). After comparing different cross-lagged structural panel models by means of the chi-squaredifference test, it was found that the reversed cross-lagged relationships better fit the data than the regular (expected) cross-lagged relationships, although the regulat pattern of relationship also showed good fit indices. This reversed cross-lagged pattem means that the scores on work characteristics at time 1 seemed to influence the scores on organisational characteristics at time 2 rather that the other way around. More specifically, a positive relationship was found between the scores of time 1 autonomy and the scores of time 2 decision authority, indicating that high levels of autonomy lead to high levels of decision authority. Furthermore, a positive relationship was found between the scores of time 1 social support and the scores of time 2 decision authority. This means that high levels of social support influence high levels of decision authority.

\section{Multilevel study results}

Because of the nested data structure of the current study, indicating that individuals are nested within units and organisations, a multilevel design was necessary to analyse the hypothesised relationships. Consequently, multilevel analyses were used, instead of ordinary regtession techniques, to get mote adecuate parameter estimations, because random coefficients and aggregated vatiables were taken into account. For this aim, individual and group (i.e., aggregated) scores were computed. It was supposed that decision authority predicts nurses' autonomy and social support. Furthermote, environmental uncertainty and complexity were supposed to predict nurses" workload. A three-level multilevel model was used encompassing 15 general hospitals (macro- 
level), 95 units (meso-lewel), and 1111 nurses (individual-level). The results of the multilevel study confirmed the suppositions at the individual-level, but no additionat effects of the group-level organisational characteristics were found. It seems that the relationships at individual level generally do not differ from those at group level, indicating that the group-level effects are similar to the individual-level effects. However, the relationships between individual-level organisational chatacteristics and work characteristics on the one hand, and between group-level organisational characteristics and work characteristics on the other were significantly different when we did not adjust for type of unit (two dummy variables). This finding could mainly be explained by the significant effects of type of unit. It could be argued that the grouplevel organisational characteristics not only teflect individual organisational characteristics, but also reflect the type of unit. The finding that the group-level organisational characteristics did not add any variance to the individual-level organisational characteristics when type of unit was taken into account, might be explained by a selection effect or a learning/adaptation process (see also section 8.4.4).

\subsubsection{Direct and indirect relationships between organisational characteristics and psychological work reactions}

\section{Cross-sectional study results}

Our starting point when investigating the relationships between organisational characteristics and psychological work reactions was the Job Modification Framework (Oldham \& Hackman, 1981), which holds that organisational characteristics are indirectly related with psychological work reactions through work characteristics. In other words, work characteristics are supposed to mediate the relationships between organisational characteristics and psychological work reactions. This framework posits that structural properties of organisations (such as centralisation and formalisation) affect the characteristics of employees' jobs. These work characteristics, in turn, are associated with employees' reactions.

The results of our cross-sectional study partly confirmed this supposition. Complexity seemed to be indirectly related with cmotional exhaustion and psychosomatic health complaints due to the effect of complexity on workload. Workload therefore seemed to operate as a mediator. However, the structural variable in our study, viz. decision authority, seemed to be directly related with intrinsic work motivation and job satisfaction. Autonomy was not a mediator variable in this relationship.

\section{Longitudinal study results direct effects}

Because of the two-wave cross-lagged panel design, it was not possible to investigate the mediation effect of work characteristics. Consequently, the cross-lagged relationships between organisational characteristics and psychological work reactions were estimated. Although the hypothesised relationships were largely confirmed cross- 
sectionally (the synchroneous telationships at time 1 and time 2), the results of the cross-lagged structural panel analyses showed no significant relationships over time.

\section{Multilevel study results}

The results of the multilevel analyses revealed that most of the relationships between individual-level organisational characteristics and psychological work reactions did not differ from the group-level organisational characteristics and psychological work reactions. This finding indicates that the gtoup-level effects of organisational characteristics are the same as the individual-Level effects. More concretely, intrinsic wotk motivation was directly predicted by high individual-level decision authority. The group-level effect did not differ from the individual-level effect.

The effect of individual-level environmental uncertainty on emotional exhaustion depended on type of unit: a positive telationship in surgical and medical units was found, indicating that higher levels of environmental uncertainty predict higher levels of emotional exhaustion. Furthermore, the effect of individual-level decision authority on emotional exhaustion depended on type of unit: emotional exhaustion was predicted by low individual-level decision authority in ICUs. Finally, a direct grouplevel effect of decision authority on emotional exhaustion was found. This means that group-level decision authotity instead of individual-level decision authority can be seen as the major source of emotional exhaustion. This finding might be explained by particular views on group behaviour, stating that a group is more than the sum of its members. In other words, a group exists as distinct from an aggregation of individuals. The co-operation of individuals within an organised group make them behave or act differendy than if they acted individually (Bion, 1961).

\subsubsection{Relationships between work characteristics and psychological work reactions}

\section{Cross-sectional study results}

The results of our cross-sectional study showed that emotional exhaustion and psychosomatic health complaints were primarily predicted by high workload, low social support at work, and high role conflict. In addition, a two-way interaction effect was found between workload and social support in the predicion of emotional exhaustion. This interaction effect suggest that high levels of social support buffer the negative effect of workload on emotional exhaustion. This finding is in line with existing theories of social support (Cohen \& Wills, 1985; Thoits, 1995), and empirical findings of, for instance, Bennett, Lowe, Matthews, Dourali and Tattersall (2001); De Jonge et al., 1996; Koniarek and Dudek, 1996; and Winnubst and Schabracq (1996). Job satisfaction was particularly predicted by high social support; and to a lesser extent, by low workload, low role ambiguity, low role conflict, and high autonomy. In addition to these main effects, two interaction effects were found, namely, workload $\mathrm{x}$ social support, and autonomy x social support. The interaction between workload and social 
support suggests that receiving high levels of social support reduces the negative effect of workload on job satisfaction. "The interaction effect between autonomy and social support suggests that high levels of social support enhance the positive effect of autonomy on job satisfaction. These two interaction effects are in line with the results of the study of De Jonge et al. (1996). Finally, intrinsic work motivation was predicted by high sociall support.

\section{Longitudinal study results}

Before testing the relationships between work characteristics (i.e., workload, autonomy, and social support) and psychological work reactions (emotional exhaustion, and intrinsic work motivation) over time, several specific hypotheses were formulated, mainly based on our cross-sectional study, but also on theoretical considerations (Hackman \& Oldham, 1976; Hackman \& Oldham, 1980; Hobfoll \& Freedy, 1993; Schaufeli \& Enzmann, 1998) and the findings of other empirical studies (Hackman \& Oldham, 1976; Houkes et al., 2001a; Landeweerd \& Boumans, 1994; Tiegs et al., 1992). It was hypothesised that high workload and low social support influence emotional exhaustion, and that high autonomy influences intrinsic work motivation. The results of the multi-sample analyses showed that the relationships were invariant, indicating that they have the same strength and direction at both time 1 and time 2. Emotional exhaustion seemed to be predicted by high workload and low social support. However, intrinsic work motivation was not predicted by high autonomy at time 1 or at time 2 . After testing these synchroneous relationships, the relationships were tested cross lagged in order to investigate the causal predominance. The results of these crosslagged analyses confirmed our hypotheses: the scores on workload at time 1 influenced the scores on emotional exhaustion at time 2, whereas the scores on social support at time 2 influenced the scores on emotional exhaustion at time 2. Although both direct effects were in the opposite direction as supposed (negative direction for workload, and positive for social support), the total effects were in the expected directions. So, we may conclude that a high level of workload, and a low level of social support lead to an increase in emotional exhaustion in the short run, and even in the long run (after 1 year).

\section{Multillevel study results}

With regard to the multilevel study, several suppositions were made. First, it was supposed that emotional exhaustion is predicted by workload and social support. Intrinsic work motivation was supposed to be predicted by autonomy. The results of the different model comparisons (by means of the difference in "deviance") revealed that no additional group-level effects of workload, social support and autonomy were found. We only found two individual-level effects of workload and social support in the prediction of emotional exhaustion. This finding indicates that the group-level effects of workload and social support did not differ significantly from the individuallevel effects in the prediction of emotional exhaustion. 


\subsubsection{The congruence between structural and environmental characteristics in the prediction of psychological work reactions}

Our sixth research question was to investigate whether psychological work reactions depend on the "congrwence" of structural and enwironmental characteristics rather than on structural and environmental characteristics alone. For this aim, the contingency approach of organisations was used as a leading framework. Differences were expected between ICUs and non-ICUs, because of the different task standardisation in both units and, consequently, the effects of organisational characteristics on burnout and psychosomatic health complaints ("health outcomes"). We hypothesised that intrinsic work motivation is particularly predicted by decision authority $(\mathrm{H} 1)$, that high decision authority buffers the negative effect of environmental uncertainty on burnout and psychosomatic health complaints $\left(\mathrm{H}_{2}\right)$, and that high environmental uncertainty enhances the positive effect of decision authority on intrinsic work motivation and job satisfaction (H3). In addition to these three hypotheses, two, more explorative, research questions were formulated. We investigated what relationships exist between environmental uncertainty on the one hand and burnout and psychosomatic health complaints on the other (RQ1), and whether ICUs and non-ICUs differ as to these relationships, because we assumed difference in task standardisation (RQ2).

The first hypothesis was confirmed in both samples. The second hypothesis was not confirmed: high decision authority did not buffer the negative effect of environmental uncertainty on health outcomes. Hypothesis 3 was partially confirmed: high environmental uncertainty enhances the positive effect of decision authority on intrinsic work motivation. This effect was, however, only found in ICUs. "Two explanations can be advanced. One might be that ICU nurses have different personal. characteristics ot coping strategies than non-ICU nurses that enable them to be intrinsically motivated by high environmental uncertainty. Another explanation might be that tasks are more standardised on ICUs.

With respect to the two explorative research questions regarding the relationship between environmental uncertainty on the one hand and emotional exhaustion and psychosomatic health complaints on the other in ICUs and non-ICUs, we found that higher levels of environmental uncertainty are related with higher levels of emotional exhaustion and psychosomatic health complaints. This relationship was, again, only found in ICUs. This finding could be explained by a higher task standardisation in ICUs. Because of the "certainty" about the way tasks have to be performed, environmental uncertainty might not negatively affect nurses" health. 


\subsubsection{Comparison between different kinds of nursing}

With respect to nursing work, differences were expected between mental health and general nurses on the one hand, and between intensive cate unit (ICU) and general nurses on the other.

With regard to the comparison between mental health and ICU nurses on the one hand and general nurses on the other, we investigated differences as to work chatacteristics and psychological work reactions, and differences regarding the pattern of relationships between these variables. In addition, we studied differences in organisational characteristics and the role of these organisational chatacteristics in the relationship with work characteristics and psychological work reactions in ICUs.

\section{Comparison between mental health nurses and general nurses}

We hypothesised that autonomy, job involvement, and emotional exhaustion were higher in mental health nursing, whereas social support was expected to be lower in comparison with general nursing. Furthermore, and in line with the propositions of the DCS model, it was hypothesised that emotional exhaustion is primarily predicted by high workload and low social support. Job involvement was supposed to be predicted by high autonomy.

Our hypotheses were confirmed with regard to differences in work characteristics and psychological work reactions, except for social support and job involvement. Autonomy and emotional exhaustion are higher among mental health nurses, whereas their job involvement turned out to be significantly lower. The latter finding was contrary to our expectations. Mental health nurses might withdraw from their work as a kind of protection or coping mechanism. Particularly in mental health work, where intensive patient contact is unavoidable, nurses may react to this intensive contact by becoming less committed to their jobs (Eisenstat \& Felner, 1984).

The hypotheses with regard to the pattern of relationships were partly confirmed in both samples. Emotional exhaustion was predicted by high wotikload and low social support. These patterns of relationships were invariant across mental health and general units, indicating that the relationships have the same strength and direction. Contrary to our expectations, autonomy did not predict job involvement in both samples.

\section{Comparison between intensive care nurses and general nurses}

With regard to the comparison between intensive care nurses and genteral nurses, we first hypothesised that complexity, envitonmental uncertainty, and decision authority are higher in ICUls than in non-ICUs. Furthermore, autonomy, emotional exhaustion, and intrinsic work motivation are hypothesised to be higher among ICU nurses. 
Second, our aim was to validate the hypothesised relationships with regard to organisational characteristics, work characteristics, and psychological work reactions. As to relationships between wotk characteristics and psychological work reactions, we hypothesised that emotional exhaustion is primarily predicted by workload and lack of social support, and that intrinsic work motivation is primarily predicted by autonomy.

With regard to the relationships between organisational and work characteristics on the one hand and, psychological work reactions on the other, the following five hypotheses were formulated. Workload was expected to be primarily predicted by environmental uncertainty and complexity. Emotional exhaustion was supposed to be primarily predicted by environmental uncertainty and complexity througb workload. Autonomy was expected to be primarily predicted by decision authority. Intrinsic work motivation was supposed to be predicted by decision authority through autonomy. Finally, it was hypothesised that social support is primarily predicted by decision authority.

The hypotheses regarding the differences in organisational characteristics were confirmed. As to the work characteristics, autonomy did not seem to differ between ICU and non-ICU nurses. With regard to the psychological work reactions, it was found that our hypothesis as to higher emotional exhaustion in ICU nurses was not confirmed: ICU nurses showed even lower levels of emotional exhaustion. This finding might be explained by a greater stress tolerance among ICU nurses. ICU nurses might build up defence mechanisms against the consequences of constant exposure to death and suffering by rationalising their feelings to protect themselves (Maloney, 1982). Another explanation might be a "selection effect" among nurses: nurses might voluntary select the area in which they prefer working and may have certain coping strategies or personality characteristics to deal with stressful circurnstances or to operate in specific organisational structures (Hollenbeck, 2000).

With regard to the hypothesised relationships, we may conclude that most of the hypotheses were confirmed. The relationships found even showed an invariant pattern across the two samples. Emotional exhaustion was primarily predicted by workload and social support: high workload and low social support appear to increase emotional exhaustion. Workload was found to be predicted by complexity, whereas complexity was a predictor for emotional exhaustion through the workload in both samples. This means that the relationship between complexity and emotional exhaustion was indirect through workload. We only found in non-ICU nursing that workload was predicted by environmental uncertainty, whereas environmental uncertainty was also predictive for emotional exhaustion through workload. Contrary to our expectations, we found that high uncertainty was predictive for lower levels of emotional exhaustion in ICU nursing. This finding could be explained by a selection effect among ICU nurses. The decision to work in an ICU alteady implies a preference for situations in which environmental uncertainty is high (cf. Reis Miranda, Ryan, Schaufeli \& Fidler, 1998). ICU nurses may 
possess cettain personality traits that enable them to handle high environmental uncertainty better. In addition, the standardisation of tasks is higher in ICUs, as mentioned before. Finally, social support was found to be predicted by decision authority.

\subsection{Methodological reflections}

In the previous section, the main findings of the study were reported. In this section, methodological issues of the study will be critically discussed. Although the methodology of the current study is straightforward, using advanced statistical analyses such as structural equation modelling and multilevel analyses, also has several methodological limitations that must be taken into account. Methodological issues with regard to the study population, the design of the study, measurement instruments, and statistical analyses are discussed in turn.

\subsubsection{Study population}

Our study population consists of a single-occupational group, nurses. The choice of such a group may have advantages as well as disadvantages (De Jonge, 1995; De Jonge et al., 2000). An advantage is (in comparison with different occupational groups) that the resuits can be generalised to the nursing population in the Netherlands. Another advantage is the restriction of confounding effects, caused by the relative homogeneity in social class. However, this advantage might be a disadvantage at the same time, because a single-occupational group might cause a restriction of tange (Spector, 1992). It is necessary to have enough variance in the independent variables (i.e., the organisational characteristics and the work characteristics), as we were interested in investigating the relationships between the variables under study. Consequently, the strength of the relationships might be underestimated. However, despite the fact that health care workers are a single occupational group, it has been shown that there is no less variability in health care samples (because of the different types of units, for instance) than there is across a fairly wide range of occupations (Elovainio et al., 2000). So, there is enough natural variation, implying that our results are probably not seriously biased.

Another issue with regard to the study population concerns the "healthy worker effect" (De Jonge \& Landeweerd, 1993; Frese, 1985). Only "active" employees have participated in the current study. People who are absent from work have not participated. This might influence the study results, in the sense that the relationships between organisational characteristics and work characteristics on the one hand and psychological work reactions on the other might be underestimated, because of a restriction of range. However, because it is difficult for people who are absent from work to give reliable answers on the "actual work situation" ("recall-bias") (Bouter \& 
Van Dongen; 2000), the inclusion of this group might bias the results (Houkes, 2002). So, we decided to obtain only data from "active" employees.

\subsubsection{Design of the study}

In the present study, a cross-sectional and a longitudinal design have been used. $A$ longitudinal design gives better possibilities of causal interpretations (Bijleveld \& Van der Kamp, 1998; Frese \& Zapf, 1988; Zapf et al., 1996). This means that the causal chain of relationships can be established more definitely. The following three conditions must be fulfilled for a plausible causal inference of a relationship: there is a co-variation of the stressor with the outcome, the stressor appeared before the outcome variable occurred, and other plausible explanations can be ruled out (Cook \& Campbell, 1979; Menard, 1991; Zapf et al., 1996). So, causal inferences cannot be proven, but can be made plausible by ruling out alternative explanations (Dwyer, 1983; Zapf et al., 1996). A longitudinal design has also its limitations, such as the problem of selecting appropriate time intervals (Frese \& Zapf, 1988; Kessler \& Greenberg, 1981) and non-response biases, such as attrition-bias (Bijleveld \& Van der Kamp, 1998; Daniels \& de Jonge, 2001).

The time interval between the two measurement times of the cross-lagged panel analysis was one year. A time lag of one year in this kind of research seems long enough to measure possible changes in individual scores (compare Frese \& Zap?s (Frese \& Zapf, 1988) 'exposure time effect' [p. 388]). In addition, a one-year time interval is not too long for much non-response in the sample (De Jonge et al., 2001; Frese \& Zapf, 1988) and may prevent instability of seasonal influence (Frese \& Zapf, 1988; Zapf et al, 1996). Despite these carefully considered arguments, it is hardly possible to decide on an appropriate causal lag on a theoretical basis, since many variants of theoretical time models exist (De Jonge, 1995; Frese \& Zapf, 1988). In our study, this problem seems to be even more relevant due to the three different categonies of relationships. The actual time lag might not also match the measured time lag, but might additionally be different for the several cross-lagged relationships. For instance, if work characteristics possibly mediate the relationships between organisational characteristics and psychological work reactions, the effect of organisational characteristics on psychological work reactions will take more time (than the time lag used of one year). In addition, emotional exhaustion and intrinsic work motivation might not have the same time lags. Emotional exhaustion does not develop immediately, but is generally visible after a longer time period (Houkes, 2002; Schaufeli \& Enzmann, 1998). On the other hand, positive outcomes, such as intrinsic work motivation, are supposed to develop within a short time interval. Accordingly, the positive effect of decision authority on intrinsic work motivation is likely to develop soon. This implies that, if the "true" time lag is much shorter than one year, the synchroneous relationships might be more valid than the cross-lagged relationships. As the respondents in our study have not been studied from the time they started their 
jobs, they might have had the opportunity to adapt to their actual working siruations (Zapf et al,; 1996). So, it might be possible that certain effects have not been measured. In this context, Sandefur and Tuma (1987) propose that the results of a cross-lagged panel analysis should always be reported in relation to the time lag in a particular study. indicating that the findings of the cross-lagged panel analysis cannot be generalised beyond the specific time lag used in the study. So, we suggest that the longitudinal relationships between organisational characteristics and psychological work reactions should be investigated more extensively and with more different time lags than one year.

Another problem in longitudinal research might be attrition-bias due to wave nonresponse. Attrition bias could occur due to the respondents who leave the panel aftert having participated at the first measurement (i.e., "dropouts"). Consequently, the internal validity of the study might be threatened (Bijleveld \& Van der Kamp, 1998), In order to investigate whether attrition bias might have occurred in our study, we performed several analyses (see chapter 7). The comparison of the panel group with the dropouts regarding age and gender by means of an independent $t$-test and a chisquare test respectively, revealed no significant differences between these two groups. With regard to the differences in mean scores of the study variables, the results of the independent t-tests showed that only the mean level of emotional exhaustion differed between the panel group and the dropouts. The dropouts showed significantly highet levels on emotional exhaustion than the panel group (mean $=2.29$ vs. 2.12 respectively). This finding means that the panel group consisted of relatively "healthy" workers compared to the dropouts. The dropouts' reason for not participating in the second measurement might be sickness absence due to high levels of emotional exhaustion; again probably an indication of the "healthy worket effect" (De Jonge \& Landeweerd, 1993), already discussed in section 8.3.1. Consequently, the mean level of emotional exhaustion might have been underestimated due to a restriction of range.

\subsubsection{Measurement instruments}

In the current study, we used subjective (self-report) measures to measure organisational characteristics, work characteristics and psychological work reactions. A disadvantage of using subjective measures might be common method variance (e.g., central tendency, acquiescence effect, see Frese \& Zapf, 1988), leading to an overestimation of correlations. However, although specific sources of method variance have been studied, no serious common method effects have been detected (Spector, 1987; 1992). We tried to reduce this problem by, for instance, using different scale categories.

Furthermore, some authors suggest that the use of self-report measures as indicators of the objective environment can be inappropriate (see for instance Spector \& Jex, 1991; Taber \& Taylor, 1990). 
In the current study, particularly the measurement of organisational characteristics by means of subjective measures may be discussed. These "perceived" organisational characteristics need not necessarily match "objective" organisational characteristics. Oti the other hand, objective measures by means of the judgements of "independent" experts or registrations also have their disadvantages. For instance, one may tise the question whether judgements by independent experts are as "objective" as might be suggested, as already mentioned in the introduction. Such "objective" ratings of an observer may also be influenced by cognitive and emotional processing (Firese \& Zapf, 1988; Meijman \& Ouwerkerk, 1999). In addition, one should be aware that "objective measures" (such as registrations) are generally small-scaled and poorly standardised, which makes it difficult to generalise the findings to the population (Erese \& Zapf, 1988).

Other authors suggest, that perceptual measures of work variables reflect the objective environment to a large extent (Spector 1992). Boumans and Landeweerd (1993) found, for example, that the correlations between "objective" and "subjective" measures were moderate to high. Even if changes rely on objective measures, it is generally advisable to take notice of the way nurses experience their wotk in order to complete the picture (cf. Spector, 1992) and to reduce resistance to change (Cummings \& Worley, 1997).

In addition, group assessments were also used in order to predict nurses' well-being and health (see chapter 6). Group assessments are more "objective" measures in the sense that the influence of individual perceptions are reduced (De Jonge, 1995; Frese \& Zapf, 1988). Taking these arguments into account, we decided not to use objective measures in our study (Frese \& Zapf, 1988).

\subsubsection{Statistical analyses}

Some considerations can be made with regard to the statistical analyses (multiple regression analyses, structural equation modelling, and multilevel analyses).

First of all, it has to be remarked that the correlations between the variables under study, especially when the organisational variables were concerned, were relatively low. The correlations between work characteristics and psychological work reactions were relatively modest. Organisational characteristics and work characteristics alone could not explain much watiance in nurses' psychological work reactions. Semmer et al. (19)6) have argued that in stressor-strain relationships the amount of explained variance is in general not very high (ranging from $5 \%$ to $30 \%$ ). This is particularly due to the multi-causal aetiology of well-being and health, which will include work-related, non-work related, but also factors that cannot be explained by theories used in a particular study. Consequently, any separate study cannot cover all relevant variables (Semmer et al, 1996).

Because we had no strict hypotheses with regard to the relationships studied beforehand, multiple regression analyses were performed. However, by using multiple 
regression analysis, it is not possible to take into account all the dependent variables simultaneously nor to correct for the intercorrelations between these variables. By means of structural equation modelling, all the dependent and independent variables can be included in one complete model. When studying the relationships over time, we used a full cross-lagged structural panel analysis, whereby the test-retest reliabilities (stability coefficients) of the variables at time 1 and time 2 wete taken into account. If these stability coefficients are high (as was the case in our study), suppression effects (i.e., a statistical artifact) might occur (Maassen \& Bakker, 2000; Tzelgov \& Henik, 1991). The chance of the occurrence of suppression in structural equation models with two measurement times is high if the stability coefficients and the coefficients of the synchroneous relationships are higher than the cross-lagged coefficients (Maassen \& Bakker, 2000). This statistical artifact is often found in this type of longitudinal research and is difficult to solve (De Jonge, 1995; Houkes, 2002). As recommended by Saris and Stronkhorst (1984), we interpreted the results of the suppression situations found by taking both direct and total effects (the sum of the direct and indirect effects) of the variables into account (cf. Houkes, 2002; Saris \& Stronkhorst, 1984; Schumacker \& Lomax, 1996). Consequently, the sign of the total effects was in accorcance with our expectations (i.e., after a time lag of one year, a positive total effect of workload on emotional exhaustion, and a negative toral effect of social support on emotional exhaustion was found).

Due to the hierarchical structure of our data, it was necessary to perform multilevel analysis. Multilevel analyses were performed to assess both individual-level and grouplevel effects of organisational and work chatacteristics on psychological work reactions. Ordinary statistical tests (such as regression analysis) treat all the data values as independent information (an assumption for performing these analyses), although nurses within the same unit or organisation tend to be similar to each other, because of selection processes, for instance. So, neglecting the dependency of observations may lead to spurious significances (Hox, 1995). In addition to analysing group-level effects, individual-level effects were taken into account, because of the ecological fallacy. This means that group-level effects are interpreted at the individual-level. In order to dew conclusions at the right level, it is necessary to take both effects (i.e, individual-level and group-level) into account. Despite the strength of multilevel analysis, it may also have some weaknesses. Group assessments are sensitive to spurious group consensus, although this aspect contributes to the homogeneity in the unit and does not have a direct relationship with the individual psychological work reactions (De Jonge, 1995). Second, we only included meso-level variables, while macro-level variables were not assessed in our multilevel models. Nevertheless, we do not think that including mactolevel variables would have improved our parameter estimations, because of power problems (only 15 organisations).

Finally, group indicators are more reliable than individwal data and less affected by attenuation (De Jonge, 1995). But again, subjective measures were used by calculating 
these group indicators. In that sense, they are not objective. The critical notes for using subjective measures have already been mentioned before (section 8.3.3).

\subsection{Theoretical implications of the study results}

In this section, the theoretical implications of the study results will be discussed. Section 8.4.1 discusses the teseatch model of our study. In section 8.4.2, the crosslagged relationships are considered, while section 8.4 .3 discusses the contingency approach of organisations. Finally, this section ends (8.4.4) with a theoretical reconsideration of the group effects found in the current study.

\subsubsection{Research model}

\section{Relationships between organisational characteristics and psychological work reactions}

Our research model was dexived from the Job Modification Framework (Oldham \& Hackman, 1981), as mentioned earlier in this chapter. Although in general we did not find strong support for our initial hypotheses (the indirect relationships), some interesting relationships between organisational characteristics and psychological work reactions can be reported.

The expectation that the structural variable "decision authority" positively influences intrinsic work motivation and job satisfaction was supported. "This relationship was, however, not an indirect one through the influence of autonomy. We found that decision authority directly influences intrinsic work motivation and job satisfaction. The mediator role of autonomy could not be confirmed in this relationship. From a statistical point of view, it is not possible that autonomy operates as a mediator variable in this relationship, as autonomy was not significantly related with intrinsic work motivation. A necessary condition for a mediation variable is, among othets, that this variable explains sufficient variance of the dependent variable (i.e., intrinsic work motivation in our study) (Baton \& Kenny, 1986; Bennett, 2000; Holmbeck, 1997). From a theoretical point of view, this finding could be explained by the difference between the concepte of decision authority and autonomy (cf. Söderfeldt et al., 1996).

Decision authotity means the authority over the resources (i.e., tasks) that are available to perform, but within certain restrictions. For instance, if employees have the authority to make decisions with regard to the planning of their tasks, these have to be performed within a certain period of time. Consequently, it is not always possible to leave the work whenever employees prefer, implying a restriction of their autonomy. Autonomy has an informal character, and is particularly determined by mutual adjustment of one's colleagues and/or supervisor. Decision authority, on the contrary, has a formal character, indicating that kind of decision making about tasks has been laid down in employees $s^{*}$ formal function profiles. So, high decision authority is not the same as high job autonomy. 
The relationship that was not in line with our suppositions beforehand, concerns that between environmental uncertainty and emotional exhaustion. A remarkable difference as to this relationship was found between intensive cate nurses and non-intensive care nurses. In general nursing, the relationship between environmental uncertainty and emotional exhaustion was through the influence of workload. This was in accordance with our expectation. However, the opposite finding was found in intensive care nursing: environmental uncertainty appeared to have a direct and even negititis relationship with emotional exhaustion. This means that high levels of environmental uncertainty lead to low levels of emotional exhaustion. A possible explanation for this finding was that the standardisation of tasks was higher in intensive care units (ICUs) than in non-intensive care units. Theoretically, standardisation of tasks means that tasks are "programmed", and in this way indirectly control nurses" behaviour. However, since we found that decision authority is significantly higher in ICUs, these "programmed decisions" do not mean that nurses are restricted in making decisions (Pugh \& Payne, 1977). Within the limits imposed by indirect control (i.e., standardisation), decisions are delegated to nurses. Standardisation of tasks might give nutses the feeling to handle highly uncertain circumstances better.

\section{Relationships between work characteristics and psychological work reactions}

The hypotheses with tegard to the relationships between work characteristics on the one hand, and emotional exhaustion and psychosomatic health complaints on the other, were largely confirmed. However, the finding that intrinsic work motivation and job satisfaction ("active" variables in our study) were not predicted by autonomy (a job content variable), but by social support, was not totally in line with our suppositions beforehand. Social support was expected to be a predictor for "strain variables", such as emotional exhaustion (Cohen \& Wills, 1985). Although this supposition was confirmed, the relationship of social support with the "active variables" was somewhat ambiguous. It might be plausible that social support is related to intrinsic work motivation or job satisfaction in general. Hackman and Oldham (1980), for example, argue for the motivating role of feedback (a form of social support). Karasek and Theorell (1990) discusses the direct and moderator role of social support both in the prediction of "active variables" and "strain variables". So, the particular role of social support in the prediction of active and strain variables, is less clear than the role of, for instance, job demands (like workload). 


\subsubsection{Cross-lagged relationships}

With regard to the cross-lagged relationships between organisational characteristics and work sbaratteristics, we found stronger support for a reverse causation pattern than for a regular causation pattern (see chapter 7 ). However, the model with a regular pattern of relationships also showed good fit indices. Because both a reverse pattern of relationships and a regular pattern of relationships fit the data, the possibility of reciprocal causation exists. After testing whether reciprocal causation finds support, we concluded that there was no evidence for a reciprocal pattern of relationships. The two different patterns of relationships found appear at least somewhat ambiguous. Theoretically, the regular pattern of relationships (organisational characteristics time 1 to work characteristics time 2) seems more plausible. From the statistical test procedure, it appears that levels of work characteristics time 1 could cause levels of organisational chatacteristics time 2. More specifically, high levels of social support seem to cause high levels of decision authority. In addition, high levels of autonomy appear to cause high levels of decision authority. In theory, an explanation for these relationships might be the true strain-stressor hypothesis (Williams \& Podsakoff, 1989; Zapf et al., 1996). According to this hypothesis, outcomes (strain) variables (i.e., work characteristics) might indeed have an influence on stressors (i.e., organisational characteristics). Applied to our two reversed relationships, it might be that the workplace has learned over time that a particular organisational structure is needed to be effective (we refer, of course, to a process that lasts longer than the one year period in which the current study has taken place). As a result, it might adapt its organisational structure to the characteristics of the workplace. This means that workplaces or units that are characterised by, for instance, high autonomy at work, might adapt in the long term their organisational. structure. Workplaces in which autonomy is high might need a suitable (decentralised and undifferentiated) structure in which this autonomy can be further maintained and developed. Despite this stronger statistical support for reverse causation compated to regular causation, regular causation is theoretically more plausible.

The hypothesised regular causal pattern of relationsbips between worke chanateristics and pigychological work reactions was confirmed. Two significant relationships were found. First, high levels of social support influence low levels of emotional exhaustion. Second, workload is positively related to levels of emotional exhaustion. As already discussed in section 8.3.4, the direct effects were in the opposite direction, and also contrary to the synchroneous relationships (see chapters 1, 4, 6, and 7). The explanation we had for this unexpected finding was the suppression phenomenon, which has also been reported by Houkes (2002) and Lee and Ashforth (1993). A statistical explanation for this finding was already given (see section 8.3.4), namely the high test-retest coefficients. Another, theotetical explanation might be an adjustment process (Frese \& Zapf, 1988; Zapf et al., 1996). This means that, although the stressor 
(iike workload) is still present, the negative health outcomes (such as emotional exhaustion) decrease. After a certain period of time, one dexelops coping strategies towards the stressors which reduce ill-health (Zapf et al., 1996).

With regard to the cross-lagged relationships between onganisational charateristics and psychological work reactions, we found no support for these relationships over time. Three possible explanations for this lack of relationships were reported.

A first, theoretical, explanation might be that the work characteristics are possible mediator variables in the relationship between organisational characteristics and psychological work reactions (Tummers et al, 2002b). As the cross-sectional relationships between complexity and emotional exhaustion on the one hand and decision authority and intrinsic work motivation on the other hold cross-sectionally, they might be eroded by the influence of work characteristics on these relationships.

A second explanation might be that the propositions of the contingency approach are not totally valid, because they are based on cross-sectional study designs. This means that the factor "time" is not taken into account. Consequently, although the propositions of the contingency approach are mostly confirmed cross-sectionally, they might not be confirmed over time.

A third explanation might be that the time lag used of one year does not match the actual causal time lag (e.g., Kessler \& Greenberg, 1981). The actual time lag might be different for the several cross-lagged relationships between organisational characteristics and psychological work reactions. For instance, if work chatacteristics possibly mediate these telationships, the effect of organisational characteristics on psychological work reactions will take more time (than the time lag used of one year). Alternatively, after a certain period of time, people may get used to these "stressors" and know how to cope with. Accordingly, the positive effect of decision authority on intrinsic work motivation might develop soon, and might take less time than the time lag of one year used in the current study.

\subsubsection{Contingency approach of organisations}

The contingency approach of organisations has been used as a leading framework to select organisational characteristics in nursing work. As alteady mentioned in the introductory chapter, the contingency approach is an open system approach to organisations. Within the open system approach of organisations, other comparable approaches can be distinguished, such as Mintzberg's configuration theory of organisations (Mintzberg, 1983) or in Miller's terms, a quantum theory of organisations (Miller \& Friesen, 1984). The main difference between the traditional contingency approach and the configuration or quantum approach is that the contingency approach assumes that the same relationships exist among variables in different types of organisations. The configuration approach, however, assumes that configurations differ not only in their individual variables, but also in their relationships among variables. In the current study, we were interested in the relationships between variables 
in health care organisations, and not between different configurations of organisations. In addition, investigating configurations would require a huge number of organisations in order to get enough variance. Practically, this is not attainable. So, we think that it was plausible to use the contingency approach as a framework instead of a configuration approach.

However, some critical points about the use of the contingency approach have to be reported. First of all, our unit of analysis was the workplace or unit, and not the entire otganisation. Consequently, some organisational characteristics, such as formalisation or the span of control, were not taken into account. So, no insight was obtained into the relationship between characteristics of the workplace, and characteristics of other parts of the organisation.

Second, and in line with the contingency approach, we tested the congruence of structural and environmental characteristics in the prediction of nurses" well-being and health. This congruence was measured at only one time moment. Consequently, the real "congruence" was not measured, as congruence encompasses an adaptation process between structure and environment (Hannan \& Freeman, 1977). In order to measure this adaptation, more than one measurement point is needed. However, the problem of congruence has not been solved yet with the solution of different time intervals. Congnuence at one time moment does not necessarily mean that this congruence remains at another time moment. Neither is it known at what time the organisation moves from "de-congruence" to "congruence". If organisational contingencies change, the structural characteristics of organisations might also change in order to adapt to these changes and to yield the best organisational effectiveness. A more profound insight is needed into the question how change in the organisational structure occurs so that the organisation moves toward congruence (Donaldson, 2001d).

\subsubsection{Group effects}

The statistical importance of measuring group effects has already been discussed in the methodological section of this chapter (section 8.3.4) and in chapter 6.

As we have seen in chapter 6 , we found hardly any differences between group-level and individual-level effects. A possible explanation for this finding might be that group and individual assessments reflect more or less the same features of the work situation due to attraction, selection, and attrition processes in a group or otganisation (De Jonge et al., 1999; Schneider, 1987). This results in similarity in behaviour within a work situation (or group). Another explanation might be that differences between subjects (i.e., nurses) exist in the level of the 'stressors' (i.e., work characteristics and organisational characteristics) within a unit. Consequently, there is more variance in the individual data than in the group data, leading to non-significant group-level effects (De Jonge, 1995; Vancouver, Millsap \& Peters, 1994). 
In addition to these non-significant differences between group-level and individuatlevel effects, we found a group effect of decision authority on nurses emotional exhaustion. Theoretically, this gtoup effect might be explained by an inter-group theory (De Jonge, 1995; Schneider, 1985). According to this theory, interactions of employees at any level of analysis partly represent the effect of group-memberships. A group is more than the sum of its members. So, an individual level of analysis is embedded in, and affected by, at least the next level of analysis (De Jonge; 1995). In other words, a group exists as distinct from an aggregation of individuals. The cooperation of individuals within an organised group, make them behave or act differenty than if they acted individually (cf. Bion, 1961). Applied to our finding, emotional exhaustion might be a product of the multi-level embeddedness of decision authority.

\subsection{Practical implications of the study results}

Some practical implications can be deduced from the findings of the present study. These are concerned with the policy of otganisational development, the logistic system, and personnel planning (see also Tummers et al., 2002d).

\section{Policy of organisational development}

Generally, the study results suggest that social support is necessary for satisfied and motivated nurses. There should be a clear policy to improve and develop social support between colleagues and supervisor on units. The role of the supervisor is very important. 'The supervisor's task is, among others, to make efforts for frequent contact between his employees, to give adequate feedback, and to give sufficient support (advise, emotional support) if necessary.

However, social support alone is not a sufficient condition for employees well-being and health. An integrated approach in which more characteristics of the organisation and/or the work are changed, might be advisable. In addition to social support, job autonomy and decision authority could be improved in order to remain satisfied and motivated. It has to be noted that an improvement in autonomy and decision authority does not necessarily mean that it is positive in all situations. By improving nurses' autonomy and decision authority, individual possibilities and preferences and also the possibilities of the organisation should be taken into account. An example of the latter is that the definition of the professional occupation (such as qualification systems) does not always match an improvement of decision authority. The organisational structure should also allow for an increase in decision authority (for instance, decentralisation of the organisation).

Job autonomy could be increased by given nurses the opportunities to decide themselves on their working goals, working method and working hours. However, 
again, this suggestion also has its negative points, because it could undermine the existing quality norms (such as protocols) that prescribe particular working methods.

The decision authority could be improved by adjusting the task- and decision-making structure. The organisation could be re-designed by small-scale, decentralised semiautonomours work groups (De Jonge, 1995; Trist, 1981; Van den Bent, 2001). This means that groups rather than individuals are responsible for the planning and performance of tasks. The organisation could contribute to develop or improve such semi-autonomous teams by providing courses such as "team-building" (in order to improve social support) or "leadership" (stressing the importance of a social-emocional leadership style in comparison with a "instrumental" leadership style). Supervisors could exert primarily a supportive role instead of a leading or instrumental role (De Jonge, 1995; Gardell, 1982).

\section{Logistic system}

The implications with regard to the improvement of the logistic system refer to workload in particular. The mean level of workload found in the current study (3.32) is higher than that found in other comparable studies (3.12 found in De Jonge's study, 1995). In addition, workload appeated to be an important predictor for emotional exhaustion. Some recommendations to reduce the workload seem worthwhile. A possibility to reduce the workload is to balance the amount of work by means of more efficient scheduling (forwards rotation, long period planning, and regularity).

There should also be an adequate admission policy. This means that there must be a balance between personnel occupation and the amount of planned admissions on the one hand and between patients' demand and personnel occupation (quantity and quality) on the other. It has to be noted, however, that capacity planning is often a choice whereby priorities must be made. For instance, optimising surgety capacity is often preferable, because of financial reasons (surgery capacity is expensive). By making such choices, the relationship with other capacities (such as nursing capacity) is not always taken into account. So, there should be an optimal match between different kind of capacities, because the use of "succeeding" capacities depends on "leading" capacities. In addition, some "under-capacity" is required in order to be able to react to emergencies.

Another implication concerned with the improvement of the logistic system refers to strategies for complexity reduction, such as decomposition (Van Merode, 1994). Decomposition means that the production system is divided into subsystems (such as teams or work groups), Each subsystem performs one or more decision functions. An advantage is that less information needs to be exchanged between groups (less coordination), and that each subsystem can be managed and controlled independently. For a good functioning of these teams, teamwork is necessary (see also the point of policy of organisational development). An inappropriate composition of teams (for 
instance, an unbalanced division of responsibilities over the professionals) might have contrary (i.e., negative) effects, such as an increase in workload (see Van den Bent, 2001).

\section{Personnel planning}

The recommendations with regard to personnel planning refer to quantitative and qualitative personnel planning. The quantitative aspect concerns adequate personnel planning per day, taking account of the amount of work of the unit. In this respect, it is necessary to consider sickness absence, vacations, and fluctuations in patient demands. The qualitative aspect refers to personnel selection. It is necessaty that nursing qualities match patients' demands (care intensity and complexity of patients). Decision authorities should be delegated to those employees who have both the needs and the knowledge to utilise decision authority adequately. This should be taken into account in order to prevent possible negative effects of high decision aurhority on nurses" health and well-being. For instance, complex patients can be assigned to highly qualified nurses or to nurses with a lot of competences. This means that functions could be differentiated. Differentiation could, however, have disadvantages. A pitfall might be, among others, that differentiation might induce more formalisation, and a de-professionalisation of nurses' occupation (see Van Merode, Janssen \& Van Raak, 2001).

\subsection{Recommendations for future research}

Although the present study has yielded some interesting tesults, there are, of course, several unsolved issues, and limitations of our study that should be addressed in future research.

First, we selected three organisational characteristics, that were supposed to be important characteristics in nursing units. As mentioned earlier (see section 8.3.4), the correlations between the organisational characteristics on the one hand, and work characteristics and psychological work reactions on the other, were generally rather low. One possible reason given for these low correlations referred to the selection of the variables. In this context, organisational variables other than those selected in the current study might also be important in the prediction of work characteristics and psychological work reactions. An example is task standardisation (Mintzberg, 1983). This structural characteristic of organisations has not been measured explicitly in the current study, although it is likely that this variable is important. It was supposed, posthoc, that the level of task standardisation influences emotional exhaustion (see chapter 5). Future research could pay attention to the influence of this structural wariable by including it in research models and measuring it. 
Second, although the current study has shed more light on organisational (structural and environmental) characteristics and their influence on nurses' well-being and health, the level of analysis was constrained to the workplace or unit. More concretely, it was investigated which organisational characteristics in nursing units were important. In order to be effective as a whole organisation, it is not only necessary to pay attention to the organisational characteristics of singular units, but also their fit with other units needs to be addressed. By doing this, knowledge about the fit between these units and the entire organisation may be obtained. This means that insight may be obtained into the question whether different organisational characteristics witbin the same organisation do match each other. So, future research should take the different path dependencies within an organisation into account.

A third point involves the relationship between environmental uncertainty and emotional exhaustion. This relationship was different for ICU nurses and general nurses: a negative relationship was found in ICU nursing, as opposed to the positive (indirect) relationship in general nursing. This finding was explained by a difference in task standardisation (as mentioned before), but also by a selection effect (see chapter 4). The latter explanation means that the responsiveness (or flexibility) to organisational characteristics may also be explained by personal factors (Hollenbeck, 2000), like openness to experience, and emotional stability. In order to get an effective, stimulating and healthy work environment, more insight should be gained into the mechanisms that determine how people are fitted to different organisational structures (e.g., decentralised structure and functional structure).

A final point for future research is that more attention should be paid on studies within experimantal and quasi-experimental settings (Kasl, 1987) in order to investigate under which conditions self-autonomous teams are beneficial for obtaining decision authotity, and social suipport. 
Samenvatting (Summary in Dutch) 
क : क 
In dit proefschrift worden de relaties tussen enerzijds organisatiekenmethen en werkkermerken en anderzijds psychologische werkreacties van verpleegkundigen onderzocht en bediscussieerd. Het huidige onderzoek dat ten grondslag ligt aan de totstandkoming van dit proefschrift, is uitgevoerd bij 15 algemene ziekenthuizen in Nederland.

In hoofdstuk 1 wordt een algemene inleiding gegeven over de achtergtond van het onderzoek en de totstandkoming van de onderzoeksvragen. Internationaal wordt het belang onderkend van werkgerelateerde gezondheids- en welzijnsproblemen, zoals werkstress. Vooral de gezondheidszorg is een sector die in toenemende mate in de belangstelling komt te staan bij onderzoekers op het gebied van de arbeids- en organisatiepsychologie en de organisatiekunde. De gezondheidszorg is een zeer arbeidsintensieve sector, die de afgelopen decennia met een aantal maatschappelijke, maar ook organisatorische veranderingen, geconfronteerd is. Ondanks dat in deze sector reeds veel onderzoek gedaan is naar werkgerelateerde determinanten van gezondheid en welzijn, is er nauwelijks onderzoek verricht naar de rol van organisatiekenmerken in deze context. Om dit te onderzoeken, is gebruik gemaakt van twee theoretische modellen die afkomstig zijn uit verschillende onderzoeksstromingen. Enerzijds zijn de organisatiekenmerken geselecteerd aan de hand van de contingentietheorie uit de organisatie- en bedrijfskunde. Anderzijds is het JobDemand-Control model en het Demand-Control-Support model gehanteerd bij het selecteren van saillante werkkenmerken en psychologische uitkomstmaten (de psychologische werkreacties). De onderzoeksvraag die in het huidige onderzoek centraal staat, is: "Welke relaties bestaan er tussen organisatiekenmerken, werkkenmerken en psychologische werkreacties in het werk van verpleegkundigen?"

In hoofdstuk 2 worden de cross-sectionele relaties tussen de organisatiekenmerken (besluitvormingsautoriteit, omgevingsonzekerheid en complexiteit), werkkenmetken. (werkdruk, autonomie, sociale steun, rolconflict en rolambiguiteit) en psychologische werkteacties (emotionele uitputting, psychosomatische gezondheidsklachten, intrinsieke werkmotivatie en arbeidssatisfactie) geëxploreerd. Drie onderzoekswragen zijn geformuleerd, namelijk: (1) welke relaties zijn er tussen organisatiekenmerken en werkkenmerken; (2) welke relaties zijn er tussen werkkenmerken en psychologische werkreacties en (3) welke relaties zijn er tussen organisatickenmerken en psychologische werkreacties en wat is de rol van werkkenmerken in deze relatiess? Om deze onderzoeksvragen te onderzoeken, zijn vragenlijsten uitgedeeld aan 1855 verpleegkundigen. Uiteindelijk participeerden 1253 verpleegkundigen aan het onderzoek. Er is gebruik gemaakt van correlatie- en hiërarchische meervoudige regressie-analyses om de onderzoeksvragen te analyseren. Uit deze analyses blijkt dat, met betrekking tot de relaties tussen organisatiekenmerken en werkkenmerken, sociale steun en autonomie vooral voorspeld worden door een hoge besluirvormingsautoriteit. Werkdruk wordt vootspeld door een hoge mate van complexiteit en omgevingsonzekerheid. Met betrekking tot de relaties tussen werkkenmerken en 
psychologische werkreacties kan geconcludeerd worden dat intrinsieke werkmotivatie voorspeld wordt doot hoge sociale steun en dat arbeidssatisfactie voorspeld wordt door hoge sociale steun en een lage werkdruk. Bovendien is er een interactie-effect gevonden tussen enerzijds werkdruk en sociale steun en anderzijds tussen autonomie en sociale steun. Vervolgens worden emotionele uitputting en psychosomatische gezondheidsklachten woorspeld door een hoge werkdruik, weinig sociale steun en veel rolconflicten. Het onderzoeken van deze relaties was noodzakelijk om de directe en indirecte relaties tussen organisatiekenmerken en psychologische werkreacties te kurnen onderzoeken. Er wordt namelijk verondersteld dat de werkkenmerken als mediatorvariabelen fungeren in deze relaties. Aan de hand van de regressie-analyses blijkt dat een directe relatie bestaat tussen enerzijds besluitvormingsautoriteit en anderzijds intrinsieke werkmotivatie en arbeidssatisfactie. Er kan geen mediator-effect worden aangetoond van autonomie en sociale steun in deze relaties. Echter, het effect van complexiteit op zowel emotionele uitputting als op psychosomatische gezondheidsklachten wordt indirect verklaard door de invloed van werkdruk. In deze relaties blijkt werkdruk dus wel als mediatorvariabele op te treden. Ten slotte worden de beperkingen van het onderzoek besproken. Deze richten zich op het crosssectionele karakter van de studie en de lage verklaarde varianties.

Hoofdstuk 3 gaat in op de vraag of er verschillen zijn in werkkenmerken (autonomie, werkdruk en sociale steun) en psychologische werkreacties (emotionele uitputting en werkbetrokkenheid) tussen algemene verpleegkundigen en psychiatrisch verpleegkundigen. Bovendien wordt door middel van Multi-Sample Analyse (MSA) integtal onderzocht of het patroon van specifieke relaties tussen werkkenmerken en psychologische werkreacties in beide steekproeven hetzelfde is. Met betrekking tot de verschillen in werkkenmerken laten de resultaten van de meervoudige variantie-analyse zien dat autonomie en emotionele uitputting hoger zijn bij psychiatrisch verpleegkundigen dan bij algemene verpleegkundigen. De werkbetrokkenheid is echter, tegen de verwachting in, lager bij psychiatrisch verpleegkundigen. Een verklaring hiervoor zou kunnen zijn dat psychiattisch verpleegkundigen zichzelf proberen te beschermen tegen het intensieve cliëntencontact. Uit de resultaten van de MSA blijkt dat het veronderstelde patroon wan relaties tussen werkkenmerken en psychologische werkreacties invariant is over beide steekproeven. Dit betekent dat zowel de richting als de sterkte van de verbanden in beide steekproeven gelijk zijn. Een hoge score op werkdruk en een lage score op sociale steun blijken gerelateerd te zijn aan emotionele uitputting.

Hoofdstuk 4 is een uitbreiding op hoofdstuk 3. In dit hoofdstuk wordt namelijk onderzocht of er verschillen bestaan tussen organisatiekenmerken, werkkenmerken en psychologische werkreacties tussen Intensive Care (IC) verpleegkundigen en algemene verpleegkundigen. Bovendien wordt onderzocht of het patroon van relaties tussen organisatiekenmerken, werkkenmerken en psychologische werkreacties in beide steekproeven hetzelfde is. Wederom is gebruik gemaakt van respectievelijk 
meervoudige variantie-analyse en MSA. Met betrekking tot de verschillen tussen ICverpleegkundigen en algemene verpleegkundigen op de genoemde varabelen, blijkt dat IC-verpleegkundigen aangeven een hogete mate van omgevingsonzekerheid te hebben, te maken krijgen met een hogere complexiteit en een hogere besluitwormingsautoriteit rapporteren. Verder blijkt dat de werkdruk significant hoger ervaren wordt door algemene verpleegkundigen en dat zij eveneens een hogere mate van emotionele uitputting aangeven. Een verklaring voor deze laatste, niet veronderstelde, bevinding zou kunnen zijn dat IC-rerpleegkundigen een hogere stresstolerantic hebben dan algemene verpleegkundigen en dat zij geleerd hebben om met bepaalde stressvolle situaties om te gaan, bijvoorbeeld door hun emoties te rationaliseren (en zichzelf hierdoor te beschermen). Met betrekking tot het patroon van relaties laten de resultaten van de MSA zien dat de telaties invariant zijn over beide steekproeven. Een aantal relaties blijkt zowel hetzelfde verband alsook dezelfde sterkte te hebben in beide steekproeven. Emotionele uitputting wordt vootal voorspeld door een hoge werkdruk en lage sociale steun. Werkdruk blijkt voorspeld te worden door complexiteit, terwijl complexiteit op zijn beurt een voorspeller blijkt te zijn voor emorionele uitputting via de invloed van de werkdruk. Dit betekent dat de relatie tussen complexiteit en emotionele uitputting indirect is via werkdruk. Ten slotte blijkt dat een hoge mate van besluitvormingsautoriteit rechtstreeks (zonder de invloed van autonomie) voorspellend is voor een hoge intrinsieke werkmotivatie in beide steekproeven. Naast deze invariante relaties over beide steekproeven, zijn ex eveneens verschillen in relaties gevonden. Alleen voor algemene verpleegkundigen is er gevonden dat omgevingsonzekerheid voorspeld wordt door een hoge werkdruk, terwijl omgevingsonzekerheid voorspellend is voor emotionele uitputting via de werkdruk. Eveneens verschilt de relatie tussen omgevingsonzekerheid en emotionele uitputting in beide steekproeven: in de steekproef van IC-verpleegkundigen is gevonden dat een hoge score op omgevingsonzekerheid voorspellend is voor een hoge mate van emotionele uitputting. Deze relatie is tegenovergesteld aan de relatie die gevonden is bij algemene verpleegkundigen. De mogelijke verklaringen voor deze bevinding zouden gezocht kunnen worden in een selectie-effect op IC afdelingen en in de taakstructuur.

In Hoofdstuk 5 worden de bevindingen gepresenteerd van een cross-sectionele studie naar de effecten van organisatiekenmerken op psychologische werktreacties. In deze studie worden niet alleen de afzonderlijke effecten van de organisatiekenmerken onderzocht. De nadruk ligt vooral op het effect van de congruentie tussen het structuurkenmerk "besluitvormingsautoriteit" en het contingentic- of omgevingskenmerk "omgevingsonzekerheid" op psychologische werkreacties. Omdat er verondersteld wordt dat de taakstandaardisatie tussen $\mathrm{IC}$ - en algemene afdelingen verschilt en dat deze taakstandaardisatie op zijn beurt van invloed kan zijn op emotionele uitputting, is een opsplitsing gemaakt tussen deze twee typen afdelingen. Drie hypothesen en twee onderzoeksvragen zijn geformuleerd om de effecten van organisatiekenmerken op de psychologische werkreacties te onderzoeken. Er wordt 
verondersteld dat intrinsieke werkmotivatie vooral voorspeld wordt door een hoge mate van besluitvormingsautoriteit. Verder wordt er verondersteld dat door een hoge mate van besluitvormingsautoriteit de negatieve effecten van omgevingsonzekerheid op emotionele uitputting en psychosomatische gezondheidsklachten afgezwakt worden. Bovendien worclt verondersteld dat door een hoge mate van omgevingsonzekerheid het positieve effect van beshitvormingsautoriteit op intrinsieke werkmotivatie en arbeidssatisfactie versterkt wordt. Naast deze drie hypothesen, wordt onderzocht wat het effect is van omgevingsonzekerheid op emotionele uitputting en psychosomatische gezondheidsklachten. Ten slotte wordt onderzocht wat de rol van taakstandaardisatie is in de relatie tussen enerzijds omgevingsonzekerheid en emotionele uitputting en psychosomatische gezondheidsklachten anderzijds. Er is gebruik gemaakt van correlatie- en meetroudige hiërarchische regtessie-analyse om de hypothesen te toetsen en de onderzoeksvragen te onderzoeken. Uit de resultaten van deze analyses blijkt dat intrinsieke werkmotivatie voorspeld wordt door een hoge besluitvormingsautoriteit. Er is geen effect gevonden van de congruentie tussen besluitvormingsautoriteit en omgevingsonzekerheid op emotionele uitputting en psychosomatische gezondheidsklachten. Aangezien het positieve effect van omgevingsonzekerheid op emotionele uitputting en psychosomatische gezondheidsklachten alleen gevonden is voor algemene verpleegkundigen, kan het ontbreken van het veronderstelde "buffer-effect" verklaard worden door het gebruik van protocollen op IC-afdelingen. Op algemene afdelingen zullen protocollen in een veel beperktere mate toegepast worden dan op IC-afdelingen. Wel is er een effect gevonden van de congruentie tussen besluitvormingsautoriteit en omgevingsonzekerheid op intrinsieke werkmotivatie. Een hoge mate van ongevingsonzekerheid blijkt het positieve effect van besluitvormingsautoriteit op intrinsieke werkmotivatie te versterken. Dit effect is echter alleen aangetoond bij ICverpleegkundigen. Een mogelijke verklating hiervoor is dat IC-verpleegkundigen waarschijnlijk bepaalde persoonlijkheidskenmerken of coping-mogelijkheden hebben waardoor zij hoge omgevingsonzekerheid (in combinatie met een hoge besluitvormingsautoriteit) als een uitdaging zien. Met betrekking tot de twee exploratieve onderzoeksvragen kan geconcludeerd worden dat een hoge mate van omgevingsonzekerheid voorspellend is voor emotionele uitputting en psychosomatische gezondheidsklachten bij algemene verpleegkundigen. Dit effect is niet gevonden bij IC-verpleegkundigen. Een mogelijke verklaring, zoals reeds eerder genoemd in hoofdstuk 4 , is de hogere taakstandaardisatie op IC-afdelingen.

In hoofdstuk 6 worden de resultaten van een multi-level studie beschreven. Er wordt niet alleen onderzocht welke effecten organisatiekenmerken en werkkenmerken op individueel niveau hebben, maar tevens wordt onderzocht welke effecten deze variabelen op groepsniveau vertonen op intrinsieke motivatie en emotionele uitputting. Voor elke onafhankelijke variabele zijn er dus twee scores berekend: een individuele en een groepsscore. Een multi-niveau model met drie niveaus is toegepast: 15 instellingen op macro-niveau, 95 afdelingen op meso-niveau en 1111 verpleegkundigen op micro- 
niveau. Met betrekking tot de relaties tussen organisatiekenmerken op individueel- en groepsniveau en werkkenmerken, laten de resultaten van de multi-niveau analyses zien dat de 'individuele' effecten van organisatiekenmerken niet significant verschillen van de groepseffecten van organisatiekenmerken. Concreet betekent dit dat de 'individuele' effecten van besluitvormingsautoriteit en autonomie hetzelfde zilin als de groepseffecten van beshuitvormingsautoriteit. Hetzelfde geldt voor de telatie tussen besluitvormingsautoriteit en autonomie, de relatie tussen omgevingsonzekerheid en werkdruk en de relatie tussen complexiteit en werkdruk. Deze bevindingen kunnen vooral verklaard worden door het significante effect van de (dummy)variabele "afdelingstype" die als covariaat in het model opgenomen is. De organisatiekenmerken op groepsniveau reflecteren niet alleen de organisatiekenmerken op individueel niveau, maar tevens het afdelingstype. Met betrekking tot de individuele- en groepseffecten van de organisatiekenmerken op de psychologische werkreacties (direct dan wel indirect via de werkkenmerken) kan geconcludeerd worden dat het directe groepseffect van besluitvormingsautoriteit op intrinsieke werkmotivatie niet verschilt van het 'individuele' effect van besluitvormingsautoriteit. Het 'individuele' effect van omgevingsonzekerheid op emotionele uitputting hangt van het afdelingstype af: een positief verband is gevonden voor medische en chirurgische afdelingen. Vervolgens hangt het 'individuele' effect van besluitvormingsautoriteit op emotionele uitputting af wan het afdelingstype: emotionele uitputting wordt voorspeld door lage 'individuele' besluitvormingsautoriteit op $\mathrm{IC}$-afdelingen. Bovendien is or een groepseffect van besluitvormingsautoriteit op emotionele uitputting gevonden. Dit betekent dat het 'individuele' effect van besluitvormingsautoriteit op emotionele uitputting verschilt van het 'groepseffect'. Deze bevinding zou verklaard kunnen worden door groepsgedrag: een groep is niet hetzelfde als een optelsom van individuen. Door de samenwerking van individuen binnen een georganiseerde groep is het gedrag van deze individuen anders dan het geval zou zijn indien zij als individu handelen. Ten slotte verschillen de 'individuele' effecten van werkkenmerken op psychologische werkreacties niet van de groepseffecten. Er is nameliik gevonden dat de groepseffecten van werkdruk en sociale steun geen additionele verklaarde variantie toevoegen aan de 'individuele' effecten van deze twee werkkenmerken.

In hoofdstuk 7 worden de resultaten wan de longitudinale studie besproken. Er is gebruik gemaakt van een cross-lagged panel model met een tijdsinterval wan 1 jaar om de relaties tussen organisatiekenmerken, werkkenmerken en psychologische werkreacties in de tijd te onderzoeken. Eerst worden enkele voorbereidende analyses uitgevoerd, zoals non-respons analyse, en Muldi-Sample Analyse. Deze laatste analyse is uitgevoerd met het doel te onderzoeken of de relaties stabiel zijn over de tijd. De meeste relaties blijken stabiel te zijn over de tijd. Hierna wordt de causaliteit van de drie typen relaties onderzocht: (1) organisatiekenmerken $\rightarrow$ werkkenmerken; (2) werkkenmerken $>$ psychologische werkreacties on (3) werkkenmerken $>$ psychologische werkreacties. 
Met betrekking tot de relaties tussen organisatiekenmerken en werkkenmerken blijkt uit de structurele covariantie-analyses dat een omgekeerd causatiepatroon van relaties sterker is dan een regulier causatiepatroon, ondanks het feit dat het regulier causatiepatroon ook goed fitmaten laat zien en dus goed bij de data past. De bevinding van een omgekeerd causatiepatroon betekent dat werkkenmerken op tijdstip 1 de organisatiekenmerken op tijdstip 2 beinvloeden. Er blijkt een positieve relatie te bestaan tussen autonomie en sociale steun op tijdstip 1 en besluitvormingsautoriteit op tijdstip 2. Met betrekking tot de relaties tussen organisatiekenmerken en psychologische werkreacties zijn geen causale effecten gevonden. Het ontbreken van deze effecten in de tijd kan verklaard worden door de invloed van werkkenmerken (mediatorvariabelen), het gekozen tijdsinterval en de veronderstellingen van de contingentietheorie, die vooral gebaseerd zijn op resultaten van cross-sectionele studies. Ten slotte wordt ondersteuning gevonden voor een regulier causatiepatroon tussen werkkenmerken en psychologische werkreacties. Werkdruk op tijdstip $\mathbb{1}$ blijkt een positief effect te hebben op emotionele uitputting op tijdstip 2, terwijl sociale steun op tijdstip 1 cen negatief effect blijkt te hebben op emotionele witputting.

In hoofdstuk 8 tenslotte worden de algemene conclusies van de studie besproken en ter discussie gesteld. Allereerst worden de belangrijkste bevindingen besproken. Hierna wordt de methodologie van het onderzoek bediscussieerd. Deze heeft betrekking op de onderzoekspopulatie, het onderzoeksdesign, de meetinstrumenten en de statistische analyses. Ook worden de theoretische implicaties van de onderzoeksresultaten besproken. Hierbij wordt het onderzoeksmodel bediscussieerd, de gevonden causale relaties, de contingentiebenadering en de betekenis van de groepseffecten. Het hoofdstuk wordt afgesloten met aanbevelingen die zich zowel tichten op de praktijk als ook op toekomstig onderzoek. De praktische aanbevelingen hebben betrekking op het organisatie-ontwikkelingsbeleid, het logistieke systeem en de personeelsplanning. De aanbevelingen voor verder onderzoek zijn gericht op de uitbreiding van organisatievariabelen, de samenhang met andere organisatie-eenheden, de invloed van persoonskenmerken en het uitwoeren van het huidige onderzoek in een (quasi)experimentele setting. 


\section{References}




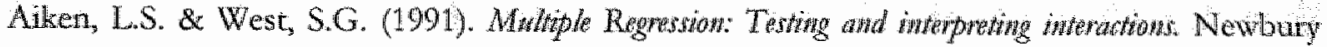
Park, California: Sage Publications:

Alexander, J.W. \& Randolph, W.A. (1985). The fit between technology and structure as a

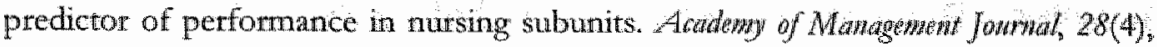
844-859.

Algera, J.A. (1990). The Job Characteristics Model of work motivation revisited. In U. Kleinbeck, H.H. Quast, H. Thieny \& H. Häcker (Eds.), Work mormatho (pp. 85103). Hillsdale, New Jersey: Lawtence Erlbaum Associates.

Baldwin, P.J. (1999). Nursing. In J. Firth-Cozens \& R.L. Payne (Eds.), Stress in bealth profersionals (pp. 93-104). Chichester: John Wiley \& Sons.

Baron, R.M. \& Kenny, D.A. (1986). The moderator-mediator variable distinction in social psychological research: Conceptual, strategic, and statistical considerationts. fournol of Personality and Social Pyothology, 57(6), 1173-1182.

Bennett, B., Lowe, R., Mathews, V., Dourali, M. \& Tattersall, A. (2001). Stress in nurses: coping, managerial support and work demand. Stress and Heath, $77,55-63$.

Bennett, J.A. (2000). Mediator and moderator variables in nursing research: conceptual and statistical differences. Researth in Nursing to Heallh, 23, 415-420.

Bentler, P.M. (1990). Comparative fite indices in structural models. Psychological Bulletin, 107, 238246.

Bentlet, P.M. \& Bonet, D.G. (1980). Significance tests and goodness of fit in the analysis of covariance structures. Psychological Bulletin, 88, 588-606.

Bergers, G.P.J., Marcelissen, E.H.G. \& de Wolff, C.J. (1986). Vragentyst Onganisatiestris-D: Handleiding [VOS-D. Work stress Questionnaire Doetinchem: Manual]. Nijmegen, The Netherlands: University of Nijmegen.

Berkhof, J. (2000). Specification methods for the multilevel moded. PhD thesis. Leiden: DSWO Press, Leiden University.

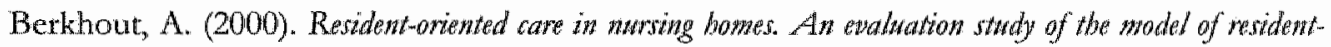
oriemted care, the implementation and the effects. PhD thesis. Maastricht: Datawyse.

Bi, S. \& Salvendy, G. (1994). A proposed methodology for the prediction of mental wotkload, based on engineering system parameters. Wonte and $S$ tres $1,8(4), 355-371$.

Bijleveld, C.C.J.H. \& Van dex Kamp, L.J.T. (1998). Langitudimal data anabisis. Detigns, modts and merbods. Jundon: Sage publications.

Bion, W.R. (1961). Experiences in grosps and ather papers. London: Tavistock Publications.

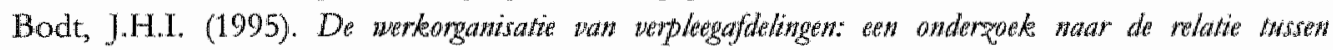
afdelingsomgening en afdelingsstructum (The work organisation of nursing units: An investigation on the relationship between unit environment and unit structure. PhD thesis. Eindhoven, The Netherlands: Technical University Eindhoven, Faculteit Bedtijfskunde.

Bodt, J.H.I. \& Van Tuijl. F.J.M. (1988). A workgroup model for nursing wards. In D. Wallis \& C.J. de Wolff (Eds.), Stress and organzational problems in baspitals. Imptications for management. (pp. 191-221). Cambridge: The University Press. 
Bodt, JH.I. \& Van Tuijl, H.F.J.M. (1985). Het optimaal organiseren van een verpleegafdeling

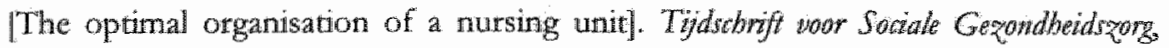
$63(14), 622-626$.

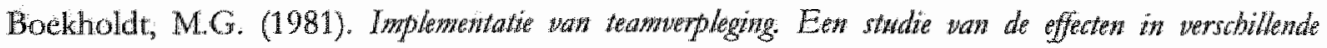
afdelongen wan en ratkenhys [Implementation of team nursing: A study of its effects in several units of a hospital. PhD thesis. Untecht, The Netherlands: University of Utrecht.

Boles, J.S. \&. Babin, B.J. (1996). On the front lines: Stress, conflict, and the customer service provider. Jowmal of Business Researh, 37(1), 41-50.

Bollen, K.A. (1989). Causality and causal models. In K.A. Bollen (Ed.), Strwtworal equation with latent warables (pp. 40-79). New York: John Wiley \& Sons.

Boone, H. \& de Jonge, J. (1996). De relatie tussen verpleegsystemen en werkkenmerken [The relationship between nursing systems and job characteristics]. Verplegkeunde, 11(2), 74.85 .

Botrill, C.S., Wall, T.D., West, M.A., Hardy, G.E., Shapiro, D.A., Haynes, C.E., Stride, C.B., Woods, D. \& Carter, $A_{y}$. (1998). Stress anwong staff in NHS Trwsts. Sheffield and Leeds: Institute of Work Psychology, University of Sheffield and Psychological Therapies Research Centre, University of Leeds.

Bosker, R.). \& Snijders, T.A.B. (1990). Statistische aspecten van multi-niveau onderzoek [Staristical aspects of multi-level research]. Tijdshrift wor Ondenuigreseanch, 15(5), 317 329.

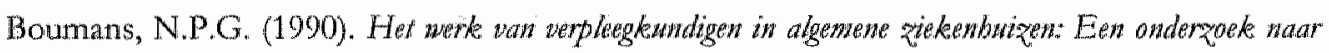
werkaspecten en bun inkloed op verpleegkundigen [The work of nurses in general hospitals: An investigation of work aspects and their influences on nurses]. PhD thesis. Maastricht, The Netherlands: Datawyse.

Boumans, N.P.G. \& Landeweetd, J.A. (1993). Some problems concerning the assessment of job characteristics in nursing work. European worke and organizational pyocholagist, 2(4), 303-317.

Boumans, N.P.G. \& Landeweerd, J.A. (1994). Working in an intensive or non-intensive care unit: Does it make any difference? Hear \& Lung, 23(1), 71-80.

Bourbonnais, R., Comeau, M., Vézina, M. \& Guylaine, D. (1998). Job strain, psychological distress, and butnout in nurses. Amervich Jowrwal of Indostrial Mediwne, 34, 20-28.

Bouter, L.M. \& Van Dongen, M.C.J.M. (2000). Epideniologith onderoek Opzet en interpratate [Epidemiological research. Design and interpretation] (4th ed.). Houten, The Netherlands: Bohn Stafleu Van Loghum.

Bradley, J.R. \& Cartwright, S. (2002). Social support, job stress, health, and job satisfaction among nurses in the United Kingdom. Themational Jowmat of Stress Mamggement, 9(3), $163-182$.

Bray, J.H. \& Maxwell, S.E. (1985), Multivariate analysis of wariance. Beverly Hills, Californie: Sage Publications.

Bridges, W. (1995) Jobstbift. London: Allen and Unwin.

Brown, D., Bartlett, H., Leary, J. \& Carson, J. (1995). The Claybury community psychiatric stress survey. Jounhal of Adranced Nursing, 22, 347-358. 
Brown, RL. (1997). Assessing specific mediational effects in complex theoretical models: Strutural equation wodedim, 4(2), 142-156.

Browne, M.W. \& Cudeck, R. (1993). Alternative ways of assessing model fit. In K.A. Bollen \& J. Scotr-Long (Eds.), Terting shmonal equation models (pp. 136-162). Newbury Park; CA: Sage Publications.

Bryk, A.S. \& Ratudenbush, S.W. (1992). Herandical linem models. Apphations and data analyas methods. Newbury Park, CA: Sage Publications.

Burke, R.J. \& Greenglass, E.R. (1995). A longitudinal examination of the Chemiss model of psychological burnont. Social Siever and Medicine, 40(10), 1357-1363.

Büssing, A. \& Schmitt, S. (1998). Atbertsbelastungen als Bedingungen von Emotionaler Erschöpfung und Depersonalisation im Bumoutprozess Dob demands as requirements of emotional exhaustion and depersonalisation in the burnout process]. Zeitschriff fir Ankeits-und Organisationspsybologie, 42(2), 76-88.

Bunnk, B.P. \& Schaufeli, W.B. (1993). Bumout: a perspective from social comparison theory. In W.B. Schaufeli, C. Maslach \& T. Marek (Eds.), Profersional bumomt: Rocent developments in theory and researh (pp. 53-69). Washington, DC. Taylot \& Francis.

Buunk, B.P., Schaufeli, W.B. \& Ybema, J.F. (1994). Bumout, Uncertainty, and the desire for social comparison among nurses. Joumal of Applied Sowal Pyotology, 24(19), 1701. 1718.

Bytne, B.M. (1998). Structural Equation modelsng with LISREL, PREIIS, and SIMPIIS. Mathwah" Lawrence Erlbaum.

Caldwell, T. \& Weiner, M.F. (1981). Stress and coping in ICU nursing: A review. Ganeral Haspital Psylataty, 3, 119-127.

Campbell, J.P. (1977). On the nature of organizational effectiveness. In J.M. Pennings (Ed.), New perpactives on onganizational effectiveness. San Francisco: Jossey-Bass.

Caplan, R.D., Cobb, S., French, J.R.P., Van Harrison, R. \& Pinneau, S.R. (1975). Job dewands and warker beath: main effects and ocoupational differwas. Washington D.C.: US Government Printing Office.

Carayon $_{*}$ P. \& Smith, M.I. (2000). Work organisation and ergonomics. Applied Eirgonomin, 31, 649-662.

Cascio, W.F. (1995). Whither industrial and organizational psychology in a changing wotld of work? The American Pychologist, 50(11), 928-939.

Cash, D. (1997). Levels of occupational bumout, personality type, and coping processes: $A$ comparison of intensive-care and nonintensive-care registered nurses in primarycare hospital settings. Dissertation Abstrach Intmational: Saction B: The Sanos and Engineering, 57(11B), 7257 .

CBS (Central Bureau voor de Statistiek) (2000). Stathe [Online]. Available: http:/ statline.cbs nl/statweb/cgi-bin.

Child, J. (1977). Organization: A gatide to problems and prawtice. London: Harper \& Row.

Chiriboga, D.A. \& Bailey, J. (1986). Stress and butnout among critical care and medical sutgical nurses: A compatative study. Critica/ Cam Nursing Quarterb, 9(3), 84-92.

Cohen, S. \& Wills, T.A. (1985). Stress, social suport, and the buffering hypothesis. Psyblological Bulletin, 98(2), 310-357. 
Constantini, A., Solano, L., Di Napoli, R. \& Bosco, A. (1997). Relationship between hardiness and risk of burnout in a sample of 92 nurses working in oncology and AIDS watds. Psychotherapy and Psycthosomatics, 66(2), 78-82.

Cook, J.D., Hepworth, S.J., Wall, T.D. \& Warr, P.B. (1981). The experience of wark: A contpendium and reviciw of 249 measures and their use. London: Academic Press.

Cook, T.D. \& Campbell, D.T. (1979). Quast-experimentation: Design and analyses for field settings. Boston: Houghton Mifflin.

Cooper, C.L. (1998). Theories of organizational stress. Oxford: Oxford University Press.

Cotcoran, S.A. (1986). Task complexily and nursing expertise as factors in decision making. Nursing Research, 35(2), 107-112.

Cox, T., Kuk, G. \& Leiter, M.P. (1993). Burnout, health, work stress and organizational healthiness. In W.B. Schaufeli, C. Maslach \& T. Marek (Eds.), Professizonal burmost: Recent developments in Theany and Research (pp. 177-197). Washingtion, DC: Taylor \& Francis.

Cronin-Stubbs, D. \& Brophy, E (1985). Burnout: can social support save the psychiatric nurse? Journal of Psychasocial Nursing and Mental Health Semices, 23(7), 8-13.

Cronin-Stubbs, D. \& Rooks, C.A. (1985). The stress, social support and burnout of eritical care nurses: The results of research. Heant Lung, 14,31-39.

Cross, D.G. \& Fallon, A. (1985). A stressor comparison of four speciality areas. Australian Journal of Advanced Nistring, 2(3), 24-38.

Crozier, M. (1964). The bureaurratic phenomenon [Eng. translation]. Chicago: University of Chicago Press.

Cummings, L.L. \& Berger, C.J. (1976). Organizational structure: How does it influence attitudes and performance? Organizational Dymamics, 5(2), 34-49.

Cummings, T.G. \& Worley, C.G. (1997). Onganizational detelopment and cbange. Cincinnat, Ohio: South-Western College Publishing.

Cumstock, D.E. (1975). Technology and context: A study of hospital patient care anits. $\mathrm{PhD}$ thesis. Ann Arbor, Michigan, USA: University Microfilms International.

Cushway, D., Tyler, P. \& Nolan, P. (1996). Development of a stress scale for mental health professionals. British fournal of Clintical Psychology, 35, 279-295.

Dallender, J., Nolan, P., Soares, J., Thomsen, S. \& Aenetz, B. (1999). A comparative study of the perceptions of British mental health nurses and psychiatrists of their work environment. Jow wal of Adwawcel Nursing, 29(1), 36-43.

Daniels, K. \& de Jonge, J. (2001). Lomgizudinal designs in wark stress reseanch and the question of validity. Paper presented at the Tenth European Congress on Work and Organizational Psychology, Prague, Czech Republic.

Dawkins, J.E., Depp, F. \& Selzer, N. (1985). Stress and the psychiatric nurse. Journal of Psydosocial Nursing, 23(11), 9-15.

De Jonge, J. (1995). Joh antonowy, well-being and bealth: A stwdy among dwtib health care workers. $\mathrm{PhD}$ thesis. Maastricht, The Netherlands: Datawyse.

De Jonge, J., Dollard, M.F., Dormann, C., le Blanc, P.L. \& Houtman, I.L.D. (2000). The demand-control model: specific demand, specific control, and well-defined groups. Intermational Journal of Stress Monagement, 7(4), 269-287. 
De Jonge, J., Dormann, C., Janssen, P.P.M., Dollard, M.F., Landeweend, J.A. de Nijhuis, FJ.N. (2001). Testing reciprocal relationships between job characteristics and psychological well being: A cross-lagged structural equation model fowmal of Occupational and Onganizational Psybology, 74, 2946.

De Jonge, J., Janssen, P.P.M. \& Van Breukelen, G.J.P. (1996). Testing the Denand-ControlSupport Model among health-care professionals: A structural equation model. Wron and Stress, $10(3), 209-224$

De Jonge, J. \& Kompier, M.A.J. (1997). A critical examination of the Demand-Control-Support model from a work psychological perspective. Intarnational fowmal of Smes Mangenten, 4(4), 235-258.

De Jonge, I. \& Landeweerd, I.A. (1993). Toetsing van de Job-Demand Control benadering bij werknemers in de gezondheidszorg: een secundaire data-analyse [Testing of the Job Demand-Control approach among health care workers: a secondary analysis|. Gedrag. on Organisatip, 6, 79-92.

De Jonge, J., Landeweerd, J.A. \& Nijhuis, F.J.N. (1995). Constrwtie en walidering wan de wragentign ten behowe wan bet project "awtowomis in bet werk" [Construction and validation of the questionnaire for the "job autonomy project"1. Maastricht: University of Limburg: Bedtrifsgezondheidszorgstudies 9 (tweede, gewijzigde druk).

De Jonge, J, van Breukelen, G.J.P., Landeweerd, J.A. \& Niplanis, F.J.N. (1999). Comparing group and individual level assessments of job characteristics in testing the job demand-control model: A multilevel apptoach. Hinzan Relations, 52(1), 95-122.

De Lange, A., Kompier, M.A.J, de Jonge, J., Taris, T.W. \& Houman, I.L.D. (2001). Hoogwaardig longitudinall vragenlijstonderzoek en het Demand-Control-(Support) model. [High quality longitudinal research and the Demand-Control-(Support) modell. Gedrag an Organisatie, 14(5), 254272.

De Sitter, L.U., Den Hertog, J.F. \& Dankbaar, B. (1997). From complex organizations with simple jobs to simple organizations with complex jobs. Human Relations, $50(5), 497$ 534.

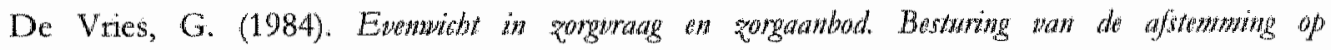
werpleegafdelingen [Balance between demand and supply. Managing nursing units. Eindhoven, The Netherlands: Technical University Eindhoven.

De Vries, G. (1993). Patientewlogwistiek im ontwikkeling [Patient logistics in development. Utrecht, The Netherlands: De Tijdstroom.

De Vries, G. \& Gtiever, A.H.G. (1991). Werkdruk en organisatie van de zorg [Workload and organisation of care]. In L. Boon (Ed.), Ontwikkelingen in de gezondheidsororg (PD. 29. 38). Amstelveen, The Netherlands: Srichting Sympoz.

Dewe, P.J. (1988). Investigating the frequency of nursing stressors: A comparison across wards. Sorial Science and Medicine, 26(3), 375-380.

Dirken, J.]. (1969). Werk en stress [Work and stress]. Groningen, The Netherlands: Wolters Noondhof.

Dollard, M.L., Winefeld, H.R., Winefield, A.H. \& de Jonge, J. (2000). Psychosoctal job strain and productivity in human service workers: A rest of the demand-control-support model. Journal of Ocoupational and Organizational Psydrology, 73, 501-510. 
Donaldson, L. (2001a). Core paradigm and theotetical integration. In L. Donaldson (Ed), The contingency theory of anganizations (pp. 1-33). Thousand Oaks, CA: Sage Publications.

Donaldson, L. (2001b). Fit affects performance. In L. Donaldson (Ed), The contingengy theory of organizutions (pp, 215-243). Thousand Oaks, CA: Sage Publications.

Donaldson, L. (2001c). Fit concept and analysis. In L. Donaldson (Ed), The contingeray theory of organizations (pp. 181-213). Thousand Oaks, CA: Sage Publications, Inc.

Donaldson, L. (2001 d). Neo-contingency theory. In L. Donaldson (Ed.), The contingency theory of organizations (pp. 245-271). Thousand Oaks, CA: Sage Publications Inc.

Draft, R.L. (1992). Organization theory and design. St.Paul, MN: West Publishing Company.

Drazin, R. \& Van de Ven, A.H. (1985). Alternative forms of fit in contingency theory. Adininnstrative Science Quarterly, 30(4), 514-539.

Driessen, R. (1980). Hartbewaking: Problemen zan verpleggkendigen op centratic betwakingsposten [Corony Care: Problems of nurses on central monitoring stations]. Eindhoven, The Netherlands: Technische Hogeschool Eindhoven, afdeling Bedrijfskunde.

Duncan, R.B. (1972). Characteristics of organizational environments and perceived environmental uncertainty. Administrative Science Quarterby, 17(9), 313-327.

Duquette, A, Ketouac, S., Sandhu, B.K. \& Beaudet, L. (1994). Factors relating to nursing burnout: A review of empirical knowledge. Isswes in Mental Health Nursing, 15(4), 337358.

Duquette, A., Kerouac, S., Sandhu, B.K. \& Ducharme, F. (1995). Psychosocial determinants of burnout in geriatric nursing. International Journal of Nursing Sizdies, 32(5), 443-456.

Dwyer, J.E. (1983). Statistical models for the social and bebanioral sciences. New York: Oxford University Press.

Eisenstat, R.A. \& Felner, R.D. (1984). Toward a differentiated view of burnout: Personal and organizational mediators of job satisfaction and stress. American Journal of Communify Psychology, 12(4), 411-430.

Elovainio, M., Kivimaeki, M., Steen, N. \& Kalliomaeki Levanto, T. (2000). Organizational and individual factors affecting mental health and job satisfaction: $A$ multilevel analysis of job control and personality. Journal of Occupational Healtb Pyychology, 5(2), $269-277$.

Emory, FE. \& Trist, E.L. (1965). The causal texture of organizational environments. Human Relations, $18(1), 21-32$

Estryt-Behar, M., Kaminski, M., Peigne, E., Bonnet, N., Vaichere, E., Gozlan, C., Azoulay, S. \& Giorgi, M. (1990). Stress at work and mental health status among female hospital workers. British Jommal of Indastrical Medicine, (47), 20-28.

Ferguson, G.A. (1976). Statistical analysis in psycbology odwcation. Tokyo: McGraw-Hill Kogakusha, Ltd.

Finkel, S.E. (1995). Causal anabsis with panel data. Thousand Oaks: Sage Publications.

Ford, J. \& Slocum, J. (1977). Size, technology, environment, and the structure of organizations. The Acadeny of Mandagement Resien, 2, 561-575.

Fornés Vives, J., Gallego Caminero, G., Barceló Oliver, M., Crespi Capó, M. \& Gutierrez Casado, A. (1994). Causal and emotional factors related to work stress in ICU nursing staff. The importance of accurate measurement. Intensive and Critical Care Nuriting, 10, 41-50. 


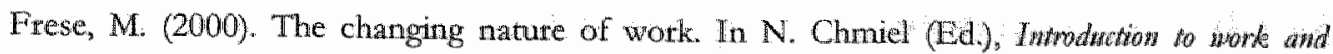
aryanizational pyodology (Pp. 424 439). Oxford: Blackwell Publishers.

Frese, M. \& Zapf, D. (1988). Methodological issues in the study of work stress: Objective vs subjective measurement of work stress and the question of longitudinal studies. In

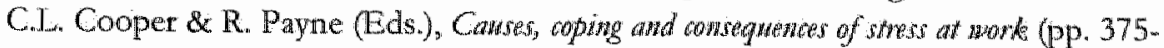
411). Chichester: Wiley \& Sons.

Fried, Y. \& Ferris, G.R. (1987). The validiry of the job characteristics model: A review and a meta-analysis. Persomel Psychology, 40(2), $287-322$.

Fry, LiW. (1982). Technology-stnucture research: Three critical issues, Aladeny of Matorgenvent Jownat, 25(3), 532-552.

Fry, L.W. \& Slocum, J.W. (1984). Technology, structure, and workgroup effectiveness: A test of a contingency model. Academy of Mandemen Jowmal, 27(2), 221-246.

Galbraich, J. (1973) Designing complex onganizations. Massachusetts: Addison-Wesley Publishing Company, Reading,

Galbuith, J. (1977). Organiontiowal design. Addison-Wesley: Reading, MA.

Gardell, B. (1982). Worker participation and autonomy: a multilevel approach to denocracy at the workplace. Intermational Jownal of Health Semices, 12(4), 527 558 m

Gärling, T., Biel, A. \& Gustafsson, M. (1998). Different kinds and roles of enwitonmental uncertainty. Joumal of Entimmenfal Psyobology, 18,75-83.

Gentry, W.D. \& Parkes, K.R. (1982). Psychological stress in intensive care unit and non intensive care unit nursing: A review of the past decade. Hearf of Lang, 17, 43-47.

Goldstein, H. (1995). Multilevel statistical madels. London: Arnold.

Greenglass, E.R., Buske, R.J. \& Riksenbaum, L. (2001). Workload and burnout in nurses. Jownal of Cammanity and Applied Sacial Pyothology, 11(3), 211-215.

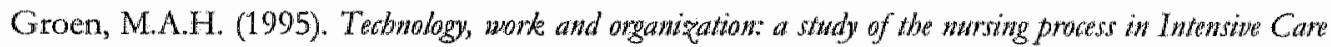
Units. PhD Thesis. Maastricht, The Netherlands: Maastricht Universitaire Press.

Grünveld, J.E. (1992). Wetklase en dienstroosters [Workload and duty rosters]. In J.K. Van Dijk, J.E. Grünveld \& J. Pool (Eds.), Persontedmanagement in de gerondheidsqong: theorie en praktije (pp. 128-149). Houten, The Netherlands: Bohn Stafleu Van Loghum.

Gutek, B.A. (1990). Work group structure and information technology: A structutal contingency approach. In J. Galegher, R.E. Kraut \& C. Egido (Eds.), Jwtellectsal

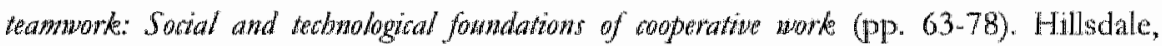
New Jersey: Lawrence Enbaum Associates.

Hackman, J.R. \& Lawler, E.E.I. (1971). Employee reactions to job characteristics. Jowrial of applied psychology Monograph, 55(3), 259-286.

Hackman, J.R. \& Oldham, G.R. (1975). Development of the job diagnostic survey, fownal of Applied Pyolology, 2, 159-170.

Hackman, J.R. \& Oldham, G.R. (1976). Motration through the design of work: Test of a theory. Organizational Bebawior and Haman Performance, 16(2), 250-279.

Hackman, J.R. \& Oldhan, G.R. (1980). Worte rederign. MA: Addison Wesiley, Reading.

Hagberg, M., Silverstein, B., Wells, R, Smith, M.J., Hendrick, H.W., Carayon, P. \& Petusse, M. (1995). Wrork-related musculosketetal disorders (WMSDs): 4 neference book for prevention. London: Taylor \& Francis. 
Hage, J. \& Aiken, M. (1967). Program change and organizational properties. American Jourthat of Sociology, 72, 503-518.

Hannan, M.T. \& Freeman, J.H. (1977). The population ecology of organizations. Amserican Journal of Sociology, 82, 929-964.

Harris, P.L. (1984). Assessing burnout: The organizational and individual perspective. Faxnily and Community Health, $6(4), 32-43$.

Harris, R.B. (1989). Reviewing nursing stress according to a proposed coping-adaption framework. Adnances in Nursing Science, 11(2), 12-28.

Hayduk, L.A. (1987). Structaral equation modeling with LISREL. Essentials and Advances. Baltimore: John Hopkins Uniwersity Press.

Heck, R.H. \& Thomas, S.L. (2000). An introduction to multilevel modeling tecbniques. Mahwah, New Jersey: Lawrence Erlbaum Associates.

Heeremans, J.G.M., Boumans, N.P.G., Algera, M. \& Landeweerd, J.A. (1994). Integrerende verpleggkende in de pratktrjk: resultaten wan een experiment in een algemeen ziekentwis [Integrated nursing in practice: Results of an experiment in a general hospital]. Maastricht, The Netherlands: University of Limburg.

Heim, E. (1991). Job stressors and coping in health professions. Psychotherapy and Pyychosonatics, $55,90-99$.

Hobfoll, S.E. \& Freedy, J. (1993). Conservation of resources: $\Lambda$ generall stress theory applied to burnout. In W.B. Schaufeli, C. Maslach \& T. Marek (Eds.), Professional burtwout: Recent developments in theory and researth (pp. 115-131). Washington, DC: Taylor \& Francis.

Hockey, G.R.J. (2000). Work environments and performance. In N. Chmiel (Ed.), Introduction to work and organizational psychology: A Exropean perspecizive (pp. 206-230.). Oxford: Blackwell Publishers.

Hollenbeck, J.R. (2000). A structural approach to external and internal person-team fit. Applied Psychology: An International Revien, 49(3), 534-549.

Holmbeck, G.N. (1997). Toward terminological, conceptual, and statistical clarity in the study of mediators and moderators: Examples from the child-clinical and pediatric psychology literatures. Journal of Consulting and Clinical Psychology, 65(4), 599-610.

Houkes, 1. (2002). Work and individual determinants of intrinsie work motivation, emotional exhawstion and inrrover intention. A strdy anong bank employees and teachers. $\mathrm{PhD}$ thesis. Maastricht, The Netherlands: Datawyse.

Houkes, I., Janssen, P.P.M., de Jonge, J. \& Nijhuis, F.J.N. (2001a). Specific relationships between work characteristics and intrinsic work motivation, burnout and turnover intention: A multi-sample analysis. European Josmal of Worke and Organizational Psychology, 10(1), 1-23.

Houkes, I., Janssen, P.P.M., de Jonge, J. \& Nijhuis, F.J.N. (2001. b). Work and individual determinants of intrinsic work motivation, emotional exhaustion, and turnover intention: A multi-sample analysis. International Journal of Stress Management, 8(4), 257283.

Houtman, I.L.D., Schaufeli, W.B. \& Taris, T.W. (2000). Psychische permoeddheid en werk: Cijfers, trends en analyser [Mental fatigue and work: Figures, trends and analyses]. Alphen aan den Rijn, The Netherlands: Samsom. 
Howard, A. (1995), The hanging Matwe of work San Fransisco: Jossey-Bass.

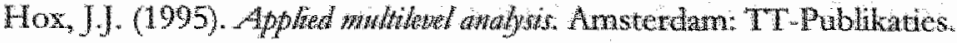

Hoyle; R.H. \& Smith, G.T. (1994). Fomulang clnical research hypotheses as strmctrin

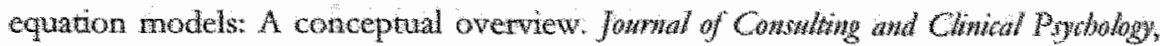
$62(3), 429440$.

Huigmans, H. (2002). (Re)organiseren. Hoe je nieuwe wijn in niewwe zakken krigt [Rejorganising. How to get new wine in new botdes]. Zonglisie, 3, 28-31.

Iskra Golec, I. Folkard, S., Marek, T. \& Noworol, C. (1996). Health, well-being and burnout of ICU nurses on 12- and 8-h shifts. Wonk and Stmis, 10(3), 251-256.

Jaccard, J., Turrissi, R. \& Wan, C.K. (1990). Interation ofects in Malkiple Regrewon. Newbury Park, CA: Sage.

Jackson, S.E. \& Schuler, R.S. (1985). A meta-analysis and conceptal critigue of research on

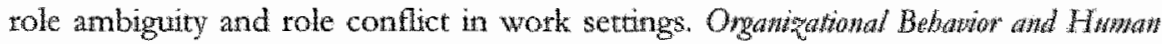
Decistom Processer, 36, 16-78.

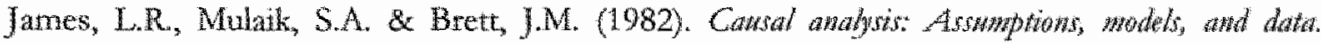
Beverly Hills, Californa: Sage Publications.

James, R.). \& Jones, A.P. (1976). Organizational structure: A review of structural dimensions and their conceptual relationships with individual attirudes and behavior. Organizational Belawtor and Human Penformatce, 16, 74-113.

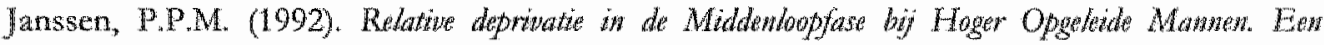
wergelijleing tusk drie leefydsgropen [Relative deprivation in Medcareer among Highly Educated Men. A comparison between thee Age Groups]. PhD thesis. Nimmegen, The Netherlands: University of Nijmegen.

Janssen, P.P.M., de Jonge, J. \& Bakker, A.B. (1999a). Specific determinants of intrinsic wotk motivation, butnout and turnover intention: A study among nurses. Jound of Adwated Narging, 29(6), 1360-1390.

Janssen, P.P.M., Schaufeli, W.B. \& Houkes, I. (1999b). Wotk-related and individual deteminants of three burnout dimensions. Work and Stwo, 131), 74-86.

Janssen, P.P.M. \& Houkes, I. (2000). Specifieke verbanden tussen wetkkenmerken en stressgevolgen: theorie en empiric [Specific relationships berween work characteristics and stress outcomes; theory and empirical studies]. In M. Schabracq, H. Maassen van den Brink, W. Groot, P.P.M. Janssen \& I. Houkes (Eds.), De prijs van stress (pp. 63-74). 's Gravenhage, The Netherlands: Elsevier Bedrijfsinformatie.

Jayatatne, S. \& Chess, W.A. (1984). Job satisfaction, burnout and turnover: A national study. Social Work, 24, 448-453.

Jehn, K.A. \& Chatman, J.A. (2000). The influence of proportional and perceptual conflict composition on team performance. Intermational Jourhal of Conflict Mantagement, $11(1)$, 56-73.

Jex, S.M. \& Bliese, P.D. (1999). Efficacy beliefs as a moderator of the impact of work-1elaticd stressors: A mulcilevel study. Joumal of Applied Psychologn, 84(3), 349-361.

Johnson, J.V. \& Hall, E.M. (1988). Job strain, work place social support, and cardiovascular disease: a cross-sectional study of a random sample of the Swedish working population. Antrican Jownual of Pwblic Health, 78, 1336-1342. 
Jones, J.G. (1987). Stress in psychiatric nursing. In R. Payne \& J. Firth-Cozens (Eds.), Shoss in hendh pirofersionals (pp. 189-210). Chichester: John Wiley \& Sons.

Jones, J.G., Janman, K., Payne, R.L. \& Rick, J.T. (1987). Some deteminants of stress in psychiattic nurses. Intematiowal Joumal of Norsing Studies, 24(2), 129-144.

Jöreskog, K.G. \& Soblbom, D. (1993). LJSREL 8: Strutural Equation Modeling with the Swaph comynawd Langwage. Chicago: Scientific Software International.

Jöreskog, KG. \& Sorbom, D. (1996). IJSREL 8: User's Reference Guäde. Chicago: Scientific Sottware International.

Kahn, R.ll (1981). Worke and Healts. New York: John Wiley \& Sons.

Kahn, R.L., Wolfe, D.M., Quinn, R.P., Snoek, J.D. \& Rosenthal, R.A. (1964). Orgaruzational Strest: Studies in Role Conflict and Ambigurty. New York: Wiley.

Karasek, R.A. (1979). Job demands, job decision latitude, and mental strain: implications for job redesigni Adwinistratise Sience Quanterly, 24, 285-308.

Karasek, R.A., Baker, D., Marxer, F., Ahbom, A. \& Theorell, T. (1981). Job decision larinude, job demands, and cardiovascular disease: A prospective study of Swedish men. Annerican Jownat of Public Health, 71, 694-705.

Karasek, R.A.J. \& Theonell, T. (1990). Healtby work: stres, prodwctinty and the reconstruction of working Bfe. New York: Basic Books.

Kasl, S.V. (1987). Methodologies in stress and health: Past, difficulties, present dilemmas, future directions. In S.V. Kasl \& C.I.. Cooper (Eds.), Stress and healh: issues in researd whothodology (pp. 307-318). Chichester: Wiley \& Sons.

Katz, R. (1978a). Job longevity as a situational factor in job satisfaction. Admimistratize Saresuce Quartery, 23, 204-223.

Katz, R. (1978b). The influence of job longevity on employee reactions to task characteristics. Huwan Relation, 31, 703-725.

Keane, A., Ducette, J. \& Adler, D.C. (1985). Stress in ICU and nonmICU nurses, Nwrimg Researd, 34(4), 231-236.

Keijsers, G.J., Schaufeli, W.B., Le Blanc, P.M., Zwerts, C. \& Reis Miranda, D. (1995). Performance and burnout in intensive care units. Work and Stress, 9(4), 513-527.

Kelly, J. \& Cross, D. (1985). Stress, coping behavior and recommendations for intensive care and medical surgical ward registered nurses. Researth in Nursing of Healws, 8, 321-328.

Kenny, D.A. (1975), Cross-lagged panel correlation: A test for spuriousness. Pyybological Bulletin, $82(6), 887-903$

Kessler, R.C. \& Greenberg, D.F. (1981). Linear Panal Awalynis. New York: Academic Press.

Kirkcaldy, B.D. \& Martin, T. (2000). Job stress and satisfaction among nurses: Individual ditferences. Sirts Medicin, 16(2), 77-89.

Kleinbaum, D.G., Kupper, L.L. \& Morgenstern, H. (1982). Epidemiologic Reseands Principles awd Qmawhow Mewodr. New York: Van Nostrand Reinhold.

Kleiner, B.H. (1983). The intertelationship of Jungian modes of mental functioning with organizational factors: Implications for management development. Human Relations, $36(11), 997-1012$

Knight, I.C.I. \& Salvendy, G. (1981). Effects of task feedback and stringency of external pacing. on mental load and work performance. Ergonomicr, 24, 757-764. 
Kompier, M.A.I. (2002). The psychosocial work envitonment and health - what do we know

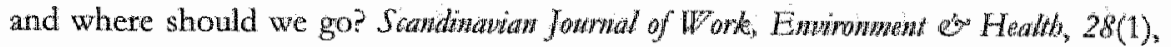
1-4.

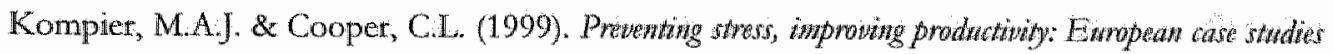
in the anortephat London and New York: Routledge.

Koniarek, J. \& Dudek, B. (1996). Social support as a buffer in the stress-burnout telationship. Interwational fownal of Sinss Managenen, 3(2),99-106.

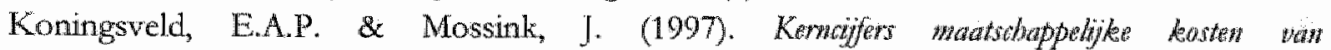
arbeidownstandigheden [Core figures on societal costs of working conditions]. Den Haag, The Netherlands: VUGA.

Koslowsky, M. (1998). Modelling the stress-strain relationship in wark setings. London: Routledge.

Kraft, K.L., Puia, G.M. \& Hage, J. (1995). Structural contingency theory revisited: main effects versus interactions in Child"s mational study of manufacturing and service sectors. Canadian Jownal of Adminstrative Sciences, 12(3), 182-194.

Kuipers, H. \& Van Eijnatten, IF.M. (1996). Modetne sociotechnick: een stand van zaken [Modern sociotechnique, a state of the art]. In FM. Van Eilinatten (Ed), Saciotedniscb ontwerpen (pp. 32-57). Utrecht, The Nethedlands: Lemma BV.

Ladewig, B.H. \& White, P.N. (1984). Dual earner marriages" "The family social envimonment and dyadic adjustment Jowmal of Fownily Isswes, 5, 343-362.

Landeweerd, J.A. \& Boumans, N.P.G. (1988). Nurses" wotk satisfaction and feelings of health and stress in three psychiatric departments. International Jotrind of Noming studien, $25(3), 225-234$.

Landeweerd, J.A. \& Boumans, N.P.G. (1994). The effect of work dimensions and need for autonomy on murses" wotk satisfaction and health. Joumat of Ocumpational and Onganizational Psychology, 67(3), 207-217.

I. andeweerd, J.A., Boumans, N.P.G. \& Nissen, J.M.J.F. (1996). De Matatrichts arbeidsatisfacieschad woor de gerondbeidszorg* MAS-GZ TThe Maastricht job satifaction scale for the health care sector: MAS-GZ]. Maastricht, The Netherlands: Bedrijfsgezondheidszorg studies 11, University of Mastricht.

Landsbergis, P.A. (1988). Occupational stress among health care workers: $\mathrm{A}$ test of the jobdemand-control model. Joumal of Organizational Behawior., 9, 217-239.

Laubach, W., Milch, W. \& Emst, R. (1999). Dimensionen der Arbeitsbelastung und Arbeitszufiedenheit in der psychiatrisch-psychotherapeutischen Pflege [Dimensions of work load and job satisfaction in psychiatric nursing]. Psydotherapio Psybosomatik Medirinische Psychologie, 49(2), 3847.

Lawler, E.E.I. (1969). Job design and employee motivation. Porsonne/ Psybology, 22, 426-435.

Lawler, E.E.I. \& Hall, D.T. (1970), Relacionship of job chatacteristics to job involvement, satisfaction, and intrinsic motivation. Jowrwal of Apphed Psyobology, 54(4), 305-312.

Lawrence, P. \& Lorsch, J. (1967a). Differentiation and integration in complex organizations. Adnimistratue Screxte Qtuatarly, 12(0), 1-47.

Lawrence, P.R. \& Lorsch, J.W. (1967b). Organization and envimonum. Managing differntiation and integration. Boston: Diwision of Research Graduate School of Busines: Administration, Harvard University. 
Lee, R.T. \& Ashforth, B.E. (1991). Work-unit structure and processes and job-related stressors as predictors of managerial burnout. Joumal of Applied Social Psychology, 21(22), 1831 1847.

Lee, R.T. \& Ashforth, B.E. (1993). A longitudinal study of burnout among supervisors and managers: Comparison between the Leiter and Maslach (1988) and Golembiewski et al. (1986) models. Organization Bebavior and Human Decision Processes, 54, 123-133.

Lee, R.T. \& Ashforth, B.E. (1996). A meta-analytic examination of the correlates of the three dimensions of job burnout. Journal of Applied Psycholog, 81(2), 123-133.

Lenderink, A. (1998). Arbo index 1999 [Index of working conditions 1999]: "s Gravenhage, The Netherlands: SDU.

Lewandowski, L.A. \& Kramer, A.M. (1980). Rolle transformations of special care unit nurses. Nursing Research, 29(3), 170-179.

Lodah丩, T.M. \& Kejner, M. (1965). The definition and measurement of job involvement. Joumal of applied psychology, 49(1), 24-33.

Longford, N.T. (1993). Randont coefficient models. Oxford: Clarendon Press,

Lourijsen, E., Houtman, I., Kompier, M. \& Gründemann, R. (1999). The Netherlands: A hospital, 'healthy working for health'. In M. Kompier \& C. Cooper (Eds.), Preventing stress, improwing productivity. Exropeam case studies in the tworkplace (pp. 86-120). London and New York: Routledge.

Lysonskt, S. (1985). A boundary theory investigation of the product manager's role. Joumd of Marketing, 49(12), 26-40.

Maassen, G.H. \& Bakker, A. (2000). Suppressor variabelen in padmodellen: Definities en interpretaties [Suppressor variables in path models: Definitions and interpretations]. Kwantitatieve Methoden, 21, 43-69.

MacCallum, R.C., Roznowski, M., Mar, C.M. \& Reith, J.V. (1994). Alternative strategies for cross-validation of covariance structure models. Multivariate Behavional Research, 29(1), $1-32$.

MacCallum, R.C., Wegener, D.T., Uchino, B.N. \& Fabrigar, L.R. (1993). The problem of equivalent models in applications of covariance structure analysis. Psychological Bulletn, 114(1), 185-199.

Maloney, J.P. (1982). Job stress and its consequences on a group of intensive care and nonintensive care nurses. Adwances in Nursing Sciences, 1, 31-42.

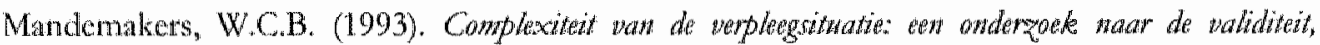

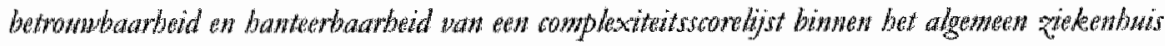
[Complexity of the nursing situation: An investigation on the validity, reliability, and manageableness of a complexity scale in a general hospital]. Master thesis. Maastricht, the Netherlands: Rijksuniversiteit Limburg.

Marshall, J. (1980). Stress amongst nurses. In C.L. Cooper \& J. Marshall (Eds.), White collar and professional stress. Chichester: Wiley.

Maslach, C. (1993). Burnout: A multidimensional theory of bumout. In W.B. Schaufeli, C. Maslach \& T. Marek (Eds.), Professional bximont: Recent dewelopments in Theory and Researcb (pp, 19-32). Washington, DC: Francis \& Taylor. 
Maslach, C. (1998), A multidimensional theory of burnout. In C.L. Cooper (Ed.), Theones of Organizational Stress. (pp. 68-85.). Oxford: Oxford University Press.

Maslach, C. \& Jackson, S.E. (1982). The bumout syndrome in the health professionals. In $G$. Sanders \& J. Suls (Eds.), Sorial Psychology of Health and IInes (pp. 126-156). Hillsdale, New Jersey: Lawrence Extlsaum.

Maslach, C. \& Jackson, S.E. (1986). MBI: Maskach Bumbout Inwentoy; mantual rerearth edtition. Palo

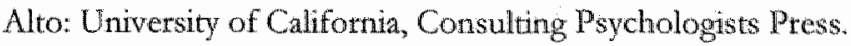

McGrath, J.E. \& Beehr, T.A. (1990). Time and the stress process: some temporal issues in the conceptualizarion and measurement of stress. Stress Medtaine, 6, 95-104.

McLeod, T. (1997). Work stress among community psychiatric nurses. Brittih Jourmal of Nursing, $6(10), 569-574$.

Medcof, J.W. \& Wegener, J.G. (1992). Work technology and the needs for achievement and nurturance among nurses. Journal of Orgamizational Behavior, 13, 413-423.

Meertens, R.W. \& Van Grumbkow, J. (1992). Sociate psychologie [Social psychology]. Groningen: Wolters Noordhoff.

Meijman, T.F. \& Van Ouwerkerk, R. (1999). Zien anderen ook wat wij wan ons werk vinden? The relations between selfreports by incumbents on psychosocial characteristics of their job with assessments of these characteristics by independent observers]. Gedrag en Organisatie, 12(6), 384-396.

Melchior, M.E.W., Bours, G.J.].W., Schmitz, P. \& Wittich, Y. (1997a). Burnout in psychiatric nursing: a meta-analysis of telated variables. Joumnal of Psychiatric and Mental Heallb Nursing, 4, 193-201.

Melchior, M.E.W., Van den Berg, A.A., Halfens, R., Hoyer Abu-Saad, H., Philipsen, H. \& Gassman, P. (1997b). Bumout and the work environment of nurses in psychiatric

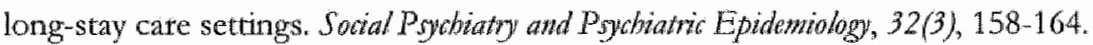

Menard, S. (1991). Longitudinal research. Beverly Hills, CA: Sage.

Miller, D. \& Friesen, P.H. (1984). The case for configuration. In D. Miller \& P.H. Friesen (Eds.), Organizations. A quantwm wein. (pp. 10-30). Englewood Cliffs, New Jersey: Ptentice-Hall, Inc.

Miller, S.M. (1979). Controllability and human stress: Method, evidence, and theory. Bebaworal Research and Therapy, 17, 287-304.

Mintzberg, H. (1983). Strwtwre in fives: designing effective onganizations. Englewood Cliffs, New York: Prentice-Hall.

Mohl, P.C., Denny, N.R., Mote, T.A. \& Coldwater, C. (1982). Hospical unit stressors that affect nurses: Primary task vs social factors. Psychosomatics, 23(4), 366-374.

Morgan, G. (1992). Beelden pan organisatios [Images of organizations]. Schiedam, The Netherlands: Scriptum Books.

Mowardi, B.H. (1983). Aspects of the impaired physician. In B. Farber (Ed.), Stress and burwout in the Human Serwite Professions. New York: Pergamon Press.

Nationale Raad voor de Volksgezondheid (1988). Vempleeglemndig Beroepsprofuel. Zoetermeer, The Netherlands: NRV. 
Neubauer, P.J. (1992). The impact of stress, hardiness, home and work environment on job satisfaction, illness, and absenteeism in critical care nurses. Medical Psycbotherapy: An International Joumal, 5, 109-122.

Nichols; K.A., Springford, V. \& Searle, J. (1981). An investigation of distress and discontent in various types of nursing. Journal of Advanced Nursing, 6, 311-318.

Numerof, R.E. \& Abrams, M.N. (1984). Sources of stress among nurses: An empirical investigation. Journal of Human Stress, 10(2), 88-100.

Nunnally, J.C. (1978). Psychometric theory (2nd ed.). New York: McGraw-Hill.

Oates, P.R. \& Oates, R.K. (1996). Stress and work relations in the neonatal intensive care unit: are they worse than in the wards? Jowrval of Paediatrics and Child Care, 32(1), 57-59.

Oldham, G.R. \& Hackman, J.R. (1981). Relationships between organizational structure and employee reactions: Comparing alternative frameworks. Administrative Sicience Qtarterly, 26, 66-83.

Paoli, P. (1997). Working conditions in Europe. The second European survey on norking conditions. Dublin: European Foundation for the Improvement of Living and Working Conditions.

Parsons, 'T. (1961). Suggestions for a sociological approach to the theory of organizations. In A. Etzioni (Ed.), Complex organiqations: A sociological reader (pp. 32-47). New York: Holt, Rinehart and Winston.

Payne, R. \& Firth-Cozens, J. (1987). Stress in bealth professionals. Chichester: Wiley.

Payne, R.L., Wall., T.D., Borrill, C. \& Carter, A. (1999). Strain as a moderator of the relationship between work characteristics and work attitudes. Joumal of Occoppational Health Psychology, 4, 3-14.

Pennings, J.M. (1998), Structural contingency theory. In P.J.D. Drenth, H. Thierry \& C.J. de Wolff (Eds.), Handbow of work and organizational psychology (2nd Edn, Vol. 4, p. 3960). Hove, England: Psychology Press/Erlbaum.

Perrow, C. (1967). A framework for the comparative analysis of organizations. Amzerican Sociological Revieny, 32, 194-208.

Perrow, C. (1970). Onganizational analysis: A soctological niew. Belmont, CA: Wadsworth.

Perrow, C. (1986). Complex organizations. A critical essoy. Dalllas, Texas: Scott, Foresman \& Cy.

Pfeffer, J. \& Salancik, G.R. (1978). The exteryal control of organizations. A resource depesdence perspective. New Yorke Harper and Row.

Piedmont, R.L. (1993). A longitudinal analysis of burnout in the health care setting: The role of personal dispositions. Journal of Personality Asxessment, 61(3), 457-473.

Pines, A. \& Kafry, D. (1978). Occupational tedium in the social sciences. Sacial Work, 23, 499507.

Pines, A. \& Kanner, A.D. (1982). Nurses" burnout: Lack of positive conditions and presence of negative conditions as two independent sources of stress. Joumal of Pychosocial Nursing and Mental Health Services, 20, 30-35.

Pines, A. \& Maslach, C. (1978). Characteristics of staff burnout in mental health settings. Happital and Community Psychiarin, 29(4), 233-237.

Porter, L.W. \& Lawler, E.E.I. (1965). Properties of organization structure in relation to job attitudes and job belavior. Psychological Bulletin, 64(1), 23-51. 


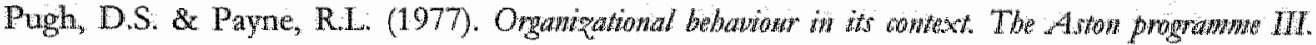
Westmead: Saxon House.

Rasbash, J., Browne, W., Goldstein, H., Yang; M., Plewis, I., Healy, M., Woodhouse, G., Draper, D., Langford, I. \& Lewis, T. (2000). A wor's gude to MLwN (2nd edition). London: Centre for multilevel modelling, Institute of Education, University of London.

Reeves, J. (1994). A comparison of the effects of stress in psychiatric and medical nurses. International Jowmal of Psychiatio Nurstug Reseant, $1(1), 21-29$.

Reis Miranda, D., Ryan, D.W., Schaufeli, W.B. \& Fidler, V. (1998). Onganiantion and Management of Intemive Care: 4 prospective sudy in 12 European Conntries. Berlin: Springer Verlag.

Roe, R.A. (1984). Individual characteristics, In P.J.D. Drenth, H. Thierry, P. J. Willems \& C.J. de Wolff (Eds.), Handbook of Work and Organisational Psyohology (Vol. 1, pp. 103-130). Chichester: Wiley\& Sons.

Rogosa, D. (1980). A critique of cross-lagged correlation. Psyolologial Bw/ltin, 88(2), $245-258$.

Rogosa, D. (1987). Causal models do not support scientific conclusions: A comment in support of Freedman. Journal of Educational Statistios, 12(2), 185-195.

Rosenthal, S.L., Schmid, K.D. \& Black, M.M. (1989). Stress and coping in a N1CU. Reram in Nacrsing and Health, 12(4), $257-265$.

Rundall, T.G. \& Hetherington, R.W. (1988). The social structure of wotk groups. In S.M. Shortell \& A.D. Kaluzny (Eds.), Healtb ane managewent. A text in ongastrotron theory and behasior (pp. 5-37). New York: John Wiley \& Sons.

Sandefur, G.D. \& Tuma, N.B. (1987). How data type affects conclusions abour individual mobility. Social Science Research, 16, 301-328.

Satason, B.R., Sheatin, E.N., Pierce, G.R. \& Sarason, I.G. (1987). Intertelations of social support measures: Theoretical and practical implications. Journal of Personality and Social Pyotology, 52, 813-832.

Saris, W. \& Stronkhorst, H. (1984). Cawsal modeling in monexperimental researda: An intwodnction to the LISREL approad. Amsterdam, The Netherlands: Sociometric Research Foundation.

Savicki, V. \& Cooley, E. (1987). The relationship of work envitonment and client contace to bumout in mental health professionals. Joumal of Commething and Dowelopmon, 65, 249. 252.

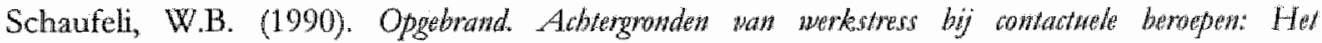
burnowisydrom [Butnout. Backgrounds of work stress in contactual occuparions: The burnout syndrom]. Rotterdam, The Netherlands: Donker.

Schanfeli, W.B. \& Buunk, A.P. (1996). Professional burnout. In M.J. Schabracq, J.A.M. Winnubst \& C.I. Cooper (Eds), Handbook of wath and bealth psydrology. New York: Willey.

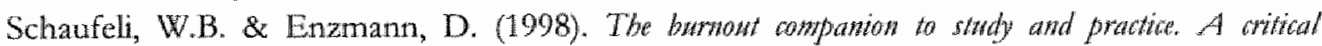
anabysis. London: Taylor \& Francis.

Schaufeli, W.B. \& Van Dierendonck, D. (1993). The constuct validity of rwo burnout measures. Jowrnal of Organizational Behautar, 14, 631-647. 


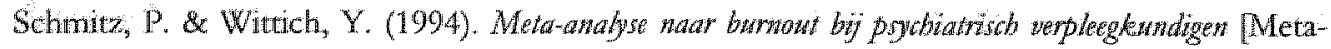
analysis of burnout in psychatric nursing]. Maastricht, The Netherlands: University of Maastricht.

Schneider, B. (1985). Organizational behavior. Awnwal Reven of Psylology, 36, 573-611.

Schneider, B. (1987). The people malke the place. Prownel Psybology, 40, 437 453.

Schulz, R., Greenley, J.R. \& Brown, R. (1995). Organzation, management, and client effects on staff burnowt. Jowrwat of Heakh and Social Bebawnor, 36, 333-345.

Schumacker, RE. \& Lomax, R.G. (1996). A begwners guide to strutumal equations modelling Mahwah: Lawtence Firlbaum Associates.

Scott, W.R. (1992). Orgamrzations, Rational, natural, and open systems. (3rd ed.). Englewood Cliffs, N]: Prentice Hall.

Scott, W.R. \& Shortell, S. (1988). Organizarional performance: managing for efficiency and effectiveness. In S.M. Shortell \& A. Kaluzny (Eds.), Healb ane managenten (pp. 418 457). New York: Wiley.

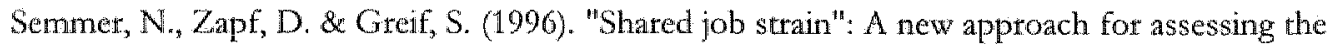
validity of job stress measurements. Jowmal of Occupatiowal and Organizationat Psybology, $69,293-310$.

Shirom, A. (1989). Bumout in work organizations. In C.L. Cooper \& I.T. Robertson (Eds.), Intemational Rewien of Industrial and Ongawizational Psychology (pp. 25-48). Chichester: John Wiley.

Slocum, J.W. \& Sims, H.P. (1980). A typology for integtating technology, organization, and job design. Human Relation, 33(3), 193-212.

Smith, M.). \& Carayon-Sainfort, P. (1989). A balance theory of job design for stress reduction. International Jownd of Industrial Engonomic $4,67-79$.

Smither, R.D. (1994). The nature of organizations. In R.D. Smither (Fd.), The psychology of worke and baman perfonmane (pp. 365-398). New York: HaperCollins College Publishers.

Snijders, T.A.B. \& Bosker, R.J. (1999). Mwitiletel anabsis" An introduction to basio and adwanced maltifered madeling. London: Sage Publications.

Söderfeldt, M., Söderfeldt, B. \& Warg, L. (1995). Burnout in social work Social Work: Jownal of the Nationd Associanon of Sorial Wrevers, 40(5), 638-647.

Spector, P.F. (1987). Method variance as an artifact in self-reported affect and perceptions at work: myth or significant problem? Joumal of Applied Psychology, 732, 438-443.

Specior, P.F. (1992). A consideration of the validity and meaning of self-report measures of job conditions. In C.L.R. Cooper \& I.T. Robertson (Eds.), Interwational Review of Indwstrial and Onganzational Pyybology (pp. 123-151). New York: Wiley \& Sons.

Spector, P.E. \& Jex, S.M. (1991). Relations of job characteristics from multiple data sources with employee affect, absence, tounover intentions, and health. Jowmal of Apphed Pychology, 76, 46-53.

Speedling, E.J. (1990). Motivation. In N. Metzger (Ed.), Handbook of bealth cam buman resownes mangegtone (pp. 63-67). Rockille Maryland: Aspen Publishers.

Stehle, J.L. (1981). Critical care nutsing stress: the findings revisited. Norring Researth, 30(3), 182186. 
Stilkwoort, R. Landeweerd, J.A. \& de Jonge, J. (1996). Werk en werkpeactes in bejaardentehuizen [Work and work reactions in elderly homes]. Wopletglewnde, $11(3)$, 156-166.

Tabachnick, B.G. \& Fidell, L.S. (1996). Utwg multwanate shation. New York: Happer Collins College Publishers.

Taber, T.D. \& Taylor, E. (1990). A review and evaluation of the psychometric properties of the Job Diagnostic Survey. Personkel Pychalogy, 43,467-500.

Taris, T.W. (2000). Longitwdinal data anabyin. London: Sage Publications.

"Terreberry, S. (1968). The evolution of organizational environments. Adwimstrathe Srence Qwaterly, 12(3), 590-613.

Thierry, H. (1990). Intrinsic motwation reconsidered. In U. Kleinbeck, H. Quast, H. Thierry \& H. Häcker (Eds.), Work monnation (pp. 67-82). Hillsdale, New Jersey: Lawrence Erlbaum Associates, Inc, Publishers.

Thoits, P.A. (1995). Stress, coping and social support processes: Where are we? What next? Jowmal of Health and Social bebavior, (Extra Issue), $53-79$.

Thompson, JD. (1967). Organiqations in action. New York: McGiraw-Hill.

Tiegs, R.B., Tetrick, L.E \& Fried, Y. (1992). Growth need strength and context satisfaction as moderators of the job charactetistics model foumal of Managenem, 18(3), 575-593.

Trist, E.L. (1981). The sociotechnical perspective: the evolution of sociotechnical systems as a conceptual framework and as an action research program. In A.H. Ven \& W.F. Joyce (Eds.), Perspectives on arganigational derign and behation (Pp. 19-75). New York: John Wiley.

Tummers, G.E.R. (1998). Onganisatioaspecten en werkebelowing. Een kwantitatief exploratief ondervele

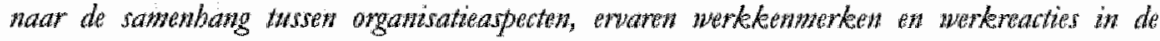
werpleging [Organisational characteristics and job perceptions. A quantitative explotative investigation on the relationship between organisational characteristics, perceived work characteristics and work reactions in nursing. Mastep thesis. Maastricht, The Netherlands: Maastricht University.

Tummers, G.E.R., Janssen, P.P.M., Landeweerd, J.A. \& Houkes, I. (2001). A comparative situdy of work characteristics and reactions between general and mental health nurses: al mult-sample analysis. Joumal of Adwance Nwrsing, 36(1), 151-162.

Tummers, G.E.R., Landeweerd, J.A. \& Van Merode, G.G. (2000). Organisaticaspecten, ervaren werkkenmerken en werkteacties in de verpleging lOrganisational characteristics, perceived work characteristics and work reactions in tursingl. Verpletgende, $15(3)$, 132-141.

'Tummers, G.E.R., Landeweerd, J.A. \& Van Merode, G.G. (2002a). Organisation, work and work reactions: a study of the relationships between organisational aspects of mursing and nurses" work characteristics and work teactions. Seandinawian fownol of Caning Sciencer, $16(1), 5258$.

Tummers, G.E.R., Landeweerd, J.A. \& Van Merode, G.G. (2002b). Work organisalion, work characteristics and the psychological effects on nurses in the Netherlands. International Jonmal of Stress Managenent, 9(3), 183-206. 
Tummers, G.E.R., Van Merode, G.G. \& Landeweerd, J.A. (2002c). The diversity of work: differences, similarities and relationships conceming characteristics of the organisation, the work and psychological work reactions in intensive care and nonintensive care nursing. International Jowrnal of Nursing Studies, 39(8), 841-855.

Tummers, G.E.R., Van Merode, G.G. \& Landeweetd, J.A. (2002d). Organisatie, werk en

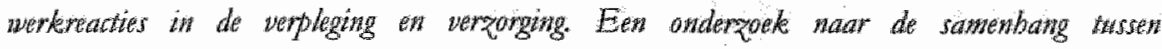

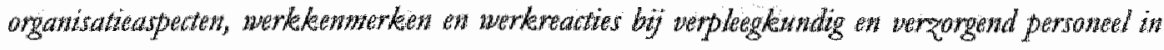
algemente zickenbutizen en werplegblyizen in Nederland [Organisation, work and work reactions in health care. An investigation on the relationship between organisational characteristics, work characteristics and work reactions among mursing personnel in general hospitals and nursing homes in the Netherlands]. OSA-publicatie ZW 26. Tillburg, The Nethetlands: OSA.

Tummers, G.E.R., Van Merode, G.G. \& Landeweerd, J.A. (2002e). Welzijn en gezondheid van verpleegkundigen [well-being and health in nursing work]. In A. Paulus \& A. Van Raak, J. A. (Eds.), Opretten en witwoeren van anderyoek in de qarg (pp. 33-49). Maarssen, The Netherlands: Elsevier.

Turnipseed, DL. (1999). An exploratory study of the hardy personality at work in the health care industry. Psychological Reports, 85(3, Pt 2 [Spec Issue]), 1199-1217.

Tyler, P.A. \& Cushway, D. (1992). Stress, coping and mental well-being in hospital nurses. Stress medicine, 8, 91-98.

Tymon, W.G., Stout, D.E. \& Shaw, K.N. (1998). Critical analysis and recommendations regarding the role of perceived environmental uncertainty in behavioral accounting research. Behawioral Research in Accounting, 10, 23-46.

Tzelgov, J. \& Henik, A. (1991). Suppression situations in psychological research: definitions, implications, and applications. Psychological Bulletin, 109(3), 524-536.

Vancouver, J.B., Millsap, R.E. \& Peters, P.A. (1994). Multilevel analysis of organizational goal congruence. Joumal of Applied Psychology, 79(5), 666-679.

Van de Ven, A., Delbecq, A. \& Koenig, R. (1976). Determinants of coordinarion modes within organizations. American Sociological Revien, 41 (322-338).

Van den Bent, A. (2001). Autonomie als valkuil [Autonomy as pitfall]. ZorgV Lire, 11, 30-31.

Van der Doef, M. \& Maes, S. (1999). The Job Demand-Control(-Support) Model and psychological well-being: A teview of 20 years of empirical research. Work and Stross, $13,87-114$.

Van Merode, F. Janssen, P. \& Van Raak, A. (2001). De toekomst van functiedifferentiatie [The future of function differentiation. Verplegetunde, 16(1), 65-71.

Van Merode, G.G. (1994). Decission support for clinical Laboratory capacity planning. $\mathrm{PhD}$ thesis. Maastricht, The Netherlands: Darawyse.

Van Metode, G.G. (1999). Kennismanagement: tussen beheersing en innowatie in de organisatie [Knowledge management: between control and innovation in the organisation]. Infarmatie Zorg, 28(3), 90-96.

Van Merode, G.G., Groothuis, S., Schoenmakers, M. \& Boersma, H.H. (2002). Stimulation studies and the alignment of interests. Health Care Managemen Science, 5, 97-102. 
Van Rossum, W. (1998). Otganization. In D. Reis Miranda, D.W. Ryan, W.B. Schaufeli \& V. Fidler (Eds.), Organization and managennent of intensive cam: A prospective study in 12 European comwthes (pp. 151-169). Berlin: Springer Verlag.

Van Tuijl, H. (1988), Coordinatie tussen ziekenhuisafdelingen; een model om tot afstemming te komen [Coordination between nursing units; a model for reaching coordination]. In J.W. Hoom (Ed.), Structurering en bebeersing wass rongtoroessers. Lochem, The Netherlands: De Tijdstroom.

Van Tuij, H.F.J.M. \& Bodt, J.H.I. (1988). Ongevingsonzekerheid en afdelingsorganisatie [Environmental uncertainty and unit organisation]. In ].W. Hoorn (Ed.), Strwturering en beheersing wan zongrocessen. Lochem, The Netherlands: De Tijdstroom.

Van Veldhoven, M. (1996). Psycbasaciale arbeidbelasting en arerkestress (Psychosocial workload and work stress]. PhD thesis. Lisse, The Netherlands: Swets \& Zeitlinger.

Van Yperen, N.W. \& Snijders, T.A.B. (2000). A multilevel analysis of the demands-control model: Is stress at work determined by factors at the group level or the individual level? Joumal of Occupational Health Psychology, 5(1), 182-190.

Verschuren, P.].M. (1991). Strwcturele modellen tussen theorie en praktijle [Structural model between theory and practice]. Meppel, The Netherlands: Het Spectrum.

Vogelaar, A.L.W. \& Van der Vlist, R. (1995). Het Job Characteristics model en taakherontwerp [The job characteristics model and job redesign]. Gedrag en Organisatie, 8, 65-87.

Warr, P.B., Cook, J. \& Wall, T.D. (1979). Scales for the measurement of some work attitudes and aspects of psychological well-being. Jowmal of Ocompational Psychology, 52, 129-148.

Wheeler, H.H. (1997). A review of nurse occupational stress research: 1. British Jourval of Nursing, 6(11), 642-645.

Wheeler, H.H. \& Riding, R. (1994). Occupational stress in general nurses and midwives. Britisth Jourryal of Narsing, $3(10), 527-534$.

White, D. \& Tonkin, J. (1991). Registered nurse stress in intensive care units - an Australian perspective. Intensize Care Nursing, 7, 45-52.

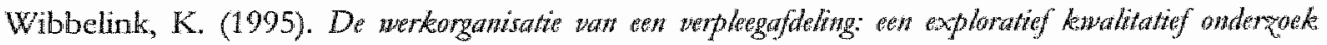

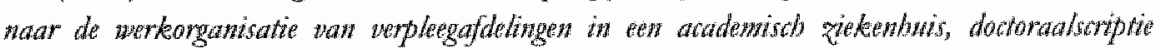
[The work organisation of a nursing unit: an explorative qualitative research of the working situation of nursing units in an academic hospital]. Master thesis. Maastricht, The Netherlands: University of Limburg.

Williams, I.J. \& Podsakoff, P.M. (1989). Longitudinal field methods for studying reciprocal relationships in organizational behavior research: Toward improved causal analysis. Researction Organizational Behavior, 11, 247-292.

Winnubst, J. (1993). Organizational structure, social support and burnout. In W.B. Schaufeli, C. Maslach \& T. Marek (Eds.), Professional Bumowt. Recent demelopments in Theory and Researts (pp. 151-162). Washington, DC: Taylor \& Francis.

Winnubst, J.A.M., de Jong, R.D. \& Schabracq, M.J. (1996). The Diagnosis of Role Strains at Work: The Dutch Version of the Organizational Stress Questionnaite. In M.J. Schabracq, J.A.M. Winnubst \& C.L. Cooper (Eds.), Handbowk of worke and bealth psychology. Chichester: John Wiley \& Sons Ltd. 
Winnulbst, J.A.M. \& Schabracq, M.J. (1996). Social support, stress and organization: Towards optimal matching. In M.J. Schabracq, J.A.M. Winnubst \& C.L. Cooper (Eds.), Handlooke of Work and Health Pyychology (pp. 87-102). Chichester: John Wiley \& Sons Ltd.

Yuchtman, E- \& Seashore, S.E. (1967). A system resource approach to organizational effectiveness. American Socialogical Reviem, 32, 891-903.

Zapf, D., Dormann, C. \& Frese, M. (1996). Longitudinal studies in organizational stress rescarch: $\mathbb{A}$ review of the literature with reference to methodological issues. Journal of Occupational Health Psychology, 1, 145-169.

Zwaga, P.G.J. (1983). Rolproblemen in algemene ziekembutizen enige effecten [Role problems in general hospitals: some effects]. Assen, The Nerherlands: Van Gorcum. 


\section{Dankwoord (Acknowledgement in Dutch)}

$\mathrm{Nu}$ al het inhoudelijke werk af is, ben ik gekomen aan de "final touch": het dankwoord! $\mathrm{Na}$ al de voorafgaande "brainwaves" en "brainstorms", dacht ith aanvankelijk dat het schrijven van het dankwoord een makkelijke takk zou zijn. Het liefst zou ik namelijk van de gellegenheid gebruik willen maken om elke persoon afzonderlijk te bedanken. Echter, ik vrees dat als ik me hieraan waag, het dankwoord langer zal worden dan de voorgaande hoofdstukken. Dit geeft al an dat ik veell personen zeer dankbaar ben voor hun steun en betrokkenheid bij het schrijven van dit proefschrift. Zonder hun hulp zou dit boekje er niet liggen.

Allereerst ben ik natuurlijk mijn twee dagelijkse begeleiders: mijn promotor Prof. dr. Frits van Merode en mijn co-promotor Dr. Ab Landeweerd mijn dank verschuldigd:

Ik zou waarschijnlijk nooit als AIO onder jullie hoede begonnen zijn als ik niet bij jullie afgestudeerd was. Door jullie enthousiasme en vertrouwen in mij werd ik gestimuleerd om mijn afstudeetonderzoek voort te zetten in de vorm van het huidige promotieonderzoek. Ondanks onze soms "verhitte" discussies (de temperatuur op Ab's kamer!), gingen onze gesprekken vaak verder dan de wetenschap. De verschillen betreffende jullie wetenschappelijke achtergrond en "blik op de wetenschap en de wereld" zorgden ervoor dat ik mijn onderzoek steeds van verschillende invalshoeken kon belichten. Dit heb ik zeer gewaardeerd.

Beste Frits. Door jou heb ik geleerd om steeds kritisch naar mijn werk te blijven kijken en vragen te blijven stellen. Ook al was ik nog zo overtuigd van mijn antwoorden op de kritische vragen die jij stelde, jij wist deze altijd wel op een dusdanige manier te formuleren dat ik van mijn geloof viel (en alweer had jij gelijk!). Het klinkt paradoxaal, maar jouw abstracte manier van denken en je gebruik van taal (metaforen) hebben eraan bijgedragen dat mijn onderzoek steeds meer ging "leven" en praktisch toepasbaar werd. Mede door jouw erudiete persoonlijkheid en je aparte humor heb ik met plezier met jou samengewerkt. Ten slotte wil ik je bedanken voor de kansen die je me gegeven hebt om ook na mijn AIO-schap onze samenwerking woort te zetten middels het uitvoeren van adviesprojecten op jouw vakgebied. Ondanks de korte periode dat ik hiermee kennis heb kunnen maken, heb ik hiervan weel geleerd en is het complexe vakgebied "logistiek" zo gek nog niet.

Beste $\mathrm{Ab}$. Jij zorgde vooral voor de structuur in mijn werk en wist altijd wel het kaf van het koten te scheiden. Jouw relativerend vermogen op momenten dat ik twijfelde aan de betekenis van mijn onderzoek voor de wetenschap, hebben mij zeet geholpen. Naast de inzichten die ik door jou verkregen heb in onder andere A\&O modellen, onderzoekstechnieken en het werken in de zorg, ben ik ook meer te weten gekomen over het leven van "trollen", "elfen", "druiden" en "magiërs". Het bestaan van deze "fantasy-personen" mag dan wel niet wetenschappelijk zijn, ik heb wel van je verhalen genoten!

Frits en $\mathrm{Ab}$, $\mathrm{k}$ heb jullie begeleiding als zeer prettig ervaren en wil jullie dan ook bedanken voor de fijne samenwerking waar ik met veel plezier naar terugkijk! 
Een speciaal woord wan dank wil ik nichten aan Dr. Peter Janssen. Peter, ondanks dat je niet formed betrokken bent geweest bij mijn onderzoek, heb je me toch bij tijd en wijlen ondersteund. Ik ben je wooral dankbaar voor de discussies die we hadden over de ingewikkelde listelanalyses en de kritische reflecties op twee artikelen in dit proefschrift.

De leden van de beoordelingscommissie: Prof.dr. Frans Nijhuis, Ptof.dr. Wim Groot, Prof.dr. Friso den Hertog, Prof.dr. Robert Roe en Dr. Jan de Jonge, ben ik erkentelijk voor de tijd die zij namen om mijn proefschrift te beoordelen.

Bob Wilkinson wil ik danken voor de moeite en tijd die hij genomen heeft om op het laatste moment nog "the English language" van het begin- en eindhoofdstuk to controleren.

Dr. Math Candel wil ik bedanken voor zijn statistische adviezen met betrekking tot de "in" en "outs" van multilevel analyse.

Alle verpleegkundigen die geparticipeerd hebben in het huidige onderzoek, wil ik bedanken voor hun deelname om de lange vragenlijst in te vullen. Zonder hen had het huidige onderzoek nooit uitgevoerd kunnen worden. Tevens wil ik de managers, afdelingshoofden en teamleiders van de 15 ziekenhuizen bedanken voor hun deelname, betrokkenheid en interesse.

De Organisatie voor Strategisch Arbeidsmarktonderzoek (OSA) dank ik voor het mede subsidiëren wan het huidige onderzoek. Mijn dank gaat hierbij voornamelijk uit naar Dr. Gerard van Essen en Drs. Frank Peters. Bedankt voor jullie commentaar op de manuscripten en de mogelijkheid die ik gehad heb om het onderzoek naar "buiten" te brengen.

Ondanks het gegeven dat het schrijven van een proefschrift een zeer solistische bezigheid is, hebben mijn kamergenootjes Susanne, Silvia, Nathalie en Mariette ervoor gezorgd dat ik niet tegen de computer hoefde te gaan praten.

Susanne, jij kwam mij als eerste kamergenootje op de Uns.50 vergezellen. Behalve onze onenigheid over "Leonardo" was het erg gezellig met jou.

Silvia en Nathalie, jullie werden met mij "opgescheept" toen we verhuisden naar de Uns.40. Ondanks onze promotiestress, die we alledrie deelden, hebben we ook een hoop lol gehad. Bedankt voor jullie gezelligheid en steun!

Nathalie, "de laatste loodjes wegen het zwaarst". Dat heb ikk ook zo ervaren. Maar ik ben ervan overtuigd dat ook jou dit gaat lukken. Succes ermee!

Mariette, iij kwam als laatste op onze kamer erbij en was al snel niet meer weg te denken. Je positieve kijk op de wereld en onze gesprekken die vaak gingen over geluk, hoop en liefde hebben ex zeker aan bijgedragen dat cle zon weer ging schijnen als het even niet meezat. Bedankt voor al je interesse, medeleven en de leuke sfeer. 
Naast mijn kamergenootjes, zijn er natuurlijk alle andere BEOZ-collega's die ervoor gezorgd hebben dat ik (bijna) elke dag fluitend naat mijn werk ging en waardoor mijn arbeidsvreugde meer dan proportioneel toenam. Peggy, Aggie, Inge, Regien, Catelinne, Amo, Gerry, Jan vdM, JanvE, WillV, WilB, Astrid, Isel, Hilde, Sylvia, Nicolle en alle anderen: bedankt voor alles!

Peggy, bij jou kon ik op elk moment binnenlopen. We hebben samen heel wat afgelachen, maar ook gehuild. Ik heb je inzichten en steun zeer gewaardeerd. Bedankt voor je vertrouwen, maar vooral voor je warme vriendschap.

Inge, met plezier denk ik terug aan onze congresbezoeken in Praag en Rolduc. Bedankt voor al je adviezen over "hoe te promoveren". Je was een voorbeeld voor me..

Lieve BEOZ-collega's. Ik wil bij de afronding wan dit proefschrift meteen van de gelegenheid gebruik maken om jullie allemaal te bedanken voor de ontzettend leuke tijd die ilk met jullie gehad heb! Met warmte denk ik terug aan de vele lunchpauzes, "kletspauzes" en uitstapjes met jullie waaraan ik mooie herinneringen heb. Het valt dan ook niet mee om jullie te verlaten. De Franse uitdrukking: "Partir, c'est mourir un peu" is dan ook zeker hier op zijn plaats. Ik zal jullie missen!

Gelukkig dat ik niet alleen op het "podium" zal staan als het "uur van de waarheid" aangebroken is, maar dat mijn twee paranimfen Swenja en Sabine bereid zijn om mijn vtagen te gaan beantwoorden (dit had ik jullie niet erbij verteld, grapjel). Ik ben jullie dan ook dankbaar dat jullie naast mij willen staan.

Beste Svenja. Het sprak eigenlijk voor zich dat jij mijn paranimf zou worden. Al bijna 24 jaar delen we lief en leed met elkaar. Spontaan zoals je bent, borrelde jouw ondernemingslust op toen ik je vroeg om mijn paranimf te willen zijn. Ook al kon je je niet altijd voorstellen wat mijn drijfveren waren voor het verrichten van wetenschappelijk onderzoek ("wat kun je daar nu mee?"), ik weet dat je trots op mij bent.

Beste Sabine. We hebben reeds een lange vriendschap die ooit in Landgraaf begonnen is. Met vreugde kijk ik dan ook terug naar de fijne gesprekken die we altijd hebben, die verder gaan dan hemel en aarde.

Lieve mam en pap. Jullie hebben mij de mogelijkheid gegeven om me optimaal te kunnen ontwikkelen en ontplooien. Mede door jullie levenswijsheid en de waarden die jullie mij meegegeven hebben, heb ik het huidige resultaat bereikt. Welke keuze ik ook makkte, altijd stonden jullie achter mij. Het is zeer fijn om te weten dat jullie er altijd zijn op wie ik kan terugvallen. Bedankt voor alles: jullie steun is voor mij van onschatbaare waarde!

Verder wil ik mijn oma bedanken. Ik weet dat het moeilijk was om te begrijpen waar ik nu precies vier jaar lang bezig mee ben geweest. Maar je toonde altijd interesse in mijn "scriptie". Ik betreur het zeer dat opa dit niet meer mee mag maken. Maar voor opa was ik al "doctor" vóórdat ik überhaupt aan mijn promotie-onderzoek begonnen was. Ik ben blij dat ik dit nu heb kunnen waarmaken. Hij zal het beslist van "boven" allemaal zien. 
Beste Ivo. Zo jong als je bent, nu al interesseer je je voor alles wat met onderzoek en techniek te maken heeft. Mijn onderzoek mag dan wel niets met neurochirurgie te maken hebben, jij vroeg altijd aan mij hoe het ermee ging. Bedankt!

Lieve Maurice. Jij wist niet beter toen we elkaar leerden kennen, dan dat "het schrijven wan het proefschrift" en alles wat hiermee te maken had, erbij hoorde. Bedankt voor de ruimte en het vertrouwen die je me gegeven hebt om deze taak te volbrengen.

Ondanks je twijfel op sommige gebieden, heb je altijd geloofd in mij. Je vertrouwde er volkomen op dat ik mijn proefschrift tot een goed einde zou brengen. Dit heeft mij zeer geholpen. Ik weet nu dat als je ergens in gelooft, je er samen voor kunt gaan. Meer woorden zijn, denk ik, niet nodig om te begrijpen wat ik bedoel.

De afgelopen tijd was niet makkelijk. Maat nu het proefschrift af is en we in rustiger vaarwater gekomen zijn, hoop ik dat we samen door dalen, maar vooral over veel "bergen" door het leven mogen "skiën"! 


\section{Curriculum Vitae}

Gladys Tummers was born on May 25, 1976 in Heetlen. In 1994, she finished high school (VWO) at Bernardinuscollege in Heerlen. In the same year, she started studying Health Sciences at Maastricht University with major in Health Policy \& Administration. During this study, she has been working as a student assistant at the department of Metholology and Statistics at the same university. She graduated in September 1998.

In October 1998, she started working as a $\mathrm{PhD}$ student/lecturer at the department of Health Organisation, Policy and Economics (Faculty of Health Sciences) of Maastricht University. During this period, the research presented in this thesis was performed. In addition, she educated Work \& Health and Health Policy \& Adminstration students.

From February to April 2003, the author has been working as an assistant professor at the same department and university, involved in projects and teaching activities in the area of logistics and operations management.

In April 2003, she started working as a research consultant at the department of Information Facility (FIF) at the municipality Heerlen. 